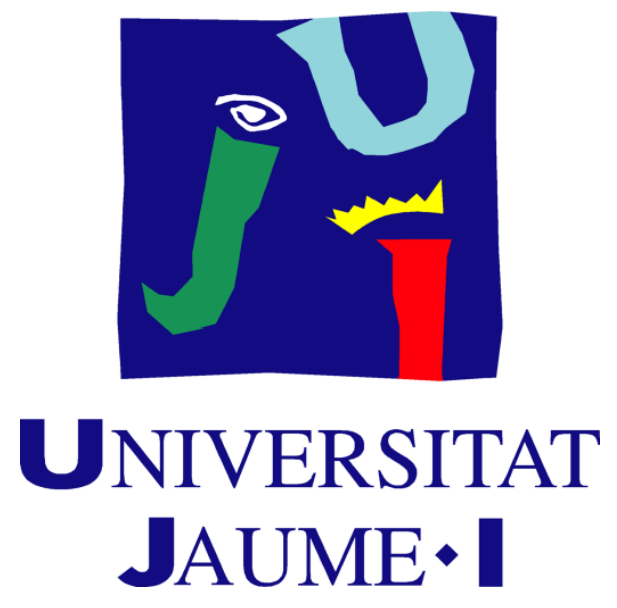

Universitat Jaume I

Escola Superior de Tecnologia I Ciències Experimentals Departament Química Inorgànica i Orgànica

Organic and Medicinal Chemistry Group

\title{
ASYMMETRIC EPOXIDATION OF ELECTRON-DEFICIENT OLEFINS AND SYNTHETIC APPLICATIONS
}

$\mathrm{PhD}$ Thesis

Andreu Vidal Albalat

Castelló de la Plana, 2016 



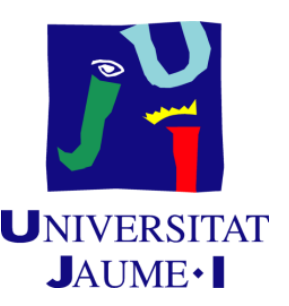

Els directors Dr. Florenci V. González Adelantado i Dr. Santiago Rodríguez Pastor, professors titulars del Departament de Química Inorgànica i Orgànica de la Universitat Jaume I de Castelló,

CERTIFIQUEN: Que la tesi doctoral "Asymmetric epoxidation of electron-deficient olefins and synthetic applications" ha estat desenvolupada per Andreu Vidal Albalat, sota la seua direcció, en l'Àrea de Química Orgànica del Departament de Química Inorgànica i Orgànica de la Universitat Jaume I de Castelló.

I per a què així conste, en compliment de la legislació vigent, signen aquesta certificació a Castelló 12 de juliol de 2016:

Florenci V. González Adelantado Santiago Rodríguez Pastor 

Aquesta Tesi Doctoral s'ha realitzat amb una beca predoctoral concedida per la Generalitat Valenciana, dins del porgrama VALi+D del 2013 per a la formació de personal investigador (FPI). El període de gaudi de la beca ha estat comprés entre 1'1 de juny de 2013 al 31 de maig del 2016.

La Tesi Doctoral s'ha complementat amb una estada d'investigació a la Università degli Studi di Salerno (Itàlia), sota la supervisió de la professora Alessandra Lattanzi, en un període comprés entre 1'1 de setembre de 2014 i el 31 de desembre de 2014. Aquesta estada ha estat finançada per les ajudes VALi+D 2014 a la mobilitat de l'estudiantat de doctorat.

Aquesta tesi s'ha realitzat i serà defesa seguint els requeriments exigits per l'obtenció del títol de Doctorat Internacional.

Prèviament a la defensa d'aquesta Tesi Doctoral, el treball ha estat avaluat per dos experts internacionals independents, relacionats directament amb l'àrea d'invetigació $i$ de reconegut prestigi internacional: Prof. Dr. Karl A. Jørgensen del departament de química de la Aarhus University (Aarhus, Dinamarca) i el Dr. Jean-Luc Decout del departament de Química Molecular i Farmacoquímica de la University Joseph Fourier (Grenoble, França). 



\section{$\underline{\text { Agraïments }}$}

A pesar de què el gruix de la tesi està escrit en anglès, aquestes paraules apareixeran escrites en la meua llengua, perquè en estes pàgines es parlarà d'afecte, i és una cosa que no es pot expressar plenament en una llengua que no siga la pròpia.

En primer lloc, voldria agrair els meus directors de tesi Dr. Florenci V. González i Dr. Santiago Rodríguez, dels quals he aprés i m'han ajudat a desenvolupar els meus coneixements en el camp de la química.

També dedico aquesta tesi als meus companys del laboratori amb qui he compartit treball i bons moments: Javi, Antonio, Bogdan, Santi, Víctor, Lledó i en especial a Joan qui va ser el meu mentor en aquest món de la investigació. També, com no, a tots els estudiants als quals he hagut d'instruir al laboratori en algun moment: Lorena, Joan, Maria, Estefania, Sarai, Hannah, Simon i Laura; dels quals he aprés com ensenyar. A tots ells els estic molt agraït també per suportar-me.

No puc oblidar-me dels companys de passadís, com Carles qui m'acompanya cada matí per prendre el café i per parlar de bicis $i$ coses trivials, $i$ a Nishant qui és com un germà per a mi. També a Ana i Marco, ja que hem estat molts mesos junts tancats en un espai de vegades massa reduit per a tres persones què es dedicaven exclusivament a escriure la tesi. I com no, a tots aquells que hem fan companyia a l'hora de dinar, i perquè també han ficat la seua part en aquesta tesi, Anna, Raül, Juanjo, César, Olga, Santi i Juan. I en general a tots els companys de departament amb qui he compartit algun congrés, sopar o Magdalena, no puc nombrarlos a tots però sí recordar aquells que van acabar ja fa temps i els guardo més estima: Cristina, Marta, Sara i Sergio.

Ah, i no vull oblidar-me del Dr. Vicent Arbona, amb qui he xarrat molt de ciència; però sobretot, de rock. I és que per a mi la 
música, més que una afició, és la meua llar. Durant aquests tres anys llargs què ha durat la meua tesi, he compartit local d'assaig i escenari amb gent meravellosa. Han fet que després de jornades llarguíssimes al laboratori, no hem penedira d'agafar el cotxe els quilòmetres que fera falta per tocar amb ells. L'AMSCAL, Coelestia, Fire Stones..., tots eixos moments els tinc gravats a foc.

Als meus amics de sempre, que quan m'han preguntat sobre la meua feina, els he explicat amb gestos $i$ peripècies diverses com s'ensamblen les molècules i què té a veure la quiralitat amb un espill. Agrair-li a Marc que dedicara el seu temps lliure a dissenyar-me aquesta portada tant fantàstica.

Tantissime grazie, a la professora Lattanzi per les seues ensenyances i consells durant la meua estada a Salerno, i als amics què vaig fer allà al laboratori, en especial a Sara Meninno i Francesco Scorzelli.

Finalment, a la meua família, perquè a pesar de què no sempre hem compartit interessos, i que de vegades no han estat d'acord amb totes les meues decisions, sempre m'han recolzat per tirar endavant en el camí que he triat.

A tots ells moltes gràcies! 
"Somewhere, something incredible is waiting to be known"

Carl Sagan

"La llengua és l'expressió del que un és"

Raimon

"Where words fail, music speaks"

Hans Christian Andersen 



\section{$\underline{\text { Abbreviations }}$}

2-HEAF = 2-Hydroxyethyl ammonium formate

$\mathrm{AcOH}=$ Acetic acid

AIBN = Azabisisobutyronitrile

$\mathrm{AKR}=$ Asymmetric kinetic resolution

Boc $=$ tert -Butoxycarbonyl

ca. $=$ circa (approximately)

$\mathrm{Cp}=$ Cyclopentadienide

$\mathrm{CPCM}=$ Conductor-like polarizable continuum model

$\mathrm{DBU}=1,8$-Diazabicyclo[5.4.0] undec-7-ene

DCC $=N, N$ '-Dicyclohexylcarbodiimide

$\mathrm{DCE}=1,2$-Dichloroethane

$\mathrm{DCM}=$ Dichloromethane

DFT $=$ Density functional theory

DMSO = Dimethyl sulphoxide

DYKAT $=$ Dynamic kinetic asymmetric transformation

$\mathrm{EI}=$ Electronic impact

$\mathrm{ESI}=$ Electrospray ionization

et al. $=$ et alii (and others)

EtOAc $=$ Ethyl acetate

$\mathrm{EtOH}=$ Ethanol

GC/MS = Gas chromatography/ Mass spectra

HFIP = 1, 1,1,3,3,3-Hexafluoroisopropanol

HIV = Human immunodeficiency virus

HPLC $=$ High performance liquid chromatography

IR $=$ Infrared

LC = Liquid crhomatography

$\mathrm{MeOH}=$ Methanol

$\mathrm{MsCl}=$ Methanesulfonyl chloride

$\mathrm{MW}=$ Microwave

NBS $=$ N-Bromosuccinimide

NMR = Nuclear magnetic ressonance

NOE $=$ Nuclear Overhauser effect 
$\mathrm{PC}=$ Product complex

PES = Potential energy surface

PTC $=$ Phase transfer catalysis

QTOF = Quadrupol - Time of flight

r.t. $=$ room temperature

$\mathrm{RC}=$ Reactant complex

TBHP = tert-Butyl hydroperoxide

TBS = tert-Butyldimethylsilyl

TFA $=$ Trifluoroacetc acid

THF $=$ Tetrahydrofuran

TLC $=$ Thin layer chromatography

TMS = Trimetylsilyl

$\mathrm{TS}=$ Transition state

$\mathrm{TsCl}=$ para-Toluenesulfonyl chloride

$\mathrm{UV}=$ Ultraviolet 


\section{Table of Contents:}

\section{Chapter 1: General Introduction}

1. Nitroepoxides 3

2. Heterocyclic Compounds 9

2.1. Quinoxalines 9

2.2. 1,2,3,4-Tetrahydroquinoxalines $\quad 12$

2.3. Piperazines 16

2.4. Pyrazines 18

3. Asymmetric Epoxidation of Electron-Deficient Olefins 21

3.1. Peptide Catalysis 21

3.2. Bifunctional Base-Catalyzed Reaction 22

3.3. Pyrrolidine Based Catalysis 24

3.4. Chiral Amine Salt Catalysis 26

3.5. Chiral Ketone-Catalyzed Epoxidation 27

3.6. Phase Transfer Catalysis 28

3.6.1. Cinchona Alkaloid-Derived Quaternary Ammonium Salts 29

3.6.2. Other Quaternary Ammonium Salts 32

3.6.3. Crown Ether-Type Catalysis 33

Chapter 2: Nitroepoxides as Precursors of 1,4-Diaminoheterocycles

1. Objectives 37

2. Results and Discussion 38

2.1. Quinoxalines 40

2.2. Piperazines 44

2.3. 1,2,3,4-Tetrahydroquinoxalines 47

2.4. Pyrazines $\quad 50$

2.5. Imidazopyridines 52

3. Conclusions 57

4. Experimental Section 58

\section{Chapter 3: Asymmetric Epoxidation of Dicyanoalkylidenes}

1. Objectives 77

2. Introduction 76 
3. Results and Discussion 79

3.1. Synthesis of Precursor $7 \quad 79$

3.2. Synthesis of Racemic 8

3.3. Synthesis of Catalysts $\mathbf{1 0}$ and 12a-e 80

3.4. Screening of the Catalysts 82

4. Conclusions 89

5. Experimental Section 90

Chapter 4: Asymmetric Epoxidation of Nitroalkenes

1. Objectives 99

2. Results and Discussion 100

2.1. Early Stage Experiments 101

2.2. Optimization Reactions 102

2.3. Scope of the Reaction 117

2.4. Computational Studies 120

2.5. Synthetic Derivations of Nitroepoxides 123

3. Synthesis of Precursors 132

4. Conclusions 134

5. Experimental Section 135

General Conclusions and Future Work 147

$\begin{array}{ll}\text { Selected Spectra } & 151\end{array}$

HPLC and GC Chromatograms 189

Annex

List of Publications 201

Summary in Catalan 203 


\section{Chapter $\mathbb{1}$}

General Introduction 



\section{Nitroepoxides}

One of the milestones for a synthetic organic chemist is the achievement of complex molecules from simple and available molecules. Moreover, the ideal synthesis of those complex molecules must be economic, non-toxic and environmentally friendly. For that purpose, exists a family of molecules called building blocks, since their reactivity allow the formation of new bonds with easyness in mild conditions, such as jigsaws in a puzzle.

Nitroepoxides are the main family of compounds studied in this research work. Nitroepoxides are strained systems which display two highly oxidized vicinal positions by nature of their chemical connectivity and hence are potentially exploitable as synthons with vicinal electrophilic centers (Scheme 1). Nitroepoxides were firstly described by Newman and Angier in 1969. ${ }^{1}$ Since then, many synthetic applications were reported but the interest in this class of compounds decreased through the years. However, in the last decade the interest for the nitroepoxides as building blocks has raised, and we think this tendency will increase partly due to an enantioselective epoxidation of nitroalkenes to obtain optically active nitroepoxides with high chemical yields and enantioselectivity, as reported on this Thesis. This introductory chapter will provide a brief background on the use of nitroepoxides in organic synthesis, focusing on the most recent examples.

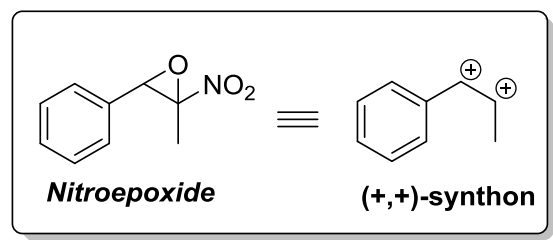

Scheme 1. Nitroepoxides as 1,2-electrophilic synthons.

\footnotetext{
${ }^{1}$ Newman, H.; Angier, R. B. J. Chem. Soc. D Chem. Commun. 1969, 186, 369.
} 
In their research, Newman and Angier synthesized the corresponding epoxide from trans- $\beta$-methyl- $\beta$-nitrostyrene, and tested different conditions in order to study its reactivity. ${ }^{2}$ As expected, the behaviour of the nitroepoxide towards a series of representative nucleophiles was rationalized as an $S_{N} 2$, in which the nucleophiles attack the beta position to the nitro group affording the corresponding ketone upon nitrous acid extrusion (Scheme 2). This reactivity makes nitroepoxides an interesting alternative to haloketones.

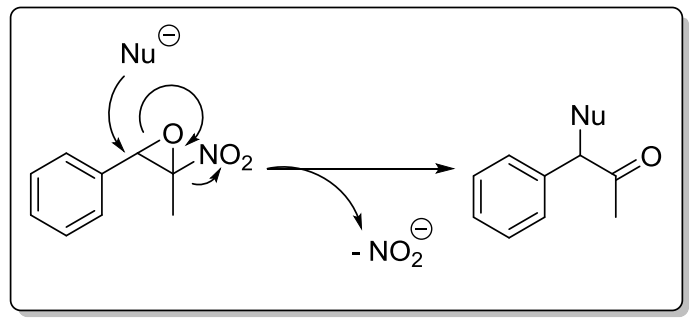

Scheme 2. Reactivity of nitroepoxides generates a carbonylic compound.

The tested nucleophiles were sodium phenoxide, sodium thiophenolate, dimethylamine and thiobenzamide (Scheme 3). The nitroepoxide also showed reactivity under acidic conditions. In diluted sulfuric acid, the $\alpha$-hydroxyketone and the oxidation product diketone were isolated. When treated with Lewis acid $\mathrm{BF}_{3} \cdot \mathrm{Et}_{2} \mathrm{O}$, the reaction gave a complex mixture of compounds. ${ }^{2}$

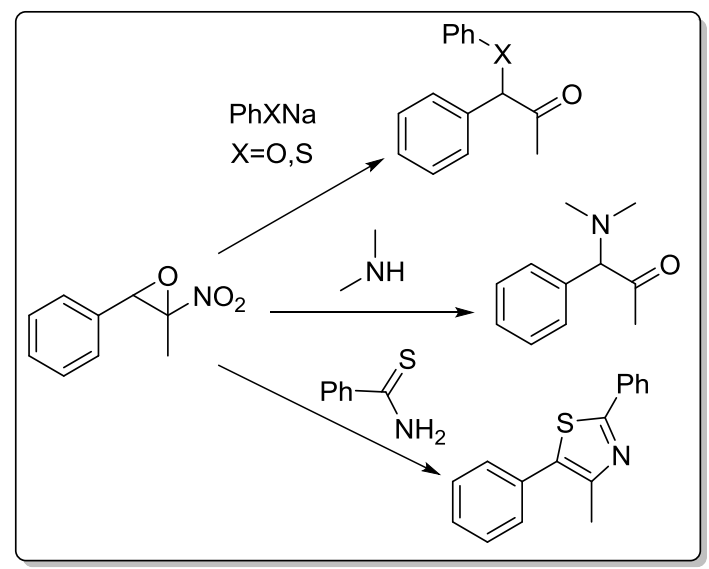

Scheme 3. Examples of ring-opening reactions

${ }^{2}$ Newman, H.; Angier, R. B. Tetrahedron 1970, 26, 826. 
More recent works have explored further the reactivity of nitroepoxides. Tsogoeva's group ${ }^{3}$ found interest in the formation of thiazoles from nitroepoxides using thiobenzamides, briefly reported before by Newman and Angier. ${ }^{2}$ Her group focused attention on the development of one-pot processes for the syntheses of 1,3-thiazoles via organocatalyzed epoxidation of nitroalkenes. First, they optimized the conditions for the organocatalytic epoxidation of trans- $\beta$-methyl- $\beta$ nitrostyrene using TBHP-DBU system as previously reported for the epoxidation of $\alpha, \beta$-unsaturated- $\delta$-lactones. ${ }^{4}$ The best conditions for the epoxidation resulted to be the use of 2 equivalents of TBHP, $5 \mathrm{~mol} \%$ of DBU in $n$-hexane as a solvent, at room temperature. Next, the ring opening step with one equivalent of thiobenzamide was carried out by using the same conditions i.e., $n$-hexane as a solvent at room temperature. However, the 1,3-thiazole was isolated only in 34\% yield. When using $\mathrm{MeOH}$ as a solvent, the chemical yield raised up to $62 \%$ and when two equivalents of the thiobenzamide were used instead, the yield raised up to $66 \%$ in $n$-hexane and up to $80 \%$ in $\mathrm{MeOH}$. Then, $\mathrm{MeOH}$ was used as an additive in the second step of the reaction in the one-pot sequence. Other additives were tested and finally, TFA gave the best results (Scheme 4).

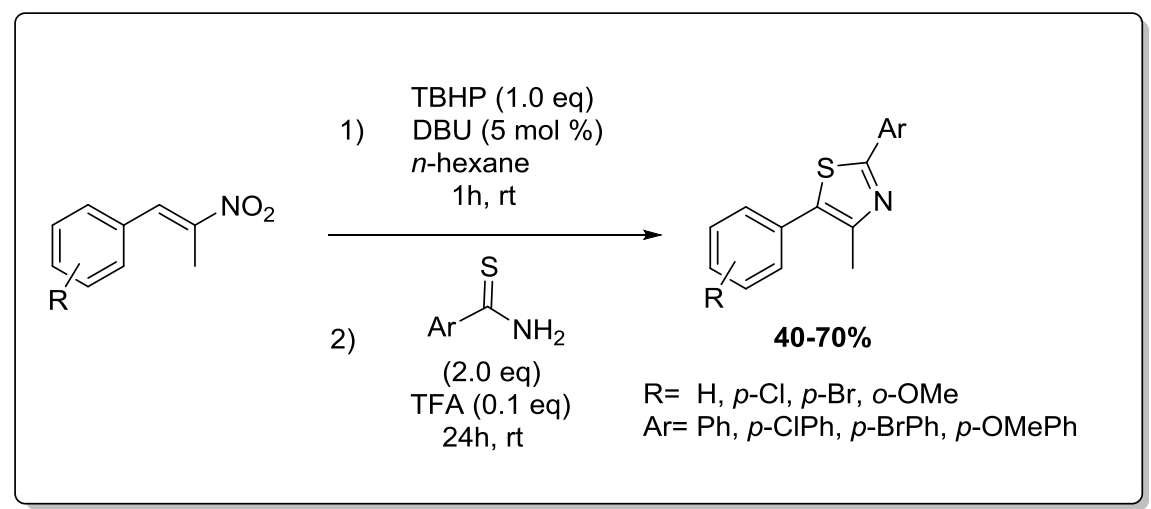

Scheme 4. One-pot synthesis of 1,3-thiazoles from nitroepoxides.

\footnotetext{
${ }^{3}$ Weiss, K. M.; Wei, S.; Tsogoeva, S. B. Org. Biomol. Chem. 2011, 9 (9), 3457.

${ }^{4}$ Yadava, V. K.; Kapoor, K. K. Tetrahedron 1995, 51 (31), 8573.
} 
X. Guo et al. published a synthetic methodology to obtain functionalized 2-aminoimidazoles from $\alpha$-nitroepoxides. ${ }^{5}$ The 2 aminoimidazole scaffold is present in a great variety of biologically relevant molecules, such as $\beta$-secretase inhibitors ${ }^{6}$ and compounds with anticancer activity. ${ }^{7}$ The privileged structure of nitroepoxides with two vicinal electrophilic centers allowed the one-pot synthesis of 2aminoimidazole using an amine (generally $p$-substituted anilines) and cyanamide (Scheme 5). The first conditions involved the use of a base, but the reaction gave higher yields in the absence of base. Also, many solvents were screened to conclude $n$-propanol to be the best solvent. The scope of the reaction was examined by coupling nitroepoxides with cyanamide and amines. Anilines bearing an electron-donating group (methyl or methoxy) afforded the desired 2-aminoimidazoles in a higher yield than those with electron-withdrawing group (-F, $-\mathrm{Cl}$ or $\mathrm{Br})$. However, no reaction was observed with $p$-nitroaniline.

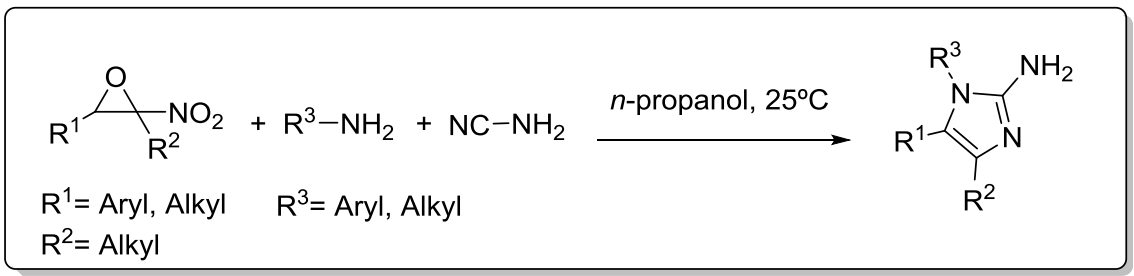

Scheme 5. One-pot synthesis of 2-aminoimidazoles from nitroepoxides.

$\mathrm{X}$. Guo et al. also reported a different approach to obtain imidazoles from nitroepoxides. ${ }^{8}$ In this case, amidines were used instead of cyanamide and an amine. This approach was useful to achieve the

\footnotetext{
${ }^{5}$ Guo, X.; Chen, W.; Chen, B.; Huang, W.; Qi, W.; Zhang, G.; Yu, Y. Org. Lett. 2015, $17(5), 1157$.

${ }^{6}$ Malamas, M. S.; Erdei, J.; Gunawan, I.; Barnes, K.; Johnson, M.; Yu, H.; Turner, J.; Yun, H.; Wagner, E.; Fan, K.; Olland, A.; Bard, J.; Robichaud, A. J. J. Med. Chem. 2009, 52 (20), 6314.

${ }^{7}$ Li, W.-T.; Hwang, D.-R.; Song, J.-S.; Chen, C.-P.; Chuu, J.-J.; Hu, C.-B.; Lin, H.L.; Huang, C.-L.; Huang, C.-Y.; Tseng, H.-Y.; Lin, C.-C.; Chen, T.-W.; Lin, C.-H.; Wang, H.-S.; Shen, C.-C.; Chang, C.-M.; Chao, Y.-S.; Chen, C.-T. J. Med. Chem. 2010, 53 (6), 2409.

${ }^{8}$ Guo, X.; Shao, J.; Liu, H.; Chen, B.; Chen, W.; Yu, Y. RSC Adv. 2015, 5 (64), 51559 .
} 
formation of the imidazole scaffold with other substituents different to amino groups, i.e. -H, alkyl or aryl (Scheme 6). In this work, the use of a base was found to be necessary: two equivalents of $\mathrm{NaOMe}$ in $\mathrm{MeOH}$ at room temperature afforded the imidazole in the highest yield of the selected example (91\%). Again, the chemical yields were higher when electron-donor substituents where present in the amidine. The reaction of nitroepoxide with 2-aminopyridine using the same conditions afforded the imidazo-[1,2-a]-pyridine scaffold.

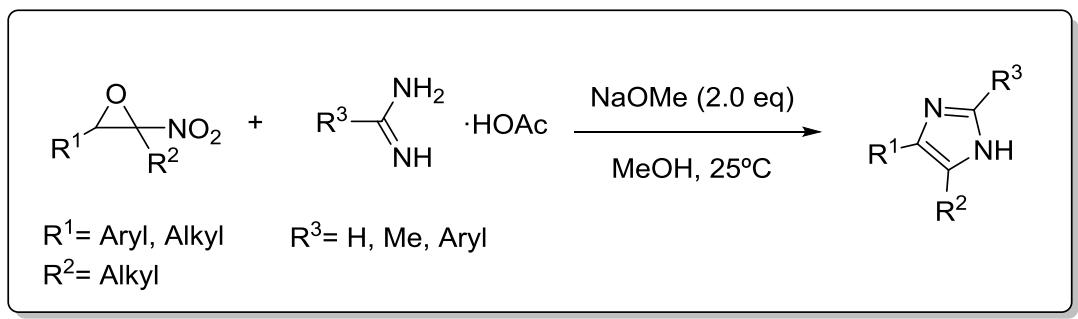

Scheme 6. Synthesis of imidazoles from nitroepoxides.

Our research group has showed interest in nitroepoxides as well. ${ }^{9,10} 3$ Hydroxy-1-nitroalkenes were prepared from optically pure O-protected (S)-lactaldehyde or (S)-mandelaldehyde via nitroaldol reaction followed by elimination. The epoxidation of the obtained nitroolefins with lithium (or potassium) tert-butylperoxide gave the corresponding niroepoxide with high stereoselectivity (up to 19/1). The palladium catalyzed hydrogenation of the resulting nitroepoxides afforded the corresponding anti-nitroaldols as main product and oximes as a secondary product (Scheme 7).

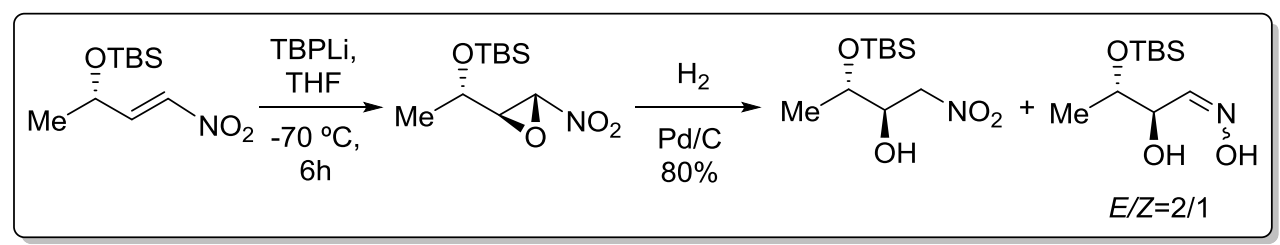

Scheme 7. Stereoselective synthesis of nitroaldols.

\footnotetext{
9 Jain, A.; Rodríguez, S.; López, I.; González, F. V. Tetrahedron 2009, 65 (40), 8362.

${ }^{10}$ Agut, J.; Vidal, A.; Rodríguez, S.; González, F. V. J. Org. Chem. 2013, 78 (11), 5717.
} 
Our most interesting contribution to the chemistry of the $\alpha$ nitroepoxides was the synthesis of 1,2-diamines starting from nitroepoxides. ${ }^{10}$ We began our studies of the preparation of vicinal diamines by combining the $\alpha$-methyl- $\beta$-phenyl-nitroepoxide with 2 equivalents of benzylamine in dichloromethane for $2 \mathrm{~h}$ and then, 2 equivalents of sodium borohydride for $12 \mathrm{~h}$. The corresponding diamine was obtained as a 9:1 mixture of stereoisomers, with the anti- isomer as the major one (Scheme 8). The chemical yield and the stereoselectivity were improved when some changes were introduced: the use of 1,2dichloroethane as a solvent, sodium triacetoxyborohydride as a reducing agent and the first step was carried out for longer. To study the scope of the reaction some nitroepoxides displaying different substituents on the structure were subjected to optimal reaction conditions. The nitroepoxides having an aryl group at the $\beta$-position and an alkyl group at the $\alpha$-position gave good yields and high stereoselectivity, while compounds with alkyl groups at both positions gave poor selectivities.

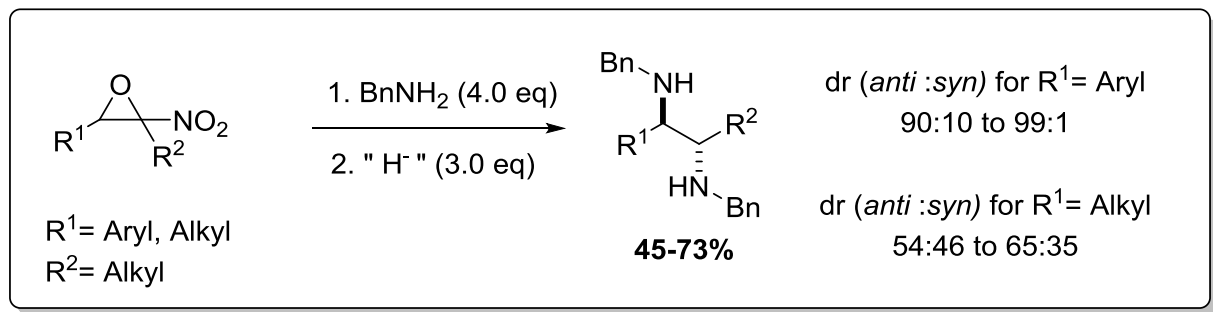

Scheme 8. Synthesis of vicinal diamines from nitroepoxides.

Under the same reaction conditions as mentioned above but, when chiral L- $\alpha$-methyl benzylamine was used, we observed something interesting. Chiral diamines were prepared with $55-70 \%$ yield and one of the possible four isomers $(1 R, 2 S)$ was formed with high stereoselectivity ( $>88 \%$ d.e.). Our understanding of this interesting process is as follows. In the case of using a chiral amine, the process constitutes a DYKAT. The reaction between aminoketone and a second equivalent of the amine would yield an isomeric mixture of $\alpha$ aminoimines (Scheme 9). These intermediates would go into a 
DYKAT: isomeric $\alpha$-aminoimines can interconvert to furnish the $R$ isomer as the main product, which upon reduction would furnish the final diamine. With this methodology, chiral vicinal diamines, which are important building blocks found in many chiral catalysts and intermediates in the synthesis of biologically active small molecules, ${ }^{11}$ can be obtained in high stereoselectivity.

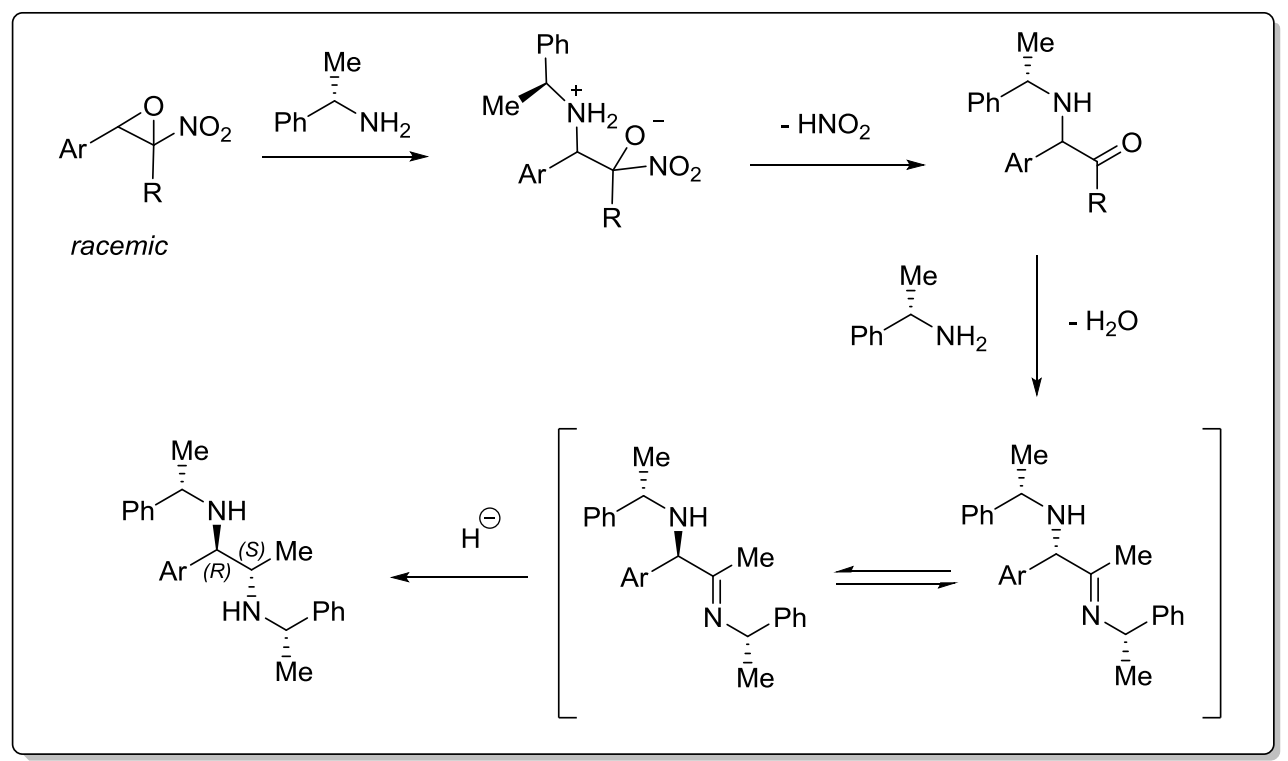

Scheme 9. DYKAT occurs when optically active amine is used.

\section{Heterocyclic Compounds}

\subsection{Quinoxalines}

Quinoxaline derivatives are an important class of heterocyclic compounds in which $\mathrm{N}$ replaces the positions 1 and 4 of the naphthalene ring. Quinoxaline structure serves as a precursor to assembly a large number of new compounds for diverse applications in

${ }^{11}$ (a) Lucet, D.; Le Gall, T.; Mioskowski, C. Angew. Chemie - Int. Ed. 1998, 37 (19), 2580. (b) Kim, H. J.; Kim, W.; Lough, A. J.; Kim, B. M.; Chin, J. J. Am. Chem. Soc. 2005, 127 (48), 16776. (c) Marqués-López, E.; Merino, P.; Tejero, T.; Herrera, R. P. European J. Org. Chem. 2009, 15, 2401. 
electrochemical materials and in pharmacological industry. ${ }^{12}$ Examples of natural products with the quinoxaline moiety exhibiting biological activities are scarce, e.g. echinomicyn and triostin A (Figure 1), but there is also a vast scope of synthetic quinoxaline derivatives which exhibited antibacterial, ${ }^{13}$ antiviral ${ }^{14}$ and/or anticancer ${ }^{15}$ activities. Thus, the development of new facile methodology to construct these heterocyclic compounds, results interesting since the actual synthetic routes have several limitations.

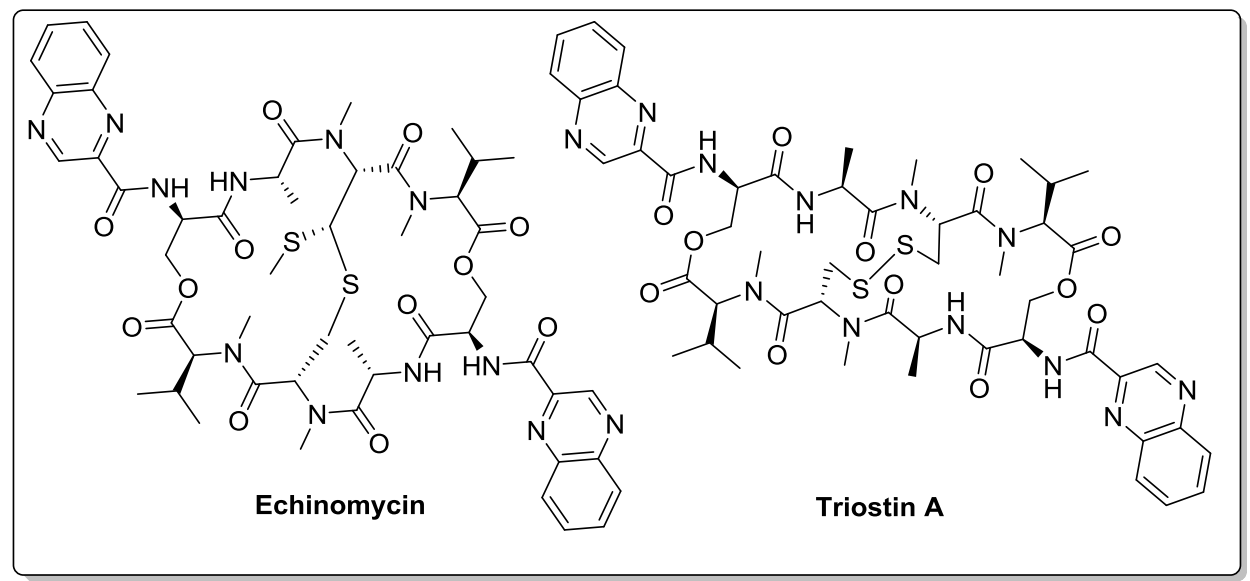

Figure 1. Natural bioactive compounds that exhibit quinoxaline moiety.

A common method for the preparation of the quinoxaline ring is the condensation of 1,2-dicarbonyl compounds with 1,2-diamines. ${ }^{16}$ However, synthetic approaches to differently substituted 1,2-dicarbonyl compounds are usually step intensive and typically involve redox approaches. Other synthetic approaches have been reported to circumvent this limitation; for example, Antoniotti et al. reported the

\footnotetext{
${ }^{12}$ Pereira, J.; Pessoa, A. M.; Cordeiro, M. N. D. S.; Fernandes, R.; Prudêncio, C.; Noronha, J. P.; Vieira, M. Eur. J. Med. Chem. 2015, 97, 664.

${ }^{13}$ Vieira, M.; Pinheiro, C.; Fernandes, R.; Noronha, J. P.; Prudêncio, C. Microbiol. Res. 2014, 169 (4), 287.

${ }^{14}$ You, L.; Cho, E. J.; Leavitt, J.; Ma, L.-C.; Montelione, G. T.; Anslyn, E. V; Krug, R. M.; Ellington, A.; Robertus, J. D. Bioorg. Med. Chem. Lett. 2011, 21 (10), 3007.

${ }^{15}$ Zarranz, B.; Jaso, A.; Aldana, I.; Monge, A. Bioorg. Med. Chem. 2004, 12 (13), 3711.

${ }^{16}$ Bandyopadhyay, D.; Mukherjee, S.; Rodriguez, R. R.; Banik, B. K. Molecules 2010, $15(6), 4207$.
} 
synthesis of quinoxalines from simple epoxides via oxidative coupling with 1,2-diamino aryl compounds catalyzed by bismuth powder in the presence of an additive (copper (II) triflate or triflic acid) (Scheme 10). ${ }^{17}$ However, under these conditions polymerization of some epoxides was observed and in consequence lower yields were obtained. This approach also needs high temperatures and DMSO as a solvent, which completely removal is usually laborious.

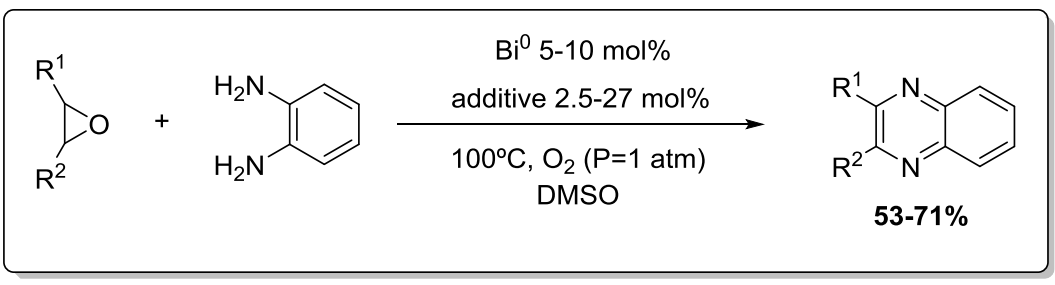

Scheme 10. Synthesis of quinoxalines from epoxides

An interesting and fast two-step sequential synthesis of quinoxalines starting from simple ketones via their $\alpha$-hydroxylimino ketone derivatives, and condensation of the latter with 1,2-diaminobenzene under microwave irradiation, was described by Padmavathy et al. ${ }^{18}$ In a first step, simple ketone was converted into $\alpha$-hydroxylamine ketone intermediate using concentrated $\mathrm{HCl}$ - sodium nitrite combination. Then, the oxime intermediate was mixed with 1,2-diaminobenzene and the mixture was subjected to $\mathrm{MW}$ irradiation during $9 \mathrm{~min}$. With this fast methodology (overall process $<2 \mathrm{~h}$ ), quinoxalines were prepared in high chemical yields (Scheme 11).

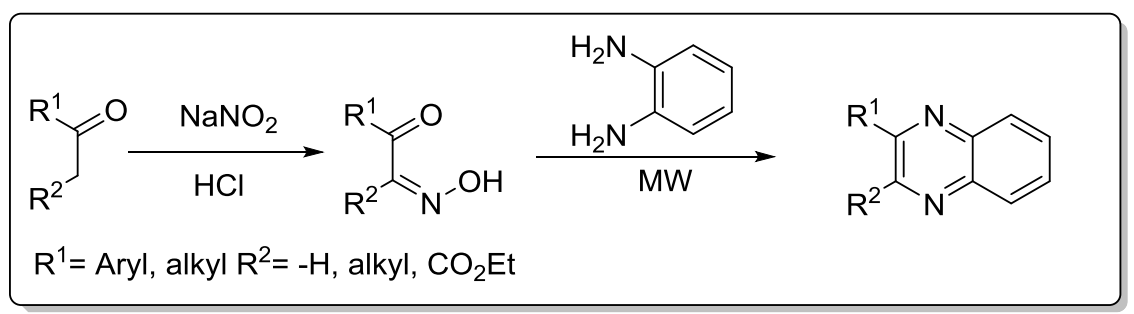

Scheme 11

\footnotetext{
${ }^{17}$ Antoniotti, S.; Duñach, E. Tetrahedron Lett. 2002, 43 (22), 3971.

${ }^{18}$ Padmavathy, K.; Nagendrappa, G.; Geetha, K. V. Tetrahedron Lett. 2011, 52 (4), 544.
} 
There are many reports that describe one-pot procedures to obtain quinoxalines from different starting materials, such as 1,2-diols, ${ }^{19}$ alkynes ${ }^{20}$ or arylallenes. ${ }^{21}$ However, all these procedures are suspect to involve the in situ formation of diketone followed by condensation with $o$-phenylenediamine, since all of them need oxidative conditions and the use of organometallic catalysts, such as ruthenium or gold.

Tsogoeva's group proposed a one-pot organocatalytic synthesis to afford quinoxalines from nitroepoxides. ${ }^{22}$ In that study, trans- $\beta$-methyl$\beta$-nitrostyrene was epoxidized to the corresponding nitroepoxide by using TBHP as an oxidant, hexane as a solvent and DBU as a catalyst. Then, $o$-phenylenediamine was added to the obtained nitroepoxide and the reaction mixture was stirred to afford the quinoxaline compound. However, these conditions afforded quinoxalines in low yield (30\%), then yields were increased (67\%) by addition of hexafluoroisopropanol (HFIP) within the $o$-phenylenediamine. The differences between her reaction and ours will be explained in the corresponding chapter of this Thesis.

\section{2. $1,2,3,4$ - Tetrahydroquinoxalines}

1,2,3,4 - Tetrahydroquinoxaline is a class of heterocyclic compounds which consists of a benzene ring fused with a piperazine ring or in other words, it is a reduced form of quinoxaline. Compounds that possess a tetrahydroquinoxaline system have been studied as potent cholesteryl ester transfer protein inhibitors, ${ }^{23}$ anticonvulsants, ${ }^{24}$ and

\footnotetext{
${ }^{19}$ Cho, C. S.; Oh, S. G. Tetrahedron Lett. 2006, 47, 5633.

${ }^{20}$ Chen, C.-Y.; Hu, W.-P.; Liu, M.-C.; Yan, P.-C.; Wang, J.-J.; Chung, M.-I. Tetrahedron 2013, 69 (46), 9735.

${ }^{21}$ Cui, D.-M. M.; Zhuang, D.-W. W.; Chen, Y.; Zhang, C. Beilstein J. Org. Chem. 2011, 7 (I), 860 .

${ }^{22}$ Ibrahim, M. M.; Grau, D.; Hampel, F.; Tsogoeva, S. B. European J. Org. Chem. 2014, 2014 (7), 1401.

${ }^{23}$ Eary, C. T.; Jones, Z. S.; Groneberg, R. D.; Burgess, L. E.; Mareska, D. a.; Drew, M. D.; Blake, J. F.; Laird, E. R.; Balachari, D.; O’Sullivan, M.; Allen, A.; Marsh, V. Bioorganic Med. Chem. Lett. 2007, 17 (9), 2608.
} 
anti- HIV agents. ${ }^{25}$ Besides medicinal chemistry, tetrahydroquinoxaline derivatives have been studied as dyes with useful photophysical properties. $^{26}$

Methods for the preparation of tetrahydroquinoxalines suffer from the same drawbacks as quinoxalines, since they are usually prepared from reduction of quinoxalines. ${ }^{27}$ Nevertheless, useful asymmetric reductions of quinoxalines have been developed i.e., hydrogenation of quinoxalines catalyzed by iridium-diphosphine complexes. ${ }^{28}$ Despite the variety of examples of different iridium catalysts employed for this reaction, the scope seems to be limited to quinoxalines with only one substitution in the heterocyclic ring. To surpass this limitation, Jie Qin and coworkers have developed cationic ruthenium complexes of chiral monotosylated diamines to afford 2- (aryl or alkyl) and 2,3- (alkyl, alkyl) tetrahydroquinoxalines. ${ }^{29}$ However, no details were reported for the hydrogenation of 2,3- aryl, alkyl or 2,3-aryl, aryl quinoxalines. Another disadvantage of both iridium and ruthenium catalyzed hydrogenations; is that high $\mathrm{H}_{2}$ pressures are required.

Other methodologies are reported in the literature. One of them involves the formation of the tetrahydroquinoxaline core from aproppiate 2-nitrosoaniline and an unsaturated electrophile via Michael addition followed by aza-aldol reaction, completed by reduction of the hydroxylamine formed (Sheme 12) ${ }^{30}$ Although only catalytic amount of base was necessary to perform the first step of the reaction from a

\footnotetext{
${ }^{24}$ Pouw, B.; Nour, M.; Matsumoto, R. R. Eur. J. Pharmacol. 1999, 386, 181.

${ }^{25}$ Patel, M.; McHugh, R. J.; Cordova, B. C.; Klabe, R. M.; Bacheler, L. T.; EricksonViitanen, S.; Rodgers, J. D. Bioorg. Med. Chem. Lett. 2001, 11, 1943.

${ }^{26}$ Chandrasekaran, Y.; Dutta, G. K.; Kanth, R. B.; Patil, S. Dye. Pigment. 2009, 83 (2), 162.

${ }^{27}$ Figueras, J. J. Org. Chem. 1966, 31 (March), 803.

${ }^{28}$ Cartigny, D.; Nagano, T.; Ayad, T.; Genêt, J.-P.; Ohshima, T.; Mashima, K.; Ratovelomanana-Vidal, V. Adv. Synth. Catal. 2010, 352 (11-12), 1886.

${ }^{29}$ Qin, J.; Chen, F.; Ding, Z.; He, Y.-M.; Xu, L.; Fan, Q.-H. Org. Lett. 2011, 13 (4), 6568.

${ }^{30}$ Królikiewicz, M.; Błaziak, K.; Danikiewicz, W.; Wróbel, Z. Synlett 2013, 24 (15), 1945.
} 
mechanistic point of view, an excess of base was used to accelerate the reaction because of the instability of intermediate. When catalytic amount of base was used, product was formed so slowly that the rate of its decomposition competed with that of its formation. Due to intermediate instability, the reduction step using $\mathrm{Zn}$ and acetic acid was performed without purification. A similar, but microwave-assisted procedure described by Merisor et al. starts from $\mathrm{N}$-prenyl-2nitroanilines instead of 2-nitrosoanilines, and triethyl phosphite as a reducing agent. ${ }^{31}$ The proposed mechanism begins with the reduction of nitro group into nitroso group, which undergoes an intramolecular ene reaction with the 2-methylpropenyl group of the molecule, resulting in the formation of a cyclic hydroxyl amine that is finally reduced by the phosphite to yield the cyclic amine. However, the formation of byproducts consisting on the N-ethylation of one or both nitrogen atoms could not be suppressed by using microwaves.

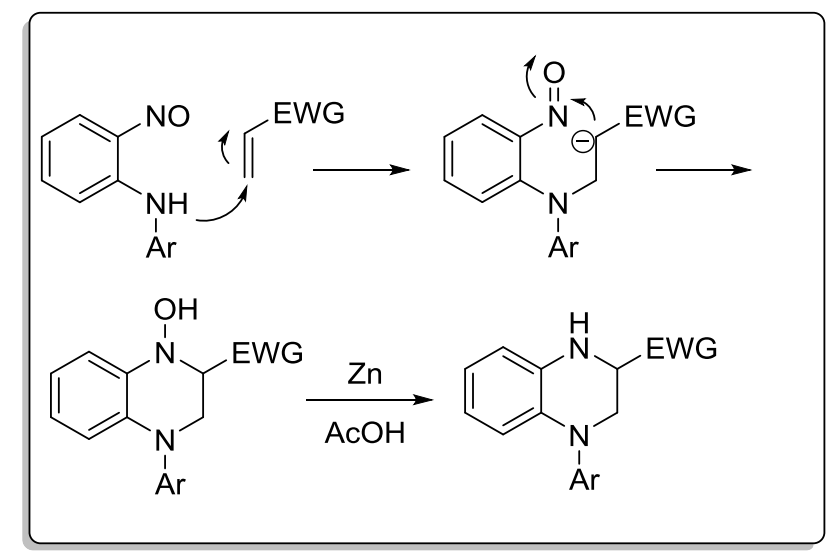

Scheme 12. Synthesis of tetrahydroquinoxalines from 2-nitrosoanilines.

An interesting method for the preparation of tetrahydroquinoxaline core and further conversion into more complex fused rings was described by Si-Li Zhou and coworkers. ${ }^{32}$ The reaction consists on an asymmetric hetero-Diels-Alder reaction to form the tetrahydroquinoxaline moiety, followed by Friedel-Crafts to construct the fused ring (Scheme 13). 1,2-

\footnotetext{
${ }^{31}$ Merisor, E.; Conrad, J.; Mika, S.; Beifuss, U. Synlett 2007, 2007 (13), 2033.

${ }^{32}$ Zhou, S.-L.; Li, J.-L.; Dong, L.; Chen, Y.-C. Org. Lett. 2011, 13 (21), 5874.
} 
Diimide (diene) and an aldehyde (which enol form constitutes the dienophile) were reacted in the presence of $O$-TMS-diphenylprolinol and benzoic acid (BA) to form the corresponding tetrahydroquinoxaline and then, TFA was added to obtain the final product with $66 \%$ yield and $94 \%$ ee.

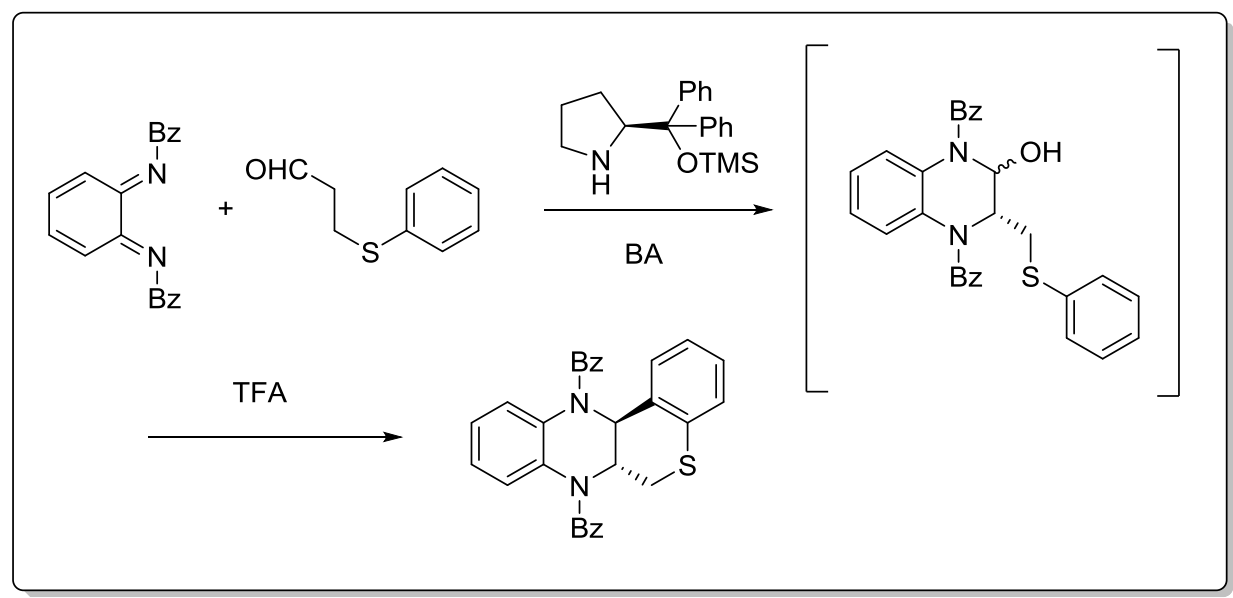

Scheme 13. Synthesis of tetrahydroquinoxalines by hetero-Diels-Alder.

Another asymmetric methodology for the synthesis of substituted heterocycles via aziridine, afforded the synthesis of $(1,2,3,4-$ tetrahydroquinoxalin-2-yl)methanols from the corresponding 2bromoanilines, which were converted into 2-aminomethyl substituted aziridines which were used as chiral scaffolds for the following synthesis. ${ }^{33}$ After many protection/deprotection steps, aziridines were sequentially transformed into the final tetrahydroquinoxaline compounds (Scheme 14).

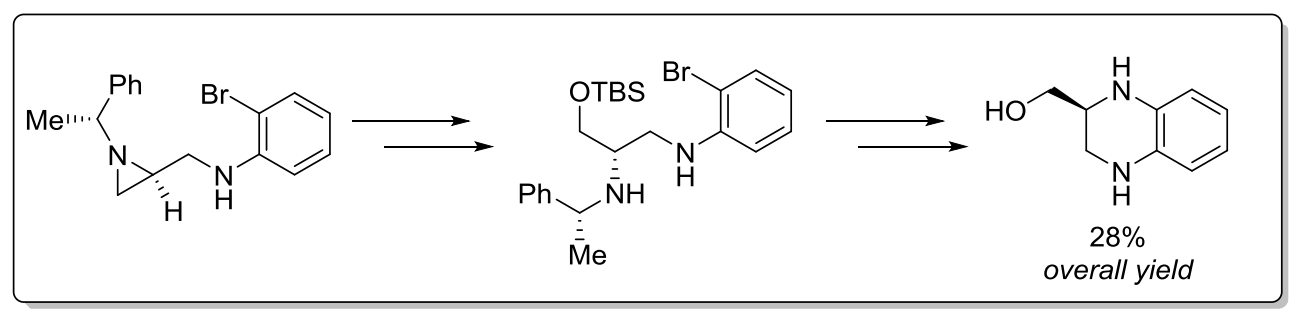

Scheme 14. Synthesis of tetrahydroquinoxalines from aziridines.

\footnotetext{
${ }^{33}$ Chan Kim, J.; Choi, H. G.; Kim, M. S.; Ha, H.-J.; Lee, W. K. Tetrahedron 2010, 66 (40), 8108.
} 


\subsection{Piperazines}

The piperazine moiety has been classified as a "privileged scaffold" in medicinal chemistry ${ }^{34}$ and is frequently found in many natural products as well as being a large class of biologically active compounds (Figure 2). Aqueous soluble piperazine derivatives are also relevant in environmental chemistry, since piperazine can react with atmospheric carbon dioxide forming stable carbamates and consequently enhance its solubility in water. ${ }^{35}$ Although the condensation of $\alpha$-amino acids to obtain diketopiperazines is quite common in the literature, ${ }^{36}$ procedures to obtain substituted piperazines are scarce and will be summarized below.

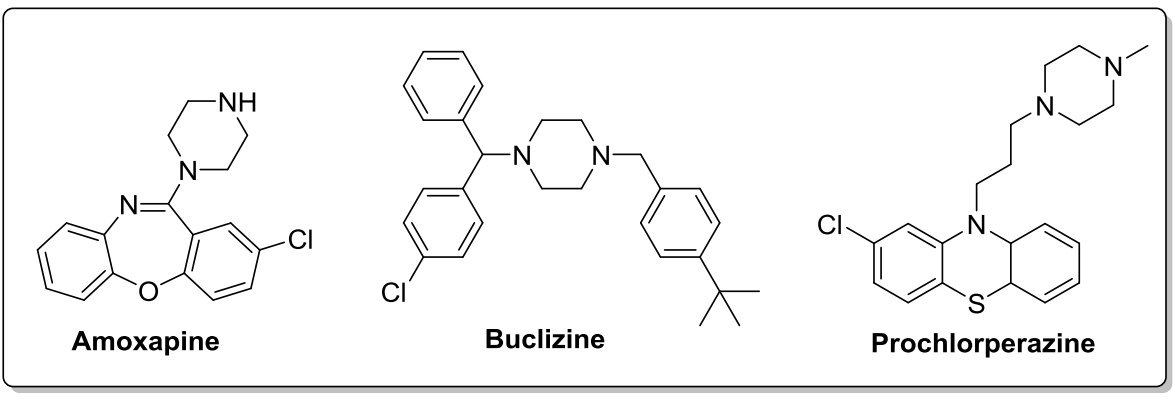

Figure 2. Bioactive compounds that exhibit piperazine moiety.

One of the first described methods consists on the condensation of 1,2diketones with ethylenediamine followed by reduction. ${ }^{37}$ This method has the same disadvantages than those to prepare tetrahydroquinoxalines: the accesibility of diketones and the proper reducing agent to generate stereoselectivity. A similar approach that solve these issues and could be used to synthetize optically pure chiral

\footnotetext{
${ }^{34}$ Horton, D.; Bourne, G. T.; Smythe, M. L. Cancer Res. 2003, 103 (3), 893.

${ }^{35}$ Ramazani, R.; Mazinani, S.; Jahanmiri, A.; Van der Bruggen, B. Int. J. Greenh. Gas Control 2016, 45, 27.

${ }^{36}$ Bull, S. D.; Davies, S. G.; Garner, C.; Parkes, A. L.; Roberts, P. M.; Sellers, T. G. R.; Smith, A. D.; Tamayo, J.; Thomson, J. E.; Vickers, R. J. New J. Chem. 2007, 31 (4), 486.

${ }^{37}$ Giardinà, D.; Gulini, U.; Massi, M.; Piloni, M. G.; Pompei, P.; Rafaiani, G.; Melchiorre, C. J. Med. Chem. 1993, 36 (6), 690.
} 
piperazines was reported by Gust et al. ${ }^{38}$ They used 1,2-diaryl ethylenediamine instead of ethylenediamine, and dimethyl oxalate (Scheme 15). The reaction affords the 2,3-diarylpiperazine-5,6-dione as an intermediate, which already has the substitution in $\mathrm{C}_{\mathrm{sp} 3}$, and thus the ketone can be reduced to methylene with borane without creating new stereogenic centers. However, authors didn't exploit this feature because the final obtained piperazines were symmetric.

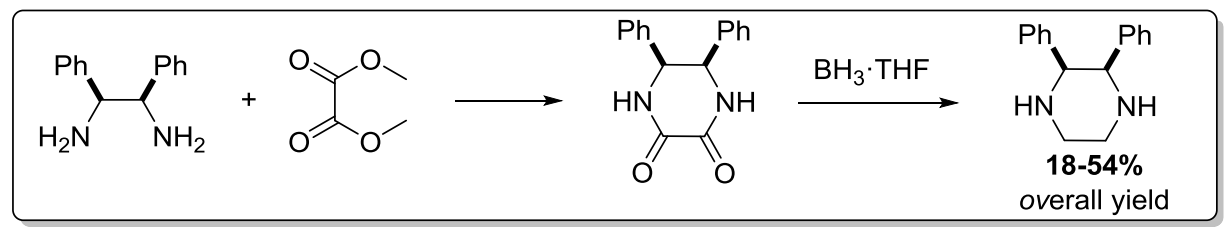

Scheme 15. Synthesis of piperazines from 1,2-diesters.

Diastereoselective synthesis of 2,3-diarylpiperazines via intramolecular reductive coupling of bisimines using a Brønsted acid and Manganese (0). ${ }^{39}$ The process presumably involves activation of the imine by the Brønsted acid followed by reduction of the iminium on the manganese surface to form a carbon-centered radical. They proposed a sixmembered transition state model for diradical termination which is consistent with the observed diastereocontrol (Scheme 16). In this model, the imine substituents are oriented trans- to each other in equatorial sites.

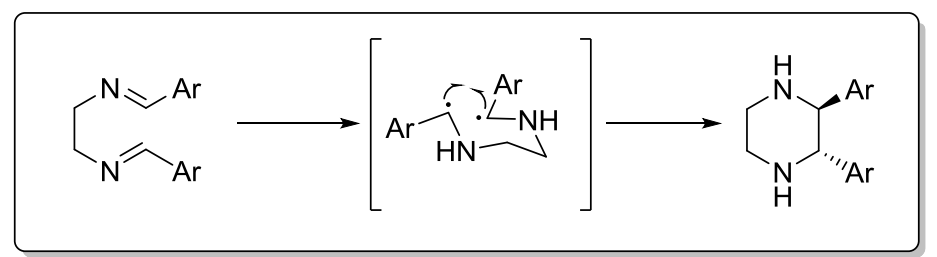

Scheme 16. Proposed transition state which explains diastereocontrol.

Madsen and coworkers have presented an atom-economical procedure for the synthesis of piperazines from amines and 1,2-diols in which

\footnotetext{
${ }^{38}$ Gust, R.; Keilitz, R.; Schmidt, K. J. Med. Chem. 2002, 45 (11), 2325.

${ }^{39}$ Mercer, G. J.; Sigman, M. S. Org. Lett. 2003, 5 (9), 1591.
} 
water is produced as the only byproduct. ${ }^{40}$ The reaction is catalyzed by $\left[\mathrm{Cp}^{*} \mathrm{IrCl}_{2}\right]_{2}$ and can be achieved in toluene as well as in aqueous solution. 1,2-Diamines condense with 1,2-diols to afford a variety of piperazines with different substitution patterns in a proposed mechanism in which the key step is an isomerization of the initially formed hydroxy imine to the corresponding amino aldehyde/ketone, followed by imination and finally a reductive elimination of the catalyst. When benzylamine is used instead of 1,2-diamines, piperazines are equally formed but two equivalents of ethyleneglycol are required. This methodology resulted to be quite substrate-dependent since the yields were excellent for the reaction between ethylenediamine and mono- or di-substituted ethyleneglycols (70 to $100 \%$ ), but lower when unsubstituted ethylene diamine or $o$-phenylendiamine was condensed with unsubstituted ethyleneglycol (35 to 69\%).

\subsection{Pyrazines}

Compounds containing the pyrazine heterocycle find numerous applications in materials science, ${ }^{41}$ medicinal chemistry, ${ }^{42}$ compounds that are responsible for the flavor and aroma of several foodstuffs and wines, ${ }^{43}$ and compounds with herbicidal activity. ${ }^{44}$ Recently, tetrasubstituted pyrazines have been discovered as semio-chemicals in orchids. $^{45}$

Main synthetic procedures for the synthesis of substituted pyrazines can be divided in two groups: self-condensation of $\alpha$-amino aldehydes ${ }^{46}$

\footnotetext{
${ }^{40}$ Lorentz-Petersen, L. L. R.; Nordstrøm, L. U.; Madsen, R. European J. Org. Chem. 2012, 2012 (34), 6752.

${ }^{41}$ Mondal, R.; Ko, S.; Bao, Z. J. Mater. Chem. 2010, 20 (47), 10568.

${ }^{42}$ Seitz, L. E.; Suling, W. J.; Reynolds, R. C. J. Med. Chem. 2002, 45, 5604.

${ }^{43}$ Adams, A.; Kimpe, N. D. Food Chem. 2009, 115 (4), 1417.

${ }^{44}$ Doležal, M.; Krá, K. 2011. Synthesis and Evaluation of Pyrazine Derivatives with Herbicidal Activity, Herbicides, Theory and Applications, Prof. Marcelo Larramendy (Ed.), ISBN: 978-953-307-975-2, InTech

${ }^{45}$ Bohman, B.; Jeffares, L.; Flematti, G.; Byrne, L. T.; Skelton, B. W.; Phillips, R. D.; Dixon, K. W.; Peakall, R.; Barrow, R. a. J. Nat. Prod. 2012, 75 (9), 1589.

${ }^{46}$ Badrinarayanan, S.; Sperry, J. Org. Biomol. Chem. 2012, 10 (10), 2126.
} 
and condensation of 1,2-diketones with primary 1,2-diamines. ${ }^{20}$ The first one is limited to symmetrically substituted pyrazines and sometimes instability of $\alpha$-amino aldehydes intermediates to certain conditions limits the scope of the reaction. The latter shares the same main limitation as quinoxaline-synthesis procedures, i.e. the access to 1,2-diketones. However, there are a few methods that describe the synthesis of unsymmetrical pyrazines avoiding the use of 1,2-diketones, e.g. the work presented by Guo and coworkers. ${ }^{47}$ In this work the total synthesis of cephalostatin 1 was described. Cephalostatin 1 is a member of a family of thirty trisdecacyclic pyrazines isolated from the marine tube worm Cephalodiscus gilchristi, which inhibits cell growth and induces apoptosis. ${ }^{48}$ In this approach, a coupling between an $\alpha$-amino methoxime and an $\alpha$-azido ketone was performed. A mechanistic pathway was also proposed (Scheme 17) in which, assuming initial formation of intermediate imine, prototropic equilibration would provide enamine which is exquisitely suited for fragmentation to bisimine. The experimental details that evoked the elucidation of the proposed mechanism were the formation of $\mathrm{N}_{2}$ gas and that the medium became basic through the production of methoxyamine.

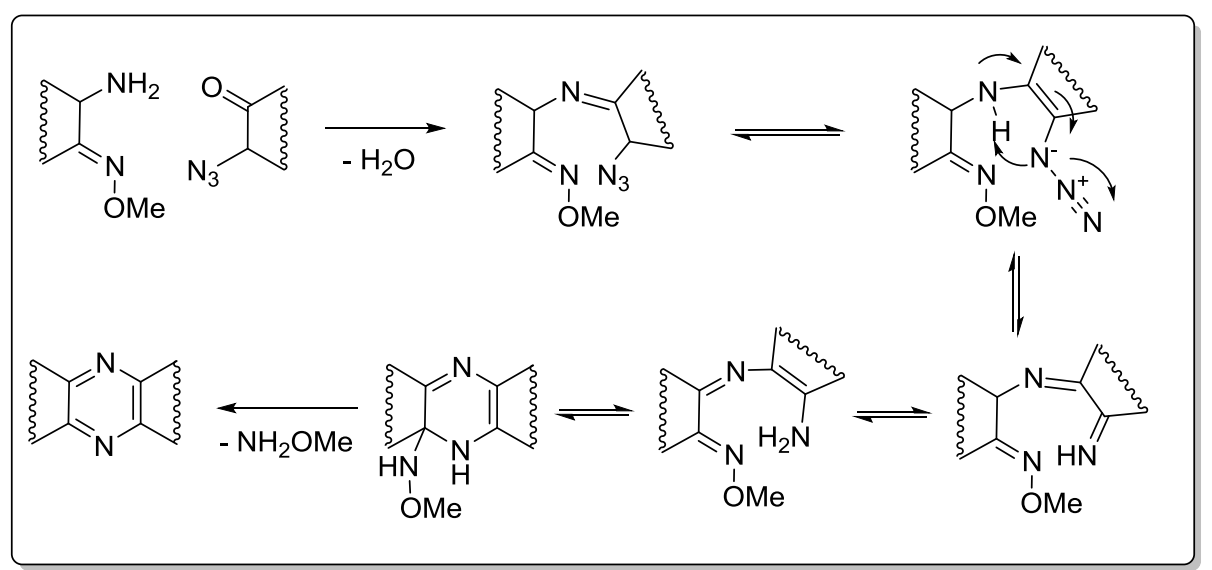

Scheme 17. Synthesis of pyrazines described by Guo et al.

\footnotetext{
${ }^{47}$ Guo, C.; Bhandaru, S.; Fuchs, P. L. J. Am. Chem. Soc. 1996, 118 (43), 10672.

${ }^{48}$ Pettit, G. R.; Inoue, M.; Kamano, Y.; Herald, D. L.; Arm, C.; Dufresne, C.; Christie, N. D.; Schmidt, J. M.; Doubek, D. L.; Krupa, T. S. J. Am. Chem. Soc. 1988, 110 (6), 2006.
} 
Another reported synthetic strategy to obtain substituted pyrazines with regiocontrol is based on reacting $\alpha$-nitro ketone with $\alpha$-amino ketone protected as the hydrochloride salt under reducing conditions, where octylviologen is used as the reducing agent. ${ }^{49}$ The use of classic reducing agents to reduce the nitro group of the nitro ketone such as zinc, tin, or iron in the presence of an acid gave a mixture of regioisomers, and in some cases, the reaction stopped at an intermediate stage, yielding hydrazines. Reaction conditions were optimized in order to afford the regiomerically pure pyrazines and avoid undesired regioisomers. Addition of the $\alpha$-amino ketone along with a hydrogen sulfite solution to the $\alpha$-nitro ketone and octylviologen solution using a syringe pump ensures that only one regioisomer is formed. Simultaneous addition over $25 \mathrm{~min}$ afforded a much cleaner product. However, it was also revealed that addition of the amino ketone must begin and end $1 \mathrm{~min}$ before the hydrogen sulfite/ potassium carbonate mixture in order to obtain a pure product. Delaying addition of the amino ketone by 1 min ensures that the amino ketone is always in excess, thus preventing reduction and selfcondensation of the nitroketone, which would result in a mixture of alkylpyrazines. The use of the syringe pump, which allows for the simultaneous addition of precise quantities of both the $\alpha$-amino ketone and the hydrogen sulfite solutions over precisely controlled times, was found to be crucial to this method (Scheme 18).

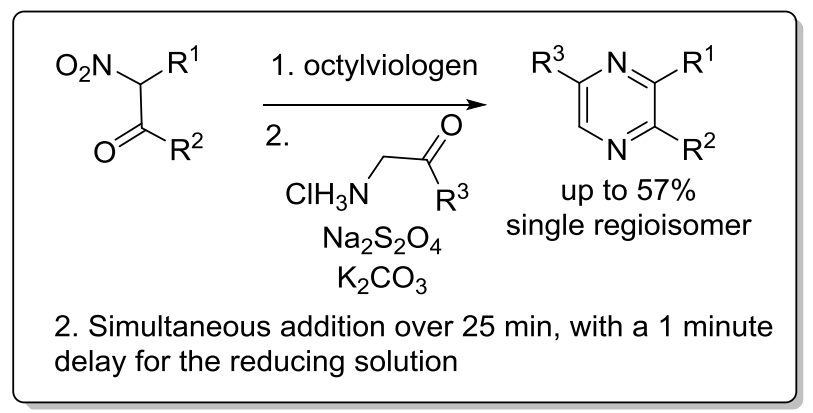

Scheme 18. Synthesis of pyrazines from 1,2-nitroketones

\footnotetext{
${ }^{49}$ Elmaaty, T. A.; Castle, L. W. Org. Lett. 2005, 7 (24), 5529.
} 


\section{Asymmetric Epoxidation of Electron-Deficient}

\section{Olefins}

Epoxides are extremely versatile synthetic compounds ${ }^{50}$ and are also present in a large array of natural products and biologically active molecules (Figure 3). ${ }^{51}$ Epoxidation of olefins constitutes one of the most convenient systems to synthetize the oxirane ring; hence the asymmetric epoxidation represents an important tool for the synthetic chemist to afford those chiral epoxides. The development by Sharpless in the early 1980s of a system which can efficiently and predictably produce either enantiomer of an epoxide from an allylic alcohol using substoichiometric quantities of titanium and tartrate became a reference for today's catalytic asymmetric synthesis. There are many reviews that illustrate the wide variety of epoxidation methodologies of olefins. ${ }^{52}$ According to the purpose of this $\mathrm{PhD}$ Thesis, representative and relevant examples for the organocatalytic asymmetric epoxidation of electron-deficient olefins will be presented.

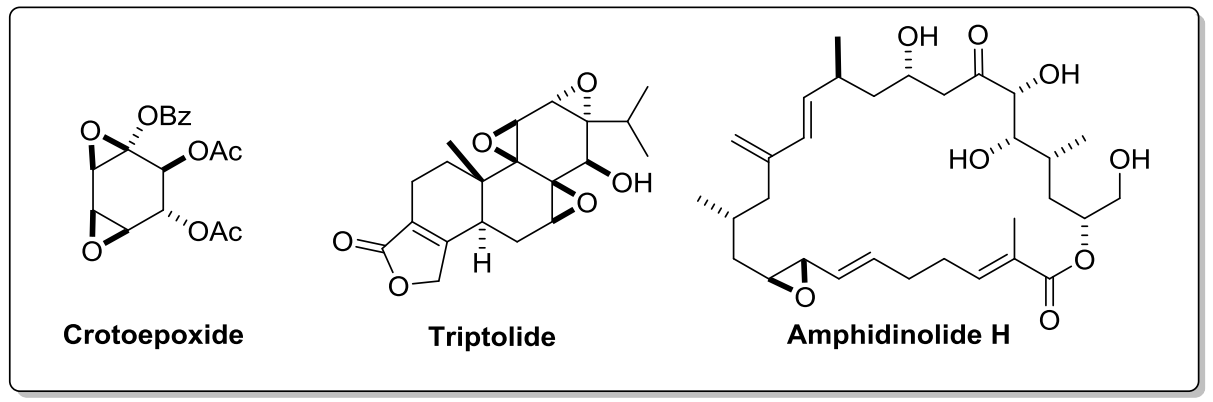

Figure 3. Epoxide moiety in natural bioactive compounds.

\subsection{Peptide Catalysis}

In recent decades, peptides have become attractive catalysts for asymmetric transformations. In early 80 s, Julià and coworkers (and

50 a) Schneider, C. Synthesis 2006, 3919

${ }^{51}$ Miyashita, K.; Imanishi, T. Chem. Rev. 2005, 105 (12), 4515.

52 (a) Porter, M. J.; Skidmore, J. Chem. Commun. 2000, 1215. (b) Davis, R. L.; Stiller, J.; Naicker, T.; Jiang, H.; Jørgensen, K. A. Angew. Chemie Int. Ed. 2014, 53 (29), 7406. (c) Zhu, Y.; Wang, Q.; Cornwall, R. G.; Shi, Y. Chem. Rev. 2014, 114, 8199. 
later in collaboration with Colonna) reported a polypeptide-catalyzed asymmetric epoxidation of $(E)$-chalcone with $\mathrm{H}_{2} \mathrm{O}_{2}-\mathrm{NaOH}$ in toluene - water. ${ }^{53}$ The reaction system was triphasic due to the insolubility of the polypeptide catalyst in toluene and water. Chalcone epoxide was obtained in $85 \%$ yield and $93 \%$ ee with poly-L-alanine at room temperature for $24 \mathrm{~h}$. In their collaborative research, Julià and Colonna concluded that an increase of the poly-L-alanine chain from $n=5$ to 30 resulted in an increase of enantioselectivity from $11 \%$ to $96 \%$, respectively. Effect of solvent, polypeptide nature, and scope of the substrate were also studied. Attempts to achieve the corresponding epoxide from trans- $\beta$-methyl- $\beta$-nitrostyrene using this methodology failed since the desired compound was obtained with only $50 \%$ yield and $7 \%$ ee.

\subsection{Bifunctional Base-Catalyzed Epoxidation}

Many chiral bifunctional bases have been developed for the asymmetric epoxidation of electron-deficient olefins. The general behavior of that class of catalyst includes in the same entity a basic amine to deprotonate the corresponding hydroperoxide and a moiety that binds non-covalently the substrate. A common example of those catalysts is the chiral $\beta$-amino alcohols. ${ }^{54}$ In 2005 , Lattanzi reported that readily available $\alpha, \alpha$ - diphenyl-L-prolinol could act as the catalyst for epoxidation of enones with TBHP, giving up to $80 \%$ ee for chalcones. ${ }^{55}$ In this reaction, TBHP was deprotonated by the amine of the catalyst to form a tight ion pair. The hydroxyl group of the catalyst was thought to coordinate with the enone via hydrogen bonding to activate the double bond and direct addition of the peroxide anion stereoselectively (Scheme 19). Many other amino alcohols different from

\footnotetext{
${ }^{53}$ Juliá, S.; Guixer, J.; Masana, J.; Rocas, J.; Colonna, S.; Annuziata, R.; Molinari, H. J. Chem. Soc. Perkin Trans. I 1982, 1317.

${ }^{54}$ Meninno, S.; Lattanzi, A. Chem. Commun. 2013, 49 (37), 3821.

${ }^{55}$ Lattanzi, A. Org. Lett. 2005, 7 (13), 2579.
} 
diphenylprolinol were tested for the epoxidation of various electrondeficient olefins aside from chalcones. ${ }^{56,57}$

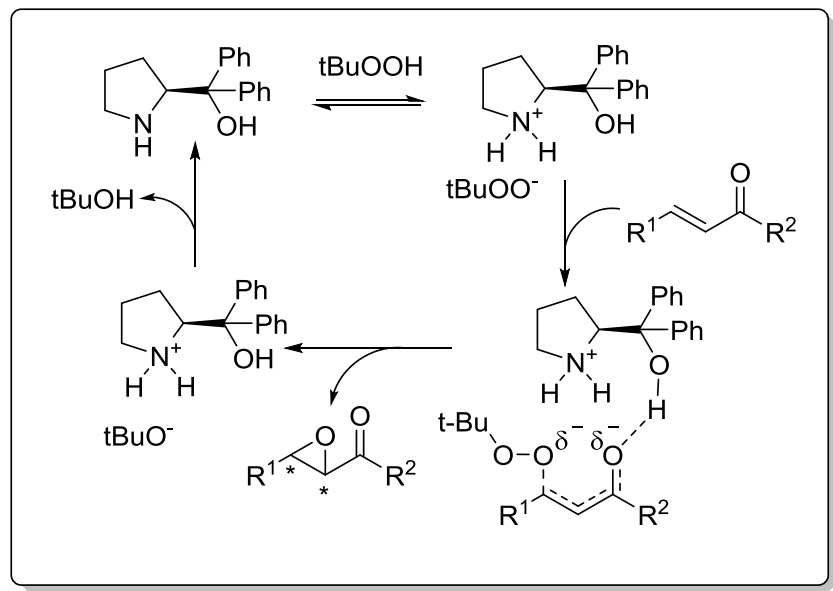

Scheme 19. Catalytic asymmetric epoxidation of enones with diphenyl prolinol.

Cinchona alkaloids and their derivatives have also been investigated for asymmetric epoxidation. Lattanzi and co-workers also reported that 1,1-dicarbonyl terminal olefins were enantioselectively epoxidized with cinchona thiourea catalyst and TBHP to give terminal epoxides with ee up to $99 \%$ (Scheme 20). ${ }^{58}$ Analogously to the aforementioned amino alcohols, the amino group from the quinuclidine moiety deprotonates TBHP and the thiourea activates the enone via H-bonding.

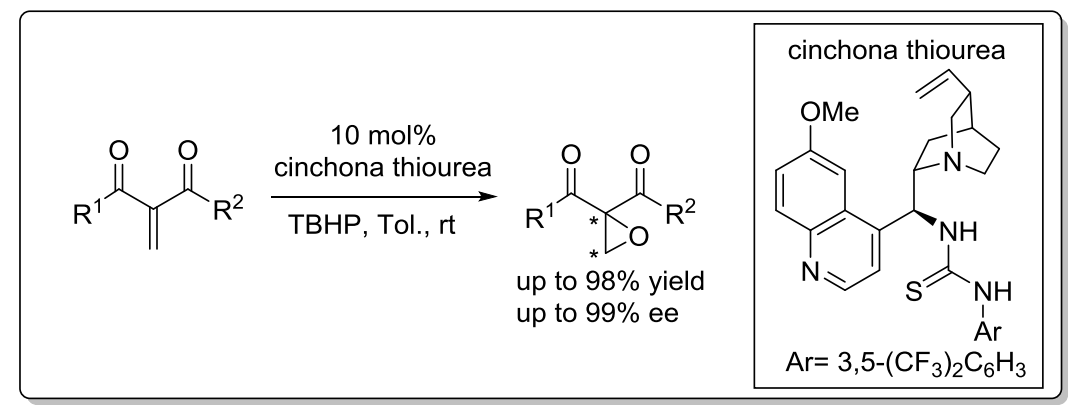

Scheme 20. Asymmetric epoxidation of terminal olefins with cinchona-derived thiourea catalyst.

\footnotetext{
${ }^{56}$ Zheng, C. W.; Li, Y. W.; Yang, Y. Q.; Wang, H. F.; Cui, H. F.; Zhang, J. K.; Zhao, G. Adv. Synth. Catal. 2009, 351 (10), 1685.

${ }^{57}$ Russo, A.; Lattanzi, A. Org. Biomol. Chem. 2010, 8 (11), 2633.

${ }^{58}$ Russo, A.; Galdi, G.; Croce, G.; Lattanzi, A. Chem. - A Eur. J. 2012, 18 (20), 6152.
} 


\subsection{Pyrrolidine-Based Catalysis}

One of the most versatile families of catalysts for the enantioselective epoxidation of olefins, as well in other reactions like Michael addition, is the diaryl prolinol derivatives family. These catalysts were developed independently in 2005 by Hayasi's ${ }^{59}$ and Jørgensen's ${ }^{60}$ groups. Concerning the application for the asymmetric synthesis of epoxides, $\alpha, \beta$-unsaturated aldehydes were epoxidized in high chemical yields, high dr values ( $\geq 90: 10$ ) and high ee's (up to 98\%) using benign conditions such as EtOH: $\mathrm{H}_{2} \mathrm{O}$ (3:1) solvent mixture and $\mathrm{H}_{2} \mathrm{O}_{2}$ as an oxidant. ${ }^{61}$ The proposed mechanism firstly involves a reaction between the chiral amine catalyst and the $\alpha, \beta$-unsaturated aldehyde to generate an iminium salt intermediate to which $\mathrm{H}_{2} \mathrm{O}_{2}$ nucleophilically adds at the $\beta$-carbon to form an enamine intermediate. Upon ring closure and subsequent hydrolysis of the epoxy iminium ion, the chiral epoxide is formed with regeneration of the amine catalyst (Scheme 21). In a subsequent computational study, ${ }^{62}$ Santos and co-workers indicated that besides being an oxidant, $\mathrm{H}_{2} \mathrm{O}_{2}$ could act also as a cocatalyst to promote initial formation of the iminium ion intermediate, and a hydroxyl ion was likely involved in the epoxidation.

\footnotetext{
${ }^{59}$ Hayashi, Y.; Gotoh, H.; Hayashi, T.; Shoji, M. Angew. Chemie - Int. Ed. 2005, 44 (27), 4212.

${ }^{60}$ Marigo, M.; Wabnitz, T. C.; Fielenbach, D.; Jørgensen, K. A. Angew. Chemie - Int. Ed. 2005, 44 (5), 794.

${ }^{61}$ Zhuang, W.; Marigo, M.; Jørgensen, K. A. Org. Biomol. Chem. 2005, 3, 3883.

${ }^{62}$ Duarte, F. J. S.; Santos, A. G. Org. Biomol. Chem. 2013, 11 (41), 7179.
} 


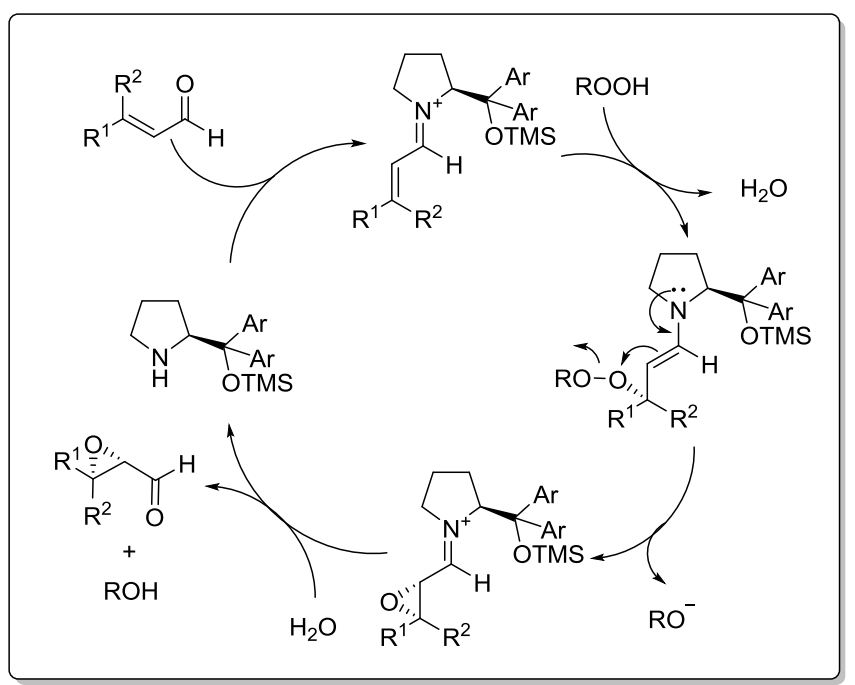

Scheme 21. Enamine catalytic asymmetric epoxidation of enals.

Chiral pyrrolidine derivatives have also been developed for enantioselective epoxidation of olefins. For example, a series of $\beta$ fluorinated pyrrolidines was investigated for epoxidation of enals by Gilmour and co-workers. Among them, (S)-2-(fluorodiphenylmethyl)pyrrolidine (Figure 4) was found to be a highly effective catalyst, giving epoxides with up to $98 \%$ ee. ${ }^{63}$ The higher ee obtained using the aforesaid catalyst, as compared to non-fluorinated version of the catalyst (Figure 4), could be attributed to the fluorine-iminium ion gauche effect, which allowed the iminium ion to adopt a conformation more favorable for asymmetric induction.

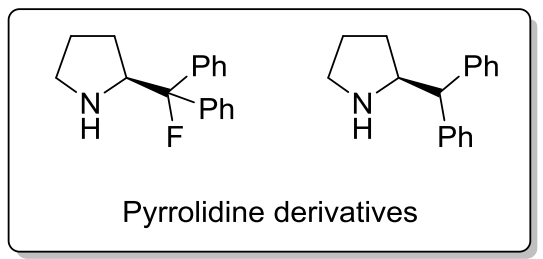

Figure 4. Pyrrolidine derivatives.

Asymmetric epoxidation of enals with diarylprolinol silyl ether catalysts has been applied to the synthesis of a number of building

\footnotetext{
${ }^{63}$ Sparr, C.; Schweizer, W. B.; Senn, H. M.; Gilmour, R. Angew. Chemie - Int. Ed. 2009, 48 (17), 3065.
} 
blocks, natural products, and bioactive molecules. For example, hirsutellone B, (-)-aspinolide A and jaspines A and B were synthetized using chiral epoxide intermediates obtained via enamine/iminium catalysis. $^{64}$

\subsection{Chiral Amine Salt Catalysis}

Various chiral amine salt catalysts were investigated for epoxidation of $\alpha, \beta$-unsaturated aldehydes and ketones. In 2006, MacMillan and coworkers reported that a variety of enals were effectively epoxidized with a chiral imidazolidinone salt catalyst in the presence of iminoiodinane $\mathrm{PhI}=\mathrm{NNs}$ and $\mathrm{AcOH}$, giving the corresponding epoxides in $72-95 \%$ yield and $85-97 \%$ ee. ${ }^{65}$ The epoxidation was proposed to proceed via an iminium/enamine pathway such as proline/pyrrolidine derived catalysts. Studies showed that $\mathrm{PhI}=\mathrm{O}$ was slowly released in situ from $\mathrm{PhI}=\mathrm{NNs}$ under mild acidic conditions and acted as the real oxidant. ${ }^{65}$ In that case, the enantioselectivity was controlled by the ammonium chiral structure, but other authors have reported catalysts being a chiral counteranion the responsible for the enantiocontrol ${ }^{66}$ or a catalyst with both chiral structures ammonium and counteranion increasing the ee (Scheme 22). ${ }^{67}$

${ }^{64}$ (a) Nicolaou, K. C.; Sarlah, D.; Robert Wu, T.; Zhan, W. Angew. Chemie - Int. Ed. 2009, 48 (37), 6870. (b) Shelke, A. M.; Rawat, V.; Suryavanshi, G.; Sudalai, A. Tetrahedron Asymmetry 2012, 23 (22-23), 1534. (c) Urano, H.; Enomoto, M.; Kuwahara, S. Biosci. Biotechnol. Biochem. 2010, 74 (1), 152.

${ }^{65}$ Lee, S.; MacMillan, D. W. C. Tetrahedron 2006, 62 (49), 11413.

${ }^{66}$ Wang, X.; List, B. Angew. Chemie - Int. Ed. 2008, 47 (6), 1119.

${ }^{67}$ Lifchits, O.; Reisinger, C. M.; List, B. J. Am. Chem. Soc. 2010, 132 (30), 10227. 


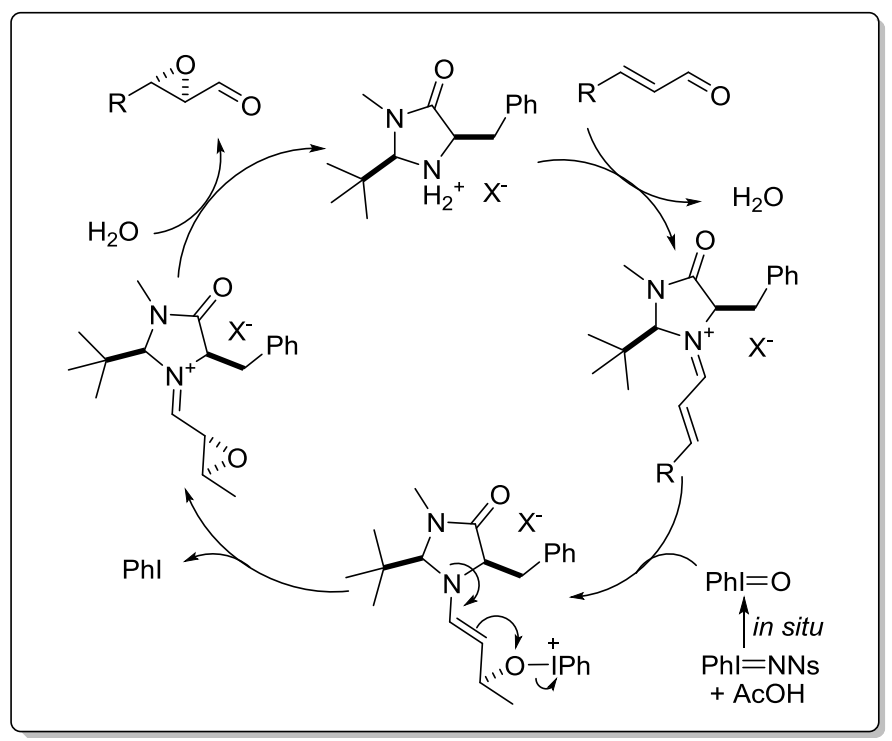

Scheme 22. Imidazolinone salt catalysis.

\subsection{Chiral Ketone-Catalyzed Epoxidation}

Dioxiranes are highly effective species for epoxidation of olefins. A chiral dioxirane can be generated in situ from a chiral ketone and an oxidant such as oxone $\left(2 \mathrm{KHSO}_{5} \cdot \mathrm{KHSO}_{4} \cdot \mathrm{K}_{2} \mathrm{SO}_{4}\right)$ or $\mathrm{H}_{2} \mathrm{O}_{2}$ and resulting dioxirane is converted back to the ketone upon epoxidation of an olefin to complete a catalytic cycle (Scheme 23). Significant progress has been made for the ketone-catalyzed asymmetric epoxidation. A variety of structurally diverse ketone catalysts have been investigated and reported by a number of laboratories. A wide range of olefins, particularly unfunctionalized trans-olefins and trisubstituted olefins, have been effectively epoxidized with high enantioselectivity. ${ }^{68}$

${ }^{68}$ (a) Adam, W.; Saha-Möller, C. R.; Ganeshpure, P. A. Chem. Rev. 2001, 101 (11), 3499. (b) Wong, O. A.; Shi, Y. Chem. Rev. 2008, 108 (9), 3958. 


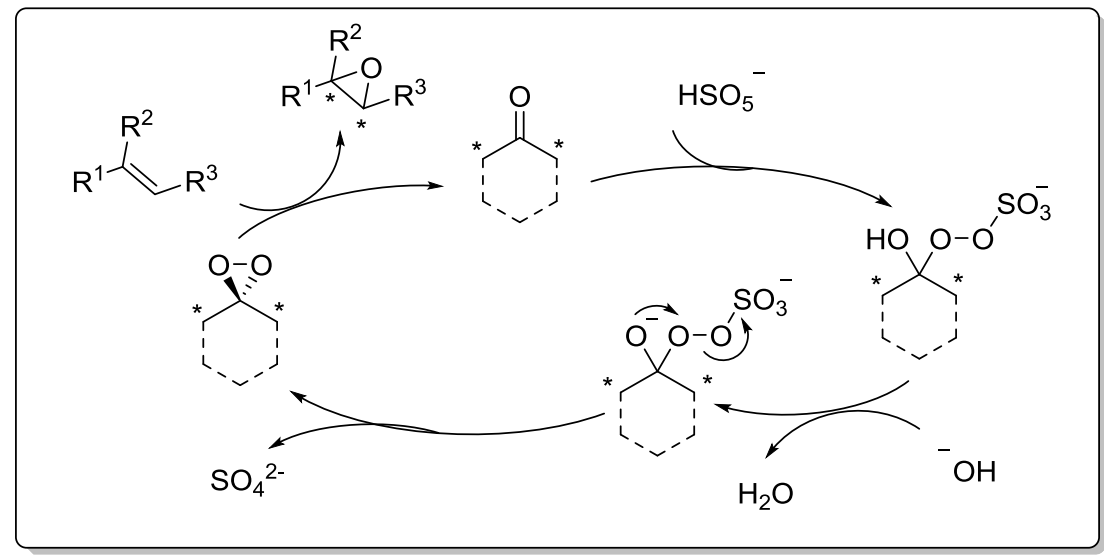

Scheme 23. Asymmetric epoxidation promoted by optically active dioxiranes.

Among all methodologies involving the in situ formation of a chiral dioxirane catalyst, Shi's epoxidation is probably the most known. ${ }^{69}$ His group reported the discovery of fructose-derived ketone, which displayed good reactivity and high selectivity to a wide range of olefins, including aromatic and aliphatic trans-olefins and trisubstituted olefins, ${ }^{70}$ silyl enol ethers and enol esters, ${ }^{71}$ and many others.

\subsection{Phase Transfer Catalysis}

In 1971, Starks introduced the term "phase-transfer catalysis" to explain the critical role of tetraalkylammonium or phosphonium salts in the reactions between two substances located in different immiscible phases. ${ }^{72}$ For example, the displacement reaction of 1-chlorooctane with aqueous sodium cyanide is accelerated many thousandfold by the addition of hexadecyltributylphosphonium bromide as a phase-transfer catalyst. Key to this tremendous enhancement in reactivity is the generation of quaternary phosphonium cyanide, which makes the cyanide anion soluble in organic solvents and sufficiently nucleophilic (Scheme 24). The high rate of displacement is mainly due to two of the

\footnotetext{
${ }^{69}$ Tu, Y.; Wang, Z.; Shi, Y. J. Am. Chem. Soc. 1996, 118 (40), 9806.

${ }^{70}$ Wang, Z.-X.; Tu, Y.; Frohn, M.; Zhang, J.-R.; Shi, Y. J. Am. Chem. Soc. 1997, 119 (46), 11224.

${ }^{71}$ Adam, W.; Fell, R. T.; Saha-möller, C. R.; Zhao, C. Tetrahedron: Asymmetry 1998, 9, 397.

${ }^{72}$ Starks, C. M. J. Am. Chem. Soc. 1971, 93 (1), 195.
} 
three characteristic features of the pairing cation $\left(\mathrm{Q}^{+}\right)$: high lipophilicity and the large ionic radius.

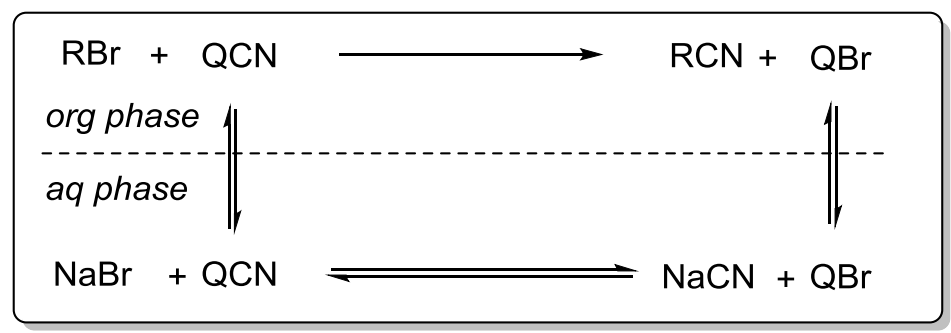

Scheme 24. General scheme for phase transfer catalysis

The use of PTC in asymmetric synthesis has been reported in wide variety of organic reactions, such as alkylations, fluorinations, Darzens, reduction and epoxidation, among others. ${ }^{73}$ Representative examples of chiral epoxidation of electron-deficient olefins (mostly enones), with catalysts such as quaternary ammonium salts and crown ethers in the presence of oxidants, will be next presented in this Thesis introduction.

\subsubsection{Cinchona Alkaloid-Derived Quaternary}

\section{Ammonium Salts}

One of the first asymmetric epoxidation attempts was reported in 1976 by Wynberg and co-workers ${ }^{74}$ utilizing $N$-benzyl quininium chloride salt to catalyze the epoxidation of $\alpha, \beta$-unsaturated ketones with up to $45 \%$ ee (Scheme 25). N-benzylated salts from cinchona tree alkaloids (cinchonine, cinchonidine, quinine and quinidine) have been prepared and widely reported as catalysts for the syntesis of epoxide-containing natural products such as (+)-manumycin $\mathrm{A}^{75}$ or palmarumycin $\mathrm{C}_{2}{ }^{76}$

\footnotetext{
${ }^{73}$ For leading reviews, see: (a) Ooi, T.; Maruoka, K. Angew. Chemie - Int. Ed. 2007, 46 (23), 4222. (b) Dalko, P. I.; Moisan, L. Angew. Chemie - Int. Ed. 2001, 40, 3726.

${ }^{74}$ Helder, R.; Hummelen, J. C.; Wiering, J. S.; Wynberg, H. Tetrahedron Lett. 1976, 17 (21), 1831.

${ }^{75}$ Alcaraz, L.; Macdonald, G.; Ragot, J. P.; Lewis, N.; Taylor, R. J. K. J. Org. Chem. 1998, 63 (11), 3526.

${ }^{76}$ Barrett, A. G. M.; Blaney, F.; Campbell, A. D.; Hamprecht, D.; Meyer, T.; White, A. J. P.; Witty, D.; Williams, D. J. J. Org. Chem. 2002, 67 (9), 2735.
} 


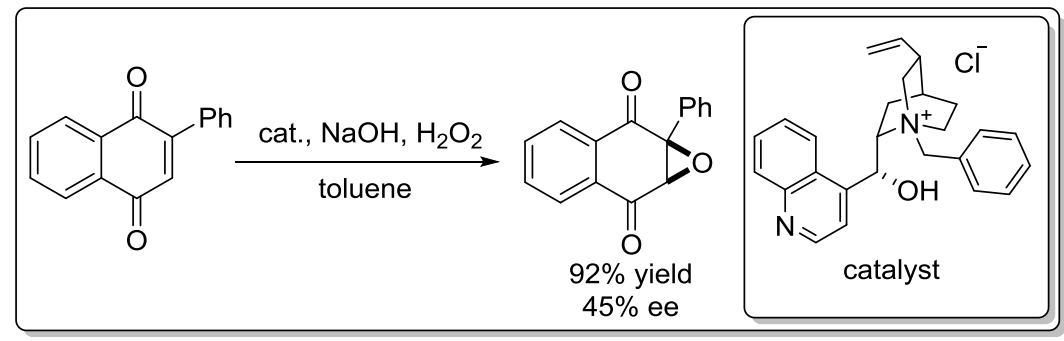

Scheme 25. Asymmetric epoxidation of 2-phenyl-naphtoquinone using a cinchonidinium salt.

The catalytic effect of various nitrogen substituents on cinchona alkaloids has been investigated by many research groups. In 1998, Arai and co-workers reported that the substituents on the phenyl ring of the $N$-benzyl unit in the cinchona alkaloid-derived catalysts played an important role in the asymmetric induction. Up to $92 \%$ ee was obtained for epoxidation of chalcones using catalyst $N$-p-iodobenzyl cinchoninium bromide. ${ }^{77}$ However, only $2 \%$ ee was obtained when the secondary alcohol of the catalyst was protected as allyl ether. In 2002, Dehmlow and co-workers reported their studies on analogues of cinchona alkaloids without the quinoline nitrogen atom as phasetransfer catalysts. Up to $84 \%$ ee was obtained for epoxidation of 2isopropyl-1,4-naphthoquinone with the modified epi-cinchonidine catalyst (Scheme 26). ${ }^{78}$

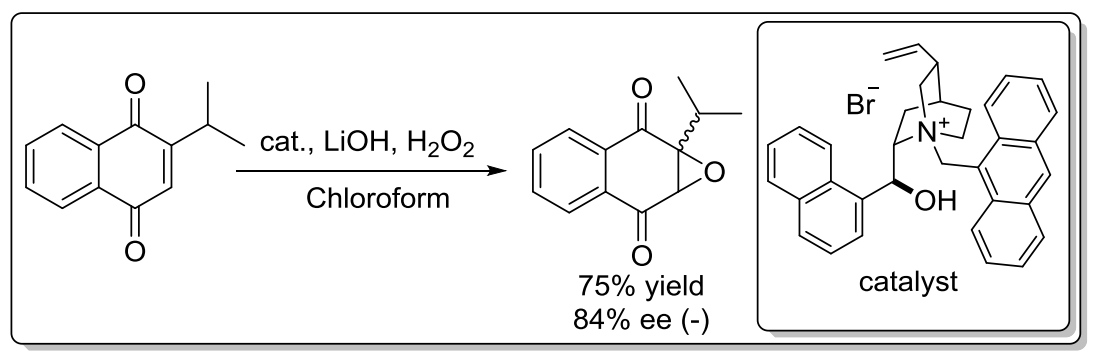

Scheme 26. Asymmetric epoxidation catalyzed by a cinchonidinium analogue.

In 1999, Corey and co-workers demonstrated remarkably high enantioselectivity $(91-98.5 \%$ ee) for epoxidation of enones with

\footnotetext{
${ }^{77}$ Arai, S.; Tsuge, H.; Shioiri, T.; City, N. Tetrahedron Lett. 1998, 39, 7563.

${ }^{78}$ Dehmlow, E. V.; Düttmann, S.; Neumann, B.; Stammler, H.-G. European J. Org.

Chem. 2002, 83, 2087.
} 
catalyst $O$-benzyl- $N$-anthracenyl dihydrocinchonidinium bromide using $\mathrm{KOCl}$ as an oxidant. ${ }^{79} \mathrm{He}$ proposed that the epoxidation proceeds via three-component transition state (Figure 5) with 4'-fluoro chalcone as substrate example. In this transition state, bromide ion is displaced by hypochlorite anion, which forms an ion pair with the cinchonidinium cation. The $\alpha, \beta$-enone in the complex is situated so that the 4fluorophenyl group is wedged between the ethyl and quinoline substituents on the quinuclidine ring and simultaneously the carbonyl oxygen is placed as close to $\mathrm{N}^{+}$as permitted by Van der Waals forces. In this arrangement the nucleophilic oxygen of hypochlorite is proximate to the $\beta$-carbon of the $\alpha, \beta$-enone, i.e., correctly positioned for nucleophilic epoxidation by conjugate addition. In fact, as the nucleophilic attack occurs, the negative charge which is developed at the carbonyl oxygen in the transition state is electrostatically stabilized by the proximate $\mathrm{N}^{+}$of the catalyst. Another feature of this geometry is that it allows a smooth transition of the resulting conjugate adduct to the $\alpha, \beta$-epoxy ketone and chloride with the latter contact ion paired to cation. Other authors have reported that a $\pi$ - $\pi$-stacking between the aryl group of the quaternary nitrogen substituent and an aryl group of the substrate could be involved during the molecular approach in the transition state. ${ }^{80}$

\footnotetext{
${ }^{79}$ Corey, E. J.; Zhang, F. Y. Org. Lett. 1999, 1 (8), 1287.

${ }^{80}$ Wu, S.; Pan, D.; Cao, C.; Wang, Q.; Chen, F. X. Adv. Synth. Catal. 2013, 355 (10), 1917.
} 


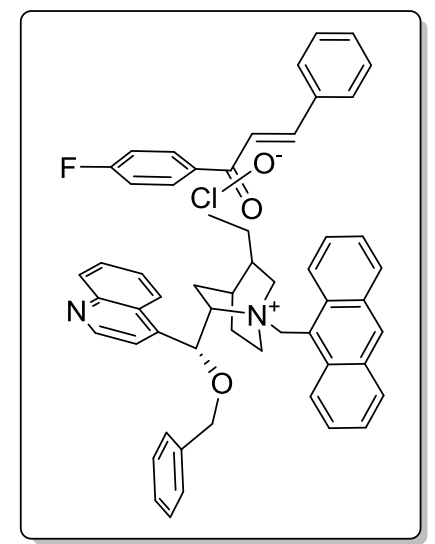

Figure 5. Proposed transition state by E. J. Corey.

\subsubsection{Other Quaternary Ammonium Salts}

Other quaternary ammonium salt catalysts have been investigated for asymmetric epoxidation of olefins (Figure 6). In 2004, Maruoka and co-workers showed that binaphthyl-based spiro quaternary ammonium salts, containing two diaryl methanol groups, were highly effective catalysts for epoxidation of enones. ${ }^{81} \mathrm{~A}$ variety of $\alpha, \beta$-epoxy ketones were obtained in $80-99 \%$ yield and $89-99 \%$ ee using such catalysts with $\mathrm{NaOCl}$ as oxidant. The hydroxyl groups of the catalyst appeared to be important for the reactivity and enantioselectivity of the epoxidation. In 1994, Masaki and co-workers reported their studies on the epoxidation of (E)-chalcones with pyrrolidinium salts as catalysts. ${ }^{82}$ However, enantioselectivity was low for all the tested substrates (up to $6.7 \%$ ee).

\footnotetext{
${ }^{81}$ Ooi, T.; Ohara, D.; Tamura, M.; Maruoka, K. J. Am. Chem. Soc. 2004, 126 (22), 6844.

${ }^{82}$ Shi, M.; Kazuta, K.; Satoh, Y.; Masaki, Y. Chem. Pharm. Bull. 1994, 42 (12), 2625.
} 


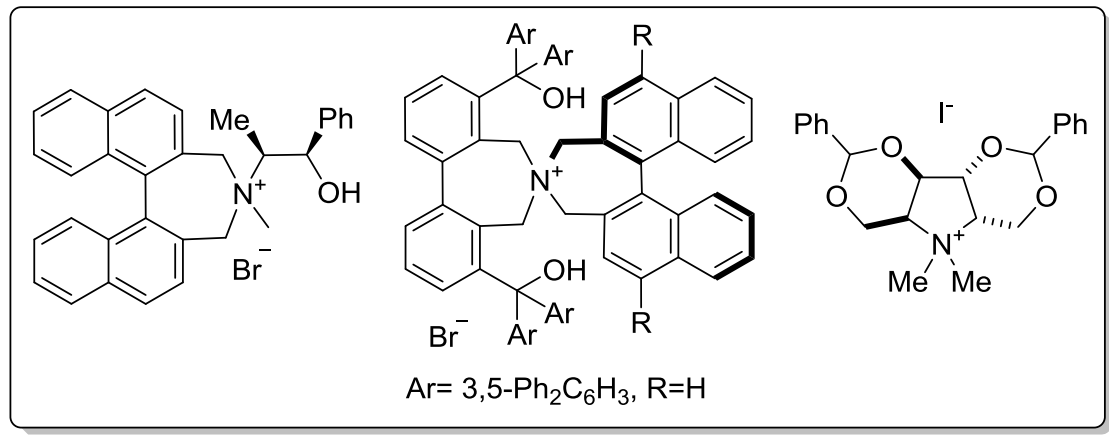

Figure 6. Ammonium phase transfer catalysts non-based on cinchona derivatives.

\subsubsection{Crown Ether-Type Catalysts.}

Crown ether-type phase-transfer catalysts with attached chiral moieties have also been examined for olefin epoxidation. Bakó and co-workers reported monosaccharide-based crown ether-type catalysts (Figure 7) for the epoxidation of chalcones, affording up to $>99 \%$ ee with TBHP as oxidant. ${ }^{83}$ The obtained results suggested that the nature of the monosaccharide unit of the catalyst is decisive with respect to the configuration of the epoxyketone. Thus, glucose-based catalyst promoted mostly the formation of the enantiomer with the negative specific rotation, while the mannose-based gave mostly the positive enantiomer.

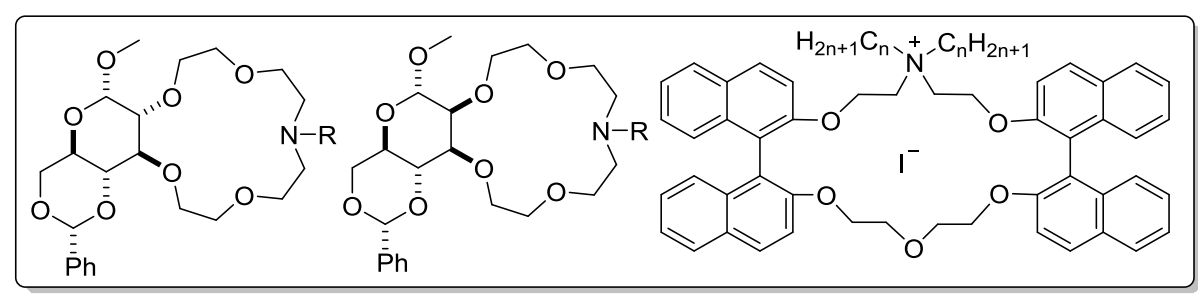

Figure 7. Crown ether-type catalysts

\footnotetext{
${ }^{83}$ Makó, A.; Rapi, Z.; Keglevich, G.; Szöllsy, Á.; Drahos, L.; Hegeds, L.; Bakó, P. Tetrahedron Asymmetry 2010, 21 (8), 919.
} 



\section{Chapter 2}

\section{Nitroepoxidles as Precursos of 1 ,4-Diaminoheterocycles}





\section{Objectives}

- Exploit the 1,2-electrophilic reactivity of the nitroepoxides as building blocks for organic chemistry

- Development of a new general synthetic methodology for the synthesis of different 1,4-heterocyclic diamino compounds, improving those previously reported in the literature. 


\section{Results and Discussion}

Previously to this Thesis research, our group reported the conversion of nitroepoxides into 1,2-diamines in a two-step sequence procedure involving nucleophilic attack followed by reductive amination. ${ }^{84}$ The model reaction consisted in the reaction between the nitroepoxide 1a and a stoichiometric excess of benzylamine in 1,2-dichloroethane (DCE), followed by the addition of sodium triacetoxyborohydride as a reductive agent in one-pot process to achieve the corresponding 1,2diamine in excellent diastereomeric ratio (Scheme 27).

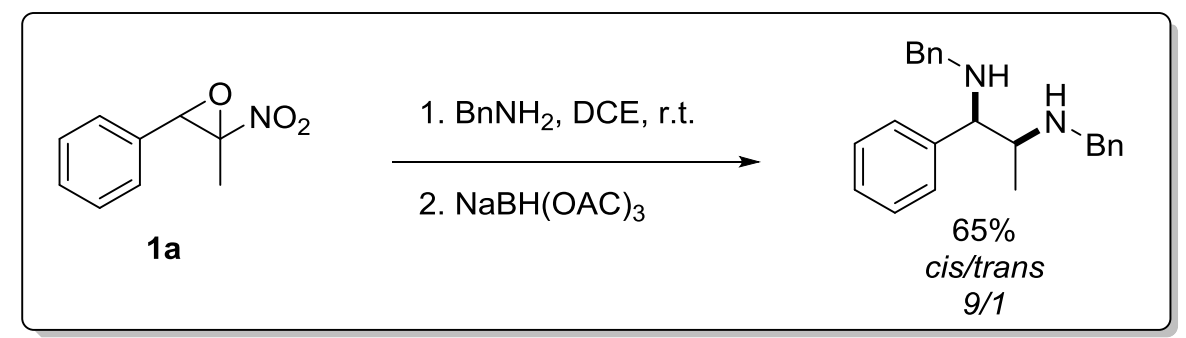

Scheme 27. Synthesis of 1,2-diamines from nitroepoxides.

The reaction described above proceeds via an amino-ketone intermediate, followed by a second step with an extra equivalent of benzylamine to form the corresponding amino-imine before reduction. Following this mechanistic hypothesis, we envisioned the ring-opening of the nitroepoxide using diamines in order to synthetize heterocyclic amino-imine intermediates, which using proper conditions, can be either oxidized or reduced to obtain unsaturated or saturated compounds, respectively (Scheme 28).

\footnotetext{
${ }^{84}$ Agut, J.; Vidal, A.; Rodríguez, S.; González, F. V. J. Org. Chem. 2013, 78 (11), 5717.
} 


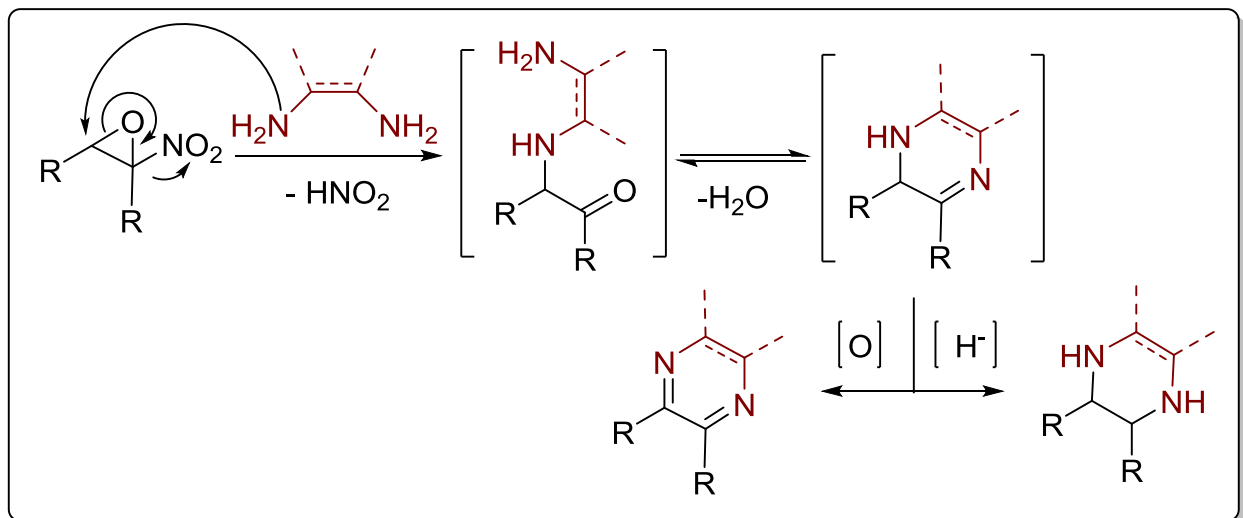

Scheme 28. Pathway to the synthesis of 1,4-diamino heterocycles from nitroepoxides.

The idea was to prepare 1,4-diamino heterocycles by using a variety of 1,2-diamines and starting from nitroepoxides displaying a range of substituents. Nitroepoxides would be prepared by epoxidation of the corresponding nitroalkenes. Nitroalkenes that were not commercially available would be synthetized from the corresponding aldehyde and nitroalkane according to two different methodologies. One of them involved a classical basic catalyzed Henry reaction, followed by dehydration of the obtained nitroaldol by mesilation of the hydroxyl group. Other method and most preferred one due to its operation easiness, was the reaction between the aldehyde and the nitroalkane in 2-hydroxyethyl ammonium formate $(2-\mathrm{HEAF}) .{ }^{85}$ This ionic liquid can perform both acid and basic catalysis for the addition and elimination steps (Scheme 29).

${ }^{85}$ Alizadeh, A.; Khodaei, M. M.; Eshghi, A. J. Org. Chem. 2010, 75 (23), 8295. 


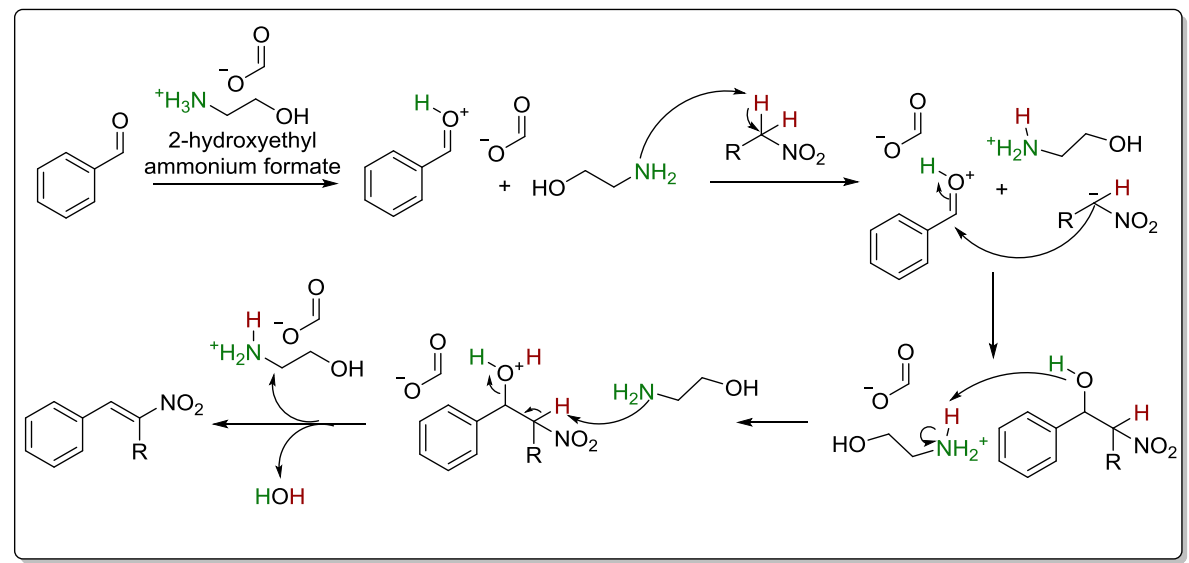

Scheme 29. Mechanistic pathway for the synthesis of nitroalkenes using ionic liquid 2-HEAF.

Nitroepoxides were prepared from the corresponding nitroalkenes with hydrogen peroxide and $\mathrm{NaOH}$ in high chemical yield. Fully detailed experimental procedures are available in the experimental section of this chapter.

\subsection{Quinoxalines}

We began our studies of the preparation of quinoxalines by combining nitroepoxide 1a with 1,2-diaminobenzene (1.5 equivalents) in 1,2dichloroethane at room temperature $\left(\mathrm{ca} .25^{\circ} \mathrm{C}\right.$ ) under nitrogen atmosphere. The excess of diamine was used to quench the nitrous acid since it can potentially react with amines to afford $N$-nitrosamines. ${ }^{86}$ The initial goal was to isolate the amino-imine intermediate to process it separately in oxidant and reductive media. However, the ${ }^{1} \mathrm{H}$ NMR spectrum of the crude mixture of the reaction showed mainly the oxidized compound quinoxaline 2a. Starting material 1a and another compound, which seemed to be the aminoketone intermediate, were also observed (Figure 8).

\footnotetext{
${ }^{86}$ Ellison, G.; Williams, D. L. H. J. Chem. Soc. Perkins Tansactions 2 1981, No. 4, 699.
} 


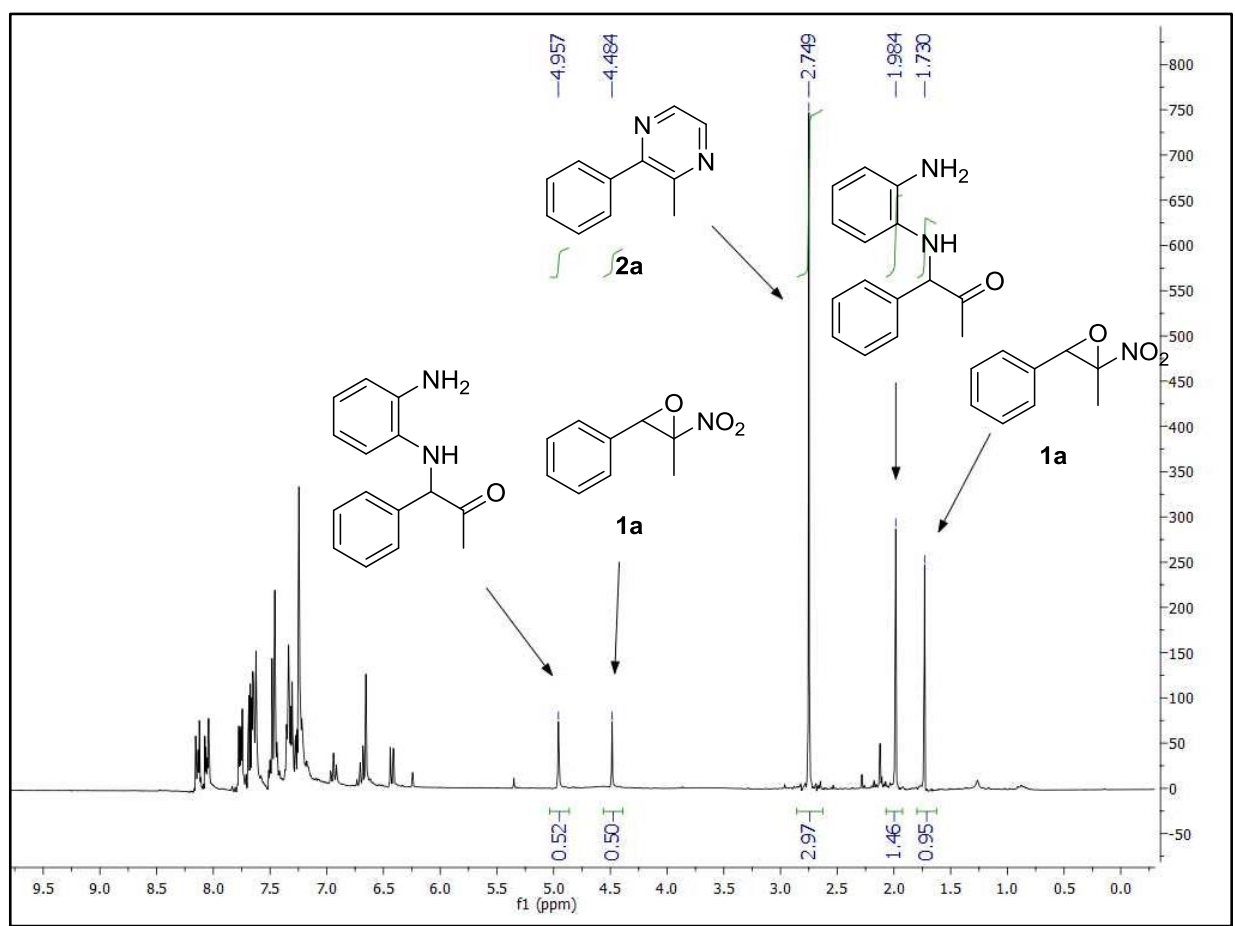

Figure 8. ${ }^{1} \mathrm{H}$ NMR spectrum of the crude mixture for the synthesis of quinoxaline 2a.

The crude mixture was purified through silica gel liquid chromatography in order to isolate quinoxaline $\mathbf{2 a}$ and the observed intermediate. For our surprise, the intermediate could not be isolated and the isolated amount of quinoxaline ( $72 \%$ yield) was greater than expected. This fact was rationalized as follows: the amino-ketone cyclizes into amino-imine which is easily oxidized by atmospheric oxygen into quinoxaline 2a during the work-up of the reaction (Scheme $30)$.

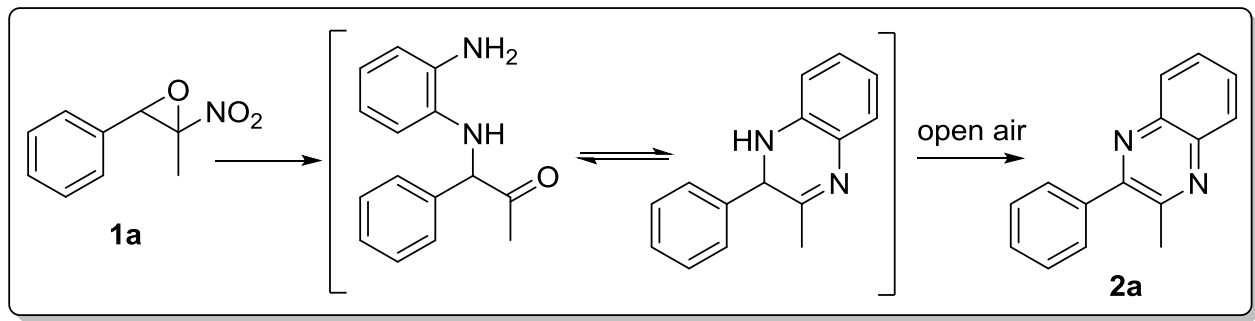

Scheme 30. Synthesis of quinoxaline 2a through oxidation of amino-imine intermediate. 
Few optimization experiments to achieve excellent yields were required. The change of solvent from DCE to ethanol increased the yield $(86 \%$, isolated yield) and also the rate of the reaction presumably, due to the solubility enhancement of $o$-phenylenediamine. The reaction was also performed in an open flask to favor the oxidative process. The mixture turned into an intense dark red when the quinoxaline was formed, which was used as an indicator of reaction completion. Finally, the purification step consisted on a filtration through a short pad of silica gel by using a mixture of hexanes/EtOAc (8:2) as eluent. With the optimal conditions in our hands, the scope of the reaction was studied using different epoxide substrates and phenylenediamines (Table 1).

As it can be observed, chemical yields were good in all cases and slightly higher for those compounds without substitution in the quinoxaline ring. For alkyl-alkyl disubstituted quinoxalines $\mathbf{2 h}$ and $\mathbf{2 i}$ yields were notably lower.

Table 1. Synthesis of Quinoxalines. ${ }^{a}$

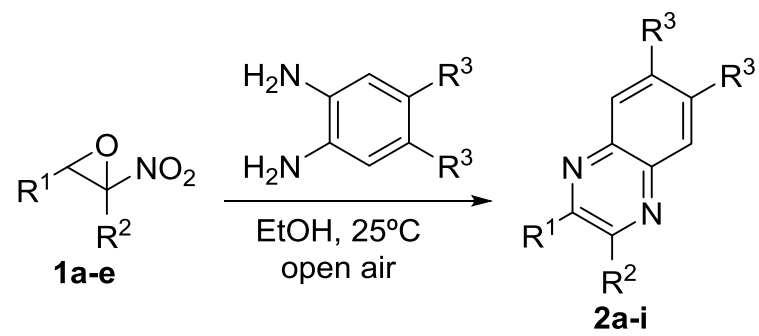

\begin{tabular}{cccccc}
\hline Entry & $\mathbf{R}^{1}, \mathbf{R}^{2}$ & Epoxide & $\mathbf{R}^{3}$ & Quinoxaline & Yield (\%) $^{b}$ \\
\hline $\mathbf{1}^{\boldsymbol{c}}$ & $\mathrm{Ph}, \mathrm{Me}$ & $\mathbf{1 a}$ & $\mathrm{H}$ & $\mathbf{2 a}$ & 72 \\
$\mathbf{2}$ & $\mathrm{Ph}, \mathrm{Me}$ & $\mathbf{1 a}$ & $\mathrm{H}$ & $\mathbf{2 a}$ & 86 \\
$\mathbf{3}$ & $\mathrm{Ph}, \mathrm{Me}$ & $\mathbf{1 a}$ & $\mathrm{Cl}$ & $\mathbf{2 b}$ & 82 \\
$\mathbf{4}$ & $p-\mathrm{F}-\mathrm{Ph}, \mathrm{Me}$ & $\mathbf{1 b}$ & $\mathrm{H}$ & $\mathbf{2 c}$ & 80 \\
$\mathbf{5}$ & $p-\mathrm{F}-\mathrm{Ph}, \mathrm{Me}$ & $\mathbf{1 b}$ & $\mathrm{Cl}$ & $\mathbf{2 d}$ & 75 \\
$\mathbf{6}$ & $p-\mathrm{Me}-\mathrm{Ph}, \mathrm{Me}$ & $\mathbf{1 c}$ & $\mathrm{H}$ & $\mathbf{2 e}$ & 78 \\
\hline
\end{tabular}




\begin{tabular}{cccccc}
\hline $\mathbf{7}$ & $p-\mathrm{Me}-\mathrm{Ph}, \mathrm{Me}$ & $\mathbf{1 c}$ & $\mathrm{Cl}$ & $\mathbf{2 f}$ & 70 \\
$\mathbf{8}$ & $p-\mathrm{F}-\mathrm{Ph}, \mathrm{Et}$ & $\mathbf{1 d}$ & $\mathrm{H}$ & $\mathbf{2 g}$ & 80 \\
$\mathbf{9}$ & $n-\mathrm{Pr}, \mathrm{Me}$ & $\mathbf{1 e}$ & $\mathrm{H}$ & $\mathbf{2 h}$ & 63 \\
$\mathbf{1 0}$ & $n-\mathrm{Pr}, \mathrm{Me}$ & $\mathbf{1 e}$ & $\mathrm{Cl}$ & $\mathbf{2 i}$ & 48 \\
\hline
\end{tabular}

${ }^{a}$ Reactions were carried out using nitroepoxide (1.0 equiv) and 1,2- benzenediamine (1.5 equiv) at room temperature for $16 \mathrm{~h} .{ }^{b}$ Yield of isolated product. ${ }^{c}$ Reaction was performed using 1,2-dichloroethane as a solvent.

Simultaneously to our work, Tsogoeva's research group had published a one-pot procedure to afford quinoxalines from nitroalkenes. ${ }^{87}$ Their approach comprises the organocatalytic generation of $\alpha$-nitroepoxides with the 1,8-diazabicycloundec-7-ene (DBU)/TBHP system and their subsequent treatment with 1,2-phenylenediamines (Scheme 31). The main disadvantage of their methodology is the use of hexane as a solvent for the epoxidation step, since $o$-phenylenediamine is quite insoluble in non-polar solvents; hence they are obliged to use polar "additives" for the second step of the reaction. Methanol resulted to be no good option since it is not miscible in hexane, so they end up using HFIP (28 equivalents), which is very expensive in comparison with our chosen solvent ethanol. Moreover, except for one case yielding $82 \%$, yields were quite moderate (36-67\%).

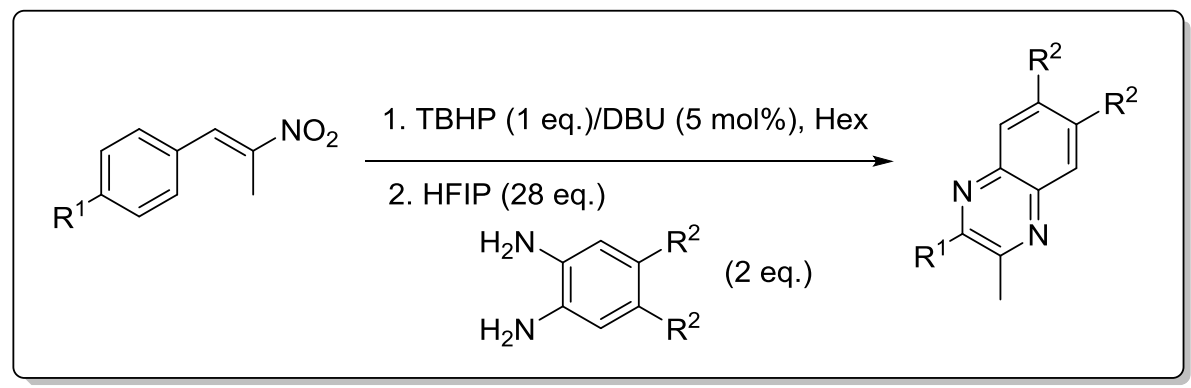

Scheme 31. Tsogoeva's approach for the synthesis of quinoxalines.

\footnotetext{
${ }^{87}$ Ibrahim, M. M.; Grau, D.; Hampel, F.; Tsogoeva, S. B. European J. Org. Chem. 2014, 2014 (7), 1401.
} 


\subsection{Piperazines}

Motivated by the results of quinoxalines, we decided to move forward to the synthesis of piperazines. Since aromatization of intermediate was not expected by simply atmospheric oxygen (two oxidative steps are required in this case compared to quinoxalines) the chosen strategy consisted in a one-pot ring-opening of the nitroepoxide with ethylenediamine, followed by reduction (Scheme 32). Initial conditions were identical to our previous work for the synthesis of 1,2-diamines from nitroepoxides: nitroepoxide was mixed with a stoichiometric excess of 1,2-ethylenediamine in DCE and stirred until the formation of the intermediate (ca. 6h), then $\mathrm{NaBH}(\mathrm{OAC})_{3}$ was added and the mixture stirred overnight. After non-extractive work-up, the crude piperazine 3a was obtained. However, in this case the reaction did not proceed as smoothly as for the quinoxalines or the vicinal diamines, the NMR spectra of the crude mixture also showed many unidentified byproducts. In addition, the desired product could not be isolated by liquid chromatography purification in a first attempt.

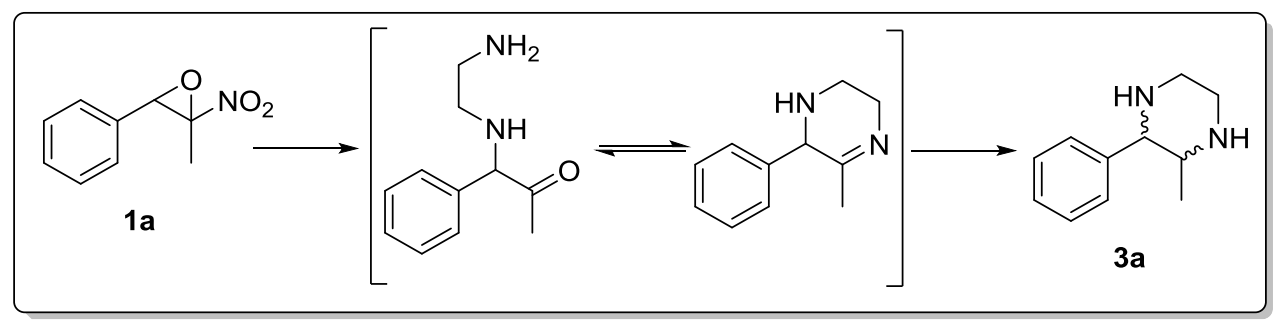

Scheme 32. Synthesis of piperazines through reduction of the amino-imine intermediate.

We guessed that the formation of byproducts might be a matter of concentration of the reaction media. So, the reaction was repeated at lower concentration and the NMR spectra showed in this case a much cleaner product. However, after liquid chromatography, piperazine 3a was obtained in very low yield and some byproducts were isolated instead. 
Chemical yield could be increased by using ethanol as a solvent of the reaction, and by adding triethylamine to the eluent mixture in the purification step. Piperazine 3a was obtained in $44 \%$ yield as a mixture of cis/trans isomers and the scope of the reaction was analyzed (Table 2). In some cases, separation by LC was not good enough to separate piperazine from remaining ethylenediamine, but the purification could be accomplished by performing liquid-liquid extraction under aqueous phase $\mathrm{pH}$ control. Acidity was regulated by addition of $2 \mathrm{M}$ aqueous $\mathrm{NaOH}$ until a $\mathrm{pH}$ of 10 . At this $\mathrm{pH}$ the piperazine was extracted with dichloromethane and the ethylenediamine remained in the aqueous phase.

\section{Table 2. Synthesis of Piperazines. ${ }^{\text {a }}$}
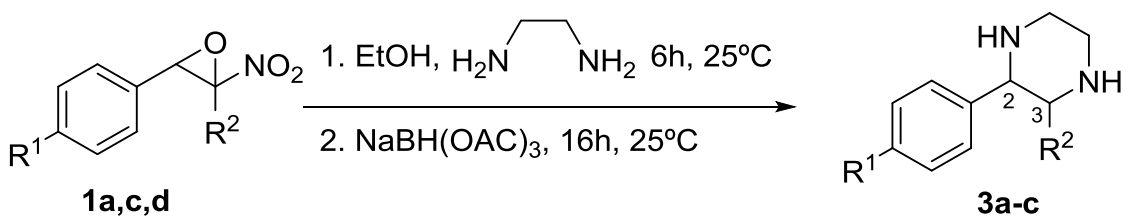

\begin{tabular}{cccccc}
\hline Entry & $\mathbf{R}^{1}, \mathbf{R}^{2}$ & Epoxide & Piperazine & $\begin{array}{c}\text { Yield } \\
(\boldsymbol{\%})^{\mathbf{b}}\end{array}$ & $\begin{array}{c}\text { d.r. } \\
(\text { cis/trans })\end{array}$ \\
\hline $\mathbf{1}$ & $\mathrm{H}, \mathrm{Me}$ & $\mathbf{1 a}$ & $\mathbf{3 a}$ & $44 \%$ & $2: 1$ \\
$\mathbf{2}$ & $\mathrm{Me}, \mathrm{Me}$ & $\mathbf{1 c}$ & $\mathbf{3 b}$ & $64 \%$ & $4: 1$ \\
$\mathbf{3}$ & F, Et & 1d & $\mathbf{3 c}$ & $58 \%$ & $2.2: 1$ \\
\hline
\end{tabular}

${ }^{a}$ Reactions were carried out using nitroepoxide (1.0 equiv) and 1,2-ethylenediamine (1.5 equiv) at room temperature for $6 \mathrm{~h}$. Then, $\mathrm{NaBH}(\mathrm{OAc})_{3}$ (3.0 equiv) was added and the mixture was stirred for $16 \mathrm{~h} .{ }^{b}$ Yield of isolated product.

The stereochemistry of the piperazines $\mathbf{3 a}-\mathbf{c}$ was assigned by NMR coupling constants $\left(J_{2,3}\right.$ for trans higher than for cis) and by NOE experiments. According to Karplus equation, ${ }^{88}$ hydrogen atoms that form a dihedral angle close to $0^{\circ}$ or $180^{\circ}$ have a higher $J$-coupling

${ }^{88}$ a) Karplus, M. J. Chem. Phys. 1959, 30 (1), 11. b) Gutowsky, H. S.; Karplus, M.; Grant, D. M. J. Chem. Phys. 1959, 31 (5), 1278. c) Minch, M. J. Concepts Magn. Reson. 1994, 6, 41. 
constant than those which are close to $90^{\circ}$ angles (Scheme 33). In our case, supposing a chair conformation for the piperazine ring, trans conformation implies the hydrogen atoms on positions 2,3 are both in axial, forming a dihedral angle near to $180^{\circ}$ and consequently, $J$ value should be high $(J>5 \mathrm{~Hz})$. For the cis conformation, one hydrogen atom is in axial position while the other is equatorial, which means their dihedral angle is near $90^{\circ}(\mathrm{J}=2-3 \mathrm{~Hz})$. Piperazine 3a showed for the major isomer a coupling constant of $3.3 \mathrm{~Hz}$ and for the minor isomer a constant of $9 \mathrm{~Hz}$, so cis conformation was assigned for the major isomer and trans for the minor. NOE experiment results were consistent with our analysis (Scheme 33). Piperazines 3b and 3c showed the same tendency and then stereochemistry was assigned by analogy.

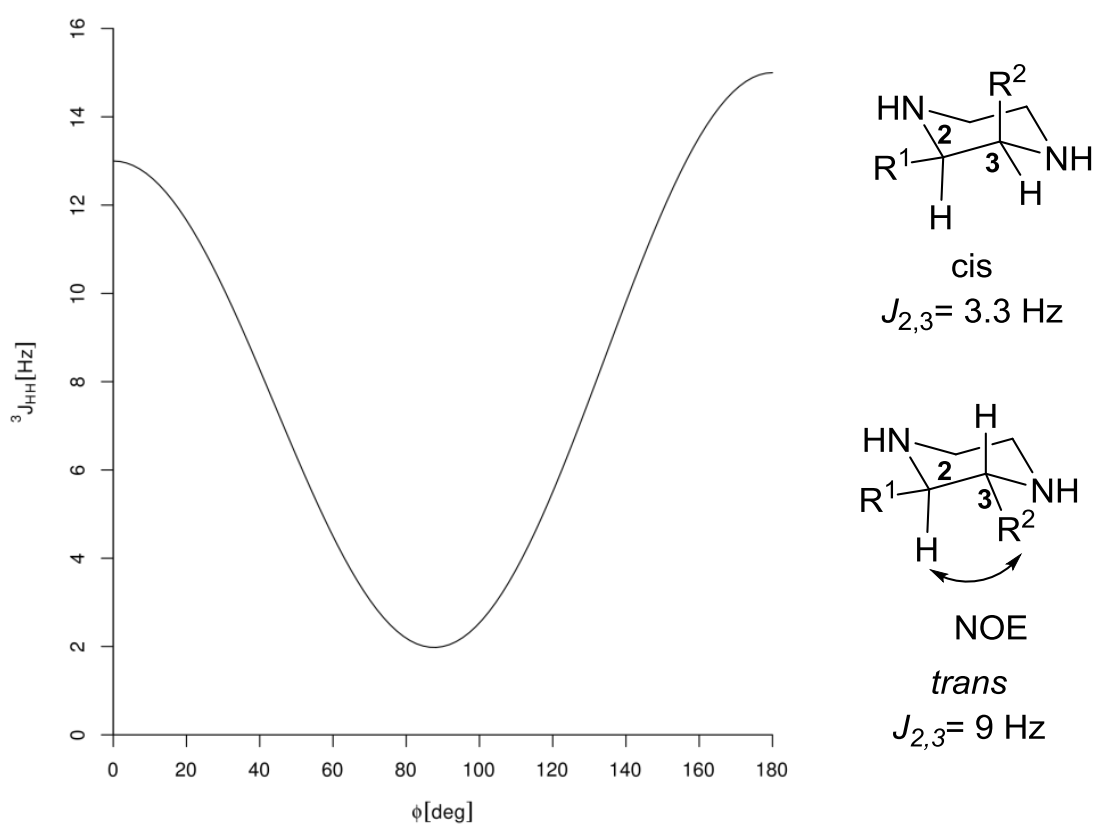

Scheme 33. General Karplus equation for ethane conformers (left). Assignment of stereochemistry for piperazines (right).

An interesting observation was made when the piperazine compound was kept on the bench: the oily product turned into a solid which was not soluble in organic solvents but it was in water. Amazed by this fact, we reached for literature in order to look for a reasonable explanation, 
and we found that aqueous piperazine can be employed in chemical enginery as a post-combustion $\mathrm{CO}_{2}$ removal technology. ${ }^{89}$ The rationalization is as follows: piperazine 3a is a highly hygroscopic compound which reacts with atmospheric $\mathrm{CO}_{2}$ to give the carbamate salt, in acid-basic equilibrium (Scheme 34). This is consistent with the fact that the aqueous solution of the salt gives slightly acidic $\mathrm{pH}$ and the oily piperazine 3a can be recovered by liquid-liquid extraction with dichloromethane from basified aqueous media. This reactivity results interesting and further experiments are considered in order to exploit its ability as potential carbon dioxide captor.

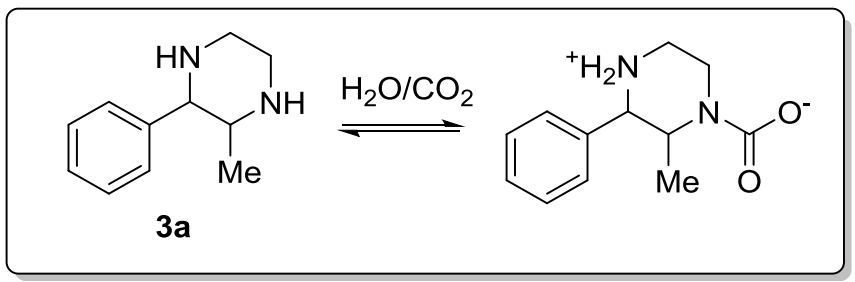

Scheme 34. Piperazine 3a as carbon dioxide trap.

\subsection{1,2,3,4-Tetrahydroquinoxalines}

As it has been pointed out in the introduction section, many compounds that possess the tetrahydroquinoxaline moiety have been studied in the medicinal chemistry field, but methods for the preparation of tetrahydroquinoxalines suffer from the same drawbacks as quinoxalines, since they are usually prepared through reduction of quinoxalines. ${ }^{90} \mathrm{~A}$ one-pot synthesis of 1,2,3,4-tetrahydroquinoxaline $\mathbf{4 a}$ starting from nitroepoxide 1a was envisioned (Scheme 35).

\footnotetext{
${ }^{89}$ Rochelle, G.; Chen, E.; Freeman, S.; Van Wagener, D.; Xu, Q.; Voice, A. Chem. Eng. J. 2011, 171 (3), 725.

${ }^{90}$ Figueras, J. J. Org. Chem. 1966, 31, 803.
} 


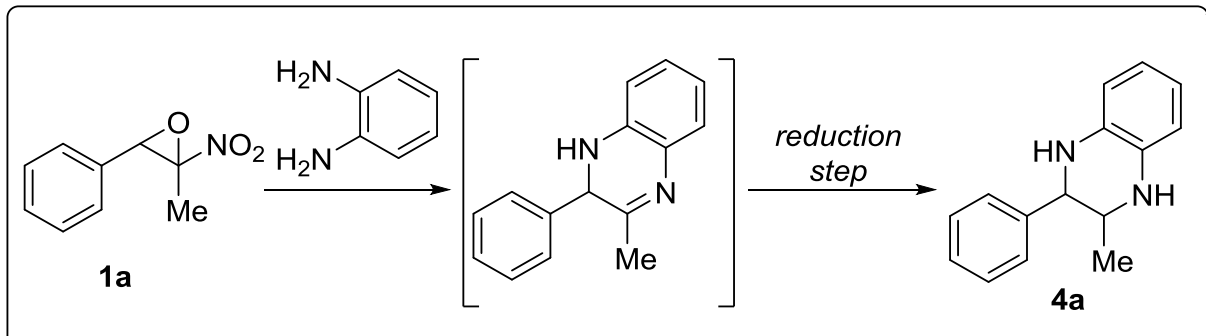

Scheme 35. Scheme for the synthesis of tetrahydroquinoxaline $\mathbf{4 a}$.

Since the amino-imine intermediate from the reaction between nitroepoxide 1a and $o$-phenylenediamine intermediate aromatizes easily in the presence of atmospheric oxygen, we imagined that controlling this step would be the key to success in the synthesis of the saturated heterocycle $\mathbf{4 a}$, so the experiment was designed in order to keep inert atmosphere in every step. Firstly, a previously purged diamine solution in ethanol was added. After the consumption of nitroepoxide (ca. 3 hours), $\mathrm{NaBH}(\mathrm{OAc})_{3}$ was added through an addition funnel under $\mathrm{N}_{2}$ atmosphere and stirred overnight. However, NMR spectra of the crude mixture showed mainly quinoxaline $\mathbf{2 a}$, which was obtained in a $68 \%$ yield after chromatography. Moreover, a new compound which seemed the desired compound $\mathbf{4 a}$ was isolated in $15 \%$ of total weight, but MS analysis did not show the expected molecular peak. The NMR and MS spectra were examined intensively, and we supposed that the unidentified product could be the $N$-nitroso tetrahydroquinoxaline 4b (Scheme 36). It had been described in the literature that similar compounds such as dihydroquinoxalinones ${ }^{91}$ can react with nitrite under acidic conditions to form the $N$-nitroso derivatives. When performing ESI-MS, the peak corresponding to the compound $\mathbf{4 b}$ plus $\mathrm{Na}$ cation $(\mathrm{m} / \mathrm{z}=276.2)$ was also detected. IR spectra showed an intense sharp peak at $1433 \mathrm{~cm}^{-1}$ that match with the

\footnotetext{
${ }^{91}$ MEDiVATION TECHNOLOGIES, INC.; Chakravarty, S.; Hart, B. P.; Jain, R. P. Patent: WO2011/103460 A1, 2011.
} 
signal for N-NO bond. ${ }^{92}$ The reaction was repeated using the same conditions and being especially careful with keeping it away from atmospheric oxygen, but the results were not significantly different. The proposed structure for compound $\mathbf{4 b}$ is tentative and more experiments are needed to properly elucidate the chemical structure.

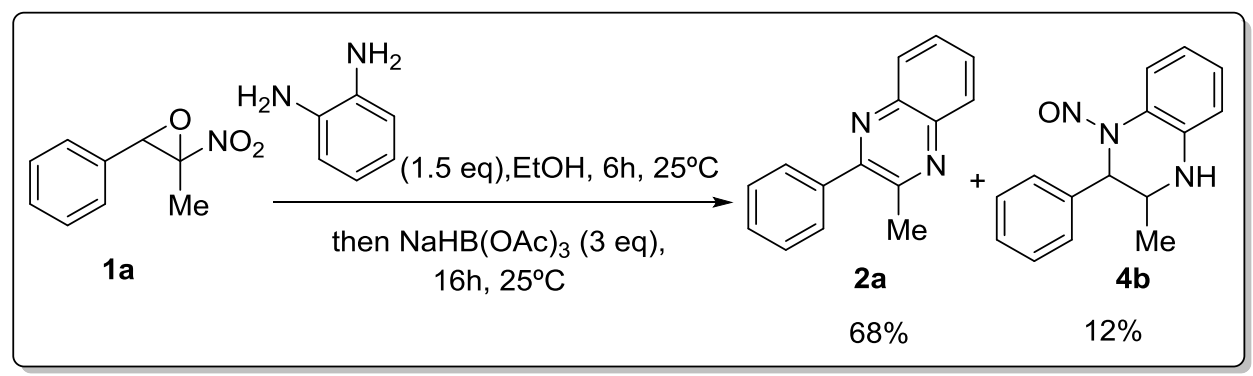

Scheme 36. First attempt for the synthesis of tetrahydroquinoxaline $\mathbf{4 a}$ resulted into 2a and $\mathbf{4 b}$.

At that point, the strategy for the reduction of the intermediate was changed. According to the work by Savrides et al., ${ }^{93}$ quinoxalines can be reduced to tetrahydroquinoxalines with borane-tetrahydrofuran complex solution, so we used this reductive agent so as to perform the reduction of the amino-imine intermediate. The reaction was performed as mentioned above but using tetrahydrofuran as solvent reaction instead of ethanol due to incompatibility with borane. Unfortunately and unexpectedly, the rate step of the ring-opening reaction decreased significatively and consequently, the consumption of the nitroepoxide took three days to be almost complete. Long reaction time allowed the formation of new byproducts as spotted by TLC. In spite of that, borane in THF solution was added and performed as described in the literature. ${ }^{93}$ After purification by silica gel LC, tetrahydroquinoxaline 4a was isolated in 33\% yield (Scheme 37), along with quinoxaline 2a (yield 32\%) and other unidentified compounds.

\footnotetext{
${ }^{92}$ Pretsch, E.; Clerc, T.; Seibl, J.; Simon, W. Tablas para la detereminación estructural por métodos espectroscópicos, 3rd ed.; Springer Verlag: Berlin, 1990 (Spanish edition)

${ }^{93}$ McKinney, A. M.; Jackson, K. R.; Salvatore, R. N.; Savrides, E.; Edattel, M. J.; Gavin, T. J. Het. Chem 2005, 42, 1031.
} 


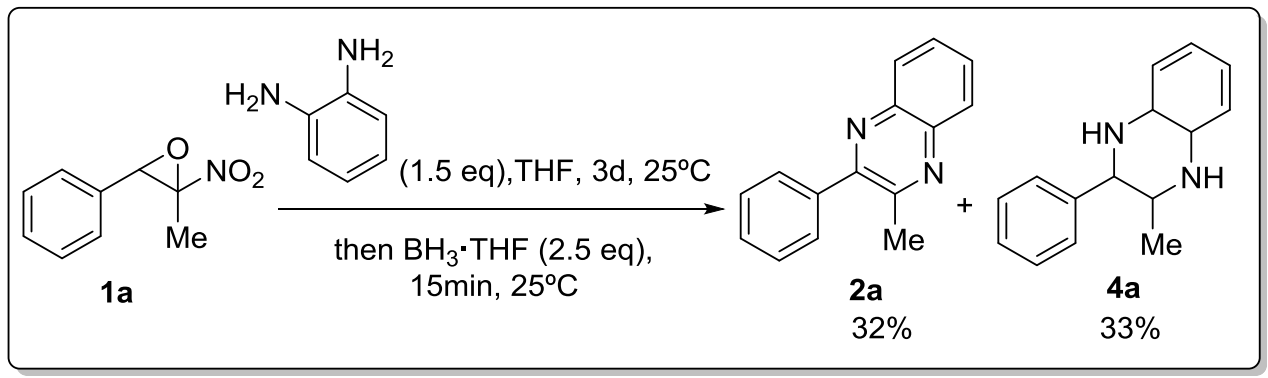

Scheme 37. One-pot process for the synthesis of $\mathbf{4 a}$ in THF.

Finally, nitroepoxide 1a was transformed into tetrahydroquinoxaline 4a in higher yield by treatment with 1,2-benzenediamine in dichloromethane as a solvent for $48 \mathrm{~h}$ in the open air to allow the formation of the quinoxaline moiety and then, addition of borane-tetrahydrofuran complex (4 equivalents) (Scheme 38). Hence, tetrahydroquinoxaline $4 \mathbf{a}$ was obtained from $1 \mathrm{a}$ in $72 \%$ yield in one-pot process as a diasteroisomeric mixture (cis/trans 3:1). The stereochemistry of tetrahydroquinoxaline $\mathbf{4 a}$ was assigned by NMR as mentioned above for piperazines $\mathbf{3 a}-\mathbf{c}$.

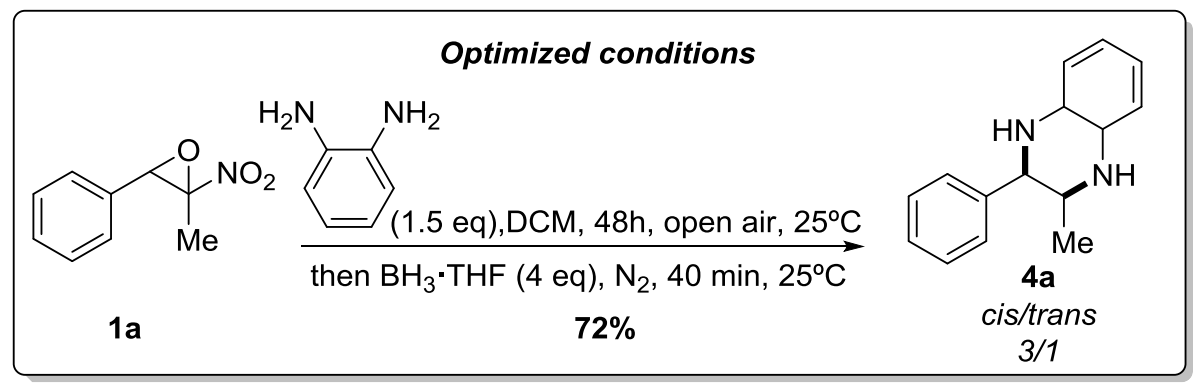

Scheme 38. Optimized conditions of the one-pot process for the synthesis of $\mathbf{4 a}$.

\subsection{Pyrazines}

During our early work about reactions between nitroepoxides and amines ${ }^{84}$ we used ammonia to open the oxirane ring in mild conditions. Since reductive amination of ketones is described using titanium (IV) isopropoxide, ${ }^{94}$ we treated nitroepoxide $1 \mathrm{a}$ with a commercially available methanolic ammonia solution $\left(7 \mathrm{M}\right.$ in methanol) and $\mathrm{Ti}\left({ }^{\mathrm{i}} \mathrm{PrO}\right)_{4}$,

\footnotetext{
${ }^{94}$ Muñoz, L.; Rodriguez, A. M.; Rosell, G.; Bosch, M. P.; Guerrero, A. Org. Biomol. Chem. 2011, 9 (23), 8171.
} 
followed by a reductive agent and a non-extractive work-up. However, only the dimer product pyrazine 5a was observed. Presumably the primary amine intermediate is more reactive than ammonia, and then it will react over another equivalent of aminoketone faster than ammonia, giving rise to a diimine intermediate which upon will furnish pyrazine (Scheme 39).

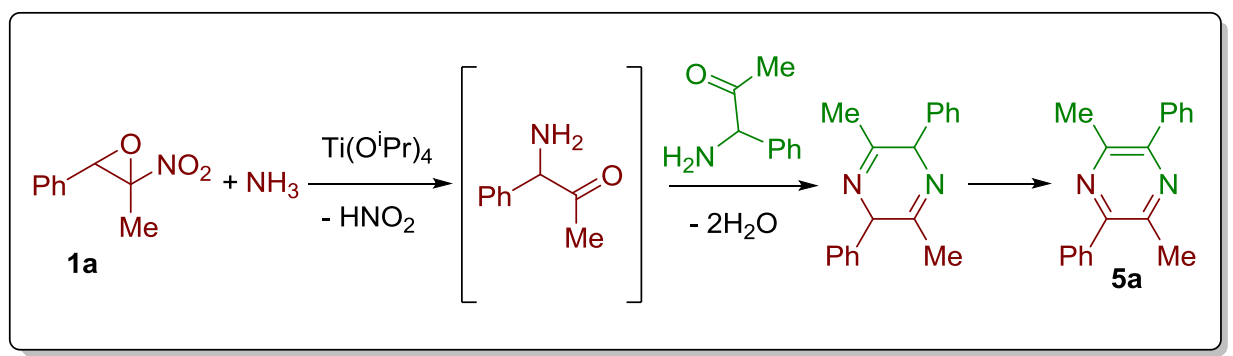

Scheme 39. Pathway of the reaction between epoxide 1a and ammonia.

To optimize conditions for the synthesis of pyrazines, reaction was repeated without $\mathrm{Ti}\left({ }^{\mathrm{i}} \mathrm{PrO}\right)_{4}$ and the result was similar when using Lewis acid. Purification step was also optimized. ${ }^{1} \mathrm{H}$ NMR spectrum of the crude mixture showed quite clean product but when purified by silica gel LC, yield decreased and some decomposition byproducts were also isolated. By simply changing a non-extractive work-up for a liquidliquid extraction with diethyl ether and water, pyrazine 5a was purely obtained as yellow needle-like crystals in $93 \%$ yield and no further purification was needed. The scope of the reaction was studied for diverse compounds (Table 3 ). 
Table 3. Synthesis of Pyrazines. ${ }^{\text {a }}$

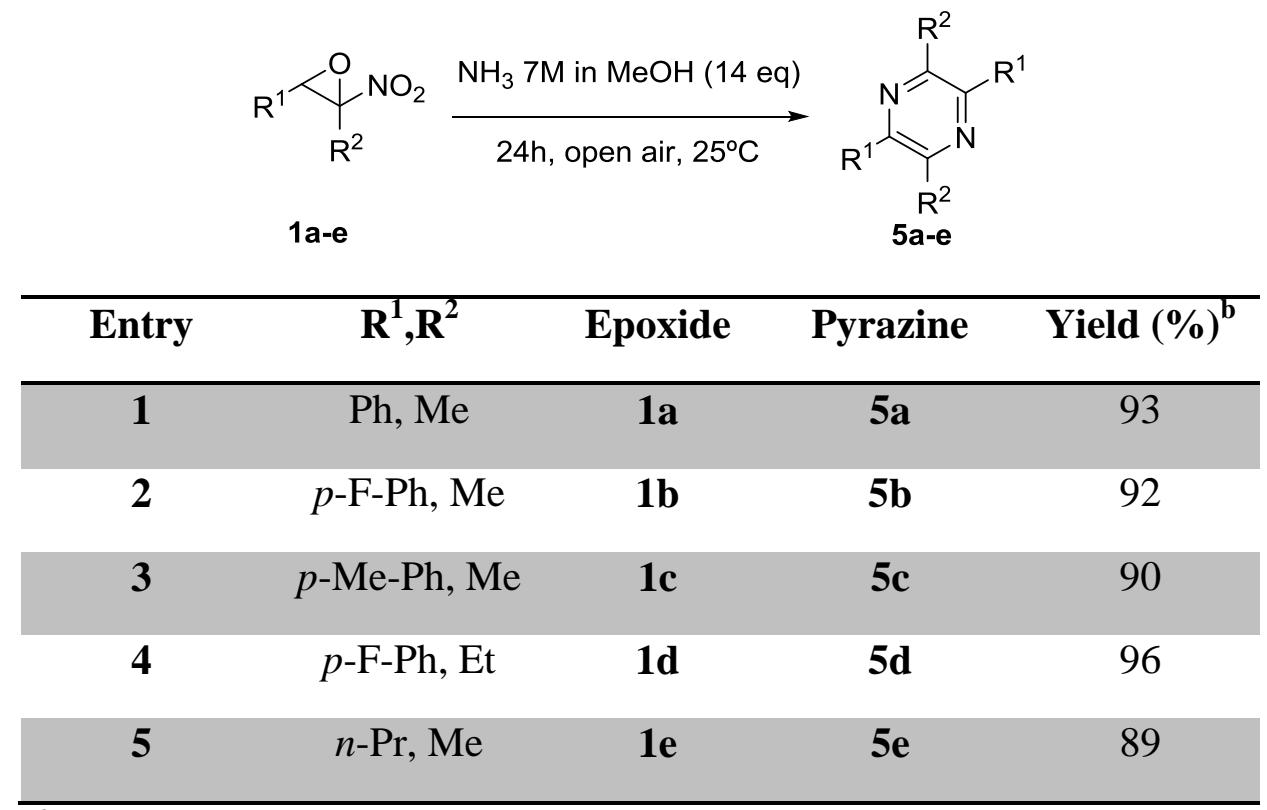

${ }^{a}$ Reactions were carried out using nitroepoxide (1.0 equiv) and a 7M methanolic ammonia solution (14 equiv) at room temperature for $24 \mathrm{~h}$.

\subsection{Imidazopyridines}

For this study, other diamines were also considered for the ringopening of nitroepoxides. Firstly we tried 1,8-diaminonaphtalene through a two-step sequence involving ring-opening and reduction as usual (Scheme 40). TLC analysis and NMR spectra of the crude mixture revealed the formation of many products, but all of them turned to be unstable, and no other compound besides starting material 1a and 1,8-diaminonaphtalene could be isolated. The research on this reaction was abandoned due to lack of interesting results. 


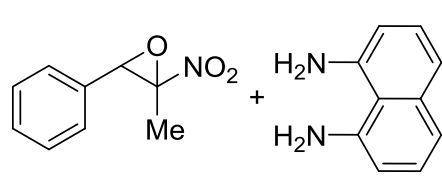

$1 a$
1. DCE

2. $\mathrm{NaBH}(\mathrm{OAc})_{3}$

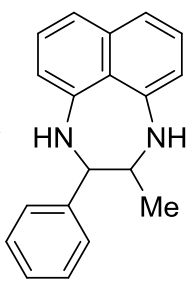

Scheme 40. Ring-opening attempt with 1,8-diaminonaphtalene.

More promising results were observed when nitroepoxide 1a was reacted with 2-aminopyridine in 1,2-DCE without reducing agent. The aim of this reaction was, analogously for the quinoxalines, the synthesis of amino-iminium intermediate which might undergo to aromatization to afford more stable compound imidazo[1,2-a]pyridine 6a (Scheme 41). The first results showed full conversion of $\mathbf{1 a}$ after $40 \mathrm{~h}$, but at least four products were formed according to ${ }^{1} \mathrm{H}$ NMR spectrum since four singlet signals corresponding to methyl were observed. Compounds from the mixture were separated by silica gel liquid chromatography, but the fraction containing the expected compound resulted to be impure and not enough amount for identification.

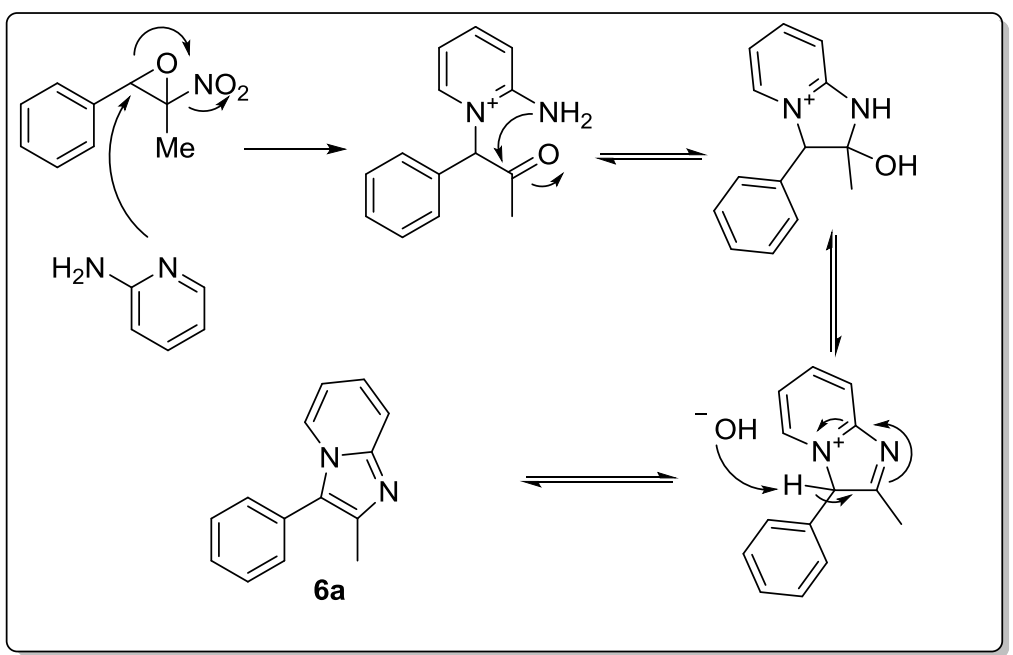

Scheme 41. Mechanistic pathway for the synthesis of imidazo[1,2-a]pyridine $6 \mathbf{6}$.

Reaction was repeated under reflux instead of room temperature in order to favor the formation of the aromatic compounds. In this 
occasion, NMR spectra of the crude mixture showed a different ratio of compounds since one of the methyl peaks was higher than the rest. The imidazo[1,2-a]pyridine compound 6a was isolated with a $21 \%$ chemical yield and NMR spectra matched for the regioisomer resulting from the nucleophilic attack by the nitrogen in the pyridine ring to the epoxide ring according to literature. ${ }^{95}$ However, since the opposite regioisomer 6b was not purely isolated, NMR experiments were performed in order to confirm the correct structure.

Signals on ${ }^{1} \mathrm{H}$ NMR were assigned according to computational prediction. The triplet at $6.7 \mathrm{ppm}$ was assigned to the $\mathrm{H}$ on the $\beta-\mathrm{C}$ in the pyridine ring (Figure 9, signal B). One-dimensional NOE irradiation over that signal showed coupling with a doublet at $8.1 \mathrm{ppm}$, assigned to the $\mathrm{H}$ on the $\alpha-\mathrm{C}$ in the pyridine ring (Figure 9, signal A), and with a triplet at $7.1 \mathrm{ppm}$ (Figure 9, signal C). Then, NOE irradiation of methyl signal showed coupling with the proton on phenyl group at $7.4 \mathrm{ppm}$ (Figure 10). Once main signals were assigned, NOESY experiment was performed and the interaction between proton from pyridine ring at $8.1 \mathrm{ppm}$ and proton from phenyl at $7.4 \mathrm{ppm}$ confirmed the proposed structure.

${ }^{95}$ Cao, H.; Zhan, H.; Lin, Y.; Lin, X.; Du, Z.; Jiang, H. Org. Lett. 2012, 14 (7), 1688. 


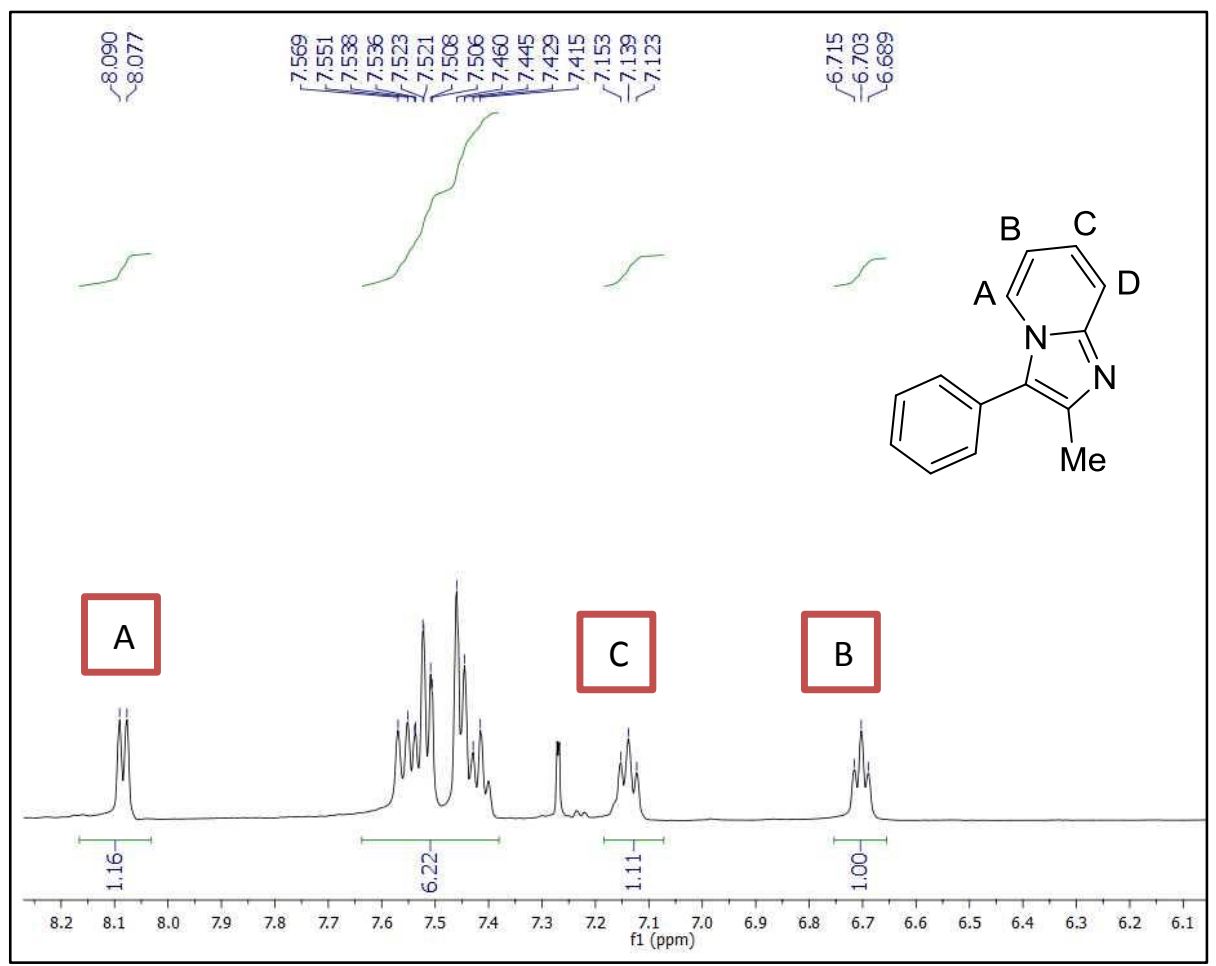

Figure 9. Signal assignation for the identification of the regioisomer.

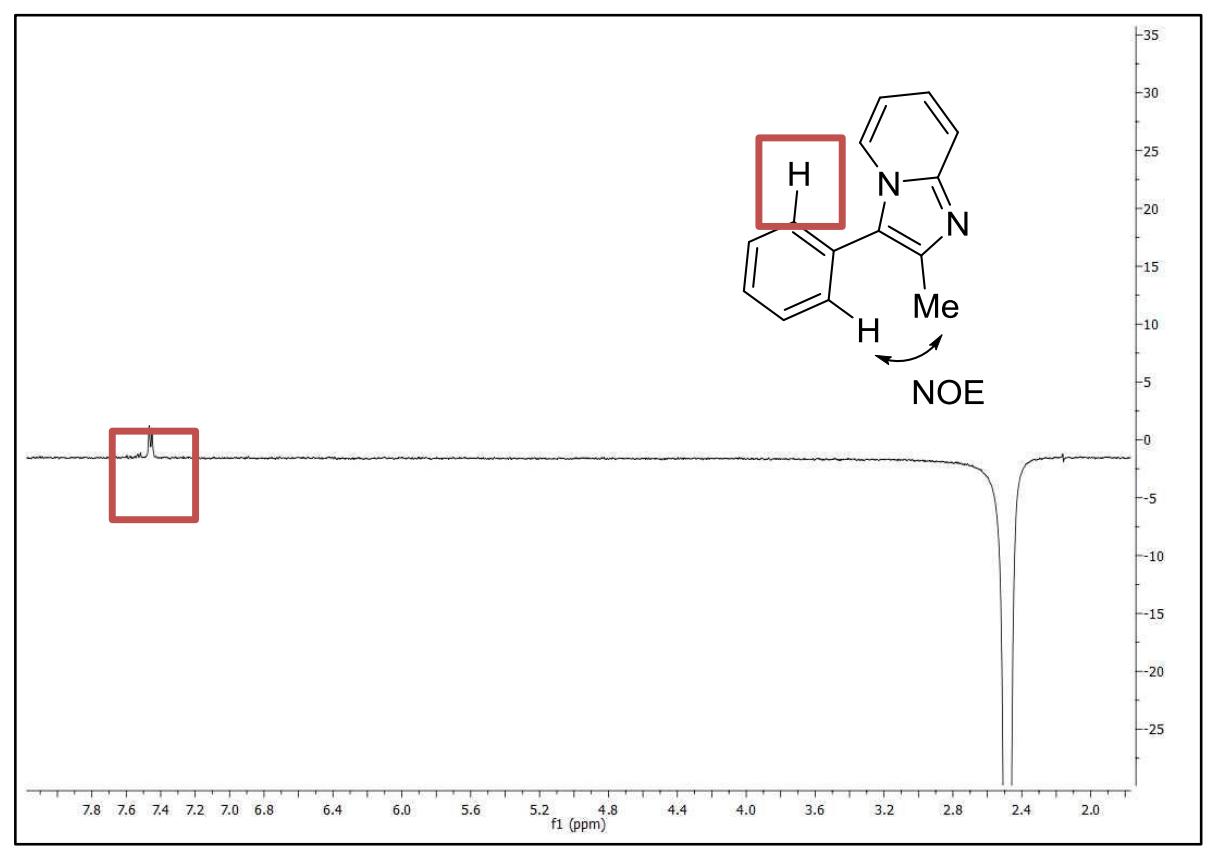

Figure 10. Identification of regioisomer by one-dimensional NOE experiment. 
Several experiments were performed in order to increase the chemical yield, however no significative increase of the yield was observed by modification of the solvent, addition of Lewis acid catalysts (e.g. $\left.\mathrm{Ti}\left(\mathrm{O}^{\mathrm{i}} \mathrm{Pr}\right)_{4}\right)$ or variations on the substrate. Temperature had an effect on the conversion rate, but not in the yield or regioselectivity. At lower temperatures than $0^{\circ} \mathrm{C}$, the reaction barely proceeded. These results were not included in our publication but interestingly, X. Guo et al. ${ }^{96}$ reported recently the synthesis of the opposite regioisomer $\mathbf{6 b}$ from nitroepoxide 1a by using two equivalents of sodium methoxide in $\mathrm{MeOH}$ in a $43 \%$ yield (Scheme 42 ).

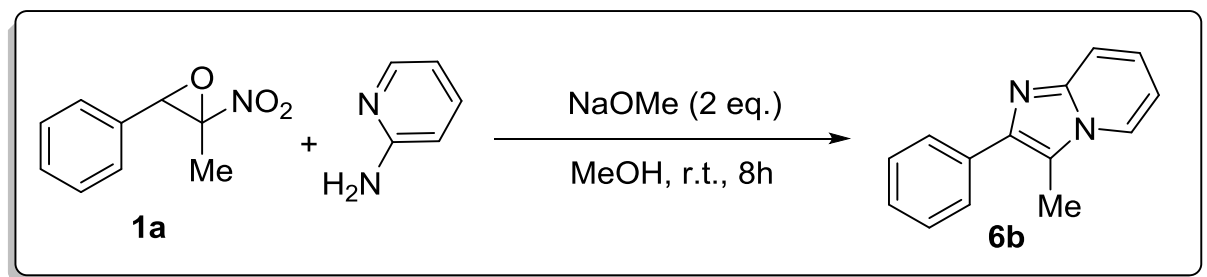

Scheme 42. Guo's synthesis of the opposite regioisomer of $\mathbf{6 b}$.

${ }^{96}$ Guo, X.; Shao, J.; Liu, H.; Chen, B.; Chen, W.; Yu, Y. RSC Adv. 2015, 5 (64), 51559. 


\section{Conclusions}

- In summary, we reported that aromatic heterocycles such as quinoxalines and pyrazines can be easily prepared by treating nitroepoxides with 1,2-benzenediamines and ammonia, respectively. These reactions give very high yields using environmentally friendly ethanol as a solvent. ${ }^{97}$

- Piperazines can also be prepared in a one-pot procedure when nitroepoxides are treated with 1,2-ethylenediamine and then sodium triacetoxyborohydride as a reductive agent in ethanol.

- In addition, tetrahydroquinoxalines can be easily obtained by using 1,2-benzenediamine in dichloromethane and then borane-tetrahydrofuran complex as a reductive agent.

${ }^{97}$ Vidal-Albalat, A.; Rodríguez, S.; González, F. V. Org. Lett. 2014, 16 (6), 1752. 


\section{Experimental Section}

\section{General Information}

Unless otherwise specified, all reactions were carried out under nitrogen atmosphere with magnetic stirring. All solvents and reagents were obtained from commercial sources and were purified according to standard procedures before use. ${ }^{1} \mathrm{H}$ NMR spectra and ${ }^{13} \mathrm{C}$ NMR spectra were measured in $\mathrm{CDCl}_{3}\left({ }^{1} \mathrm{H}, 7.27 \mathrm{ppm} ;{ }^{13} \mathrm{C} 77.0 \mathrm{ppm}\right)$ solution at $30{ }^{\circ} \mathrm{C}$ on a $300 \mathrm{MHz}$ or a $500 \mathrm{MHz}$ NMR spectrometer. Mass spectra were measured in a QTOF I (quadrupole-hexapole-TOF) mass spectrometer with an orthogonal Z-spray-electrospray interface. EM Science Silica Gel 60 was used for column chromatography while TLC was performed with precoated plates (Kieselgel $60, \mathrm{~F}_{254}, 0.25 \mathrm{~mm}$ ).

\section{Experimental Procedures}

Experimental Procedure for the Preparation of 2-Hydroxyethyl Ammonium Formate (2-HEAF): ${ }^{98}$<smiles>[NH3+][CH+]CO</smiles>

2-Amino ethanol (20.2 g, $331 \mathrm{mmol})$ was placed in a two-necked flask equipped with a reflux condenser and a dropping funnel. The flask was mounted in an ice bath. Under vigorous stirring with a magnetic stirring bar, formic acid (12.8 $\mathrm{mL}, 331 \mathrm{mmol})$ was added dropwise to the flask in about $45 \mathrm{~min}$. The stirring was continued for $24 \mathrm{~h}$ at room temperature, to obtain a slightly orange viscous liquid. No further purification was performed. ${ }^{1} \mathrm{H}$ NMR $\left(300 \mathrm{MHz}, \mathrm{DMSO}-\mathrm{d}_{6}\right) \delta 8.40(\mathrm{~s}$, 1H), 7.30 (bs, 4H), 3.55 (t, J = 5.1 Hz, 2H), 2.80 (t, J = 5.4 Hz, 2H).

\footnotetext{
${ }^{98}$ Bicak, N. J. Mol. Liq. 2005, 116 (1), 15.
} 
General Experimental Procedure for the Preparation of Nitroalkenes: $:^{85}$

A mixture of the aldehyde ( $7 \mathrm{mmol}, 1 \mathrm{eq})$, the nitroalkane $(7 \mathrm{mmol}$, 1eq), and 2-HEAF ( $7 \mathrm{~mL}$ ) was vigorously stirred for $24 \mathrm{~h}$ at room temperature. An insoluble solid was observed in the mixture. Then, addition of water $(7 \mathrm{~mL})$ to the flask led to the immediate formation of a solid which was filtered and washed with water to afford yellow crystals. The 2-HEAF was rinsed with EtOAc $(2 \times 10 \mathrm{~mL})$, the water from the aqueous phase removed under vacuum, and the ionic liquid used again. The purification of the crude solid was performed only when indicated.<smiles>CC/C(=C\c1ccc(F)cc1)[N+](=O)[O-]</smiles>

(E)-1-Fluoro-4-(2-nitrobut-1-en-1-yl)benzene. Yellow crystals, mp $63-70{ }^{\circ} \mathrm{C}$ (yield $\left.1.09 \mathrm{~g}, 80 \%\right)$ : ${ }^{1} \mathrm{H}$ NMR $(300 \mathrm{MHz}$, $\left.\mathrm{CDCl}_{3}\right) \delta 7.93(\mathrm{~s}, 1 \mathrm{H}), 7.45-7.35(\mathrm{~m}, 2 \mathrm{H}), 7.11(\mathrm{t}, \mathrm{J}=8.6 \mathrm{~Hz}, 2 \mathrm{H}), 2.81$ $(\mathrm{q}, \mathrm{J}=7.4 \mathrm{~Hz}, 2 \mathrm{H}), 1.23$ (t, J = 7.4 Hz, 3H); ${ }^{13} \mathrm{C} \mathrm{NMR}\left(75 \mathrm{MHz}, \mathrm{CDCl}_{3}\right)$ $\delta 163.4(\mathrm{~d}, \mathrm{~J}=250.5 \mathrm{~Hz}), 153.1,131.9,131.7(\mathrm{~d}, \mathrm{~J}=9 \mathrm{~Hz}), 128.5$, 116.2(d, J = 21.8 Hz), 20.6, $12.3 \mathrm{ppm}$; HRMS (EI) calcd for $\mathrm{C}_{10} \mathrm{H}_{10} \mathrm{FNO}_{2}$ (M) 195.0696, found 195.0697; IR (KBr) $\delta 3052$, 2976, $1520,1328,1232,1159,836 \mathrm{~cm}^{-1}$.

\section{Experimental Procedure for the Preparation of (E)-2-nitro-2- hexene: ${ }^{99}$}

To a stirred solution of butyraldehyde $(2.7 \mathrm{~mL}, 30 \mathrm{mmol})$ in nitroethane (11 $\mathrm{mL}, 150 \mathrm{mmol}$ ) at room temperature was added dropwise triethylamine $(420 \mu \mathrm{L}, 3 \mathrm{mmol})$. The resulting mixture was stirred under $\mathrm{N}_{2}$ for $16 \mathrm{~h}$. The excess solvent was evaporated in vacuo and the crude nitroaldol was dissolved in $\mathrm{CH}_{2} \mathrm{Cl}_{2}(12 \mathrm{~mL})$, cooled with an icebath and then methanesulfonylchloride $(2.9 \mathrm{~mL}, 36 \mathrm{mmol})$ and ethyldiisopropylamine $(11.1 \mathrm{~mL}, 63 \mathrm{mmol})$ were added. The solution

\footnotetext{
${ }^{99}$ Anderson, J. C.; Blake, A. J.; Mills, M.; Ratcliffe, P. D. Org. Lett. 2008, 10 (18), 4141.
} 
was allowed to warm up to room temperature and stirred until TLC analysis indicated consumption of nitroaldol $(19 \mathrm{~h})$. Water and $\mathrm{CH}_{2} \mathrm{Cl}_{2}$ (10 mL each) were added, and the organic phase was separated, washed with $2 \mathrm{M} \mathrm{HCl}(10 \mathrm{~mL})$, brine, dried $\left(\mathrm{MgSO}_{4}\right)$ and concentrated to yield an orange oil, which was purified by silica-gel chromatography (9:1 to $7: 3$, hexane/ethyl acetate) to give the pure product as an orange oil. 2,65g, (yield 68\%). ${ }^{1} \mathrm{H}$ NMR (300 MHz, $\left.\mathrm{CDCl}_{3}\right) \delta 7.02$ (t, J = 7.9 Hz, 1H), 2.14 (q, J = 7.4 Hz, 2H), 2.07 (s, 3H), 1.64-1.25 (m, 2H), 0.88 (t, J $=7.4 \mathrm{~Hz}, 3 \mathrm{H}) ;{ }^{13} \mathrm{C} \mathrm{NMR}\left(75 \mathrm{MHz}, \mathrm{CDCl}_{3}\right) \delta 147.6,136.0,30.0,21.5$, 13.5, 12.2 ppm; HRMS (EI) calcd for $\mathrm{C}_{6} \mathrm{H}_{11} \mathrm{NO}_{2}$ (M) 129.0790, found 129.0791; IR (KBr) $\delta 3056,2961,1671,1512,1389,1330 \mathrm{~cm}^{-1}$.

General Experimental Procedure for the Preparation of Nitroepoxides 1a-e:

To a stirred ice-bath suspension of the corresponding nitroalkene (12.1 mmol) in methanol (37.6 mL) containing hydrogen peroxide $50 \%$ aqueous solution $(2400 \mu \mathrm{L}, 42.8 \mathrm{mmol})$ was added aqueous $\mathrm{NaOH} 2 \mathrm{M}$ $(3900 \mu \mathrm{L}, 6.1 \mathrm{mmol})$ and stirred at $0^{\circ} \mathrm{C}$ for 10 minutes. Then, ice water was added $(30 \mathrm{mg})$, extracted with diethyl ether $(3 \times 50 \mathrm{~mL})$, the combined organic phases washed with brine $(45 \mathrm{~mL})$, dried with $\mathrm{Na}_{2} \mathrm{SO}_{4}$ and concentrated under vacuum to afford a yellowish oil. When needed, crude oil was purified by silica gel liquid chromatography (hexane/ethyl acetate, 9:1).<smiles>CC(C1OC1c1ccccc1)[N+](=O)[O-]</smiles>

2-methyl-2-nitro-3-phenyloxirane 1a, pale yellow oil, $1.8 \mathrm{~g}$ (yield 84\%): ${ }^{1} \mathrm{H}$ NMR (500 MHz, $\left.\mathrm{CDCl}_{3}\right) \delta 7.41(\mathrm{~m}, 3 \mathrm{H}), 7.30(\mathrm{~m}$, $2 \mathrm{H}), 4.56(\mathrm{~s}, 1 \mathrm{H}), 1.78(\mathrm{~s}, 3 \mathrm{H}) ;{ }^{13} \mathrm{C} \mathrm{NMR}\left(126 \mathrm{MHz}, \mathrm{CDCl}_{3}\right) \delta 131.0$, 129.3, 128.7, 126.3, 88.8, 62.6, 12.2 ppm; HRMS (EI) calcd for $\mathrm{C}_{9} \mathrm{H}_{9} \mathrm{NO}_{3}\left(\mathrm{M}^{+}\right)$179.0582, found 179.0587; IR (KBr) $\delta 3062,3028$, $2948,1555,1495,1448,1354,1158,1105,982,899 \mathrm{~cm}^{-1}$ 


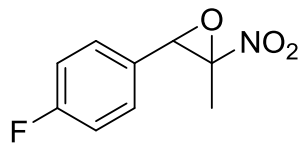

3-(4-fluorophenyl)-2-methyl-2-nitrooxirane $1 \mathrm{~b}$, colorless oil, $1.9 \mathrm{~g}$ (yield 79\%): ${ }^{1} \mathrm{H}$ NMR $\left(300 \mathrm{MHz}, \mathrm{CDCl}_{3}\right) \delta$ 7.33-7.26 (m, 2H), 7.13-7.05 (m, 2H), $4.51(\mathrm{~s}, 1 \mathrm{H}), 1.76(\mathrm{~s}, 3 \mathrm{H}) ;{ }^{13} \mathrm{C}$ NMR (75 MHz, $\left.\mathrm{CDCl}_{3}\right) \delta 163.2(\mathrm{~d}, \mathrm{~J}=247.8 \mathrm{~Hz}), 128.3(\mathrm{~d}, \mathrm{~J}=8.4 \mathrm{~Hz})$, $126.8(\mathrm{~d}, \mathrm{~J}=4.0 \mathrm{~Hz}), 115.8(\mathrm{~d}, \mathrm{~J}=22.0 \mathrm{~Hz}), 88.8,62.1,12.1 \mathrm{ppm}$; HRMS (EI) calcd for $\mathrm{C}_{9} \mathrm{H}_{8} \mathrm{NFO}_{3}\left(\mathrm{M}^{+}\right)$197.0488, found $197.0492 \mathrm{IR}$ $(\mathrm{KBr}) \delta 3059,3024,2944,1546,1490,1452,1205,896,830 \mathrm{~cm}^{-1}$.

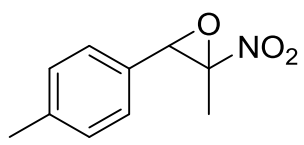

2-methyl-2-nitro-3-(p-tolyl)oxirane 1c, yellow oil, $1.7 \mathrm{~g}$ (yield 75\%): ${ }^{1} \mathrm{H}$ NMR (500 MHz, $\left.\mathrm{CDCl}_{3}\right) \delta$ 7.26-7.17 (m, 4H), $4.50(\mathrm{~s}, 1 \mathrm{H}), 2.38(\mathrm{~s}, 3 \mathrm{H}), 1.80(\mathrm{~s}, 3 \mathrm{H}) ;{ }^{13} \mathrm{C} \mathrm{NMR}\left(75 \mathrm{MHz}, \mathrm{CDCl}_{3}\right) \delta$ 139.6, 129.5, 128.0, 126.4, 89.1, 62.8, 21.1, 12.4 ppm; HRMS (EI) calcd for $\mathrm{C}_{10} \mathrm{H}_{11} \mathrm{NO}_{3}\left(\mathrm{M}^{+}\right)$193.0739, found 193.0745; $\mathrm{IR}(\mathrm{KBr}) \delta 3062$, $3025,2948,1552,1449,1346,1158,899,768 \mathrm{~cm}^{-1}$.

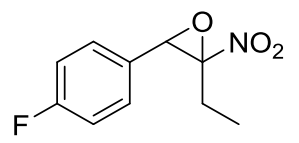

2-Ethyl-3-(4-fluorophenyl)-2-nitrooxirane 1d, yellow oil, $2.2 \mathrm{~g}$ (yield 88\%): ${ }^{1} \mathrm{H}$ NMR (300 MHz, $\left.\mathrm{CDCl}_{3}\right) \delta 7.37-7.19$ (m, 2H), 7.10 (t, J = 8.6 Hz, 2H), 4.49 (s, 1H), 2.45 (dq, J = 15.1, 7.4 $\mathrm{Hz}, 1 \mathrm{H}), 1.67(\mathrm{dq}, \mathrm{J}=14.8,7.3 \mathrm{~Hz}, 1 \mathrm{H}), 1.05(\mathrm{t}, \mathrm{J}=7.4 \mathrm{~Hz}, 3 \mathrm{H}) .{ }^{13} \mathrm{C}$ $\operatorname{NMR}\left(75 \mathrm{MHz}, \mathrm{CDCl}_{3}\right) \delta 163.2(\mathrm{~d}, \mathrm{~J}=247.5 \mathrm{~Hz}), 128.2(\mathrm{~d}, \mathrm{~J}=8.3 \mathrm{~Hz})$, $127.0(\mathrm{~d}, \mathrm{~J}=2.3 \mathrm{~Hz}), 115.9$ (d, J = 21.8 Hz), 92.37, 62.62, 19.44, 7.53 ppm; HRMS (EI) calcd for $\mathrm{C}_{10} \mathrm{H}_{10} \mathrm{FNO}_{3}\left(\mathrm{M}^{+}\right)$211.0645, found 211.0651; IR $(\mathrm{KBr}) \delta 3052,2979,1710,1606,1552,1510,1347$, $1227,1156 \mathrm{~cm}^{-1}$.

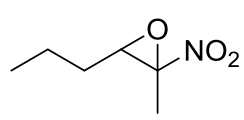

2-methyl-2-nitro-3-propyloxirane 1e, yellow oil $1.2 \mathrm{~g}$ (yield 68\%): ${ }^{1} \mathrm{H}$ NMR (300 MHz, $\left.\mathrm{CDCl}_{3}\right) \delta 3.39$ (t, J = $5.7 \mathrm{~Hz}, 1 \mathrm{H}$ ), 1.89 (s, 3H), 1.66-1.43 (m, 4H), $0.96(\mathrm{t}, \mathrm{J}=7.2 \mathrm{~Hz}, 3 \mathrm{H}) ;{ }^{13} \mathrm{C}$ NMR $(75$ 
$\left.\mathrm{MHz}, \mathrm{CDCl}_{3}\right) \delta 87.9,62.9,29.7,19.1,13.6 \mathrm{ppm}$; HRMS (EI) calcd for $\mathrm{C}_{6} \mathrm{H}_{11} \mathrm{NO}_{3}\left(\mathrm{M}^{+}\right)$145.0739, found 145.0741; IR (KBr) $\delta 3028,1555$, $1029 \mathrm{~cm}^{-1}$

General Experimental Procedure for the Synthesis of Quinoxalines 2a-2i:

To a solution of the corresponding nitroepoxide $(0.558 \mathrm{mmol})$ in ethanol $(3.1 \mathrm{~mL}), 1,2$-benzenediamine $(0.837 \mathrm{mmol})$ was added in oneportion and the mixture was stirred in the open air for $20 \mathrm{~h}$. Intense red color was an indicator of reaction completion. Then anhydrous $\mathrm{MgSO}_{4}$ (50mg) was added and stirred for 15 minutes. Then the mixture was filtered washing with EtOAc, and concentrated under vacuum. A red viscous oil was obtained which was further purified through a silica-gel chromatography (hexane/ethyl acetate, 8:2).<smiles>Cc1nc2ccccc2nc1-c1ccccc1</smiles>

2-Methyl-3-phenylquinoxaline 2a, red solid, $106 \mathrm{mg}$ (yield 86\%), mp 50-55 ${ }^{\circ} \mathrm{C}$ (lit. ${ }^{100} 54-56^{\circ} \mathrm{C}$ ): ${ }^{1} \mathrm{H} \mathrm{NMR} \mathrm{(300} \mathrm{MHz}, \mathrm{CDCl}_{3}$ ) $\delta 8.04$ (ddt, $J=10.1,4.9,2.1 \mathrm{~Hz}, 2 \mathrm{H}$ ), $7.71-7.56$ (m, 4H), $7.53-7.39$ $(\mathrm{m}, 3 \mathrm{H}), 2.73(\mathrm{~s}, 3 \mathrm{H}),{ }^{13} \mathrm{C} \mathrm{NMR}\left(75 \mathrm{MHz}, \mathrm{CDCl}_{3}\right) \delta 154.7,152.3$, 141.1, 140.9, 138.9, 129.5, 129.1, 129.0, 128.8, 128.4, 128.2, 24.2.; HRMS (ESI) calcd for $\mathrm{C}_{15} \mathrm{H}_{13} \mathrm{~N}_{2}\left(\mathrm{M}+\mathrm{H}^{+}\right)$221.1079, found 221.1076. IR $(\mathrm{KBr}) \delta 3051,2983,1641,1413,1369,1266,902 \mathrm{~cm}^{-1}$.

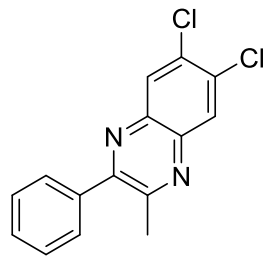

6,7-Dichloro-2-methyl-3-phenylquinoxaline $\mathbf{2 b}$, red crystal, $132 \mathrm{mg}$ (82\% yield) $\mathrm{mp} 148-152{ }^{\circ} \mathrm{C}$ (lit. ${ }^{101} 152-154{ }^{\circ} \mathrm{C}$ ): ${ }^{1} \mathrm{H}$

\footnotetext{
${ }^{100}$ Padmavathy, K.; Nagendrappa, G.; Geetha, K. V. Tetrahedron Lett. 2011, 52 (4), 544.

${ }^{101}$ Chen, Y.; Li, K.; Zhao, M.; Li, Y.; Chen, B. Tetrahedron Lett. 2013, 54 (13), 1627.
} 
NMR (300 MHz, $\left.\mathrm{CDCl}_{3}\right) \delta 8.17(\mathrm{~s}, 1 \mathrm{H}), 8.11(\mathrm{~s}, 1 \mathrm{H}), 7.67-7.59(\mathrm{~m}$, $2 \mathrm{H}), 7.56-7.46(\mathrm{~m}, 3 \mathrm{H}), 2.74(\mathrm{~s}, 3 \mathrm{H}) .{ }^{13} \mathrm{C} \mathrm{NMR}\left(75 \mathrm{MHz}, \mathrm{CDCl}_{3}\right) \delta$ 155.8, 153.9, 139.9, 139.7, 138.3, 134.0, 133.6, 129.8, 129.4, 129.1, 128.9, 128.6, 24.5.; HRMS (ESI) calcd for $\mathrm{C}_{15} \mathrm{H}_{11} \mathrm{Cl}_{2} \mathrm{~N}_{2}\left(\mathrm{M}+\mathrm{H}^{+}\right)$ 289.0299, found 289.0295; IR (KBr) $\delta 3059.1,2982,1444,1366,1258$, $891,747 \mathrm{~cm}^{-1}$.

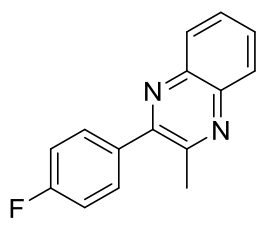

2-(4-Fluorophenyl)-3-methylquinoxaline 2c, pale orange solid, $106 \mathrm{mg}$ (yield 80\%), mp 76-79 ${ }^{\circ} \mathrm{C}$ (lit. ${ }^{100} 78^{\circ} \mathrm{C}$ ): ${ }^{1} \mathrm{H}$ NMR $\left(300 \mathrm{MHz}, \mathrm{CDCl}_{3}\right) \delta 8.04(\mathrm{dd}, J=11.0,9.4 \mathrm{~Hz}, 2 \mathrm{H}), 7.72-7.58(\mathrm{~m}$, $4 \mathrm{H}), 7.18(\mathrm{t}, J=8.5 \mathrm{~Hz}, 2 \mathrm{H}), 2.74(\mathrm{~s}, J=1.3 \mathrm{~Hz}, 3 \mathrm{H}) .{ }^{13} \mathrm{C} \mathrm{NMR}(75$ $\left.\mathrm{MHz}, \mathrm{CDCl}_{3}\right) \delta 163.2(\mathrm{~d}, J=249.0 \mathrm{~Hz}), 153.7,152.2,141.2,140.9$, $135.1(\mathrm{~d}, J=3.4 \mathrm{~Hz}), 130.9$ (d, $J=8.4 \mathrm{~Hz}), 129.8,129.3,129.1,128.3$, $115.6(\mathrm{~d}, J=21.7 \mathrm{~Hz}), 24.3$. HRMS (ESI) calcd for $\mathrm{C}_{15} \mathrm{H}_{12} \mathrm{FN}_{2}\left(\mathrm{M}+\mathrm{H}^{+}\right)$ 239.0985, found 239.0979; IR (KBr) $\delta 3022,2983,1643,1351,1281$, $846 \mathrm{~cm}^{-1}$.

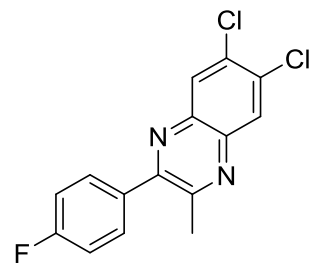

\section{6,7-Dichloro-2-(4-fluorophenyl)-3-methyl-}

quinoxaline 2d, pale orange crystal, $128 \mathrm{mg}$ (75\% yield), mp 167-169 ${ }^{\circ} \mathrm{C}:{ }^{1} \mathrm{H}$ NMR (300 MHz, $\left.\mathrm{CDCl}_{3}\right) \delta 8.18(\mathrm{~s}, 1 \mathrm{H}), 8.15$ (s, 1H), 7.65 (dd, $J$ $=8.9,5.3 \mathrm{~Hz}, 2 \mathrm{H}), 7.22(\mathrm{t}, J=8.8 \mathrm{~Hz}, 2 \mathrm{H}), 2.75(\mathrm{~s}, 3 \mathrm{H}) .{ }^{13} \mathrm{C} \mathrm{NMR}$ $\left(126 \mathrm{MHz}, \mathrm{CDCl}_{3}\right) \delta 163.5(\mathrm{~d}, J=249.9 \mathrm{~Hz}), 154.8,153.7,140.0$, 139.8, 134.4, 133.9, 131.0 (d, $J=8.4 \mathrm{~Hz}), 129.8,129.1,115.8$ (d, $J=$ $21.8 \mathrm{~Hz}$ ), 24.5. HRMS (ESI) calcd for $\mathrm{C}_{15} \mathrm{H}_{10} \mathrm{Cl}_{2} \mathrm{FN}_{2}\left(\mathrm{M}+\mathrm{H}^{+}\right) 307.0205$, found 307.0203; IR (KBr) $\delta 3035,2953,1677,1452,1332,1265$, 999, $761 \mathrm{~cm}^{-1}$. 


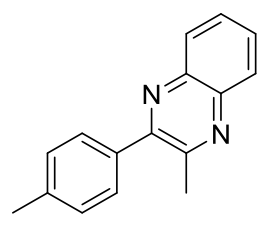

2-Methyl-3-(p-tolyl)quinoxaline 2e, yellow-brown solid, $101 \mathrm{mg}$, (yield 78\%), mp 59-62 ${ }^{\circ} \mathrm{C}$, (lit. ${ }^{102} 60-61{ }^{\circ} \mathrm{C}$ ): ${ }^{1} \mathrm{H} \mathrm{NMR}$ $\left(300 \mathrm{MHz}, \mathrm{CDCl}_{3}\right) \delta 8.08(\mathrm{~d}, J=10.6 \mathrm{~Hz}, 1 \mathrm{H}), 8.03(\mathrm{~d}, J=9.2 \mathrm{~Hz}, 1 \mathrm{H})$, $7.71-7.66(\mathrm{~m}, 2 \mathrm{H}), 7.54(\mathrm{~d}, J=6.8 \mathrm{~Hz}, 2 \mathrm{H}), 7.31(\mathrm{~d}, J=7.6 \mathrm{~Hz}, 2 \mathrm{H})$, $2.77(\mathrm{~s}, 3 \mathrm{H}), 2.43(\mathrm{~s}, 3 \mathrm{H}) .{ }^{13} \mathrm{C} \mathrm{NMR}\left(75 \mathrm{MHz}, \mathrm{CDCl}_{3}\right) \delta 154.9,152.6$, $141.1,141.1,139.0,136.2,129.5,129.2,129.1,129.0,128.9,128.3$, 24.4, 21.3. HRMS (ESI) calcd for $\mathrm{C}_{16} \mathrm{H}_{15} \mathrm{~N}_{2}\left(\mathrm{M}+\mathrm{H}^{+}\right)$235.1235, found 235.1235; IR (KBr) $\delta 3042,2963,2917,1644,1345,1264,1001,838$ $\mathrm{cm}^{-1}$.

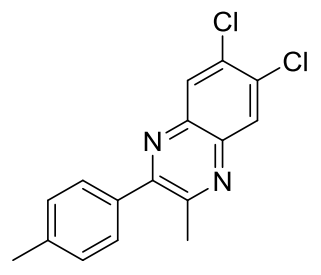

6,7-Dichloro-2-methyl-3-(p-tolyl)quinoxaline 2f, brown solid, $118 \mathrm{mg}$ (70\% yield), mp 126-128 ${ }^{\circ} \mathrm{C}:{ }^{1} \mathrm{H}$ NMR $(500 \mathrm{MHz}$, $\left.\mathrm{CDCl}_{3}\right) \delta 8.19(\mathrm{~s}, J=7.6 \mathrm{~Hz}, 1 \mathrm{H}), 8.14(\mathrm{~s}, 1 \mathrm{H}), 7.54(\mathrm{~d}, J=8.0 \mathrm{~Hz}, 2 \mathrm{H})$, $7.33(\mathrm{~d}, J=8.1 \mathrm{~Hz}, 2 \mathrm{H}), 2.76(\mathrm{~s}, 3 \mathrm{H}), 2.44$ (s, $J=27.5 \mathrm{~Hz}, 3 \mathrm{H}) .{ }^{13} \mathrm{C}$ NMR $\left(126 \mathrm{MHz}, \mathrm{CDCl}_{3}\right) \delta 156.0,154.0,140.0,139.8,139.6,135.5$, 134.0, 133.6, 129.8, 129.3, 129.1, 128.9, 24.6, 21.4; HRMS (ESI) calcd for $\mathrm{C}_{16} \mathrm{H}_{13} \mathrm{Cl}_{2} \mathrm{~N}_{2}\left(\mathrm{M}+\mathrm{H}^{+}\right)$303.0456, found 303.0454; IR (KBr) $\delta 3055$, $2988,1439,1320,1267,1003,761 \mathrm{~cm}^{-1}$

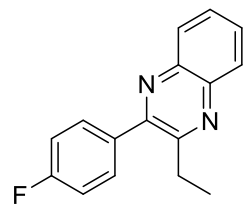

2-Ethyl-3-(4-fluorophenyl)quinoxaline $\mathbf{2 g}$, orange solid, $112 \mathrm{mg}$ (yield 80\%), mp 73-76 ${ }^{\circ} \mathrm{C}:{ }^{1} \mathrm{H}$ NMR (300 MHz, $\left.\mathrm{CDCl}_{3}\right) \delta 8.08$ $(\mathrm{d}, J=8.6 \mathrm{~Hz}, 2 \mathrm{H}), 7.79-7.66(\mathrm{~m}, 2 \mathrm{H}), 7.59(\mathrm{dd}, J=7.0,5.3 \mathrm{~Hz}, 2 \mathrm{H})$, $7.20(\mathrm{t}, J=8.7 \mathrm{~Hz}, 2 \mathrm{H}), 3.04(\mathrm{q}, J=7.5 \mathrm{~Hz}, 2 \mathrm{H}), 1.29(\mathrm{t}, J=7.5 \mathrm{~Hz}$,

\footnotetext{
${ }^{102}$ Schwaiger, W.; Ward, J. P. Recl. des Trav. Chim. des Pays-Bas 1972, 91 (10), 1175.
} 
$3 \mathrm{H}) .{ }^{13} \mathrm{C}$ NMR $\left(75 \mathrm{MHz}, \mathrm{CDCl}_{3}\right) \delta 163.2(\mathrm{~d}, J=248.9 \mathrm{~Hz}), 156.9$, 153.8, 141.4, 140.7, 135.1 (d, $J=3.6 \mathrm{~Hz}), 130.8$ (d, $J=8.4 \mathrm{~Hz}), 129.8$, 129.3, 129.1, 128.5, 115.6 (d, $J=21.7 \mathrm{~Hz}), 29.3,13.0$. HRMS (ESI) calcd for $\mathrm{C}_{16} \mathrm{H}_{14} \mathrm{FN}_{2}\left(\mathrm{M}+\mathrm{H}^{+}\right)$253.1141, found 253.1145; IR $(\mathrm{KBr}) \delta$ $3024,2982,2932,1648,1345,1268,857 \mathrm{~cm}^{-1}$

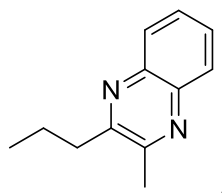

2-Methyl-3-propylquinoxaline $\mathbf{2 h}$, brown solid, $65 \mathrm{mg}$ (yield 63\%), mp 58-63 ${ }^{\circ} \mathrm{C}$ (lit. ${ }^{103} 60-61.5{ }^{\circ} \mathrm{C}$ ): ${ }^{1} \mathrm{H}$ NMR (300 MHz, $\left.\mathrm{CDCl}_{3}\right) \delta 7.98-7.85(\mathrm{~m}, 2 \mathrm{H}), 7.58(\mathrm{dd}, J=6.4,3.4 \mathrm{~Hz}, 2 \mathrm{H}), 2.90(\mathrm{dd}$, $J=8.6,6.9 \mathrm{~Hz}, 2 \mathrm{H}), 2.68(\mathrm{~s}, J=3.9 \mathrm{~Hz}, 3 \mathrm{H}), 1.93-1.72(\mathrm{~m}, 2 \mathrm{H}), 1.02$ $(\mathrm{t}, J=7.4 \mathrm{~Hz}, 3 \mathrm{H}) .{ }^{13} \mathrm{C} \mathrm{NMR}\left(75 \mathrm{MHz}, \mathrm{CDCl}_{3}\right) \delta 156.6,153.0,141.1$, 140.8, 128.6, 128.6, 128.5, 128.2, 37.7, 22.7, 21.3, 14.1. HRMS (ESI) calcd for $\mathrm{C}_{12} \mathrm{H}_{15} \mathrm{~N}_{2}\left(\mathrm{M}+\mathrm{H}^{+}\right)$187.1235, found 187.1236; IR $(\mathrm{KBr}) \delta$ $3046,3056,2965,2939,1269,759 \mathrm{~cm}^{-1}$

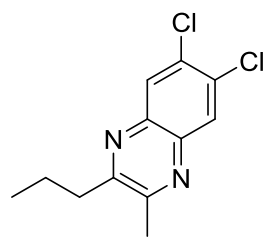

6,7-Dichloro-2-methyl-3-propylquinoxaline $2 \mathbf{2 i}$, brown solid, $68 \mathrm{mg}$ (48\% yield) $\mathrm{mp} 92-95{ }^{\circ} \mathrm{C}$, (lit. ${ }^{104} 90-91{ }^{\circ} \mathrm{C}$ ): ${ }^{1} \mathrm{H}$ NMR $\left(500 \mathrm{MHz}, \mathrm{CDCl}_{3}\right) \delta 8.05(\mathrm{~s}, 1 \mathrm{H}), 8.01(\mathrm{~s}, 1 \mathrm{H}), 2.91(\mathrm{dd}, J=8.3$, $7.1 \mathrm{~Hz}, 2 \mathrm{H}), 2.69$ (s, 3H), $1.91-1.78(\mathrm{~m}, 2 \mathrm{H}), 1.04$ (t, $J=7.4 \mathrm{~Hz}, 3 \mathrm{H})$. ${ }^{13} \mathrm{C} \mathrm{NMR}\left(126 \mathrm{MHz}, \mathrm{CDCl}_{3}\right) \delta 158.0,154.6,139.9,139.6,133.0,132.9$, 129.3, 129.3, 129.1, 129.0, 37.7, 22.8, 21.0, 14.1; HRMS (ESI) calcd for $\mathrm{C}_{12} \mathrm{H}_{13} \mathrm{Cl}_{2} \mathrm{~N}_{2}\left(\mathrm{M}+\mathrm{H}^{+}\right)$255.0456, found 255.0454; IR (KBr) $\delta 3047$, $2973,2918,1450,1329,1268,751 \mathrm{~cm}^{-1}$

\footnotetext{
${ }^{103}$ Kaiser, E. M.; Petty, J. D. J. Organomet. Chem. 1976, 108 (2), 139

${ }^{104}$ Shaabani, A.; Maleki, A. Chem. Pharm. Bull. (Tokyo). 2008, 56 (1), 79
} 
General Experimental Procedure for the Synthesis of Piperazines 3a-c.

To a solution of the corresponding nitroepoxide $(0.837 \mathrm{mmol})$ in ethanol ( $4.6 \mathrm{~mL}), 1,2$-ethylenediamine $(90 \mu \mathrm{L}, 1.225 \mathrm{mmol})$ was added dropwise. The resulting mixture was stirred for 6 hours at room temperature under $\mathrm{N}_{2}$ atmosphere. Then $\mathrm{NaBH}(\mathrm{OAc})_{3}$ (549 mg, 2.511 mmol) was added and the resulting mixture was stirred for additional 16 hours. Then a solution of aqueous $\mathrm{NaOH} 50 \%(200 \mu \mathrm{L}, 5 \mathrm{mmol})$ was added and the mixture was stirred for $2 \mathrm{~h}$. Then magnesium sulfate ( $84 \mathrm{mg}, 0.7 \mathrm{mmol}$ ) was added and the mixture was stirred for additional 1.5 hours. Then the mixture was filtered and concentrated to yield a yellow crude oil, which was purified through silica gel chromatography $\left(\mathrm{CH}_{2} \mathrm{Cl}_{2} / \mathrm{MeOH} / \mathrm{Et}_{3} \mathrm{~N}, 95: 4: 1\right)$. If the resulting compound was contaminated by 1,2-ethylenediamine, the product was solved in the minimum amount of water, then treated with $5 \%$ aqueous $\mathrm{NaOH}$ solution (until $\mathrm{pH}=10)$ and extracted with dichloromethane $(3 \times 10 \mathrm{~mL})$ to afford a yellowish oil after evaporation.<smiles>CC1NCCNC1c1ccccc1</smiles>

2-Methyl-3-phenylpiperazine 3a, yellowish oil, $65 \mathrm{mg}$ (44\% yield): ${ }^{1} \mathrm{H}$ NMR (500 MHz, $\left.\mathrm{CDCl}_{3}\right) \delta 7.38-7.28(\mathrm{~m}, 5 \mathrm{H}), 4.16$ $(\mathrm{d}, J=3.4 \mathrm{~Hz}, 1 \mathrm{H}), 3.34(\mathrm{dt}, J=10.3,6.8 \mathrm{~Hz}, 2 \mathrm{H}), 3.23-3.13(\mathrm{~m}, 1 \mathrm{H})$, $3.11-3.03$ (m, 1H), 2.55-2.25 (bs, 2H), $2.90-2.80$ (m, 1H), 1.03 (d, $J$ $=6.8 \mathrm{~Hz}, 1 \mathrm{H}) .{ }^{13} \mathrm{C} \mathrm{NMR}\left(75 \mathrm{MHz}, \mathrm{CDCl}_{3}\right) \delta 142.6,128.2,128.0,126.8$, 64.0, 53.1, 47.8, 40.2, 12.8; HRMS (ESI) calcd for $\mathrm{C}_{11} \mathrm{H}_{17} \mathrm{~N}_{2}\left(\mathrm{M}+\mathrm{H}^{+}\right)$ 177.1392, found 177.1393; IR $(\mathrm{KBr}) \delta 3342,3056,2965,2939,1269$, $759 \mathrm{~cm}^{-1}$

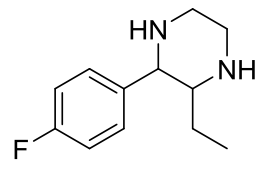

2-Ethyl-3-(4-fluorophenyl)piperazine 3b, pale yellow oil, $101 \mathrm{mg}$ (64\% yield): ${ }^{1} \mathrm{H} \mathrm{NMR}\left(500 \mathrm{MHz}, \mathrm{CDCl}_{3}\right) \delta 7.37$ (dd, $J=$ $8.5,5.4 \mathrm{~Hz}, 2 \mathrm{H}), 7.00$ (t, $J=8.6 \mathrm{~Hz}, 2 \mathrm{H}), 5.00-4.57$ (bs, 2H), 4.38 (d, $J$ 
$=3.2 \mathrm{~Hz}, 1 \mathrm{H}), 3.32-2.98(\mathrm{~m}, 5 \mathrm{H}), 1.86-1.71(\mathrm{~m}, 1 \mathrm{H}), 1.40-1.26(\mathrm{~m}$, $1 \mathrm{H}), 0.75(\mathrm{t}, J=7.5 \mathrm{~Hz}, 3 \mathrm{H}) .{ }^{13} \mathrm{C}$ NMR $\left(75 \mathrm{MHz}, \mathrm{CDCl}_{3}\right) \delta 162.2(\mathrm{~d}, J$ $=246.3 \mathrm{~Hz}), 135.6(\mathrm{~d}, J=3.1 \mathrm{~Hz}), 128.8(\mathrm{~d}, J=8.0 \mathrm{~Hz}), 115.3(\mathrm{~d}, J=$ $21.3 \mathrm{~Hz}$ ), 60.7, 59.4, 44.6, 39.5, 17.7, 11.0. HRMS (ESI) calcd for $\mathrm{C}_{11} \mathrm{H}_{16} \mathrm{FN}_{2}\left(\mathrm{M}+\mathrm{H}^{+}\right)$209.1454, found 209.1451; IR (KBr) $\delta 3358,3026$, $2977,2966,1414,1255,898 \mathrm{~cm}^{-1}$

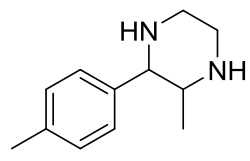

2-Methyl-3-(p-tolyl)piperazine 3c, pale yellow oil 92 mg (58\% yield): ${ }^{1} \mathrm{H}$ NMR $\left(300 \mathrm{MHz}, \mathrm{CDCl}_{3}\right) \delta 7.20(\mathrm{~d}, J=8.1 \mathrm{~Hz}, 2 \mathrm{H})$, $7.10(\mathrm{~d}, J=8.1 \mathrm{~Hz}, 2 \mathrm{H}), 3.99$ (d, $J=3.3 \mathrm{~Hz}, 1 \mathrm{H}), 2.30$ (s, 3H), $1.74(\mathrm{br}$ s, 2H), 2.69-3.19 (m, 5H), $0.94(\mathrm{~d}, J=8.1 \mathrm{~Hz}, 3 \mathrm{H})$ (majoritary), 0.77 (d, $J=7.8 \mathrm{~Hz}, 3 \mathrm{H})$ (minoritary). ${ }^{13} \mathrm{C} \mathrm{NMR}\left(75 \mathrm{MHz}, \mathrm{CDCl}_{3}\right) \delta 139.7$, 136.3, 128.9, 126.7, 63.8, 53.2, 47.8, 40.3, 21.0, 12.9. HRMS (ESI) calcd for $\mathrm{C}_{12} \mathrm{H}_{19} \mathrm{~N}_{2}\left(\mathrm{M}+\mathrm{H}^{+}\right)$191.1548, found 191.1542; IR (KBr) $\delta$ $3338,3054,2982,1427,1268,889 \mathrm{~cm}^{-1}$

Experimental Procedure for the Synthesis of Tetrahydroquinoxaline $4 a$.

To a solution of nitroepoxide 1a $(50 \mathrm{mg}, 0.279 \mathrm{mmol})$ in dichloromethane (1.6 mL), 1,2-benzenediamine (46mg, $0.418 \mathrm{mmol}$ ) was added in one-portion and the mixture was stirred in the open air for 48h. After the formation of quinoxaline (TLC, reaction mixture turned red), dichloromethane ( $1 \mathrm{~mL}$ ) was added in order to compensate the solvent lost by evaporation. Then the atmosphere was purged with $\mathrm{N}_{2}$ and the reaction mixture was cooled down with an ice-bath. Then $1 \mathrm{M}$ borane-tetrahydrofuran complex in THF solution $(1.1 \mathrm{~mL}, 1.116 \mathrm{mmol})$ was added dropwise, and the resulting reaction mixture was stirred at room temperature for 40 minutes. Then methanol $(4 \mathrm{~mL})$ was added, then concentrated under vacuum, methanol $(4 \mathrm{~mL})$ added again and concentrated under vacuum. The resulting residue was dissolved in dichloromethane $(10 \mathrm{~mL})$, treated with an aqueous $5 \% \mathrm{NaOH}$ solution $(10 \mathrm{~mL})$ and extracted with dichloromethane $(4 \times 5 \mathrm{~mL})$. The combined 
organic layers were dried $\left(\mathrm{MgSO}_{4}\right)$, filtered and concentrated under vacuum. The crude was purified through silica gel chromatography (hexanes/ethyl acetate, 8:2) to afford an orange-brown oil. (When pure compound 4 was stored under non-inert conditions it was gradually converted into the corresponding quinoxaline 2a).

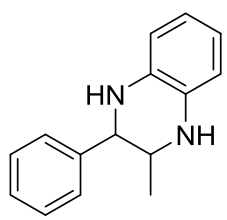

cis-2-Methyl-3-phenyl-1,2,3,4-tetrahydroquinoxaline 4a, orange-brown oil $45 \mathrm{mg}$ (yield 72\%) ${ }^{1} \mathrm{H} \mathrm{NMR}\left(300 \mathrm{MHz}, \mathrm{CDCl}_{3}\right) \delta$ $7.38-7.26(\mathrm{~m}, 5 \mathrm{H}), 6.79-6.60(\mathrm{~m}, 3 \mathrm{H}), 6.58(\mathrm{~d}, J=7.3 \mathrm{~Hz}, 1 \mathrm{H}), 4.56$ $(\mathrm{d}, J=3.1 \mathrm{~Hz}, 1 \mathrm{H}), 3.75(\mathrm{qd}, J=6.5,3.3 \mathrm{~Hz}, 1 \mathrm{H}), 0.98(\mathrm{~d}, J=6.5 \mathrm{~Hz}$, $3 \mathrm{H}) .{ }^{13} \mathrm{C} \mathrm{NMR}\left(126 \mathrm{MHz}, \mathrm{CDCl}_{3}\right) \delta 141.7,133.4,128.6,128.3,127.6$, 127.4, 119.6, 118.4, 115.2, 114.1, 58.5, 49.6, 17.4; HRMS (ESI) calcd for $\mathrm{C}_{15} \mathrm{H}_{17} \mathrm{~N}_{2}\left(\mathrm{M}+\mathrm{H}^{+}\right)$225.1392, found 225.1396; IR (KBr) $\delta 3400$, $3042,2979,1604,1500,1440,1014 \mathrm{~cm}^{-1}$

General Experimental Procedure for the Synthesis of $\mathrm{N}$-NitrosoTetrahydroquinoxaline $\mathbf{4 b}$.

For this reaction, all solvents and reagents were manipulated under inert conditions. A solution of nitroepoxide 1a $(150 \mathrm{mg}, 0.837 \mathrm{mmol})$ in dry ethanol $(4.6 \mathrm{~mL})$ was added under $\mathrm{N}_{2}$ atmosphere into a twonecked round bottom flask equipped with a magnetic stirrer and an addition funnel. Then, a previously purged solution of 1,2diaminobenzene (139 $\mathrm{mg}, 1.225 \mathrm{mmol})$ in dry ethanol $(2 \mathrm{~mL})$, was added and the reaction mixture was stirred for 5 hours. Then, powdered $\mathrm{NaBH}(\mathrm{OAc})_{3}$ was added through the addition funnel under $\mathrm{N}_{2}$ atmosphere, and the reaction mixture was stirred overnight. A nonextractive work-up was performed by adding $200 \mu \mathrm{l}$ of $25 \mathrm{M}$ aqueous $\mathrm{NaOH}$ and the mixture was stirred for 2 hours. Then, $\mathrm{MgSO}_{4}$ (ca. 84 $\mathrm{mg}$ ) was added and the mixture stirred for additional $1.5 \mathrm{~h}$. Finally, the reaction mixture was filtered under vacuum, dried with $\mathrm{MgSO}_{4}$ and filtered again and the solvent was removed under vacuum to afford a 
yellowish oil which was purified by silica gel liquid chromatography (hexanes/ethyl acetate 8:2).<smiles>CC1Nc2ccccc2N([O-])C1c1ccccc1</smiles>

\section{3-methyl-1-nitroso-2-phenyl-1,2,3,4-tetrahydro-}

quinoxaline 4b, orange-brown oil, $25 \mathrm{mg}$ (12\% yield). ${ }^{1} \mathrm{H}$ NMR (300 $\left.\mathrm{MHz}, \mathrm{CDCl}_{3}\right) \delta 8.03(\mathrm{~d}, J=8.2 \mathrm{~Hz}, 1 \mathrm{H}), 7.61-7.32(\mathrm{~m}, 5 \mathrm{H}), 7.25-$ $7.08(\mathrm{~m}, 1 \mathrm{H}), 7.00-6.78(\mathrm{~m}, 2 \mathrm{H}), 5.33(\mathrm{qd}, J=6.5,3.3 \mathrm{~Hz}, 1 \mathrm{H}), 4.45$ $(\mathrm{d}, J=3.3 \mathrm{~Hz}, 1 \mathrm{H}), 4.18$ (bs, $1 \mathrm{H}), 0.86(\mathrm{~d}, J=6.6 \mathrm{~Hz}, 3 \mathrm{H}) .{ }^{13} \mathrm{C} \mathrm{NMR}$ $\left(126 \mathrm{MHz}, \mathrm{CDCl}_{3}\right) \delta 137.9,134.3,128.9,128.3,127.0,119.7,116.8$, 116.1, 57.1, 48.0, 10.0. MS (ESI) calcd for $\mathrm{C}_{15} \mathrm{H}_{15} \mathrm{~N}_{3} \mathrm{O}(\mathrm{M}+\mathrm{Na})^{+} 276.1$, found 276.2; IR $(\mathrm{KBr}) \delta 3362,2918,1488,1433,1271,1146,752 \mathrm{~cm}^{-1}$

General Experimental Procedure for the Synthesis of Pyrazines 6ae.

The corresponding nitroepoxide $(0.558 \mathrm{mmol})$ was solved into a commercially available $7 \mathrm{~N}$ solution of ammonia in $\mathrm{MeOH}(1.1 \mathrm{~mL})$. The mixture was stirred for 24 hours at room temperature. Then the mixture was concentrated under vacuum, water $(5 \mathrm{~mL})$ and ethyl ether $(5 \mathrm{~mL})$ were added and the resulting mixture was extracted with ethyl ether $(3 \times 5 \mathrm{~mL})$, the combined organic phases were washed with brine $(15 \mathrm{~mL})$, dried $\left(\mathrm{MgSO}_{4}\right)$ and concentrated. The resulting yellow solid resulted to be highly pure compound.

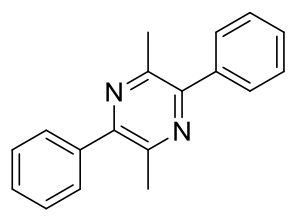

2,5-Dimethyl-3,6-diphenylpyrazine 5a, pale yellow solid, $67 \mathrm{mg}$ (93\% yield), mp 120-125 ${ }^{\circ} \mathrm{C}$ (lit. ${ }^{105} 125-126{ }^{\circ} \mathrm{C}$ ): ${ }^{1} \mathrm{H}$ NMR $\left(300 \mathrm{MHz}, \mathrm{CDCl}_{3}\right) \delta 7.63(\mathrm{~d}, J=6.6 \mathrm{~Hz}, 4 \mathrm{H}), 7.54-7.41(\mathrm{~m}, 6 \mathrm{H})$, $2.64(\mathrm{~s}, 6 \mathrm{H}) .{ }^{13} \mathrm{C} \mathrm{NMR}\left(75 \mathrm{MHz}, \mathrm{CDCl}_{3}\right) \delta 151.1,147.8,138.8,129.1$,

${ }^{105}$ Schmitt, V.; Moschel, S.; Detert, H. European J. Org. Chem. 2013, 25, 5655 
128.6, 128.5, 22.7; HRMS (ESI) calcd for $\mathrm{C}_{18} \mathrm{H}_{17} \mathrm{~N}_{2}\left(\mathrm{M}+\mathrm{H}^{+}\right)$261.1392, found 261.1391 IR (KBr) $\delta 3057,2987,1682,1424,1391,904 \mathrm{~cm}^{-1}$

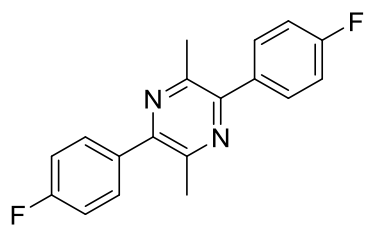

2,5-Bis(4-fluorophenyl)-3,6-dimethylpyrazine

5b, pale yellow crystals, $76 \mathrm{mg}$ (92\% yield), mp 179-181 ${ }^{\circ} \mathrm{C}:{ }^{1} \mathrm{H}$ NMR $\left(300 \mathrm{MHz}, \mathrm{CDCl}_{3}\right) \delta 7.62(\mathrm{dd}, J=7.7,5.4 \mathrm{~Hz}, 4 \mathrm{H}), 7.17(\mathrm{t}, J=8.6 \mathrm{~Hz}$, $4 \mathrm{H}), 2.62(\mathrm{~s}, 6 \mathrm{H}) .{ }^{13} \mathrm{C}$ NMR $\left(75 \mathrm{MHz}, \mathrm{CDCl}_{3}\right) \delta 163.0(\mathrm{~d}, J=248.5$ $\mathrm{Hz}), 150.1,147.7,134.7$ (d, $J=3.3 \mathrm{~Hz}), 131.0(\mathrm{~d}, J=8.3 \mathrm{~Hz}), 115.5$ (d, $J=21.7 \mathrm{~Hz}$ ), 22.7; HRMS (ESI) calcd for $\mathrm{C}_{18} \mathrm{H}_{15} \mathrm{~F}_{2} \mathrm{~N}_{2}\left(\mathrm{M}+\mathrm{H}^{+}\right)$ 297.1203, found 297.1204; IR (KBr) $\delta 3036,2968,1610,1504,1412$, $1220,850 \mathrm{~cm}^{-1}$

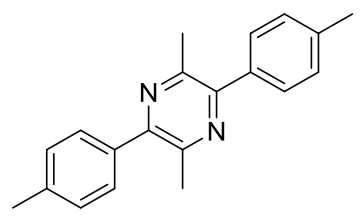

2,5-Dimethyl-3,6-di-p-tolylpyrazine 5c, pale yellow solid, $72 \mathrm{mg}$ (90\% yield), mp 162-166 ${ }^{\circ} \mathrm{C}$ (lit. ${ }^{106} 168{ }^{\circ} \mathrm{C}$ ): ${ }^{1} \mathrm{H}$ NMR $\left(500 \mathrm{MHz}, \mathrm{CDCl}_{3}\right) \delta 7.54(\mathrm{~d}, J=8.0 \mathrm{~Hz}, 4 \mathrm{H}), 7.29(\mathrm{~d}, J=7.7 \mathrm{~Hz}$, $4 \mathrm{H}), 2.64(\mathrm{~s}, 6 \mathrm{H}), 2.42(\mathrm{~s}, 6 \mathrm{H}) .{ }^{13} \mathrm{C} \mathrm{NMR}\left(75 \mathrm{MHz}, \mathrm{CDCl}_{3}\right) \delta 150.8$, 147.6, 138.4, 136.0, 129.1, 129.0, 22.7, 21.3; HRMS (ESI) calcd for $\mathrm{C}_{20} \mathrm{H}_{21} \mathrm{~N}_{2}\left(\mathrm{M}+\mathrm{H}^{+}\right)$289.1705, found 289.1707; IR (KBr) $\delta 3062,2984$, $1692,833 \mathrm{~cm}^{-1}$

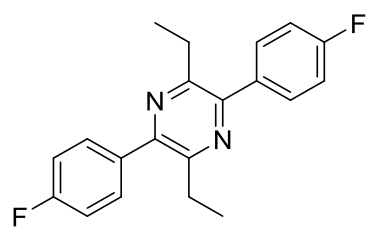

2,5-Diethyl-3,6-(4-fluorophenyl)pyrazine 5d, pale yellow crystals, $87 \mathrm{mg}$ (96\% yield), mp 115-116 ${ }^{\circ} \mathrm{C}:{ }^{1} \mathrm{H}$ NMR (500 $\left.\mathrm{MHz} \mathrm{CDCl}_{3}\right) \delta 7.61(\mathrm{dd}, J=8.5,5.4 \mathrm{~Hz}, 2 \mathrm{H}), 7.17(\mathrm{t}, J=8.6 \mathrm{~Hz}, 2 \mathrm{H})$, 2.91 (q, $J=7.5 \mathrm{~Hz}, 2 \mathrm{H}), 1.27$ (t, $J=7.4 \mathrm{~Hz}, 3 \mathrm{H}) .{ }^{13} \mathrm{C} \mathrm{NMR}(126 \mathrm{MHz}$,

\footnotetext{
${ }^{106}$ Tiffeneau; Levy; Ditz, Bull. Soc. Chim. Fr. 1935, 5, 1855.
} 
$\left.\mathrm{CDCl}_{3}\right) \delta 163.0(\mathrm{~d}, J=248.2 \mathrm{~Hz}), 152.1,150.0,135.0(\mathrm{~d}, J=3.3 \mathrm{~Hz})$, $130.9(\mathrm{~d}, J=8.3 \mathrm{~Hz}), 115.4$ (d, $J=21.6 \mathrm{~Hz}), 27.8,13.5$; HRMS (ESI) calcd for $\mathrm{C}_{20} \mathrm{H}_{19} \mathrm{~F}_{2} \mathrm{~N}_{2}\left(\mathrm{M}+\mathrm{H}^{+}\right)$325.1516, found 325.1514; IR (KBr) $\delta$ $3044,2979,2936,1608,1509,1409,1229,855 \mathrm{~cm}^{-1}$

2,5-Dimethyl-3,6-dipropylpyrazine 5e, orange oil 48 mg (89\% yield): ${ }^{1} \mathrm{H}$ NMR (300 MHz, $\left.\mathrm{CDCl}_{3}\right) \delta 2.73-2.61(\mathrm{~m}, 1 \mathrm{H})$, $2.45(\mathrm{~s}, 1 \mathrm{H}), 1.66(\mathrm{dq}, J=14.9,7.4 \mathrm{~Hz}, 1 \mathrm{H}), 0.95(\mathrm{t}, J=7.4 \mathrm{~Hz}, 2 \mathrm{H})$. ${ }^{13} \mathrm{C}$ NMR $\left(75 \mathrm{MHz}, \mathrm{CDCl}_{3}\right) \delta 151.7,147.8,36.6,22.1,21.0,14.1$; HRMS (ESI) calcd for $\mathrm{C}_{12} \mathrm{H}_{21} \mathrm{~N}_{2}\left(\mathrm{M}+\mathrm{H}^{+}\right)$193.1705, found 193.1703; IR (KBr) $\delta 3053,2983,2963,1673,1424,1260,900 \mathrm{~cm}^{-1}$

\section{Experimental Procedure for the Synthesis of Imidazopyridine 6.}

To a solution of nitroepoxide 1a (120 mg, $0.670 \mathrm{mmol})$ in ethanol (3.7 $\mathrm{mL}$ ), 2-aminopyridine (96 mg, $1.004 \mathrm{mmol}$ ) was added in one-portion and the mixture was stirred for $20 \mathrm{~h}$. Then anhydrous $\mathrm{MgSO}_{4}$ (50mg) was added and stirred for 15 minutes. Then the mixture was filtered washing with EtOAc, and concentrated under vacuum. An orange/yellow oil was obtained which was further purified through a silica-gel chromatography (hexane/ethyl acetate, 8:2 to 6:4). Spectra of the pure compound matched with those reported in the literature. ${ }^{95}$<smiles>Cc1nc2ccccn2c1-c1ccccc1</smiles>

2-methyl-3-phenylimidazo[1,2-a]pyridine 6, yellow oil, $29 \mathrm{mg}$ (21\% yield): ${ }^{1} \mathrm{H}$ NMR $\left(500 \mathrm{MHz}, \mathrm{CDCl}_{3}\right) \delta 8.08(\mathrm{~d}, J=6.9 \mathrm{~Hz}$, $1 \mathrm{H}), 7.53(\mathrm{~m}, 3 \mathrm{H}), 7.44(\mathrm{~m}, 3 \mathrm{H}), 7.14(\mathrm{t}, J=7.5 \mathrm{~Hz}, 1 \mathrm{H}), 6.70(\mathrm{t}, J=$ $6.5 \mathrm{~Hz}, 1 \mathrm{H}), 2.47$ (s, 3H). 



\section{Chapter 3}

Asymmetric Eporidation of Dicyanoallkylidenes 



\section{Objectives}

The work present in this chapter was performed during a four-month stay at Università degli Studi di Salerno (Italy) under the supervision of Professor Alessandra Lattanzi and in collaboration with Dr. Sara Meninno.

The main purpose of the work in this chapter is the asymmetric epoxidation of dicyanoalkylidenes, which is organized as follows:

The synthesis of dicyanoalkylidene $\mathbf{7}$ as study for the optimization study of the asymmetric epoxidation conditions.

The synthesis of the racemic epoxide $\mathbf{8}$ from the corresponding dicyanoalkylidene $\mathbf{7}$ and the separation of the enantiomers by HPLC for identification.

The rational design and synthesis of various bifunctional catalysts to achieve the asymmetric epoxidation of dicyanoalkylidenes.

The screening of the conditions for the optimization of the enantioselective epoxidation of dicyanoalkylidene 7. 


\section{Introduction}

As it is extensively reported in the general introduction of the present Thesis dissertation, plenty of organocatalytic methodologies have been described for the synthesis of chiral epoxides from electron-deficient alkenes with high chemical yields and enantioselectivity. Despite the success, there is room to expand the substrate scope of electrondeficient alkenes, whose enantioenriched epoxides would be potentially highly attractive for further elaborations such as readily available alkylidenemalononitriles (Scheme 43).

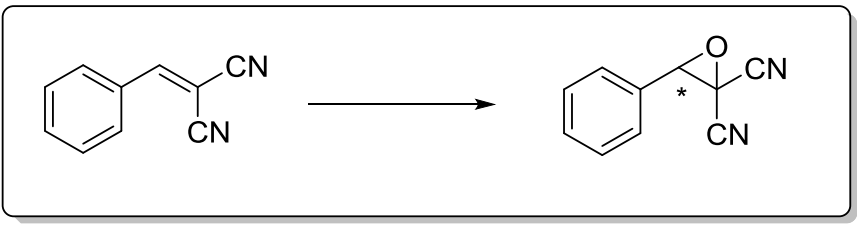

Scheme 43. Epoxidation of 2-benzylidenemalononitrile generates a tertiary stereocenter.

These alkenes are challenging Michael acceptors as demonstrated by the few methodologies reported on asymmetric carbon-carbon bond formation, ${ }^{107}$ likely ascribed to their significant reactive nature ${ }^{108}$ and weak H-bonding acceptor ability of the cyano group. ${ }^{109}$ The only example by Sekiya and co-workers on an asymmetric epoxidation of alkylidenemalononitriles using alkyl hydroperoxides or molecular oxygen and stoichiometric amounts of chiral bases afforded nearly racemic epoxides in low chemical yield (Scheme 44). ${ }^{110}$

107 a) Yue, L.; Du, W.; Liu, Y. K.; Chen, Y. C. Tetrahedron Lett. 2008, 49 (24), 3881. b) Xiao, H.; Chai, Z.; Zheng, C. W.; Yang, Y. Q.; Liu, W.; Zhang, J. K.; Zhao, G. Angew. Chem. Int. Ed. 2010, 49 (26), 4467. c) Ding, D.; Zhao, C. G. Tetrahedron Lett. 2010, 51 (9), 1322.

${ }^{108}$ Lemek, T.; Mayr, H. J. Org. Chem. 2003, 68 (18), 6880.

${ }^{109}$ Sagawa, N.; Shikata, T. J. Phys. Chem. B 2014, 16, 13262.

${ }^{110}$ Nanjo, K.; Suzuki, K.; Sekiya, M. Chem. Pharm. Bull. 1981, 29, 336. 


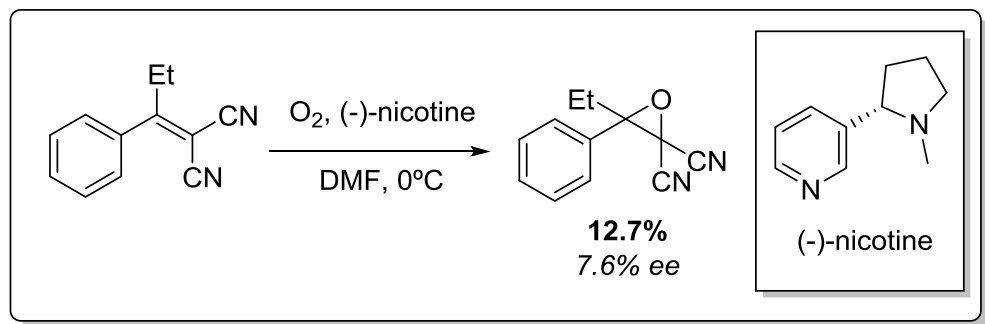

Scheme 44. Epoxidation of alkylidenemalononitriles using molecular oxygen.

It has been demonstrated by a few reports that racemic gemdicyanoepoxides behave like the synthetic equivalent of dication ketenes. For example, Baudy-Floc'h et al. isolated a 3-aryl piperazin-2one in $10 \%$ yield working under mild conditions. ${ }^{111}$ The reaction proceeded at room temperature via regioselective ring-opening of the corresponding gem-dicyanoepoxide by ethylenediamine as a binucleophile (Scheme 45).

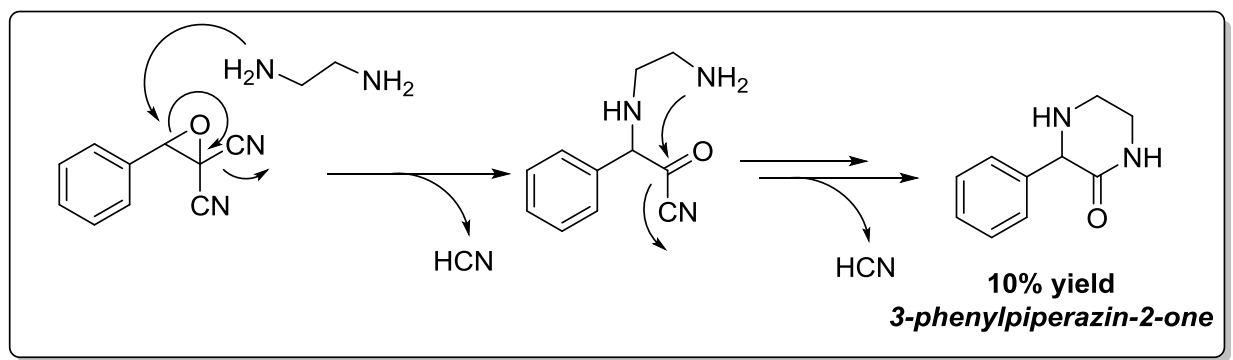

Scheme 45. Pathway for the synthesis of 2-piperazinones from $\alpha, \alpha$-dicyanoepoxides.

Chiral substituted piperazin-2-ones have shown interest in medicinal chemistry since the synthesis of various bioactive compounds with this chemical moiety have been reported. ${ }^{112}$ For example, piperazin-2-one moiety can be found on the p53/MDM2 inhibitor (-)-nutlin- $3^{113}$ and in several naturally occurring bioactive compounds including the

\footnotetext{
${ }^{111}$ Hurtaud, D.; Baudy-Floc'h, M.; Robert, A.; Le Grel, P. J. Org. Chem. 1994, 59 (16), 4701

112 a) Kakarla, R.; Liu, J.; Naduthambi, D.; Chang, W.; Mosley, R. T.; Bao, D.; Steuer, H. M. M.; Keilman, M.; Bansal, S.; Lam, A. M.; Seibel, W.; Neilson, S.; Furman, P. A.; Sofia, M. J. J. Med. Chem. 2014, 57, 2136. b) Yamashita, T.; Hatamoto, E.; Takenaka, H.; Kojima, Y.; Inoue, Y., Gemba, M.; Yasuda, M. Chem. Pharm. Bull. (Tokyo) 1996, 44 (4), 856.

${ }^{113}$ Korch, K. M.; Eidamshaus, C.; Behenna, D. C.; Nam, S.; Horne, D.; Stoltz, B. M. Angew. Chem. Int. Ed. 2015, 54 (1), 179
} 
marcfortines, ${ }^{114}$ pseudotheonamides, ${ }^{115}$ and malbrancheamides ${ }^{116}$ (Scheme 46).

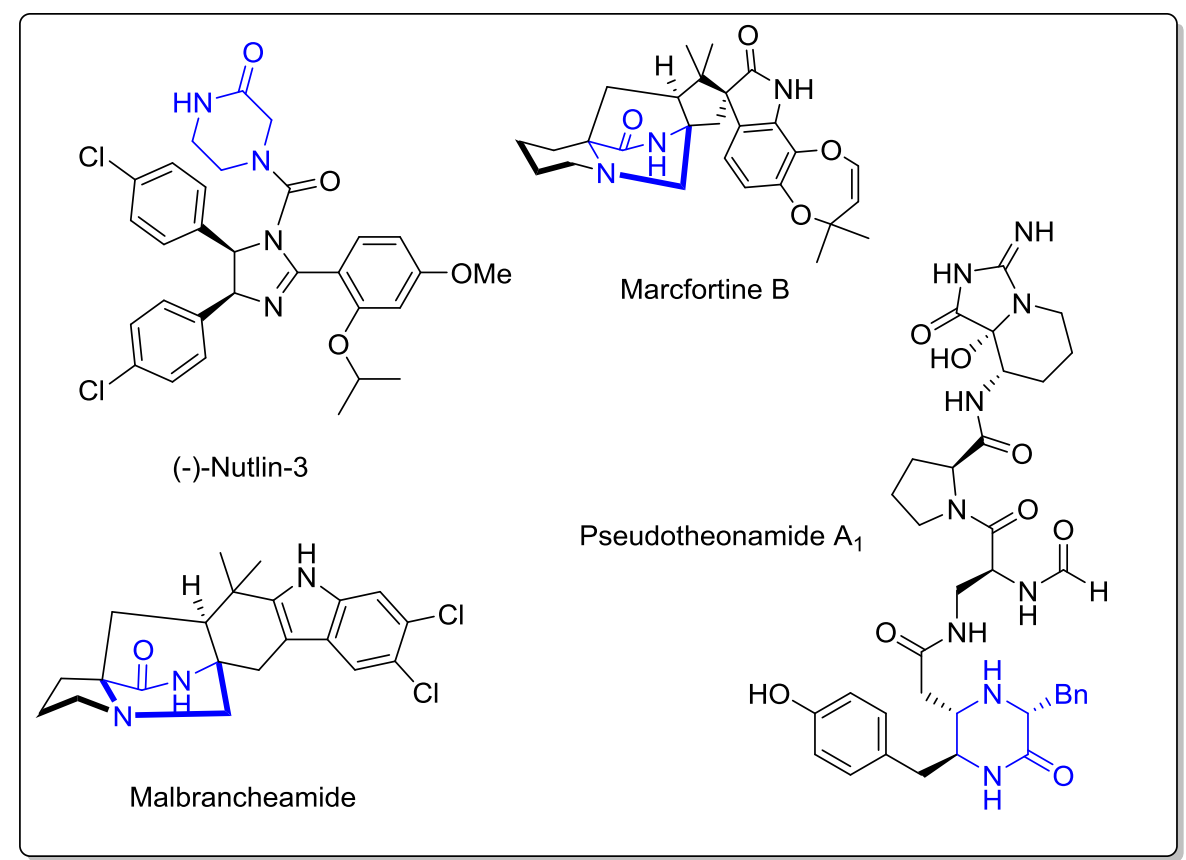

Scheme 46. Bioactive compounds containing the piperazin-2-one moiety.

${ }^{114}$ Prangé, T.; Billion, M. A.; Vuilhorgne, M.; Pascard, C.; Polonsky, J. Tetrahedron Lett. 1981, 22 (21), 1977

${ }^{115}$ Nakao, Y.; Masuda, A.; Matsunaga, S.; Fusetani, N. J. Am. Chem. Soc. 1999, 121 (11), 2425.

${ }^{116}$ Martínez-Luis, S.; Rodríguez, R.; Acevedo, L.; González, M. C.; Lira-Rocha, A.; Mata, R. Tetrahedron 2006, 62 (8), 1817. 


\section{Results and Discussion}

\subsection{Synthesis of Precursor 7}

2-Benzylidenemalononitrile 7 was selected as the compound for the optimization study. It was easily prepared according to literature ${ }^{117}$ from benzaldehyde and malononitrile via Knoevenagel condensation reaction catalyzed by 1 -methylimidazole in water (Scheme 47). The reaction underwent cleanly and fast, affording the pure alkene 7 as white solid which was isolated from the reaction mixture by simply filtration when the reaction was complete (ca. 1 hour).

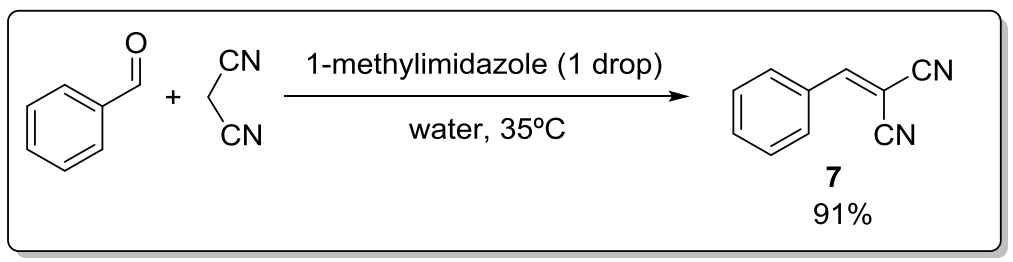

Scheme 47. Synthesis of 2-benzylidenemalonitrile 7.

\subsection{Synthesis of Racemic 8}

First of all, before starting with the optimization for the asymmetric epoxidation, compound 7 was epoxidized under racemic conditions to identify compound $\mathbf{8}$ by NMR and to split the enantiomeric peaks by HPLC. A general methodology, which consisted in a nucleophilic epoxidation with TBHP (1.3 eq) as oxidizing agent and 2piperidinemethanol ( $0.2 \mathrm{eq})$ as catalyst, afforded epoxide $\mathbf{8}$ from alkene 7 within 2 hours. The same methodology was further applied to all reported racemic epoxides (Scheme 48). ${ }^{118}$

\footnotetext{
${ }^{117}$ Pande, A.; Ganesan, K.; Jain, A. K.; Gupta, P. K.; Malhotra, R. C. Org. Proc. Res. Dev. 2005, 9 (2), 133.

${ }^{118}$ Meninno, S.; Vidal-Albalat, A.; Lattanzi, A. Org. Lett. 2015, 17 (17), 4348.
} 


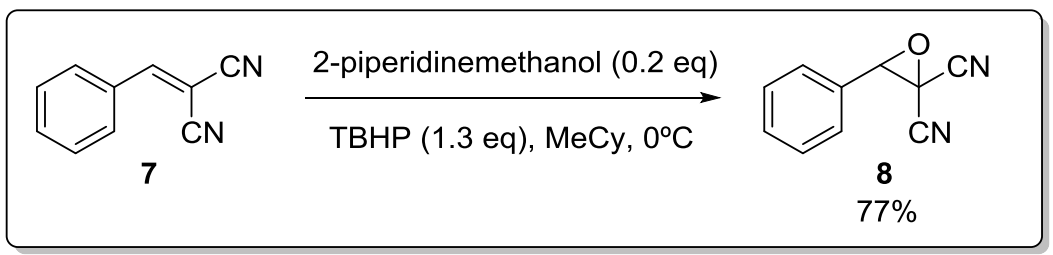

Scheme 48. Synthesis of 3-phenyloxirane-2,2-dicarbonitrile 8.

The racemic epoxide $\mathbf{8}$ was purified by flash chromatography, and the corresponding enantiomers were successfully separated by HPLC with Chiralcel OD-H column, 90:10 $n$-hexane:2-propanol, $1 \mathrm{~mL} / \mathrm{min}, 254$ $\mathrm{nm}$; resulting in retention times of $9.8 \mathrm{~min}$ and $10.9 \mathrm{~min}$. There is more detailed information in the experimental section of this chapter.

\subsection{Synthesis of the Catalysts 10 and $12 a-e$}

For the present work, it was envisioned that bifunctional catalysts bearing double $\mathrm{H}$ - bonding donors would have been effective in engaging an $\mathrm{H}$-bonding network with alkylidenemalononitrile. This idea was supported by recent published research performed by Lattanzi's group, which disclosed the ability of cinchona derived thioureas, namely epi-quinine thiourea (eQNT) to catalyze the enantioselective nucleophilic epoxidation of electron-poor 1,1disubstituted terminal alkenes with TBHP (Scheme 49). ${ }^{119}$

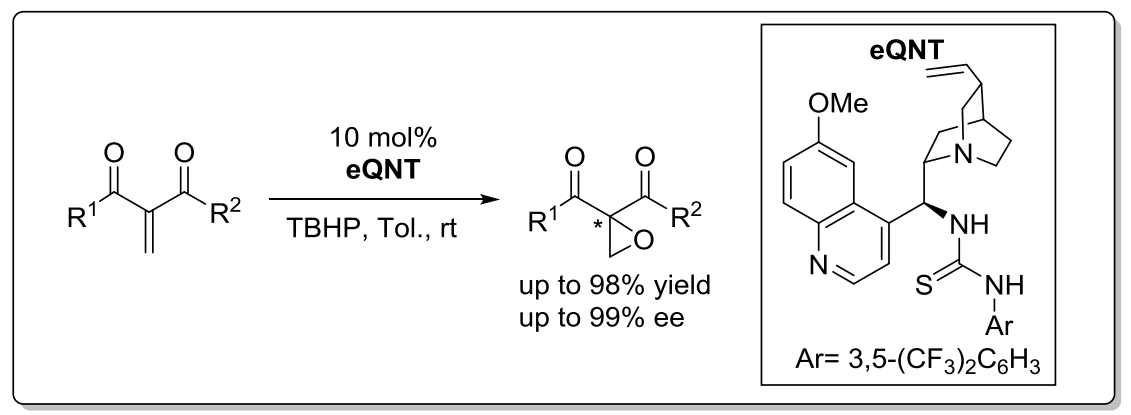

Scheme 49. Asymmetric epoxidation of terminal alkenes.

Many cinchona derived ureas, thioureas and squaramides have been described as bifunctional organocatalysts for several reactions such as

${ }^{119}$ Russo, A.; Galdi, G.; Croce, G.; Lattanzi, A. Chem. Eur. J. 2012, 18 (20), 6152. 
Michael, aldol and Strecker-type reactions. ${ }^{120}$ Inspired by the plenitude of examples in the literature, catalysts $\mathbf{1 0}$ and 12a-e (Figure 11) were designed in order to test them as organocatalysts for the asymmetric epoxidation of $\mathbf{7}$ and furtherly, to elucidate how changes in the stereochemistry and the structure affect the conversion and the enantiomeric ratio.

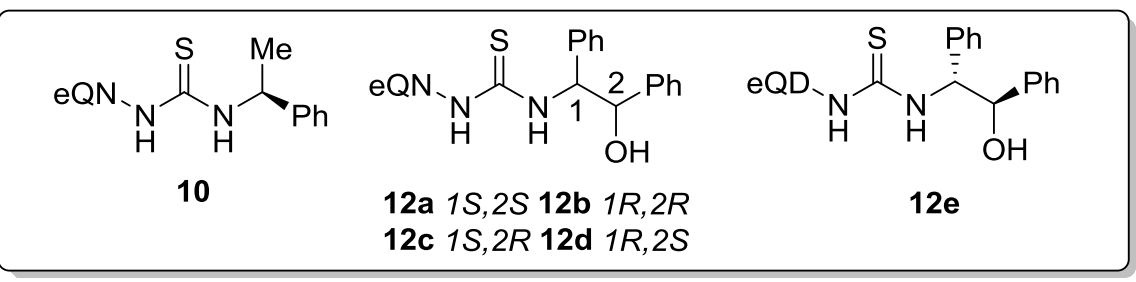

Figure 11. Catalysts 10 and 12a-e.

Catalyst 12c is a known compound described by Ma et al. ${ }^{121}$ and the rest of the aforementioned compounds were prepared in a similar procedure. Starting from quinine and quinidine, a Mitsunobu reaction was performed to obtain the 9-amino-(9-deoxy)-epi-quinine and 9amino-(9-deoxy)-epi-quinidine. ${ }^{122}$ Then, both were activated with DCC and treated with carbon disulfide to obtain the isothiocyanate intermediates $\mathbf{A}_{\mathbf{1}}$ and $\mathbf{A}_{\mathbf{2}}$, which were finally converted into catalysts 12a-e when the appropriate chiral 2-amino-1,2-diphenylethanol was used, or $\alpha$-(S)-methylbenzylamine in the case of catalyst 10 (Scheme 50). Full description of the synthesis is available on the experimental section of the current chapter.

\footnotetext{
${ }^{120}$ a) For a mini-review on cinchona derived ureas and thioureas: Connon, S. J. Chem. Commun. 2008, (22) 2499. b) Li, N.; Liu, Z.; Huang, X.; Zhang, J.; Chen, X.; Wang, Y.; Wang, X. RSC Adv. 2013, 3, 9154. c) Bassas, O.; Huuskonen, J.; Rissanen, K.; Koskinen, A. M. P. Eur. J. Org. Chem. 2009, 1340.

${ }^{121}$ Ma, H.; Matsuzaki, K.; Yang, Y.-D.; Tokunaga, E.; Nakane, D.; Ozawa, T.; Masuda, H.; Shibata, N. Chem. Commun. 2013, 49 (95), 11206 ${ }^{122}$ Cassani, C.; Martín-Rapún, R.; Arceo, E.; Bravo, F.; Melchiorre, P. Nat. Protoc. 2013, 8 (2), 325 .
} 


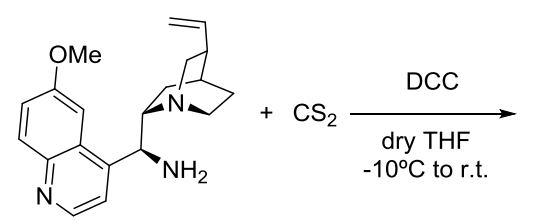

9-amino-(9-deoxy)-epi-quinine

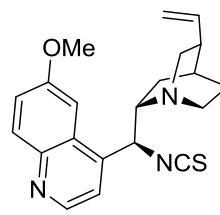

$A_{1}$

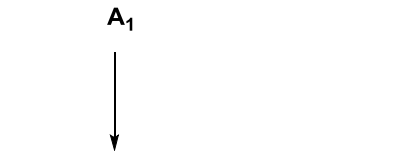

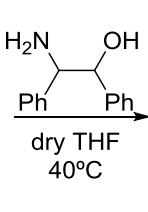
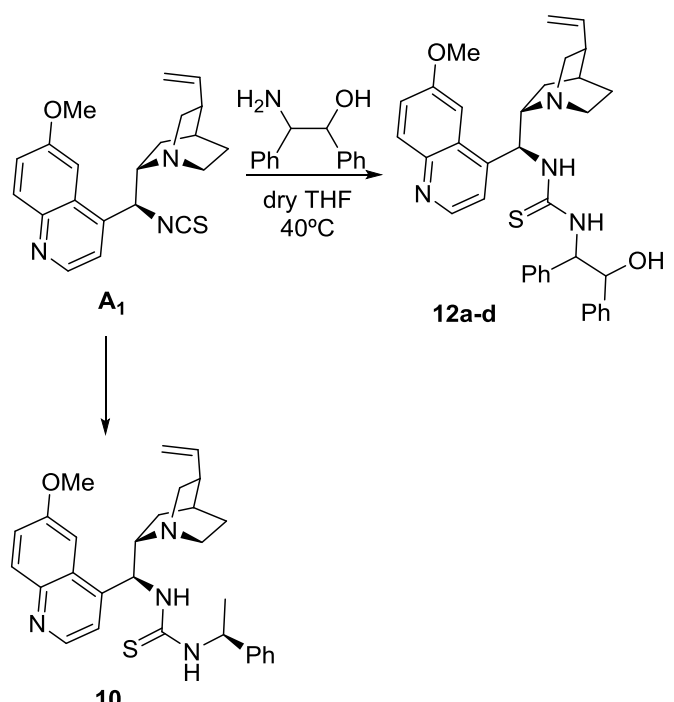

10

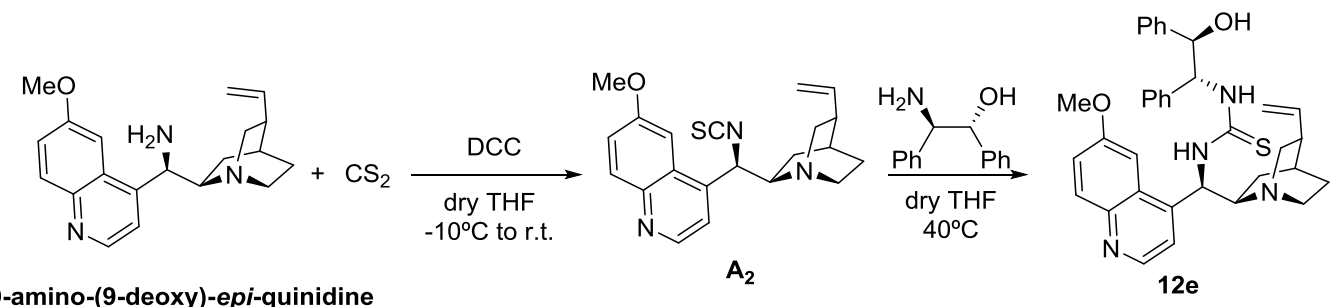

Scheme 50. Synthetic route to catalysts $\mathbf{1 0}$ and $\mathbf{1 2 a - e}$ from quinine and quinine amino-derivatives.

\subsection{Screening of the Catalysts}

As previously intensely described in the general introduction chapter of this $\mathrm{PhD}$ Thesis, bifunctional organocatalysis follows this general mechanism: a basic moiety in the organocatalyst structure (usually a tertiary amine) deprotonates the pronucleophile while a non-covalent H-bonding interaction activates the electrophile, forming a transition state which controls the enantioselectivity by the chiral scaffold of the catalyst (Scheme 51). According to that, initial experiments were performed with phenylidenemalononitrile 7 and TBHP in toluene at room temperature screening different organocatalysts at a $10 \mathrm{~mol} \%$ loading (Table 4). We were pleased to observe that epi-quinine thiourea 
eQNT satisfactorily catalyzed the reaction affording the epoxide with a 67.5:32.5 er value (entry 1). The corresponding urea eQNU and squaramide eQNS proved to be slightly less efficient (entries 2 and 3, respectively). One possible explanation can be found in the literature, since some studies have recently examined the structure-activitystereoselectivity regarding the acidity of (thio)urea moiety in the catalyst for the Michael reaction. ${ }^{123}$ In general, it was found that the more acid the thiourea is, the more catalytic effect is observed, both in terms of conversion and enantioselectivity. ${ }^{123}$ However, that shouldn't be taken as the only factor in consideration, since pKa of eQNT is $12.4^{123}$, higher than the pKa of eQNS which is $10.5^{123}$. The observed results for the tested catalysts cannot be explained only by invocking acidity and strongness of $\mathrm{H}$-bonds. Other structural modifications of the catalyst can have a great impact on activity and enantioselectivity.

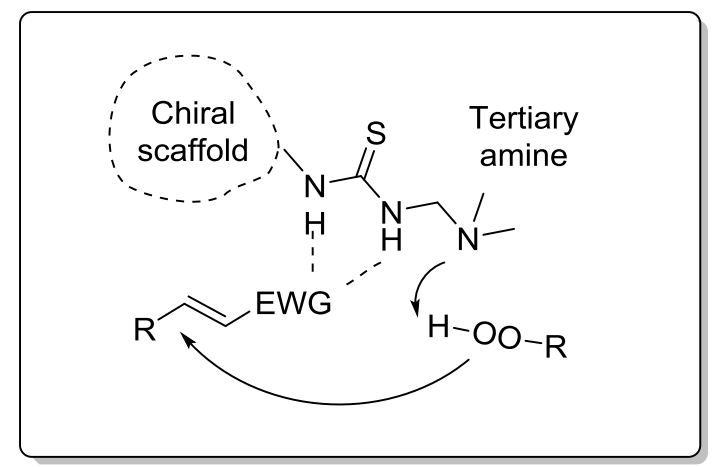

Scheme 50. Common transition state rationalization

At that point, considering that the thiourea based catalyst gave better results than urea and squaramide, other thiourea amine catalysts were prepared. First, other easily available thiourea catalysts derived from different cinchona alkaloids, i.e., cinchonidine, hydroquinine and quinidine were tested. The epoxidation reactions performed with epicinchonidine thiourea eCDT and epi-hydroquinine thiourea eHQNT

123 a) Li, X.; Deng, H.; Zhang, B.; Li, J.; Zhang, L.; Luo, S.; Cheng, J. P. Chem. Eur. J. 2010, 16 (2), 450. b) Jakab, G.; Tancon, C.; Zhang, Z.; Lippert, K. M.; Schreiner, P. R. Org. Lett. 2012, 14 (7), 1724 c) Ni, X.; Li, X.; Wang, Z.; Cheng, J. P. Org. Lett. 2014, $16(6), 1786$ 
were less effective (entries 4 and 5), whereas the pseudoenantiomeric epi-quinidine thiourea eQDT afforded the opposite enantiomer of the epoxide in high yield but with lower enantioselectivity (entry 6).

Catalyst 9, where the thiourea moiety is positioned in the quinoline ring, was tested in order to check the effect of spatial distribution of functional groups over the quinine's core in terms of reactivity and enantioselectivity. Unfortunately, it proved to be the worst in the series, indicating that the quinuclidine nitrogen and hydrogen bonding donating groups are catalytically more effective when located in proximity (entry 7 ).

Previously described catalysts have in common the achiral 3,5bis(trifluoromethyl)-phenyl group attached to thiourea moiety. Derived epi-quinine catalyst $\mathbf{1 0}$ was designed to test its activity when the aromatic ring is replaced with a chiral fragment. The conversion was good $(72 \%)$ in a relatively short period of time. However, the presence of a chiral amine moiety was detrimental for the enantioselectivity (entry 8). These results clearly suggested the involvement of mismatching effects on affecting the catalytic activity. Structurally different thiourea amines such as Takemoto's bifunctional catalyst and 11 (entries 9 and 10) did not improve the result obtained with eQNT (entry 1).

Given the reactive nature of alkylidene malononitrile, we thought improvements might be achieved using amine thioureas bearing multiple hydrogen-bonding donors incorporating chiral aminoalcohol moieties. ${ }^{124}$ The catalytic activity of epi-quinine derived thioureas 12a-e was then investigated under the standard conditions (entries $11-$ 15). Pleasingly for us, promoter 12a (entry 11) proved to be more active and enantioselective than eQNT (entry 1), with the best matching effect displayed by the (S,S)-amino alcohol portion, giving epoxide $\mathbf{8}$ in $90 \%$ yield and 77.2:22.8 er. The absolute configuration of

${ }^{124}$ For a recent review: Fang, X.; Wang, C.-J. Chem. Commun. 2015, 51 (7), 1185 
the amino alcohol played an important role as the opposite enantiomer of 8 was obtained when passing from catalyst 12a to $\mathbf{1 2 b}$, containing the enantiomeric amino alcohol moiety (entries 11 and 12), which was translated in a great loss of enantioselectivity. The corresponding amino alcohol diastereomers $12 \mathrm{c}$ and $\mathbf{1 2 d}$ showed also diverse results (entries 13 and 14). Curiously 12c, having the opposite absolute configuration of the carbinol than 12a, gave a similar result in yield and er (entry 13). On the other hand, catalyst 12d, bearing the same enantiomeric amino alcohol portion than that used for 12c, afforded almost a racemic product (entry 14). The pseudoenantiomeric catalyst 12e (with respect to 12a) nicely afforded the opposite enantiomer of product 7 with the same level of enantioselectivity (entry 15). 
Table 4. Screening of Catalysts in the Asymmetric Epoxidation of Alkene $7^{\mathrm{a}}$

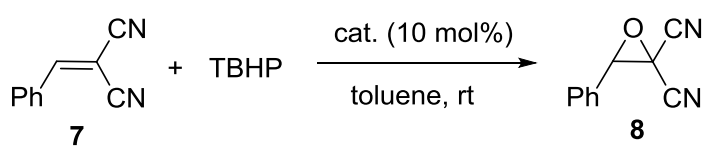

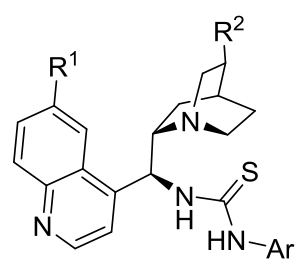

eQNT $\mathrm{R}^{1}=\mathrm{OMe}, \mathrm{R}^{2}=\mathrm{CH}=\mathrm{CH}_{2}$ eCDT $\mathrm{R}^{1}=\mathrm{H}, \mathrm{R}^{2}=\mathrm{CH}=\mathrm{CH}_{2}$ eHQNT $\mathrm{R}^{1}=\mathrm{OMe}, \mathrm{R}^{2}=\mathrm{CH}_{2} \mathrm{CH}_{3}$<smiles>C=CC1CN(C(NC(=S)NC2CCCCC2)c2ccnc3ccc(OC)cc23)C2CCC1C2</smiles><smiles>S=C(NC(=S)c1ccccc1)NC(c1ccccc1)C(c1ccccc1)N([Tl])C1CCCCC1</smiles><smiles>O=C(NC(=S)NC(c1ccccc1)c1ccccc1)c1ccccc1</smiles>

$12 a$<smiles>O=C(NC(=S)NC(c1ccccc1)c1ccccc1)c1ccccc1</smiles>

12d<smiles></smiles>

eQNU

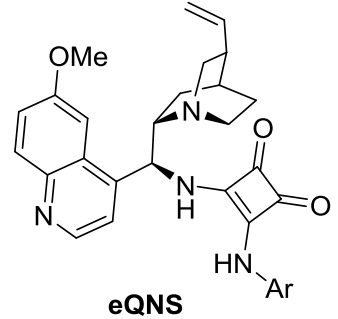

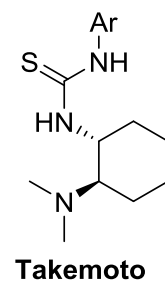

10<smiles>O=C(NNC(=S)NC(c1ccccc1)C(O)c1ccccc1)C(c1ccccc1)C(O)c1ccccc1</smiles>
$\mathrm{Ar}=3,5-\left(\mathrm{CF}_{3}\right)_{2} \mathrm{C}_{6} \mathrm{H}_{3}$

\begin{tabular}{ccccc}
\hline Entry & Catalyst & Time $(\mathrm{h})$ & ${\text { Yield }(\%)^{\mathrm{b}}}$ & er $(\%)^{\mathrm{c}}$ \\
\hline $\mathbf{1}$ & eQNT & 15 & 58 & $67.5: 32.5$ \\
$\mathbf{2}$ & eQNU & 16 & 48 & $65.4: 34.6$ \\
$\mathbf{3}^{\text {d }}$ & eQNS & 40 & 70 & $62.2: 37.8$ \\
$\mathbf{4}$ & eCDT & 21 & 57 & $59.5: 40.5$ \\
\hline
\end{tabular}




\begin{tabular}{ccccc}
\hline $\mathbf{5}$ & eHQNT & 24 & 63 & $56.2: 43.8$ \\
$\mathbf{6}^{\mathbf{e}}$ & $\mathbf{e Q D T}$ & 21 & 84 & $44.9: 55.1$ \\
$\mathbf{7}$ & $\mathbf{9}$ & 29 & 43 & $54.2: 45.8$ \\
$\mathbf{8}$ & $\mathbf{1 0}$ & 15 & 72 & $52.4: 47.6$ \\
$\mathbf{9}^{\mathbf{e}}$ & Takemoto & 24 & 55 & $44.3: 55.7$ \\
$\mathbf{1 0}^{\mathbf{e}}$ & $\mathbf{1 1}$ & 24 & 34 & $31.3: 68.7$ \\
$\mathbf{1 1}^{\mathbf{1 2}}$ & $\mathbf{1 2 a}$ & 22 & 90 & $77.2: 22.8$ \\
$\mathbf{1 3}^{\mathbf{e}}$ & $\mathbf{1 2 b}$ & 21 & 80 & $42.8: 57.2$ \\
$\mathbf{1 4}^{\mathbf{e}}$ & $\mathbf{1 2 c}$ & 18 & 75 & $71: 29$ \\
$\mathbf{1 5}^{\mathbf{e}}$ & $\mathbf{1 2 d}$ & 17 & 74 & $49.8: 50.2$ \\
\hline
\end{tabular}

${ }^{\mathrm{a}}$ Reactions were carried out at $0.1 \mathrm{mmol}$ scale of $7(\mathrm{C} 0.2 \mathrm{M})$ using TBHP (1.2 equiv). ${ }^{\mathrm{b}}$ Determined by $1 \mathrm{H}$ NMR analysis with $1,3,5-(\mathrm{MeO})_{3} \mathrm{C}_{6} \mathrm{H}_{3}$ as an internal standard. ${ }^{\mathrm{c}}$ Determined by chiral HPLC analysis. ${ }^{\mathrm{d}}$ Reaction carried out with $5 \mathrm{~mol} \%$ of eQNS in $\mathrm{CHCl}_{3}$. ${ }^{\mathrm{e}}$ The opposite enantiomer was preferentially obtained.

On the basis of experimental data, a plausible transition state model for the oxa-Michael step of the nucleophilic epoxidation is proposed (Figure 12). The alkylidenemalononitrile is activated and oriented by a $\mathrm{H}$-bonding network of the thiourea $\mathrm{NH}$ and the $\mathrm{OH}$ bonds. A possible transition state were each cyano group is $\mathrm{H}$-bonded by a single $\mathrm{NH}$ of the thiourea moiety was not considered, since Qi et al. recently reported a DFT study that showed the latter interaction to be less plausible. ${ }^{125}$

\footnotetext{
${ }^{125}$ Qi, Z.-H.; Zhang, Y.; Ruan, G.-Y.; Zhang, Y.; Wang, Y.; Wang, X.-W. RSC Adv.
} 2015, 5 (43), 34314. 


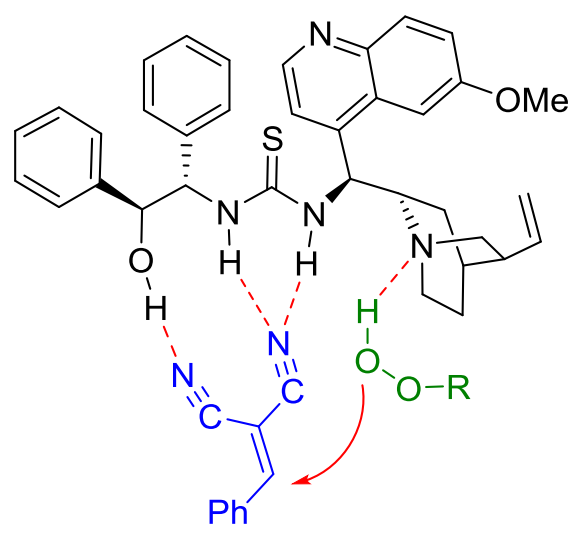

Figure 12. Proposed transition state for the enantioselective epoxidation.

Compound 12a was chosen as the best performing catalyst and an extensive screening of the reaction conditions such as solvent, oxidant and temperature, was designed to further optimize the process. The screening of conditions won't be reported in this Thesis since it was performed by Dr. Sara Meninno and the results are fully available on the Supporting Information of the published article. ${ }^{118}$ 


\section{Conclusions}

- Extensive screening of catalysts for the asymmetric epoxidation of 2benzylidenemalononitrile 7 was performed.

- Asymmetric epoxidation of 7 was successfully achieved in great yield and er with catalyst 12a in mild conditions, which opens the door to further optimization of the reaction parameters.

- A transition state was proposed to explain activity and enantioselectivity according to the obtained experimental data. 


\section{Experimental Section}

\section{General Methods}

All reactions requiring dry or inert conditions were conducted in flamedried glassware under a positive pressure of nitrogen. THF and DCM were freshly distilled prior to use respectively over metallic $\mathrm{Na}$ and calcium hydride and stored under nitrogen, all other solvents were dried over molecular sieves. Molecular sieves (Aldrich Molecular Sieves, 3 Å, $1.6 \mathrm{~mm}$ pellets) were activated under vacuum at $200{ }^{\circ} \mathrm{C}$ overnight. Reactions were monitored by thin layer chromatography (TLC) on Macherey-Nagel pre-coated silica gel plates $(0.25 \mathrm{~mm})$ and visualized by UV light and, when necessary, by phosphomolybdic acid, ninhydrin, $\mathrm{KMnO}_{4}$ staining solutions or $\mathrm{I}_{2}$ vapor. Flash chromatography was performed on Merck silica gel (60, particle size: 0.040-0.063 mm). ${ }^{1} \mathrm{H}$ NMR and ${ }^{13} \mathrm{C}$ NMR spectra were recorded on Bruker Avance-400 spectrometer, Bruker Avance-300 or Bruker Avance-250 spectrometer in $\mathrm{CDCl}_{3}$ or methanol- $\mathrm{d}_{4}$ as solvent at room temperature. Chemical shifts for protons are reported using residual solvent protons $\left({ }^{1} \mathrm{H}\right.$ NMR: $\delta=7.26 \mathrm{ppm}$ for $\mathrm{CDCl}_{3}, \delta=3.33 \mathrm{ppm}$ for methanol-d4) as internal standard. Carbon spectra were referenced to the shift of the ${ }^{13} \mathrm{C}$ signal of $\mathrm{CDCl}_{3}(\delta=77.0 \mathrm{ppm}), \mathrm{CD}_{3} \mathrm{OD}(\delta=49.0 \mathrm{ppm})$.

The following abbreviations are used to indicate the multiplicity in NMR spectra: (s) singlet; (d) doublet; (t) triplet; (q) quartet; (dd) double doublet; (ddd) doublet of doublet of doublet; (dt) doublet of triplets; (td) triplet of doublets; (m) multiplet; (bs) broad signal. FTIR spectra were recorded as thin films on $\mathrm{KBr}$ plates using Bruker Tensor 27 spectrometer and absorption maxima are reported in wavenumber $\left(\mathrm{cm}^{-}\right.$ ${ }^{1}$ ). ESI-MS was performed using a Bio-Q triple quadrupole mass spectrometer (Micromass, Manchester, UK) equipped with an electrospray ion source. Elemental analyses were carried out by using Flash EA 1112 (Thermo Electron Corporation) analyzer. Melting points 
were measured with a Stuart Model SMP 30 melting point apparatus and are uncorrected.

\section{Experimental Procedures}

General experimental procedure for the synthesis of 2benzylidenemalononitrile 7 .

To a mixture of malononitrile $(1.00 \mathrm{~g}, 0.015 \mathrm{~mol})$ and 1methylimidazole $(0.01 \mathrm{~g}, 1 \mathrm{~mol} \%)$ in water $(8.2 \mathrm{~mL})$ at $35{ }^{\circ} \mathrm{C}$, benzaldehyde $(0.015 \mathrm{~mol})$ was added with constant stirring. A crystalline white solid was obtained, separated by filtration and dried under vacuum at room temperature. The product was used without further purification.<smiles>N#C/C(C=N)=C\c1ccccc1</smiles>

2-Benzylidenemalononitrile (7). White solid, $2.08 \mathrm{~g}$, $90 \%$ yield. mp $83^{\circ} \mathrm{C}$ [lit. $\left.82-84^{\circ} \mathrm{C}\right] .{ }^{126}$ NMR spectra matched with that reported in the literature. ${ }^{117}$

General Experimental Procedure for the Synthesis of Racemic epoxide 8.

2-Benzylidenemalononitrile 7 (1 mmol) in anhydrous toluene $(10 \mathrm{~mL})$, 2-piperidinemethanol (23 mg, $0.2 \mathrm{mmol})$ followed by TBHP ( 5.5 M in decane, $240 \mu \mathrm{L}, 1.3 \mathrm{mmol})$ were added. The reaction was stirred at $0{ }^{\circ} \mathrm{C}$ for 1.5 hours. Product 8 was isolated by flash chromatography (eluting from PE/ ethyl acetate 100/1 to 90/10).<smiles>CC(N)(N)C1OC1c1ccccc1</smiles>

3-phenyloxirane-2,2-dicarbonitrile. White solid, 146 mg, 86\% yield. mp 50-52 ${ }^{\circ} \mathrm{C}$. FTIR $v(\mathrm{KBr}) / \mathrm{cm}^{-1} 3069,3039,2257$, 1498, 1457, 1399, 1382, 1318, 1298, 1268, 1192, 893, 875, 762, 697, 637, 620. ${ }^{1} \mathbf{H}$ NMR $\left(\mathrm{CDCl}_{3}, 400 \mathrm{MHz}\right): \delta$ 7.56-7.40 (m, 5H), $4.71(\mathrm{~s}$, $1 \mathrm{H}) .{ }^{13} \mathrm{C}$ NMR $\left(\mathrm{CDCl}_{3}, 100 \mathrm{MHz}\right): \delta 131.4,129.1,127.5,126.8,111.6$,

${ }^{126}$ Gupta, P.; Kour, M.; Paul, S.; Clark, J. H. RSC Adv. 2014, 4, 7461. 
110.2, 65.8, 41.7. Elemental analysis calcd (\%) for $\mathrm{C}_{10} \mathrm{H}_{6} \mathrm{~N}_{2} \mathrm{O}$ : C, 70.58; H, 3.55; N, 16.46; found C, 70.84; H, 3.64; N, 16.30. HPLC analysis with Chiralcel OD-H column, 90:10 $n$-hexane:2-propanol, 1 $\mathrm{mL} / \mathrm{min}, 254 \mathrm{~nm} ; \mathrm{t}_{\mathrm{R} 1}=9.8 \mathrm{~min}, \mathrm{t}_{\mathrm{R} 2}=10.9 \mathrm{~min}$.

General Experimental Procedure for the Synthesis of Catalysts 10, 12a-e

Precursors $\mathbf{A}_{\mathbf{1}}{ }^{120}$ and $\mathbf{A}_{\mathbf{2}}{ }^{120}$ are known compounds and were prepared according to the literature.

To a stirred solution of $\mathbf{A}_{\mathbf{1}}$ or $\mathbf{A}_{\mathbf{2}}(401 \mathrm{mg}, 1.1 \mathrm{mmol})$ under nitrogen atmosphere in dry THF $(2 \mathrm{~mL})$ a solution of appropriate chiral 2amino-1,2-diphenylethanol or methylbenzylamine $(1 \mathrm{mmol})$ in dry THF $(2 \mathrm{~mL})$ was added via syringe. The mixture was stirred at $40{ }^{\circ} \mathrm{C}$ for $24-$ $72 \mathrm{~h}$, monitored by TLC (eluent diethyl ether/MeOH 8/2). The products 12a-e were isolated by flash chromatography (eluent: diethyl ether to diethyl ether $/ \mathrm{MeOH} 90 / 10$ ). Catalyst 12c is a known compound and spectral data were consistent with those in the literature.

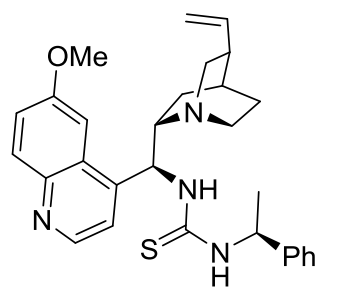

Thiourea derived from quinine and $S-(-)-\alpha-$ methylbenzylamine. 1-((S)-(6-methoxyquinolin-4-yl)((1S,2S,4S,5R)5-vinylquinuclidin-2-yl)methyl)-3-((S)-1-phenylethyl)thiourea (10). Pale yellow solid, $62.0 \mathrm{mg}, 79 \%$ yield (the reaction was carried out at 0.16 mmol scale of $\mathbf{A}_{\mathbf{1}}$ ). $\mathbf{m p} 86.7-90.0{ }^{\circ} \mathrm{C}$. $[\boldsymbol{\alpha}]_{\mathbf{D}}{ }^{\mathbf{2 6}}=-120.9$ (c 0.55, $\left.\mathrm{CHCl}_{3}\right)$. FTIR $v_{\max }(\mathrm{KBr}) / \mathrm{cm}^{-1} 2927,1622,1534,1508,1474,1453$, 1432, 1347, 1262, 1242, 1228, 1083, 1030, 918, 853, 759, 700. ${ }^{\mathbf{1}} \mathbf{H}$ NMR $\left(\mathrm{CDCl}_{3}, 400 \mathrm{MHz}\right): \delta 8.74(\mathrm{~d}, 1 \mathrm{H}, J=4.5 \mathrm{~Hz}), 8.03(\mathrm{~d}, 1 \mathrm{H}, J=$ $9.2 \mathrm{~Hz}), 7.58(\mathrm{~s}, 1 \mathrm{H}), 7.41-7.22(\mathrm{~m}, 7 \mathrm{H}), 6.76(\mathrm{bs}, 1 \mathrm{H})$, 5.66-5.55 (m, $1 \mathrm{H}), 5.29$ (bs, $1 \mathrm{H}), 4.98-4.87$ (m, 3H), $3.94(\mathrm{~s}, 3 \mathrm{H}), 3.04-2.62(\mathrm{~m}, 3 \mathrm{H})$, 2.57-2.42 (m, $1 \mathrm{H}), 2.25-2.12(\mathrm{~m}, 1 \mathrm{H}), 1.64-1.57(\mathrm{~m}, 1 \mathrm{H}), 1.55-1.45(\mathrm{~m}$, 
2H), $1.39(\mathrm{~d}, 3 \mathrm{H}, J=6.4 \mathrm{~Hz}), 1.34-1.21(\mathrm{~m}, 2 \mathrm{H}), 0.95-0.90(\mathrm{~m}, 1 \mathrm{H})$.

${ }^{13} \mathrm{C}$ NMR $\left(\mathrm{CDCl}_{3}, 100 \mathrm{MHz}\right): \delta 181.9,157.8,147.7,144.8,142.5$, $140.7,131.9,128.9,128.5,127.7,126.8,126.0,125.7,121.7,114.8$, 101.9, 55.7, 55.1, 54.4, 51.3, 40.2, 39.2, 30.3, 29.7, 27.5, 27.2, 25.7, 25.5. MS $(\mathrm{ESI} \mathrm{m} / \mathrm{z}) 487.5\left[\mathrm{M}+\mathrm{H}^{+}, 100 \%\right]$.

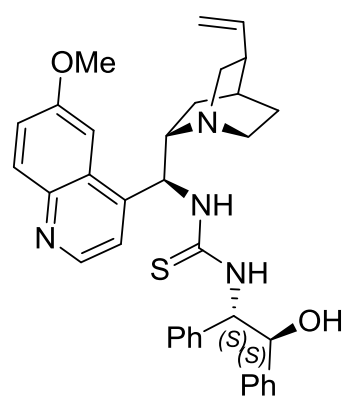

Thiourea derived from quinine and $(1 S, 2 S)-2-$ amino-1,2-diphenylethanol. 1-((1S,2S)-2-hydroxy-1,2-diphenylethyl)3-((S)-(6-methoxyquino-lin-4-yl) $((1 S, 2 S, 4 S, 5 R)-5$-vinylquinuclidin2-yl)methyl)thiourea (12a). White solid, $463 \mathrm{mg}, 80 \%$ yield (the reaction was carried out at $1.1 \mathrm{mmol}$ scale of $\mathbf{A}_{\mathbf{1}}$ ). $\mathbf{m p} 156.5-158.2{ }^{\circ} \mathrm{C}$. $[\alpha]_{\mathbf{D}}{ }^{27}=-117.0\left(c 0.56, \mathrm{CHCl}_{3}\right)$. FTIR $v_{\max }(\mathrm{KBr}) / \mathrm{cm}^{-1} 3456,2948$, 2866, 1623, 1510, 1474, 1454, 1263, 1242, 1228, 1029, 775, 701. ${ }^{\mathbf{1}} \mathbf{H}$ NMR $\left(\mathrm{CDCl}_{3}, 400 \mathrm{MHz}\right): \delta 8.54$ (bs, $\left.1 \mathrm{H}\right), 7.96(\mathrm{~d}, 1 \mathrm{H}, J=9.4 \mathrm{~Hz})$, $7.69(\mathrm{~s}, 1 \mathrm{H}), 7.36(\mathrm{~d}, 1 \mathrm{H}, J=8.8 \mathrm{~Hz}), 7.32-6.77$ (partially overlapped by $\left.\mathrm{CDCl}_{3}, \mathrm{~m}, 12 \mathrm{H}\right), 5.64-5.53(\mathrm{~m}, 1 \mathrm{H})$ partially overlapped with 5.70 (br, 1H) and $5.39(\mathrm{br}, 1 \mathrm{H}), 4.94-4.84(\mathrm{~m}, 3 \mathrm{H}), 3.94(\mathrm{~s}, 3 \mathrm{H}), 3,18(\mathrm{br}$, $1 \mathrm{H}), 2.91$ (br, 1H), 2.58-2.36 (m, 2H), 2.26-2.13 (m, 1H), 1.87 (br, 1H), 1.64-1.46 (m, 3H), 1.32-1.20 (m, 2H), 0.90-0.77 (m, 1H). ${ }^{13} \mathbf{C}$ NMR $\left(\mathrm{CD}_{3} \mathrm{OD}, 100 \mathrm{MHz}\right): \delta 184.2,159.6,148.1,145.0,143.2,142.1,131.0$, 130.1, 129.0, 128.6, 128.2, 127.5, 123.9, 120.8, 115.2, 104.3, 77.4, 65.0, $61.2,56.6,56.4,42.8,40.4,28.7,28.1,26.8$. MS (ESI $\mathrm{m} / \mathrm{z}) 579.8$ $\left[\mathrm{M}+\mathrm{H}^{+}, 100 \%\right]$. 
<smiles>C=CC1CN2CCC1CC2[C@H](NC(=S)NC(c1ccccc1)c1ccccc1)c1ccnc2ccc(OC)cc12</smiles>

amino-1,2-diphenylethanol.

Thiourea derived from quinine and $(1 R, 2 R)-2-$ diphenylethyl)-3-((S)-(6-methoxyquino-lin-4-yl)((1S,2S,4S,5R)-5vinylquinuclidin-2-yl)methyl)thiourea (12b). Yellow solid, $54.1 \mathrm{mg}$, $68 \%$ yield (the reaction was carried out at $0.137 \mathrm{mmol}$ scale of $\mathbf{A}_{\mathbf{1}}$ ). $\mathbf{m p}$ $119.3-122.6{ }^{\circ} \mathrm{C} .[\boldsymbol{\alpha}]_{\mathbf{D}}{ }^{27}=-62.8\left(c 0.51, \mathrm{CHCl}_{3}\right)$. FTIR $v_{\max }(\mathrm{KBr}) / \mathrm{cm}^{-1}$ 3445, 2931, 2864, 1624, 1541, 1508, 1474, 1454, 1262, 1242, 1229 , 1029, 757, 700. ${ }^{1} \mathbf{H}$ NMR $\left(\mathrm{CDCl}_{3}, 400 \mathrm{MHz}\right): \delta 8.70(\mathrm{~d}, 1 \mathrm{H}, J=4.4$ $\mathrm{Hz}), 8.01(\mathrm{~d}, 1 \mathrm{H}, J=9.1 \mathrm{~Hz}), 7.61(\mathrm{~s}, 1 \mathrm{H}), 7.52(\mathrm{br}, 1 \mathrm{H}), 7.38(\mathrm{dd}, 1 \mathrm{H}$, $J=9.3,2.0 \mathrm{~Hz}), 7.30-7.27(\mathrm{~m}, 1 \mathrm{H}), 7.25-7.15(\mathrm{~m}, 7 \mathrm{H}), 7.13-7.02(\mathrm{~m}$, $4 \mathrm{H})$, 5.67-5.55 $(\mathrm{m}, 1 \mathrm{H})$ partially overlapped with $5.38(\mathrm{bs}, 2 \mathrm{H}), 4.99-$ $4.88(\mathrm{~m}, 2 \mathrm{H}), 4.81(\mathrm{~d}, 1 \mathrm{H}, J=5.8 \mathrm{~Hz}), 3.90(\mathrm{~s}, 3 \mathrm{H}), 3.33-2.88(\mathrm{~m}, 3 \mathrm{H})$, 2.67-2.51 (m, 1H), 2.28-2.16 (m, 1H), $1.87(\mathrm{br}, 1 \mathrm{H}), 1.68-1.47(\mathrm{~m}, 3 \mathrm{H})$, 1.36-1.17 (m, 2H), 0.94-0.76 (m, 1H). ${ }^{13} \mathbf{C ~ N M R ~}\left(\mathrm{CD}_{3} \mathrm{OD}, 100 \mathrm{MHz}\right)$ : $\delta$ 184.0, 159.5, 148.1, 145.0, 142.9, 142.3, 141.3, 131.1, 130.0, 129.0, 128.9, 128.7, 128.4, 128.1, 128.0, 123.7, 121.2, 115.1, 104.1, 78.1, 65.7, 61.7, 56.6, 56.5, 42.7, 40.6, 28.7, 28.3, 26.9. MS (ESI $\mathrm{m} / \mathrm{z}) 579.7$ $\left[\mathrm{M}+\mathrm{H}^{+}, 21 \%\right]$.<smiles>C=CC1CN2CCC1CC2C(NC(=S)NC(c1ccccc1)c1ccccc1)c1ccnc2ccc(OC)cc12</smiles>

Amino-1,2-diphenylethanol.

Thiourea derived from quinine and $(1 R, 2 S)-2-$ diphenylethyl)-3-((S)-(6-methoxyquino-lin-4-yl)((1S,2S,4S,5R)-5- 
vinylquinuclidin-2-yl)methyl)thiourea (12d). White solid, $80.8 \mathrm{mg}$, $85 \%$ yield (the reaction was carried out at $0.164 \mathrm{mmol}$ scale of $\mathbf{A}_{\mathbf{1}}$ ). $\mathbf{m p}$ $130.9-132.6{ }^{\circ} \mathrm{C} .[\boldsymbol{\alpha}]_{\mathbf{D}}{ }^{27}=-63.6\left(c 0.57, \mathrm{CHCl}_{3}\right)$. FTIR $v_{\max }(\mathrm{KBr}) / \mathrm{cm}^{-1}$ 3443, 2944, 2865, 1623, 1538, 1511, 1475, 1453, 1262, 1242, 1229, 1029, 755, 705. ${ }^{1} \mathbf{H}$ NMR $\left(\mathrm{CDCl}_{3}, 400 \mathrm{MHz}\right): \delta 8.76(\mathrm{~d}, 1 \mathrm{H}, J=4.5$ $\mathrm{Hz}), 8.05$ (d, 1H, $J=9.2 \mathrm{~Hz}), 7.61$ (bs, $1 \mathrm{H}), 7.58-7.38$ (m, 3H), 7.23$7.11(\mathrm{~m}, 5 \mathrm{H}), 7.06(\mathrm{~s}, 2 \mathrm{H}), 6.94-6.87(\mathrm{~m}, 2 \mathrm{H}), 6.87-6.80(\mathrm{~m}, 2 \mathrm{H}), 5.61$ (ddd, 1H, $J=17.2,10.0,7.4 \mathrm{~Hz}$ ), 5.30 (bs, 2H), 5.06 (bs, 1H), 4.964.89 (m, 2H), 3.94 (s, 3H), 3.01 (br, 1H), 2.81 (br, 1H), 2.67-2.49 (m, $1 \mathrm{H}), 2.26-2.14(\mathrm{~m}, 1 \mathrm{H}), 1.79-1.58(\mathrm{~m}, 5 \mathrm{H}), 1.58-1.46(\mathrm{~m}, 1 \mathrm{H}), 1.39-$ $1.28(\mathrm{~m}, 1 \mathrm{H}), 0.97-0.88(\mathrm{~m}, 1 \mathrm{H}) .{ }^{13} \mathbf{C}$ NMR $\left(\mathrm{CD}_{3} \mathrm{OD}, 100 \mathrm{MHz}\right): \delta$ 183.3, 159.6, 148.2, 145.1, 142.5, 142.4, 138.9, 131.0, 130.1, 129.6, $129.1,129.0,128.7,128.5,128.1,127.5,123.8,121.0,115.1,104.2$, 79.5, 76.2, 65.0, 61.8, 56.8, 56.6, 42.9, 40.6, 28.8, 28.4, 27.0. MS (ESI $\mathrm{m} / \mathrm{z}) 579.8\left[\mathrm{M}+\mathrm{H}^{+}, 100 \%\right]$.

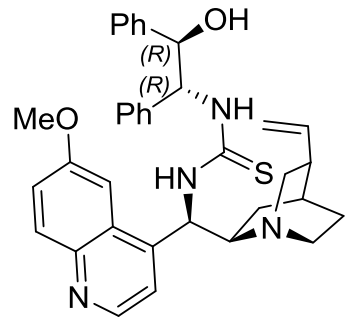

Thiourea derived from quinidine and $(1 R, 2 R)-2-$

Amino-1,2-diphenylethanol.

1-((1R,2R)-2-hydroxy-1,2diphenylethyl)-3-((R)-(6-methoxyquino-lin-4-yl)((1S,2R,4S,5R)-5vinylquinuclidin-2-yl)methyl)thiourea (12e). White solid, $53.5 \mathrm{mg}$, $67 \%$ yield (the reaction was carried out at $0.137 \mathrm{mmol}$ scale of $\mathbf{A}_{2}$ ). $\mathbf{m p}$ $135.6-139.3{ }^{\circ} \mathrm{C} .[\boldsymbol{\alpha}]_{\mathbf{D}}{ }^{27}=+184.6\left(c 0.55, \mathrm{CHCl}_{3}\right)$. FTIR $v_{\max }(\mathrm{KBr}) / \mathrm{cm}^{-}$ ${ }^{1}$ 3449, 2940, 2872, 1623, 1534, 1509, 1474, 1455, 1433, 1242, 1227, 1029, 754, 701. ${ }^{1} \mathbf{H}$ NMR $\left(\mathrm{CDCl}_{3}, 300 \mathrm{MHz}\right): \delta 8.56$ (bs, $\left.1 \mathrm{H}\right), 7.96$ (d, $1 \mathrm{H}, J=9.2 \mathrm{~Hz}$ ), $7.61(\mathrm{bs}, 1 \mathrm{H}), 7.45-7.00$ (partially overlapped by $\left.\mathrm{CDCl}_{3}, \mathrm{~m}, 11 \mathrm{H}\right), 6.79$ (br, 2H), 5.84 (ddd, $1 \mathrm{H}, J=17.3,10.4,6.0 \mathrm{~Hz}$ ), $5.42(\mathrm{br}, 2 \mathrm{H})$ partially overlapped with 5.19-5.09 (m, 2H), $4.81(\mathrm{~d}, 1 \mathrm{H}$, $J=5.9 \mathrm{~Hz}), 3.96(\mathrm{~s}, 3 \mathrm{H}), 3.26-2.67$ (m, 4H), 2.35-2.17 (m, 1H), 1.73$1.38(\mathrm{~m}, 4 \mathrm{H}), 1.31-1.16(\mathrm{~m}, 2 \mathrm{H}), 1.01-0.77(\mathrm{~m}, 1 \mathrm{H}),{ }^{13} \mathbf{C} \mathbf{N M R}$ 
(CD $\left.{ }_{3} \mathrm{OD}, 75 \mathrm{MHz}\right): \delta 189.1,159.6,148.1,145.0,143.8,143.2,141.2$, 131.0, 130.1, 129.0, 128.7, 128.2, 127.5, 124.1, 120.0, 115.5, 104.1, 77.4, 65.2, 65.0, 61.4, 56.6, 40.9, 39.8, 28.6, 26.8, 26.3. MS (ESI $\mathrm{m} / \mathrm{z})$ $579.6\left[\mathrm{M}+\mathrm{H}^{+}, 100 \%\right]$. 


\section{Chapter 4}

\section{Asymmetric Epoxidation of Nitroallkenes}





\section{Objectives}

The main goal of this work is the organocatalytic asymmetric epoxidation of nitroalkenes, which can be summarized as follows:

- The study of diverse organocatalytic epoxidation systems and selection of the most suitable in terms of chemical yield, ee, and operability.

- The study and screening of solvents and conditions such as temperature, concentration, etc., to achieve the optimum media for asymmetric epoxidation.

- The rational design and synthesis of diverse catalysts to achieve the asymmetric epoxidation of nitroalkenes.

- The proof-based elucidation of a transition state which explains catalytic activity and enantioselectivity. 


\section{Results and Discussion}

Since some time ago, our group has shown interest in nitroepoxides as useful synthons for organic synthesis. ${ }^{127}$ Few examples of diastereoselective epoxidation of nitroalkenes have been reported ${ }^{128}$ and as far as we know only one methodology, described by Enders' group, is reported in the literature for the enantioselective epoxidation of nitroalkenes in moderate chemical yields and moderate to good ee. ${ }^{129}$ Still, in the aforementioned example, the scope of the reaction is limited to the synthesis of 3-alkyl-2-nitrooxiranes and with high variations on ee depending on the substrate (Scheme 51). There's another example reported by Julià and Colonna, using a chiral polypeptide as a catalyst, but the reported enantioselectivity barely reached a $7 \%$ ee for the corresponding nitroepoxides. ${ }^{130}$

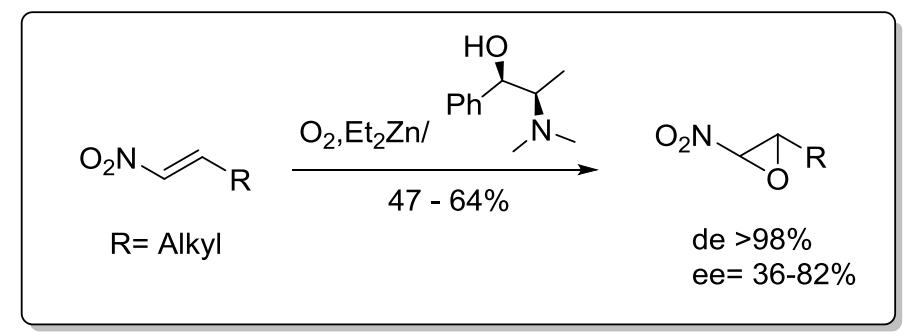

Scheme 51. Enders' asymmetric epoxidation of nitroalkenes.

More recently, S. Mennino et al. have reported the synthesis of enantioenriched nitroepoxides via catalytic enantioselective aminolytic kinetic resolution (AKR). ${ }^{131}$ In their approach, ring-opening reaction of racemic $\alpha$-nitroepoxides with aniline in the presence of a bifunctional thiourea catalyst affords unreacted epoxides in up to $95 \%$ ee (Scheme

\footnotetext{
${ }^{127}$ Agut, J.; Vidal, A.; Rodríguez, S.; González, F. V. J. Org. Chem. 2013, 78 (11), 5717.

128 a) Jain, A.; Rodríguez, S.; López, I.; González, F. V. Tetrahedron 2009, 65 (40), 8362. b) Jackson, R. F. W.; Palmer, N. J.; Wythes, M. J.; Clegg, S. W. J. Org. Chem. 1995, 60 (5), 6431.

${ }^{129}$ Enders, D.; Kramps, L.; Zhu, J. Tetrahedron: Asymmetry 1998, 9 (22), 3959.

${ }^{130}$ Juliá, S.; Guixer, J.; Masana, J.; Rocas, J.; Colonna, S.; Annuziata, R.; Molinari, H. J. Chem. Soc. Perkin Trans. I 1982, 1317.

${ }^{131}$ Meninno, S.; Napolitano, L.; Lattanzi, A. Catal. Sci. Technol. 2015, 5 (1), 124.
} 
52). Although it is an interesting approach to obtain enantioenriched nitroepoxides, the main inconvenience of this methodology resides in the kinetic resolution itself since it limits the yield to a maximum of $50 \%$. An asymmetric epoxidation with high chemical and enantioselective yields would be more desirable.

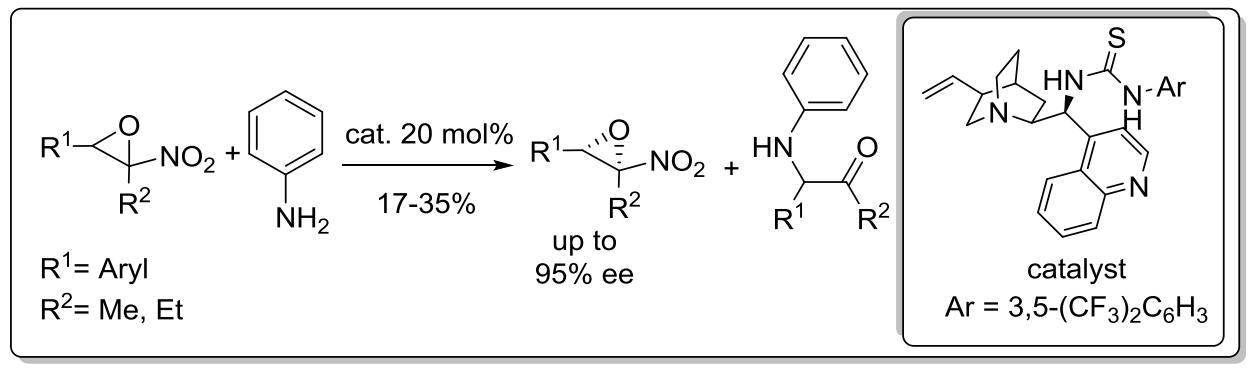

Scheme 52. Asymmetric kinetic resolution of nitroepoxides.

\subsection{Early Stage Experiments}

As described in Chapter 1, many methodologies have been reported for the synthesis of epoxides from electron-deficient olefins. When facing the nitroalkenes, we envisioned their organocatalytic epoxidation by oxa-Michael addition of peroxides to nitroalkenes followed by ringclosure, catalyzed by diarylprolinol derivatives since they were previously reported as effective catalysts for epoxidation of enones. ${ }^{132}$ However, Russo and Lattanzi already tested that catalytic system for the epoxidation of nitroalkenes and they found that the system was ineffective for the epoxidation. Instead, they found that the reaction stopped at oxa-Michael addition step, affording asymmetric peroxides which could be further transformed into 1,2-aminoalcohols (Scheme 53). Developing that catalytic methodology for the enantioselective $\beta$ addition of peroxides to nitroalkenes, they afforded the corresponding peroxides in high yields (up to $83 \%$ ) and ee (up to $84 \%$ ), and the

132 a) Lattanzi, A. Org. Lett. 2005, 7 (13), 2579. b) Lattanzi, A. Adv. Synth. Catal. 2006, 348 (3), 339. 
corresponding 1,2-aminoalcohols also in high chemical yields but with a bit loss of enantioselectivity (Scheme 53). ${ }^{133}$

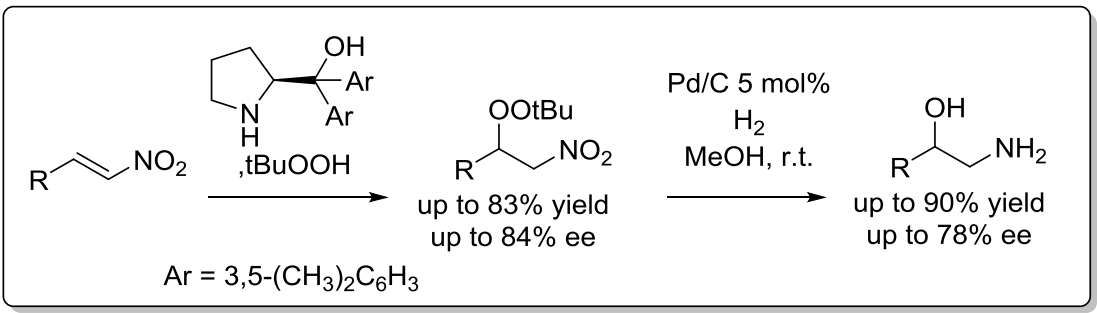

Scheme 53. Epoxidation attempts with diphenyl prolinol and ter-butyl peroxide.

Due to the present limitations for the epoxidation of nitroalkenes by non-covalent bifunctional catalysts, we decided to change strategy into phase transfer catalysis. Initial tests involved the epoxidation of trans$\beta$-methyl- $\beta$-nitrostyrene using $N$-benzyl cinchoninium bromide $(\mathbf{C N}-1)$ as a catalyst (10 mol \% load) and an oxidant (sodium hypochlorite, hydrogen peroxide and TBHP) in DCM (Scheme 54). Gratifyingly, reaction with sodium hypochlorite afforded nitroepoxide in full conversion within two hours, and an ee of $18 \%$. This result encouraged us to optimize conditions in order to develop a phase transfer catalytic system able to epoxidize a variety of nitroalkenes in high chemical yields and ee.

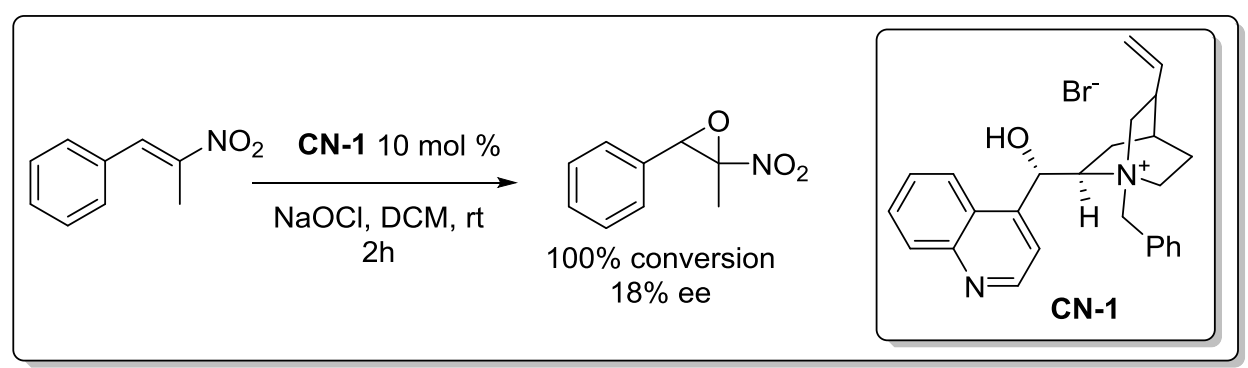

Scheme 54. Phase transfer catalyzed epoxidation of trans- $\beta$-methyl- $\beta$-nitrostyrene.

\subsection{Optimization Reactions}

An optimization study of the reaction was carried out by modifying the following parameters: amount of oxidant, reaction solvent,

${ }^{133}$ Russo, A.; Lattanzi, A. Adv. Synth. Catal. 2008, 350 (13), 1991. 
organic/aqueous phase ratio, concentration, catalyst load, catalyst structure and temperature. Influence of number of equivalents of $\mathrm{NaOCl}$ over conversion and enantioselectivity was studied first. For that purpose, the volume ratio between organic and aqueous phases was kept constant 1:1, ergo the volume of the aqueous phase was adjusted with distilled water when the number of equivalents of oxidant was decreased. The reactions were carried out at a scale of $20 \mathrm{mg}$ of trans$\beta$-methyl- $\beta$-nitrostyrene, $10 \mathrm{~mol} \%$ catalyst $\mathbf{C N}-1$ load, $0.15 \mathrm{M}$ concentration of the alkene in DCM (Table 5).

\section{Table 5. Influence of Number of Equivalents of $\mathrm{NaOCl}$ over} Conversion and Enantioselectivity. ${ }^{\text {a }}$

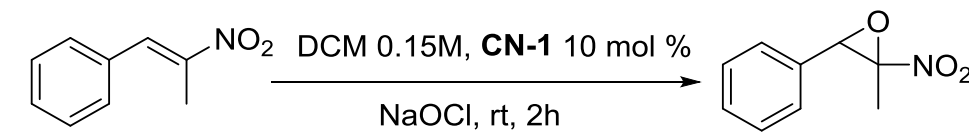

\begin{tabular}{cccc}
\hline Entry & Eq. of $\mathrm{NaOCl}$ & ${\text { Conversion }(\%)^{\mathrm{b}}}$ & e.r. $^{\mathrm{c}}$ \\
\hline $\mathbf{1}$ & 14 & 100 & $58: 42$ \\
$\mathbf{2}$ & 12 & 95 & $56.5: 43.5$ \\
$\mathbf{3}$ & 10 & 97 & $56: 44$ \\
$\mathbf{4}$ & 7 & 96 & $56: 44$ \\
$\mathbf{5}$ & 5 & 95 & $56: 44$ \\
$\mathbf{6}$ & 1.5 & 84 & $55: 45$ \\
\hline
\end{tabular}

${ }^{a}$ Reactions were carried out at room temperature for 2 hours with vigorous stirring, with 1:1 ratio of organic and aqueous phase. ${ }^{b}$ Based on ${ }^{1} \mathrm{H}$ NMR. ${ }^{\mathrm{c}}$ Measured on HPLC chiralpak-IA with $n$-hexane/ $i$-propanol.

Results revealed no significant differences in terms of conversion when the number of equivalents of oxidants were reduced (Table 5, entries 15 ), except for the last one (entry 6) in which a small excess of oxidant leads to a decrease of conversion. Comparing the obtained data, we observed a small decrease of enantioselectivity with the reduction of $\mathrm{NaOCl}$ equivalents (entries 1-3), which was more evident for the 
reaction with less excess of oxidant (entry 6). However, results did not expose a clear correlation between oxidant equivalents and enantioselectivity.

We thought that variations of conversion and enantioselectivity shown in Table 5 might be caused by a dilution effect of the aqueous phase rather than by the amount of oxidant. To check that hypothesis, a battery of reactions was performed with decreasing amounts of the commercial $\mathrm{NaOCl}$ solution but without any volume compensation (Table 6).

Table 6. Effect of the Amount of Oxidant at a Constant Concentration $^{\mathrm{a}}$

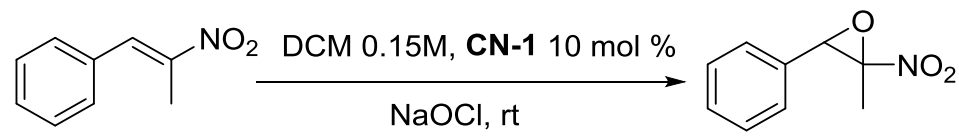

\begin{tabular}{cccccc}
\hline Entry & Eq. of NaOCl & Org:Aq ratio $^{\text {b }}$ & Time (h) & ${\text { Conversion }(\%)^{c}}^{c}$ & e.r. $^{\text {d }}$ \\
\hline $\mathbf{1}$ & 14 & $1: 1$ & 2 & 100 & $58: 42$ \\
$\mathbf{2}$ & 13 & $8: 7$ & 2.5 & 100 & $57: 43$ \\
$\mathbf{3}$ & 9 & $8: 5$ & 18 & 100 & $57: 43$ \\
$\mathbf{4}$ & 5 & $8: 3$ & 20 & 97 & $57: 43$ \\
$\mathbf{5}$ & 3 & $16: 3$ & 20 & 95 & $57: 43$ \\
$\mathbf{6}$ & 1.1 & $40: 3$ & 28 & 31 & $56.5: 44.5$
\end{tabular}

${ }^{\mathrm{a}}$ The reactions were carried out at scale of $20 \mathrm{mg}$ of trans- $\beta$-methyl- $\beta$-nitrostyrene, 10 mol \% catalyst load, $0.15 \mathrm{M}$ concentration of the alkene in DCM and a commercially available solution of $\mathrm{NaOCl}$ (14.5\% in active chlorine), for the specified time. ${ }^{\mathrm{b}}$ Ratio in volume of each phase. ${ }^{\mathrm{c}}$ Measured on ${ }^{1} \mathrm{H}$ NMR. ${ }^{\mathrm{d}}$ Measured on HPLC chiralpak-IA with $n$-hexane/i-propanol.

After comparing the data of Table 5 and 6, the drawn conclusions were that the amount of oxidant did have no effect on enantioselectivity but it had effect on reaction time, which was severely prolonged when almost stoichiometric amount of $\mathrm{NaOCl}$ was used (Table 6, entry 6). 
The solvents volume had no significant effect on the enantioselectivity or the conversion. From that moment, the commercially available concentrated solution of $\mathrm{NaOCl}$ was used since it seemed to work better in terms of reaction rate or enantioselectivity.

The properties that an ideal asymmetric organocatalytic system must have include fast and full conversion of the substrate, absolute control of enantioselectivity and/or diasteroselectivity, reusability of the catalyst and low load of the catalyst. The efficiency of our system in front of catalyst load was examined (Table 7). Initial conditions reproduced previous results when a $10 \mathrm{~mol} \%$ load of CN-1 was used in DCM at room temperature (entry 2). Unfortunately, enantioselectivity and conversion rate decreased along with the lowering of catalyst load (entries 3 and 4). Furthermore, increasing the catalyst load to $20 \mathrm{~mol} \%$ did not improve enantioselectivity enough to justify double catalyst loading (entry 1). $10 \mathrm{~mol} \%$ was established as the optimum load of catalyst for further optimization studies.

Table 7. Effect of Catalyst Load on Conversion and Enantioselectivity $^{\text {a }}$

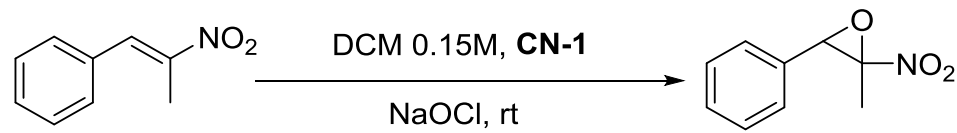

\begin{tabular}{lllll}
\hline Entry & Catalyst load & Time $(\mathrm{h})$ & Conversion $(\%)^{\mathrm{b}}$ & e.r. $^{\mathrm{c}}$
\end{tabular}

\begin{tabular}{ccccc}
\hline $\mathbf{1}$ & $20 \mathrm{~mol} \%$ & 2 & 100 & $59: 41$ \\
$\mathbf{2}$ & $10 \mathrm{~mol} \%$ & 2 & 100 & $58: 42$ \\
$\mathbf{3}$ & $5 \mathrm{~mol} \%$ & 2 & 76 & $54: 46$ \\
$\mathbf{4}$ & $1 \mathrm{~mol} \%$ & 4 & 20 & $50.5: 49.5$
\end{tabular}

${ }^{\mathrm{a}}$ The reactions were carried out at scale of $20 \mathrm{mg}$ of trans- $\beta$-methyl- $\beta$-nitrostyrene, in DCM with 1:1 org:aq phase ratio of a commercially available solution of $\mathrm{NaOCl}$ (14.5\% in active chlorine), for the specified time. ${ }^{b}$ Measured on ${ }^{1} \mathrm{H}$ NMR. ${ }^{\mathrm{c}}$ Measured on HPLC chiralpak-IA with $n$-hexane/i-propanol. 
As reported by Lygo et al. ${ }^{134}$, concentration of the substrate in the organic phase was found to be an important parameter to be optimized. In their case, the asymmetric epoxidation of chalcones with a cinchona salt derivative as PTC and $\mathrm{NaOCl}$ as oxidant, by varying the concentration of substrate it was possible to obtain $100 \%$ conversion of the chalcone within $24 \mathrm{~h}$ at $25^{\circ} \mathrm{C}$ with catalyst loading down to 0.5 mol\%. They also found that the more concentrated was the organic phase, the less catalyst load was needed to achieve the same conversion and enantioselectivity. However, they observed that for a $0.5 \mathrm{~mol} \%$ catalyst load (or lower) the reaction led to a significant reduction in enantioselectivity, even for highly concentrated solutions. For example, excellent e.e. were obtained when using 1-10 mol\% load of the catalyst and an initial chalcone concentration of $0.09 \mathrm{M}-0.34 \mathrm{M}$ in toluene $(86 \%$ ee), but the enantioselectivity dropped considerably when an initial chalcone concentration of $3.4 \mathrm{M}$ and $0.1 \mathrm{~mol} \%$ of PTC were used $(60 \%$ ee).

We tested how concentration would affect to our catalytic system, and for that we designed a series of reactions varying the organic phase concentration, but keeping a constant catalyst load and oxidant amount and therefore, the volume of the aqueous phase (Table 8).

Table 8. Variation of Yield and e.r. Depending on Organic Phase Concentration $^{\mathrm{a}}$

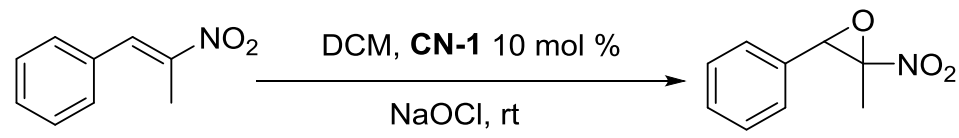

\begin{tabular}{cccccc}
\hline Entry & Conc. $(\mathrm{M})$ & Org:Aq ratio $^{\mathrm{b}}$ & Time $^{(\mathrm{h})}$ & ${\text { Conversion }(\%)^{\mathrm{c}}}$ & e.r. $^{\mathrm{d}}$ \\
\hline $\mathbf{1}$ & 0.6 & $1: 1$ & 2.5 & 100 & $54: 46$ \\
$\mathbf{2}$ & 0.3 & $2: 1$ & 3 & 100 & $59: 41$ \\
$\mathbf{3}$ & 0.15 & $4: 1$ & 5 & 100 & $57: 43$ \\
\hline
\end{tabular}

${ }^{134}$ Lygo, B.; To, D. C. M. Chem. Commun. 2002, 20, 2360 


\begin{tabular}{cccccc}
\hline $\mathbf{4}$ & 0.07 & $7.5: 1$ & 6 & 96 & $55: 45$ \\
$\mathbf{5}$ & 0.024 & $25: 1$ & 20 & 90 & $53: 47$ \\
\hline
\end{tabular}

${ }^{\mathrm{a}}$ The reactions were carried out at a scale of $20 \mathrm{mg}$ of trans- $\beta$-methyl- $\beta$-nitrostyrene, $10 \mathrm{~mol} \%$ load of catalyst $\mathbf{C N}-\mathbf{1}$, in DCM and a commercially available solution of $\mathrm{NaOCl}$ (14.5\% in active chlorine), for the specified time. ${ }^{\mathrm{b}}$ Ratio in volume of each phase. ${ }^{\mathrm{c}}$ Measured on ${ }^{1} \mathrm{H}$ NMR. ${ }^{\mathrm{d}}$ Measured on HPLC chiralpak-IA with $n$-hexane/ $i$ propanol.

Obtained data suggested that enantioselectivity is strongly dependent of the organic phase concentration. The measured enantiomeric ratio diminished along with the concentration (entries 2-5). However, for higher concentrations (entry 1), enantioselectivity was also negatively affected. As suggested by Lygo ${ }^{134}$, higher concentrations lead to a lower solubility of catalyst $\mathbf{C N}-\mathbf{1}$ (during the reaction, a considerable amount of PTC remained visibly as a solid suspension) which resulted in a loss of catalytic efficiency. Higher concentration might also imply a change in the reaction media, concerning the polarity and intermolecular interactions. Since a concentration of $0.3 \mathrm{M}$ and an organic: aqueous phase ratio of 2:1 showed the best results in terms of conversion and enantioselectivity, those conditions were used for further optimization experiments.

Another parameter expected to be relevant for the catalytic activity was the solvent. Many authors have reported excellent results when nonpolar solvents where used for epoxidation in phase-transfer catalytic systems, which were significantly reduced when polar solvents were used instead. ${ }^{135}$ We performed the solvent screening to elucidate the mechanism of the reaction and how the phase transfer catalyst activity was affected by the media. The optimization of the solvent was carried out at a scale of $20 \mathrm{mg}$ of trans- $\beta$-methyl- $\beta$-nitrostyrene, $10 \mathrm{~mol} \%$ load of catalyst $\mathbf{C N}-1,0.3 \mathrm{M}$ concentration of the nitroalkene in the

135 a) Macdonald, G.; Alcaraz, L.; Lewis, N. J.; Talyor, R. J. K. Tetrahedron Lett. 1998, 39, 5433. b) Arai, S.; Tsuge, H.; Oku, M.; Miura, M.; Shioiri, T. Tetrahedron 2002, 58 (8), 1623. c) Arai, S.; Tsuge, H.; Shioiri, T. Tetrahedron Lett. 1998, 39, 7563. d) Lygo, B.; Wainwright, P. G. Tetrahedron 1999, 55, 6289. 
specified solvent (Table 9) and a commercially available aqueous solution of $\mathrm{NaOCl}$ (14.5\% in chlorine) in 2:1 organic phase:aqueous phase ratio.

Table 9. Screening of the Solvent and its Effect on Enantioselectivity and Conversion Rates. ${ }^{\text {a }}$

\begin{tabular}{|c|c|c|c|c|}
\hline Entry & Solvent & Time (h) & Conversion $(\%)^{b}$ & e.r. ${ }^{c}$ \\
\hline 1 & $\overline{\mathrm{DCM}}$ & 2 & 100 & $59: 41$ \\
\hline 2 & EtOAc & 6 & 48 & $50: 50$ \\
\hline 3 & Toluene & 24 & 20 & n.d. ${ }^{\mathrm{d}}$ \\
\hline 4 & Hexane & 24 & $<5$ & n.d. \\
\hline 5 & Methanol & 24 & No reaction & n.d. \\
\hline 6 & THF & 6 & 45 & $50: 50$ \\
\hline 7 & $\mathrm{Et}_{2} \mathrm{O}$ & 24 & No reaction & n.d. \\
\hline 8 & 1,2-DCE & 2 & 75 & $55: 45$ \\
\hline 9 & Chloroform & 1.5 & 70 & $74: 26$ \\
\hline
\end{tabular}

${ }^{a}$ Reactions were carried out at room temperature with vigorous stirring, with 2:1 ratio of organic and aqueous phase. ${ }^{b}$ Measured on ${ }^{1} \mathrm{H}$ NMR. ${ }^{\mathrm{c}}$ Measured on HPLC chiralpak-IA with $n$-hexane/ $i$-propanol. ${ }^{\mathrm{d}}$ Not determined.

Solvent, indeed, resulted to be a very important parameter to take in consideration. Dichloromethane was used as a control (entry 1) giving full conversion with short times and $18 \%$ ee. Ethyl acetate was able to solubilize both the substrate and the catalyst $\mathbf{C N - 1}$ and the reaction underwent smoothly with a $48 \%$ conversion in 6 hours, although the enantioselectivity was null (entry 2). Non-polar solvents such as hexane and diethyl ether (entries 4 and 7) barely showed conversion, probably due to the lack of solubility of $\mathbf{C N - 1}$ in those solvents. For our concern, 
one of the most employed solvents in phase transfer catalysis, toluene (entry 3), afforded the conversion of nitroalkene into nitroepoxide only with $20 \%$ yield. In that case, $\mathbf{C N}-1$ seemed to be more soluble than in hexane or diethyl ether, but still not completely soluble. When methanol was used (entry 5), no reaction occurred since its miscibility with aqueous media caused homogenization of the system. However, despite being an aqueous miscible solvent, tetrahydrofuran (entry 6) allowed a biphasic system while stirring, which afforded nitroepoxide in $45 \%$ yield but with no enantioselectivity. Halogenated non-polar solvents such as 1,2-dichloroethane (entry 8) and chloroform (entry 9) were good in terms of catalyst solubility and showed fast conversion in short times. While enantioselectivity for 1,2-dichloroethane was poor compared to dichloromethane, chloroform afforded satisfactory results both in terms of reactivity, $70 \%$ conversion in only one and a half hours, and enantioselectivity, $48 \%$ ee. Carbon tetrachloride was expected to be even greater solvent because it is less polar than chloroform, but due to environmental and economic restrictions, it was not tested at that moment.

Having optimized the conditions for the enantioselective epoxidation of nitroalkenes, we proceeded to the screening of the catalyst (Table 10). Following bibliographic work, first modification on the catalyst involved the insertion of methylanthracene group in the $\mathrm{N}$ atom of the quinuclidine ring from the cinchonine to form the corresponding ammonium salt $(\mathbf{C N}-2) .{ }^{136}$ For our content, $\mathbf{C N}-2$ exhibited good results in $\mathrm{CHCl}_{3}$ at $10 \mathrm{~mol} \%$ load in terms of conversion and enantioselectivity (entry 2). As it is described in literature, electronic interactions and major steric hindrance of the anthracenyl group compared to benzyl might be responsible of the increment on the selectivity. ${ }^{137}$

\footnotetext{
${ }^{136}$ Lygo, B.; Wainwright, P. G. Tetrahedron Lett. 1997, 38 (49), 8595.

${ }^{137}$ Corey, E. J.; Xu, F.; Noe, M. C. J. Am. Chem. Soc. 1997, 119 (50), 12414.
} 
Table 10. Screening of the Catalyst ${ }^{\mathrm{a}}$

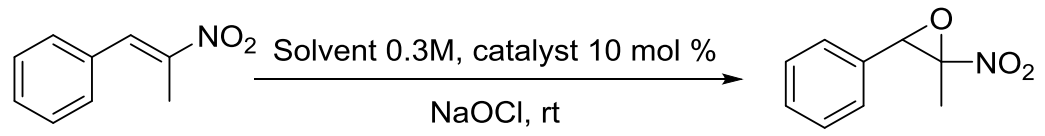

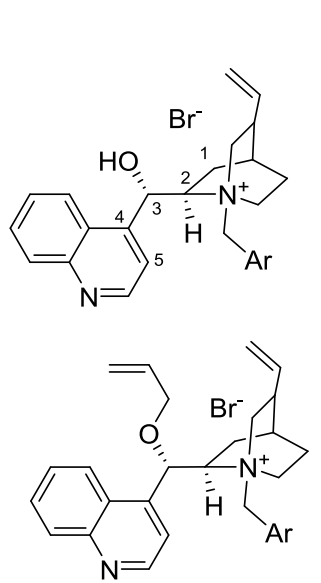

CN-6 Ar = Anthracenyl CN-7 Ar $=0-\mathrm{F}-\mathrm{Ph}$
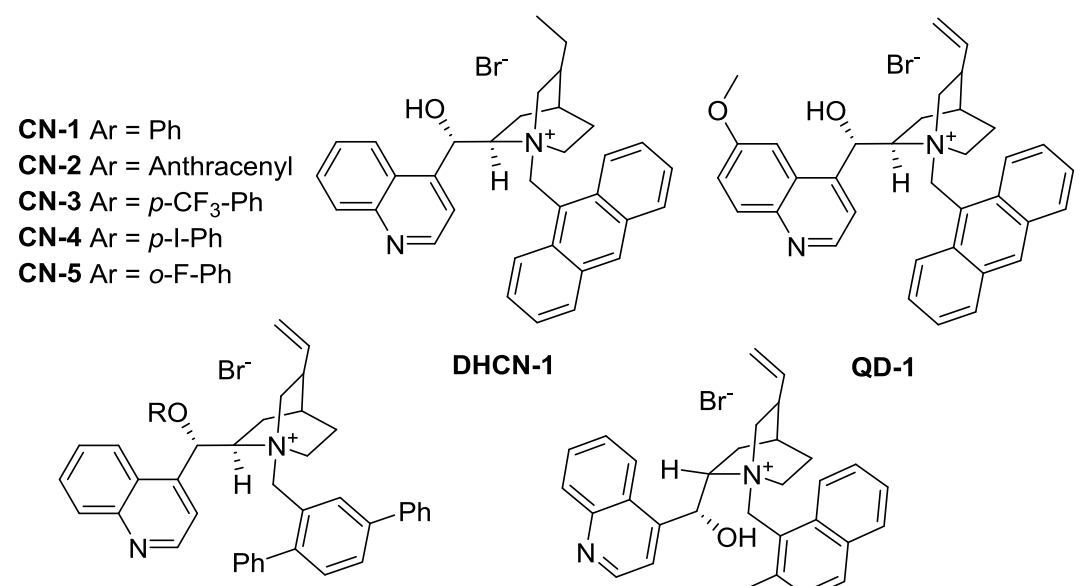

CN-8 R $=\mathrm{H}$ CN-9 $R=$ allyl
DHCN-1

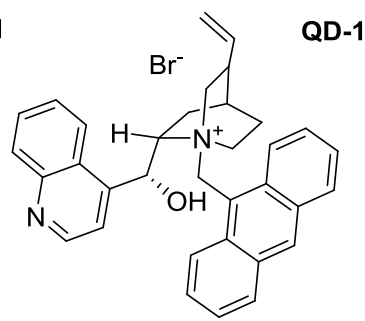

CD-1

\begin{tabular}{llllll}
\hline Entry & Solvent & Catalyst & Time (h) & Conversion $(\%)^{\mathrm{b}}$ & e.r. $^{\mathrm{c}}$
\end{tabular}

\begin{tabular}{cccccc}
\hline $\mathbf{1}$ & $\mathrm{CHCl}_{3}$ & $\mathbf{C N - 1}$ & 5 & 100 & $74: 26$ \\
$\mathbf{2}$ & $\mathrm{CHCl}_{3}$ & $\mathbf{C N - 2}$ & 3 & 100 & $84: 16$ \\
$\mathbf{3}$ & $\mathrm{CHCl}_{3}$ & $\mathbf{C N - 3}$ & 5 & 100 & $81: 19$ \\
$\mathbf{4}$ & $\mathrm{CHCl}_{3}$ & $\mathbf{C N - 4}$ & 3 & 100 & $81: 19$ \\
$\mathbf{5}$ & $\mathrm{CHCl}_{3}$ & $\mathbf{C N - 5}$ & 5 & 100 & $53: 47$ \\
$\mathbf{6}$ & $\mathrm{CHCl}_{3}$ & $\mathbf{D H C N - 1}$ & 2 & 100 & $81: 19$ \\
$\mathbf{7}$ & $\mathrm{CCl}_{4}$ & $\mathbf{C N - 2}$ & 2 & 100 & $89: 11$ \\
$\mathbf{8}$ & $\mathrm{Toluene}$ & $\mathbf{C N - 2}$ & 24 & 100 & $87: 13$ \\
$\mathbf{9}$ & $\mathrm{Toluene}$ & $\mathbf{C N - 4}$ & 16 & 60 & $84: 16$ \\
$\mathbf{1 0}$ & $\mathrm{CHCl}_{3}$ & $\mathbf{Q D - 1}$ & 4 & 100 & $62: 38$ \\
\hline & & & & & \\
\hline
\end{tabular}




\begin{tabular}{cccccc}
\hline $\mathbf{1 1}$ & Toluene & $\mathbf{Q D - 1}$ & 4 & 98 & $75: 25$ \\
$\mathbf{1 2}$ & $\mathrm{CHCl}_{3}$ & $\mathbf{C N - 6}$ & 5 & 80 & $45: 55$ \\
$\mathbf{1 3}$ & Toluene & $\mathbf{C N - 6}$ & 5 & 100 & $33.5: 66.5$ \\
$\mathbf{1 4}$ & $\mathrm{CHCl}_{3}$ & $\mathbf{C N - 7}$ & 4 & 38 & $50: 50$ \\
$\mathbf{1 5}$ & Toluene & $\mathbf{C N - 7}$ & 4 & 98 & $39.5: 60.5$ \\
$\mathbf{1 6}$ & Toluene & $\mathbf{C N - 8}$ & 4.5 & 100 & $41: 59$ \\
$\mathbf{1 7}$ & Toluene & $\mathbf{C N - 9}$ & 5 & 100 & $25: 75$ \\
$\mathbf{1 8}^{\mathbf{d}}$ & Toluene & $\mathbf{C N - 2}$ & 16 & $92^{\mathrm{e}}$ & $96.5: 3.5$ \\
$\mathbf{1 9}^{\mathbf{d}}$ & Toluene & $\mathbf{C D - 1}$ & 16 & $86^{\mathrm{e}}$ & $18: 82$ \\
\hline
\end{tabular}

${ }^{2}$ The reactions were carried out at a scale of $20 \mathrm{mg}$ of trans- $\beta$-methyl- $\beta$-nitrostyrene, $10 \mathrm{~mol} \%$ load of catalyst, with $0.3 \mathrm{M}$ concentration of substrate and a commercially available solution of $\mathrm{NaOCl}$ (14.5\% in active chlorine) in a 2:1 organic:aqueous phase ratio, at room temperature. ${ }^{b}$ Measured on ${ }^{1} \mathrm{H}$ NMR. ${ }^{c}$ Measured on HPLC chiralpak-IA with $n$-hexane/i-propanol. ${ }^{\mathrm{d}}$ Reaction was carried out at $-20^{\circ} \mathrm{C}$. ${ }^{\mathrm{e}}$ Isolated yield.

Arai and coworkers reported that substitutions on the benzyl ring of CN-1 had a tremendous impact on enantioselectivity for the asymmetric epoxidation of diverse enones. ${ }^{135 b, c}$ For example, electronwithdrawing groups such as I- at position 4 increased enantioselectiviy, while electron-donor groups had the opposite effect. Moreover, the position of the substituent was found to be also crucial, since the efficacy of catalyst diminished when iodine atom was placed in positions 2 or 3 . Thus, catalyst with trifluoromethyl group in para position $\mathbf{C N - 3}$ (entry 3) and catalyst with iodide group in para position CN-4 (entry 4) were tested for the enantioselective epoxidation of nitroalkenes. Both catalysts showed better efficiency than the unsubstituted catalyst CN-1 (entry 1), but the obtained results also indicated that both $\mathbf{C N - 3}$ and $\mathbf{C N}-4$ were slightly worse than the cinchoninium salt with the anthracenyl group CN-2 (entry 2). Despite the aforementioned, it has been reported that unusual aromatic-F electronic effect enhanced the enantioselectivity of PTC mediated 
alkylation of a glycine anion equivalent when the corresponding cinchonidinium catalyst possessed a fluoride in orto- position at benzylic ring (Scheme 55). ${ }^{138} \mathrm{We}$ tested the cinchoninium analogue CN-5 (entry 5) for the epoxidation reaction in chloroform, but we did not obtain the expected result. In fact, the enantioselectivity dropped to a $6 \%$ ee, quite much lower than the previous entries.

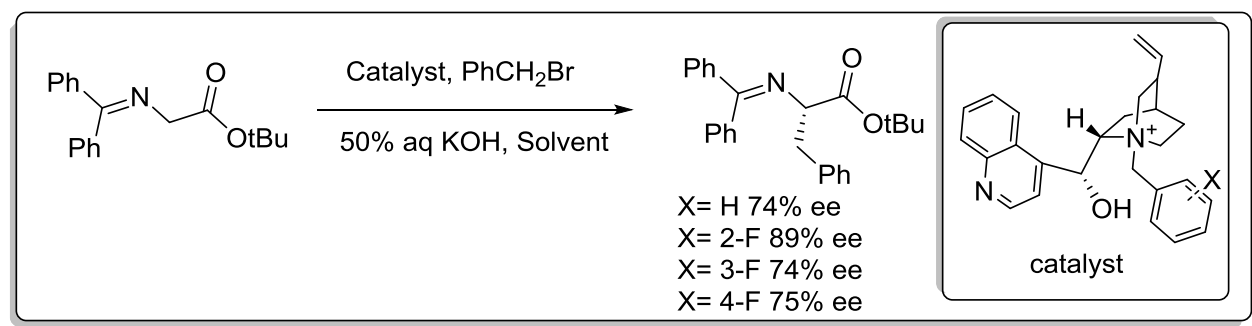

Scheme 55. F-effect on enantioselectivity in a phase transfer alkylation.

In one of the many studies published by Lygo and Wainwright, they reported an increase of the enantioselectivity when a hydrogenated analogue of cinchonine or chinconidine was used as phase transfer catalyst. $^{136}$ According to that, we prepared $N$-anthracenylmethyl dihydrocinchoninium bromide DHCN-1 and tested it for the epoxidation of trans- $\beta$-methyl- $\beta$-nitrostyrene (entry 6). A slight increment on the rate of the reaction was observed, but the enantioselectivity was identical to that obtained with the unsaturated analogue $\mathbf{C N}-2$ (entry 2). We decided to continue the experiments with CN-2 because its synthesis requires one step less than for DHCN-1 and the catalytic activity has been exposed to be practically the same.

With the present results, we decided to test more apolar solvent than chloroform, namely carbon tetrachloride with catalyst CN-2 (entry 7). Enantioselectivity rose from $68 \%$ ee (entry 2 ) to $78 \%$ ee. However, we were still intrigued by the fact that most published research on anthracenylmethyl cinchona derived salts describes toluene-water as the optimal solvent system. So, we performed the reaction with $\mathbf{C N}-2$

\footnotetext{
${ }^{138}$ Jew, S. S.; Yoo, M. S.; Jeong, B. S.; Park, I. Y.; Park, H. G. Org. Lett. 2002, 4 (24), 4245 .
} 
in toluene (entry 8) and we found that the reaction became slower, but it was compensated with a $74 \%$ ee, which was better than with chloroform. We tested toluene also for catalyst CN-4 (entry 9) in order to find how enantioselectivity was affected, by comparing the results with those for the reaction in chloroform (entry 4). Interestingly, the same results for enantioselectivity were observed but worse conversion was obtained. Affinity between solvent and catalyst seemed to be a decisive factor regarding efficiency of the enantioselective epoxidation. Since toluene is more environmentally acceptable solvent than carbon tetrachloride, further optimization was performed with toluene.

Quinidine is a cinchona alkaloid that displays the same stereochemistry than cinchonine. We guessed that a methoxy group in the quinoline ring might modify the activity of the catalyst. In order to study that hypothesis, we synthetized $N$-anthracenylmethyl quinidinium bromide and assayed it for the epoxidation reaction in chloroform (entry 10) and toluene (entry 11). In both experiments, it resulted that quinidine salt is less effective than its cinchonine analogue. Another common structural modification is the alkylation of the hydroxyl group in position 9. For example, E. J. Corey reported excellent results for the enantioselective epoxidation of chalcones using $O$-allyl- $N$-anthracenylmethyl cinchonidinium bromide as a catalyst and $\mathrm{KOCl}$ as an oxidant. ${ }^{139}$ Catalysts CN-6 (entries 12 and 13) and CN-7 (entries 14 and 15) were prepared and tested for our epoxidation system and surprisingly, the opposite nitroepoxide enantiomer was obtained in moderate enantioselectivity $(<-33 \%$ ee). In the light of the obtained results, we hypothesized that the hydroxyl group must be somehow, via polar interaction or via H-bond, partially responsible of the interaction between catalyst and substrate determining the conformation of the transition state.

${ }^{139}$ Corey, E. J.; Zhang, F. Y. Org. Lett. 1999, 1 (8), 1287. 
Having suggested that $N$-anthracenylmethyl catalyst $\mathbf{C N}-2$ worked better for its steric hindrance compared to benzyl group in $\mathbf{C N}-\mathbf{1}$, we looked for a more voluminous group. We found that K. A. Scheidt and coworkers designed a cinchonidinium salt catalyst with a 2,5-diphenyl benzyl group in the quinuclidine nitrogen efficiently used for the asymmetric alkylation of isoflavanones (Scheme 56). ${ }^{140}$ We synthetized the cinchoninium analogues $\mathbf{C N - 8}$ and $\mathbf{C N}-9$ and tested for the epoxidation of nitroalkenes (entries 16 and 17, respectively). Unexpectedly, catalyst $\mathbf{C N - 8}$ (entry 16) showed an inversion on enantioselectivity, affording nitroepoxide in $-8 \%$ ee. To explain that experimental observation, we reasoned that the 2,5-diphenyl group might be too voluminous for the nitroalkene to adopt the proper transition state geometry since the present phenyl substituents can afford non-planar conformation in comparison with anthracenyl group which is completely planar. The O-allylated compound CN-9 (entry 17) afforded the epoxide with bigger enantioselectivity ( $-50 \%$ ee) than the analogue $\mathbf{C N - 8}$, also with opposite enantioselectivity.

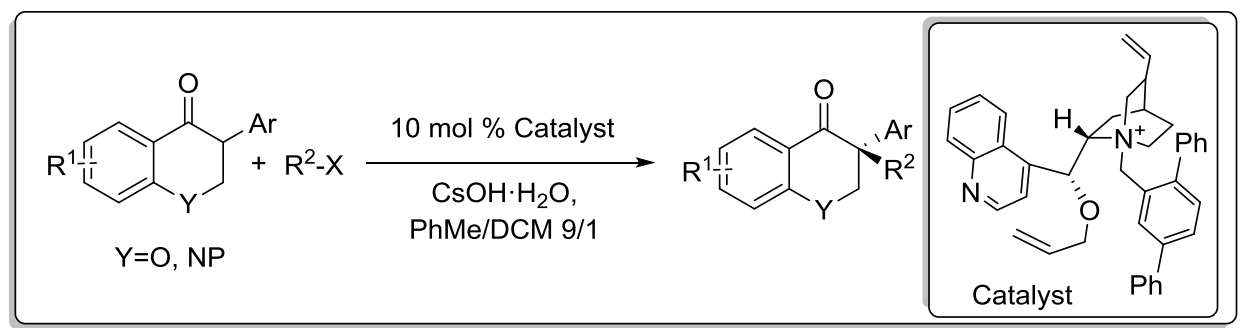

Scheme 56. Asymmetric alkylation of disubstiuted isoflavanones.

Being catalyst $\mathbf{C N}-2$ in toluene the best results in our hands (entry 8) we proceeded to the temperature optimization. We set up the reaction at $-20^{\circ} \mathrm{C}$ with a cryogenic bath and the enantioselectivity was greatly increased up to $93 \%$ ee (entry 18). At lower temperatures, aqueous phase frezees and the reaction did not advance. With the optimized conditions, we also performed the reaction with the pseudoenantiomeric catalyst $\mathrm{N}$-anthracenylmethyl cinchoninidinium

\footnotetext{
${ }^{140}$ Nibbs, A. E.; Baize, A. L.; Herter, R. M.; Scheidt, K. A. Org. Lett. 2009, 11 (17), 4010.
} 
bromide CD-1 (entry 19). Then, the opposite enantiomer was obtained with a $-64 \%$ ee.

The effect of diverse additives was also studied. It has been reported for many kinds of organic reactions that the presence of some additives in catalytic amounts can increase the yields and enantioselectivities. ${ }^{141} \mathrm{We}$ tested commonly employed additives such as Lewis acid metal salts and organocatalysts (Table 11).

Table 11. Effect of Additives on Conversion and Enantioselectivity ${ }^{\mathrm{a}}$

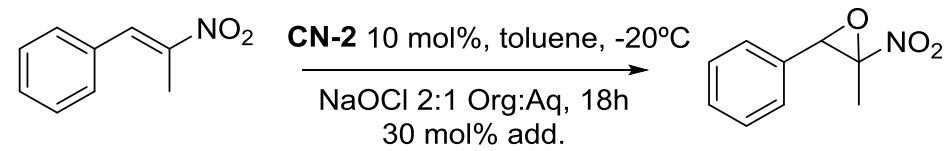<smiles>FC(F)(F)c1cc(NC(=S)Nc2cc(C(F)(F)F)cc(C(F)(F)F)c2)cc(C(F)(F)F)c1</smiles>

Schreiner's Thiourea

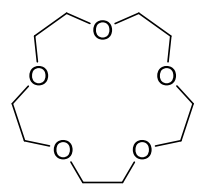

15-crown-5-ether

\begin{tabular}{cccc}
\hline Entry & Additive & Conversion $(\%)^{b}$ & e.r. $(\%)^{c}$ \\
\hline $\mathbf{1}$ & - & 100 & $96.6: 3.4$ \\
$\mathbf{2}$ & $\mathrm{LiCl}$ & 95 & $94: 6$
\end{tabular}

$\begin{array}{cccc}\mathbf{3} & \text { ST } & \text { No reaction } & \text { n.d. } \\ \mathbf{4} & \mathrm{CuCl} & 70 & 86: 14\end{array}$

$\begin{array}{cccc}\mathbf{5} & \mathrm{AlCl}_{3} & \text { Decomposition } & \text { n.d. } \\ \mathbf{6} & \mathrm{CsF} & 94 & 90.5: 9.5\end{array}$

$7 \quad 15$-crown-5 $\quad 90 \quad 90: 10$

${ }^{\mathrm{a}}$ The reactions were carried out at a scale of $20 \mathrm{mg}$ of trans- $\beta$-methyl- $\beta$-nitrostyrene, $10 \mathrm{~mol} \%$ load of catalyst, $30 \mathrm{~mol} \%$ load of additive, with $0.3 \mathrm{M}$ concentration of

${ }^{141}$ a) For a general review: Vogl, E. M.; Gröger, H.; Shibasaki, M. Angew. Chemie Int. Ed. 1999, 38 (11), 1570. b) Lee, J. M.; Na, Y.; Han, H.; Chang, S. Chem. Soc. Rev. 2004, 33 (5), 302. c) Roy, D.; Patel, C.; Sunoj, R. B. J. Org. Chem. 2009, 74 (18), 6936. 
substrate and a commercially available solution of $\mathrm{NaOCl}$ (14.5\% in active chlorine) in a 2:1 organic:aqueous phase ratio, at $-20^{\circ} \mathrm{C}$. ${ }^{b}$ Measured on ${ }^{1} \mathrm{H}$ NMR. ${ }^{c}$ Measured on HPLC chiralpak-IA with $n$-hexane/ $i$-propanol.

When $\mathrm{LiCl}$ was used as an additive (entry 2), a bit loss of conversion rate and enantioselectivity was observed, although it was not significant. However, when a thiourea was used (entry 3), no reaction occurred and only starting material was recovered. A feasible explanation might be that thiourea moiety interacts with the nitro group via $\mathrm{H}$-bond avoiding nitroalkene to interact with $\mathbf{C N}-2$ impeding the reaction to occur. In the case of $\mathrm{Cu}$ (I) salt (entry 4), conversion was severely affected and a loss of enantioselectivity could also be observed. The use of a stronger Lewis acid such as $\mathrm{AlCl}_{3}$ (entry 5) resulted in the decomposition of the starting material. CsF (entry 6) also had a minor negative effect on conversion and enantioselectivity. Crown ethers function as an ion trap enhancing the activity of the counterion. However, 15-crown-5-ether (entry 7) did not favor the epoxidation reaction. We thought that 15crown-5-ether might be able to trap sodium cation liberating the hypochlorite as a consequence, but that had no positive impact on enantioselectivity. In view of the results, we decided not to further investigate the use of additives to improve the enantioselectivity.

With the best results in our hands (Table 10, entry 18), reaction was scaled up to $200 \mathrm{mg}$ of the substrate and the same results were obtained. During the process, several problems occurred, mainly involving the stirring. A proper interphase is necessary for the reaction to happen, since the catalyst must carry counterions from aqueous phase to organic phase and vice versa. So, homogeneous and vigorous stirring is needed to achieve maximum yield and enantioselectivity (ca. $1000 \mathrm{rpm}$ ). Another significant problem we found was the degradation of commercial hypochlorite solution; that is, lower concentration of oxidant in the aqueous phase, which was translated into higher freezing point. That problem affected reproducibility of the reaction at $-20^{\circ} \mathrm{C}$ but it was easily solved by purchasing a new aqueous solution of $\mathrm{NaOCl}$. 
Work-up was simplified by pouring hexane to the reaction mixture, which caused precipitation of the catalyst, and filtering the mixture through an anhydrous magnesium sulfate pad to afford the pure nitroepoxide without further purification. Since CN-2 seemed not completely soluble in the final conditions, we thought we could reduce the catalyst load without affecting the yield or the enantioselectivity. In fact, we were able to reduce the catalyst load to $8 \mathrm{~mol} \%$ without affecting conversion and enantioselectivity.

Absolute configurations of enantiopure nitroepoxides 13a and 13g were assigned by X-ray crystallography (Figure 14) and 13a was also confirmed by optical rotation in comparison with the enantiomeric nitroepoxide reported by Lattanzi et al. ${ }^{131}$
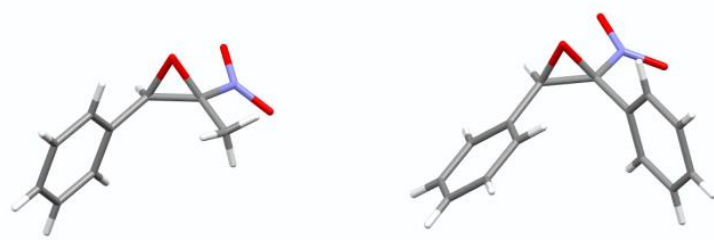

Figure 14. X-ray crystal structure for compounds 13a (left) and 13g (right).

\subsection{Scope of the Reaction}

With the optimized conditions, the scope of the epoxidation reaction was explored (Table 12). The reactions were carried out at a scale of 50 $\mathrm{mg}$ of the corresponding nitroalkene at $0.3 \mathrm{M}$ concentration in toluene, with $8 \mathrm{~mol} \%$ load of $\mathbf{C N}-2$, at $-20^{\circ} \mathrm{C}$. 
Table 12. Scope of the Reaction for the (+)-Nitroepoxide.<smiles>[R]/C=C(/[R])[N+](=O)[O-]</smiles>

13a-h

\begin{tabular}{ccccc}
\hline Entry & $\mathrm{R}^{1}, \mathrm{R}^{2}$ & Epoxide & ${\text { Yield }(\%)^{b}}^{b}$ & e.r. $(\%)^{c}$ \\
\hline $\mathbf{1}$ & $\mathrm{Ph}, \mathrm{Me}$ & $\mathbf{1 3 a}$ & 92 & $96.6: 3.4$ \\
$\mathbf{2}$ & $p$-F-Ph, Me & $\mathbf{1 3 b}$ & 96 & $96.1: 3.9$ \\
$\mathbf{3}$ & $p$-Cl-Ph, Me & $\mathbf{1 3 c}$ & 92 & $94.2: 5.8$ \\
$\mathbf{4}$ & $m-\mathrm{Cl}-\mathrm{Ph}, \mathrm{Me}$ & $\mathbf{1 3 d}$ & 87 & $91.5: 8.5$ \\
$\mathbf{5}$ & $p-\mathrm{F}-\mathrm{Ph}, \mathrm{Et}$ & $\mathbf{1 3 e}$ & 91 & $95.1: 4.9$ \\
$\mathbf{6}$ & $p-\mathrm{Me}-\mathrm{Ph}, \mathrm{Me}$ & $\mathbf{1 3 f}$ & 92 & $91.3: 8.7$ \\
$\mathbf{7}$ & $\mathrm{Ph}, \mathrm{Ph}$ & $\mathbf{1 3 g}$ & 90 & $91.5: 8.5$ \\
$\mathbf{8}$ & $i-\mathrm{Bu}, \mathrm{Me}$ & $\mathbf{1 3 h}$ & 63 & $56.5: 43.5$
\end{tabular}

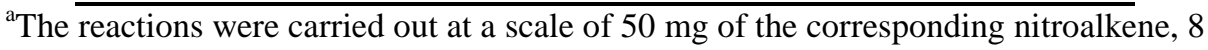
mol \% load of $\mathbf{C N}-2$, with $0.3 \mathrm{M}$ concentration of substrate and a commercially available solution of $\mathrm{NaOCl}(14.5 \%$ in active chlorine) in a 2:1 organic:aqueous phase ratio, at $-20^{\circ} \mathrm{C}$. ${ }^{\mathrm{b}}$ Isolated yield. ${ }^{\mathrm{c}}$ Measured on HPLC chiralpak-IA with $n$-hexane/ $i$ propanol.

Diverse nitroalkenes were epoxidized under the optimized conditions. Being $\mathrm{R}^{1}$ an aryl group and $\mathrm{R}^{2}$ an alkyl group (entries 1-6), results were excellent both in terms of yield and enantioslectivity. When olefin substituents were both phenyl groups, good results were also obtained (entry 7). However, when both substituents were alkyl group, the yield and the enantioselectivity were considerably lower (entry 8). The volatility of both the starting material and the nitroepoxide $13 \mathrm{~h}$ might explain the decrease in the yield. The loss of enantioselectivity suggested that nitroalkene's aryl group might have stabilizing interactions with the anthracenyl group, e.g. $\pi-\pi$ interactions, which 
directs the position of the nitroalkene in the transition state affording preferably one enantiomer over the other.

We also explored the epoxidation of the aforementioned nitroalkenes with the pseudoenantiomeric catalyst CD-1 (Table 13).

Table 13. Scope of the Reaction for the (-)-Nitroepoxide.

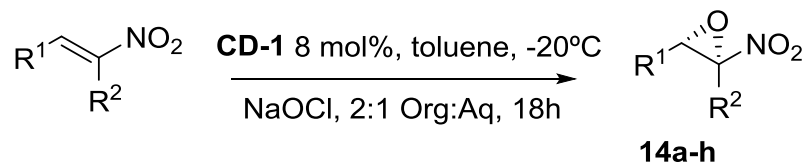

\begin{tabular}{ccccc}
\hline Entry & $\mathrm{R}^{1}, \mathrm{R}^{2}$ & Epoxide & ${\text { Yield }(\%)^{b}}^{b}$ & e.r. $(\%)^{c}$ \\
\hline $\mathbf{1}$ & $\mathrm{Ph}, \mathrm{Me}$ & $\mathbf{1 4 a}$ & $86 \%$ & $18: 82$ \\
$\mathbf{2}$ & $p$-F-Ph, Me & $\mathbf{1 4 b}$ & $85 \%$ & $16: 84$ \\
$\mathbf{3}$ & $p$-Cl-Ph, Me & $\mathbf{1 4 c}$ & $92 \%$ & $13: 87$ \\
$\mathbf{4}$ & $m-\mathrm{Cl}-\mathrm{Ph}, \mathrm{Me}$ & $\mathbf{1 4 d}$ & $92 \%$ & $27.5: 72.5$ \\
$\mathbf{5}$ & $p$-F-Ph, Et & $\mathbf{1 4 e}$ & $87 \%$ & $22: 78$ \\
$\mathbf{6}$ & $p-\mathrm{Me}-\mathrm{Ph}, \mathrm{Me}$ & $\mathbf{1 4 f}$ & $90 \%$ & $15.5: 84.5$ \\
$\mathbf{7}$ & $\mathrm{Ph}, \mathrm{Ph}$ & $\mathbf{1 4 g}$ & $88 \%$ & $25: 75$ \\
$\mathbf{8}$ & $i$-Bu, Me & $\mathbf{1 4 h}$ & $63 \%$ & $26: 74$ \\
\hline
\end{tabular}

${ }^{\mathrm{a}}$ The reactions were carried out at a scale of $50 \mathrm{mg}$ of the corresponding nitroalkene, 8 mol \% load of CD-1, with $0.3 \mathrm{M}$ concentration of substrate and a commercially available solution of $\mathrm{NaOCl}$ ( $14.5 \%$ in active chlorine) in a 2:1 organic:aqueous phase ratio, at $-20^{\circ} \mathrm{C}$. ${ }^{\mathrm{b}}$ Isolated yield. ${ }^{\mathrm{c}}$ Measured on HPLC chiralpak-IA with $n$-hexane $/ i$ propanol.

As expected, the epoxidation of nitroalkenes with CD-1 as a catalyst afforded the opposite nitroepoxides 14a-h with similar yields and a loss of enantioselectivity compared with the synthesis of 13a-h with $\mathbf{C N}-2$ (Table 12). However, for the alkyl-alkyl disubsituted nitroepoxide 14h (Table 13, entry 8) an increase of the enantioselectivity was observed compared with $\mathbf{1 3 h}$. 


\subsection{Computational Studies}

In order to explain the experimental data, computational studies were performed by Dr. Katarzyna Świderek and Prof. Vicent Moliner from Computational Biochemistry group at Universitat Jaume I. Quantum molecular simulations have been employed to study the observed catalytic enantioselective epoxidation of trans- $\beta$-methyl- $\beta$-nitrostyrene by catalyst $\mathbf{C N - 2}$. All calculations have been carried out in toluene solution with the conductor-like polarizable continuum model $(\mathrm{CPCM}),{ }^{142}$ as implemented in Gaussian 09 package. ${ }^{143}$ The calculations have been performed at density functional theory (DFT) level with the B97d hybrid functional, ${ }^{144}$ which has been proved to provide exceptionally good performance for non-covalently bound systems ${ }^{144}$ involving large polynuclear aromatic molecules. ${ }^{145}$ The selected reaction was the one corresponding to the entry 18 in Table 10. The first step of the study was exploring the possible conformers adopted by the catalyst $\mathbf{C N}-2$ in toluene. In this regard, a Potential Energy Surface (PES) has been generated as a function of the dihedral angles describing the relative orientation of the quinoline moiety (Figure 15), similarly to previous conformational analysis of different cinchona alkaloid scaffolds. ${ }^{146}$

142 a) Barone, V.; Cossi, M. J. Phys. Chem. A 1998, 102 (11), 1995. b) Cossi, M.; Rega, N.; Scalmani, G.; Barone, V. J. Comput. Chem. 2003, 24 (6), 669.

${ }^{143}$ M. J. Frisch, et al Gaussian 09, revision D.01; Gaussian, Inc., Wallingford CT, 2009

${ }^{144}$ Grimme, S. J. Comput. Chem. 2006, 27 (15), 1787.

145 Peverati, R.; Baldridge, K.K. J. Chem. Theory Comput. 2008, 4, 2030.

${ }^{146}$ a) Prakash, G.K.S.; Wang, F.; Ni, C.; Shen, J.; Haiges, R.; Yudin, A. K.; Mathew, T.; Olah, G. O. J. Am. Chem. Soc. 2011, 133, 9992. b) Prakash, G.K.S.; Wang, F.; Rahm, M.; Zhang, Z.; Ni, C.; Shen, J.; Olah, G. A. J. Am. Chem. Soc. 2014, 136, 10418. 


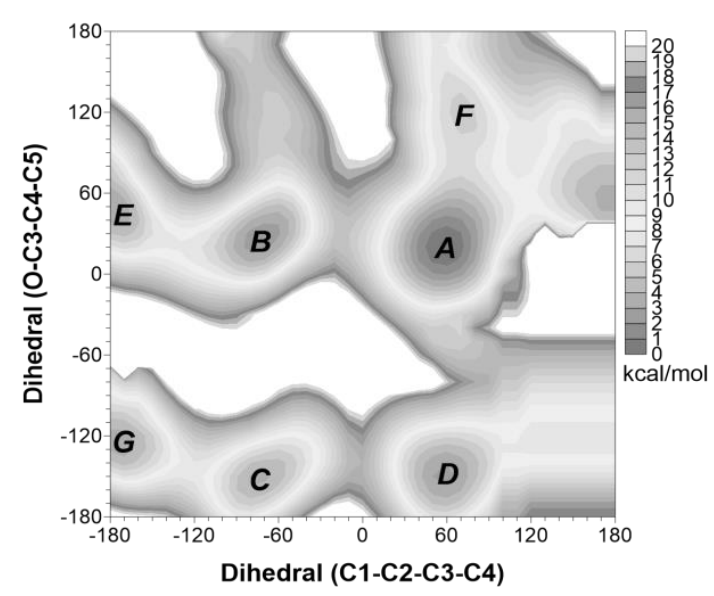

Figure 15. Gas phase PES computed at B97d/6-31+G(d,p) level as a function of the dihedral angles describing the relative orientation of the quinoline moiety and -OH group of $\mathbf{C N}-2$ catalyst. See Table 10 for numbering of the atoms.

All possible conformations of $\mathbf{C N}-2$ catalyst were explored. From the two lowest energy $\mathbf{C N}-2$ conformers A and B (Figure 15), the study of the binding of the $\mathrm{ClO}^{-}$and the nitroalkene substrate provides different reactant complex, RC, conformations. Interestingly, while the conformation of $\mathbf{C N - 2}$ is comparable to the one observed for other cinchona-based catalysts, ${ }^{147}$ this is not the case when comparing the RCs. Indeed our most stable RCs for the epoxidation reaction show $\pi-\pi$ stacking interactions between the catalyst and the substrate (Figure 16), which is not detected in the indanone-catalyst complexes previously reported for the cinchoninium ion asymmetric phase transfer catalyzed alkylation reaction. ${ }^{147}$ Moreover, the $\mathrm{ClO}^{-}$moiety interacts by a hydrogen bond with the hydroxyl group of the catalyst in both RCs dictating the orientation and interaction between the nitroalkene and the catalyst. The difference between both RCs structures depends on the $\pi$ $\pi$ stacking interaction that is established between the nitroalkene and the aryl substituent of the catalyst; while RC in A.II.1 interacts through the anthracenyl moiety of the catalyst, RC in A.II.2 interacts through the quinoline moiety. Interestingly, there is no significant difference in

${ }^{147}$ Martins, E. F.; Pliego, J. R. ACS Catal. 2013, 3, 613. 
energy between both conformations. Nevertheless, this is not the case when comparing the transition states, TSs, and product complexes, PCs, that connect with the RCs. Thus, the reaction from RC A.II.1 shows lower energy barrier than the reaction from RC A.II.2 (8.4 vs. 12.5 $\left.\mathrm{kcal} \cdot \mathrm{mol}^{-1}\right)$, and more stable PCs $\left(-44.2\right.$ and $-41.4 \mathrm{kcal} \cdot \mathrm{mol}^{-1}$, respectively). Importantly, the nitroepoxides that are obtained in both reactions are different enantiomers: (2S,3R)-nitroepoxide 13a in reaction from A.II.1 and (2R,3S)-nitroepoxide 14a in reaction from A.II.2. According to the relative energies of their corresponding TSs and PCs, (2S,3R)-nitroepoxide would be the most favorable enantiomer when employing catalysts $\mathbf{C N}-2$ from the thermodynamic and kinetic point of view. This computational result is in very good agreement with the experimental data reported in Table 10 entry 18, where $2 \mathrm{~S}, 3 \mathrm{R}$ enantiomer is obtained in a 96.5/3.5 ratio.

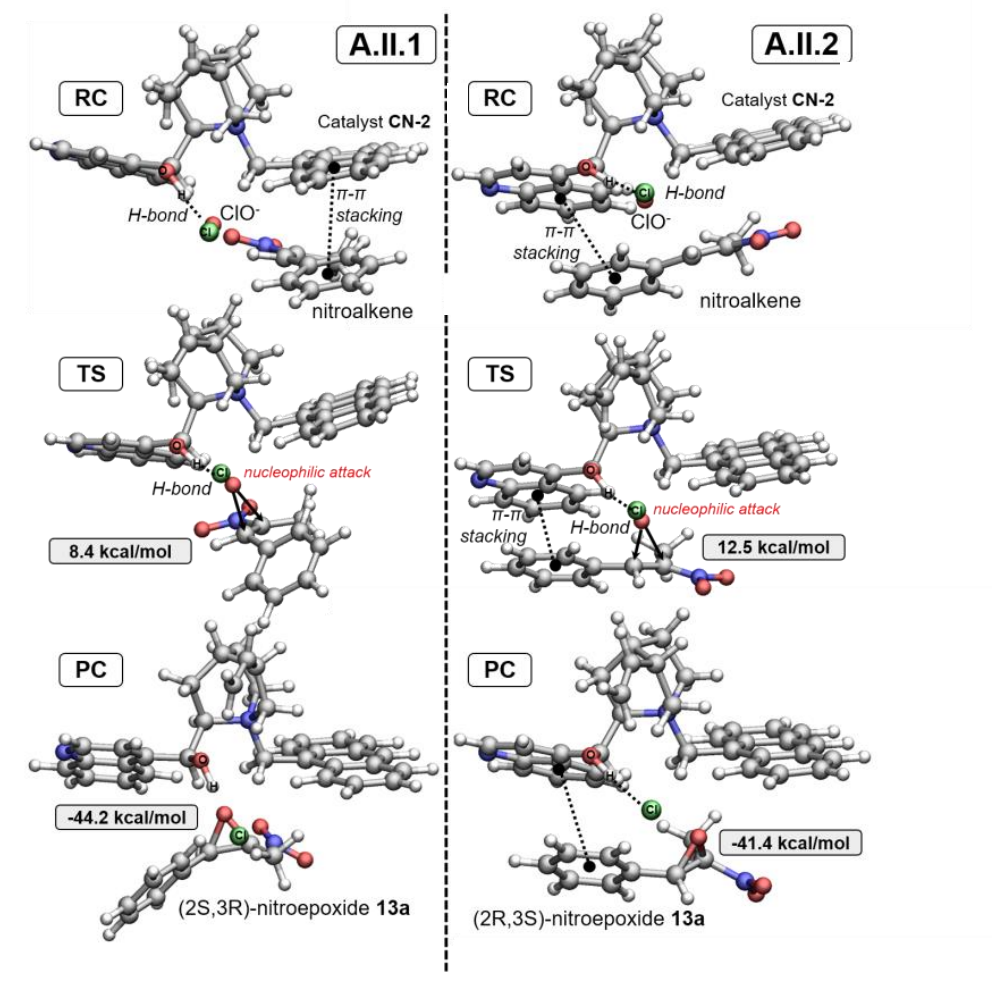

Figure 16. Optimized structures and relative energies of RC, TS and PC of the epoxidation of trans- $\beta$-methyl- $\beta$-nitrostyrene catalyzed by $\mathbf{C N - 2}$ starting from the most stable conformations of the nitroalkene- $\mathrm{ClO}-\mathbf{C N}-2$ reactant complexes. 
A deep analysis of the RCs, TSs and PCs structures reveals that the $\pi$ $\pi$ stacking interaction between the aromatic rings of the catalysts and the substrate are important to stabilize and to orient the two moieties in RCs. This explains the synthesis of nitroepoxide $\mathbf{1 3 h}$, having no aromatic substituent, not to be enantioselective. Nevertheless, the presence of hydrogen bond interactions and the most favourable conformation of the catalyst appear to be the factor determining the relative energies of TSs and PCs that, in turn, determines the ratio of obtained enantiomers.

It is important to point out that the epoxidation of trans- $\beta$-methyl- $\beta$ nitrostyrene catalyzed with CD-1 has been also studied from different $\mathrm{RC}$ conformers. Any alternative reaction path has been revealed as not only thermodynamically but kinetically less favourable than the reaction from A.II.1 displayed in Figure 15.

\subsection{Synthetic Derivations of Nitroepoxides}

In order to increase the interest of the enantioselective epoxidation of nitroalkenes, we envisioned many synthetic applications of asymmetric nitroepoxides. Lattanzi ${ }^{131}$ already reported the one-pot synthesis of highly valuable 1,2 -aminoalcohol ${ }^{148}$ from nitroepoxides in great diastereoselctive and enantioselective fashion.

From our experience with nitroepoxides and their conversion into heterocycles (Chapter 2 of the present $\mathrm{PhD}$ Thesis), we envisioned the synthesis of morpholine 15 from nitroepoxide 13a using 1,2aminoalcohols (Scheme 57). Morpholines are considered to be privileged scaffolds in medicinal chemistry. ${ }^{149}$ Some commercial drugs display morpholine moiety (Figure 17). For example, phenmetrazine is

\footnotetext{
${ }^{148}$ For a review on enantioenriched 1,2-aminoalcohols: Klingler, F. D. Acc. Chem. Res. 2007, 40 (12), 1367.

${ }^{149}$ a) Taylor, R. D.; MacCoss, M.; Lawson, A. D. G. J. Med. Chem. 2014, 57, 5845.

b) Wijtmans, R.; Vink, M. K. S.; Schoemaker, H. E.; van Delft, F. L.; Blaauw, R. H.;

Rutjes, F. P. J. T. Synthesis 2004, 641.
} 
a potent releaser of norepinephrine and dopamine. ${ }^{150}$ Phendimetrazine (Bontril) is an anorexigenic drug; ${ }^{151}$ and aprepitant (Emend) is a potent and orally active NK1 receptor antagonist for chemotherapy-induced emesis, depression and other potential indications ${ }^{152}$ (Figure 17). Although some works have been reported for the preparation of morpholines, ${ }^{153}$ their use is currently limited by the scarcity of methods for their preparation, particularly for 2,3-disubstituted morpholines.

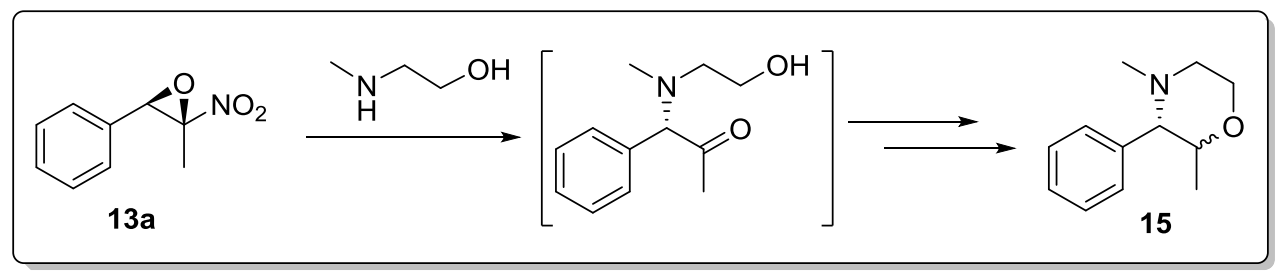

Scheme 57. Synthetic approach to morpholines from nitroepoxides

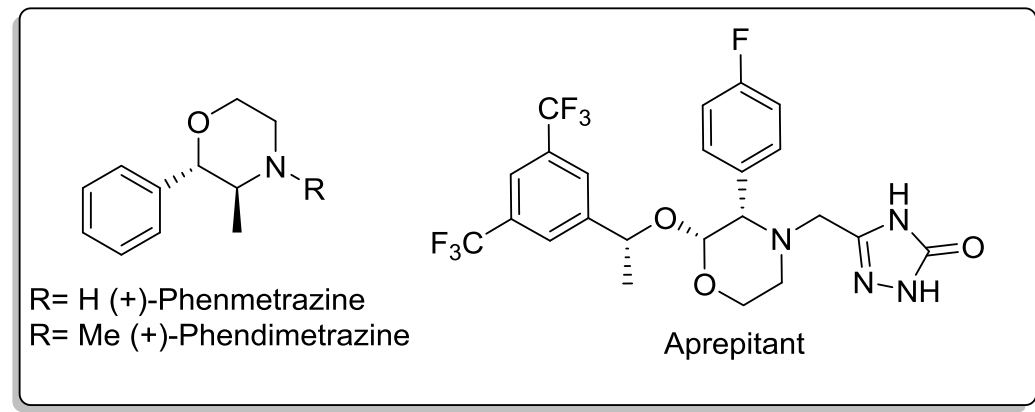

Figure 17. Commercial drugs with morpholine moiety

Racemic nitroepoxide 1a was submitted to reaction with 2(methylamino)ethanol to afford morpholinol 16 with high chemical

\footnotetext{
${ }^{150}$ Rothman, R. B.; Katsnelson, M.; Vu, N.; Partilla, J. S.; Dersch, C. M.; Blough, B. E.; Baumann, M. H. Eur. J. Pharmacol. 2002, 447 (1), 51.

${ }^{151}$ Rogovik, A. L.; Chanoine, J.-P.; Goldman, R. D. Drugs 2010, 70 (3), 335.

${ }^{152}$ Brands, K. M. J.; Payack, J. F.; Rosen, J. D.; Nelson, T. D.; Candelario, A.; Huffman, M. A.; Zhao, M. M.; Li, J.; Craig, B.; Song, Z. J.; Tschaen, D. M.; Hansen, K.; Devine, P. N.; Pye, P. J.; Rossen, K.; Dormer, P. G.; Reamer, R. A.; Welch, C. J.; Mathre, D. J.; Tsou, N. N.; Mcnamara, J. M.; Reider, P. J. J. Am. Chem. Soc. 2003, 125,2129

153 a) Lai, J.-Y.; Shi, X.-X.; Gong, Y.-S.; Dai, L.-X. J. Org. Chem. 1993, 58 (18), 4775. b) Ritzen, B.; Hoekman, S.; Verdasco, E. D.; Van Delft, F. L.; Rutjes, F. P. J. T. J. Org. Chem. 2010, 75 (10), 3461. c) Uozumi, Y.; Tanahashi, A.; Hayashi, T. J. Org. Chem. 1993, 58 (24), 6826. d) Zhou, L.; Tan, C. K.; Zhou, J.; Yeung, Y. Y. J. Am. Chem. Soc. 2010, 132 (30), 10245.
} 
yield and a diastereomeric mixture of $86 / 14$ (Scheme 58). The hydroxy ketone resulting from the attack of the secondary amine to the nitroepoxide, cyclized into hemiacetalic form (Scheme 58).

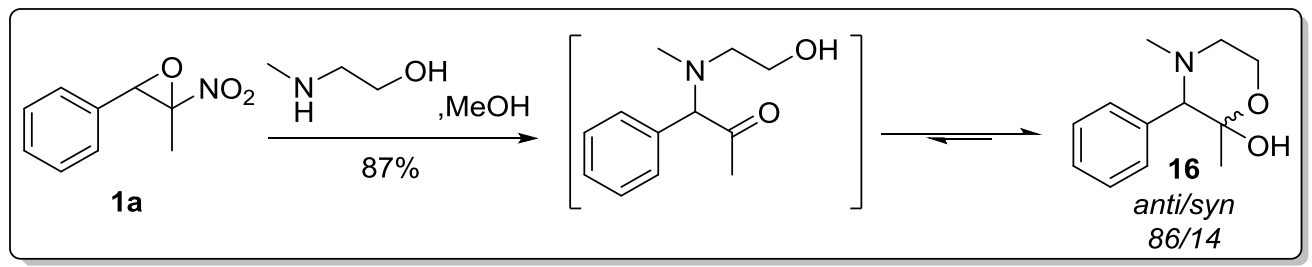

Scheme 58. Synthesis of morpholinol 16.

Although their presence in literature is no so relevant compared to morpholines, morpholinols are still an interesting scaffold in medicinal chemistry. ${ }^{154}$ Stereochemistry of $\mathbf{1 6}$ was determined by NMR measurements (Figure 18). As it can be observed in the monodimensional NOE experiment, irradiation of the methyl group on the major diasteromer $(1.10 \mathrm{ppm})$ gave NOE effect with the benzylic proton (3.06 ppm), whilst irradiation of methyl on the minor diasteromer $(1.25 \mathrm{ppm})$ did not show correlation with the benzylic proton, or at least it was not so evident.

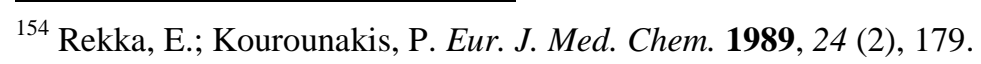



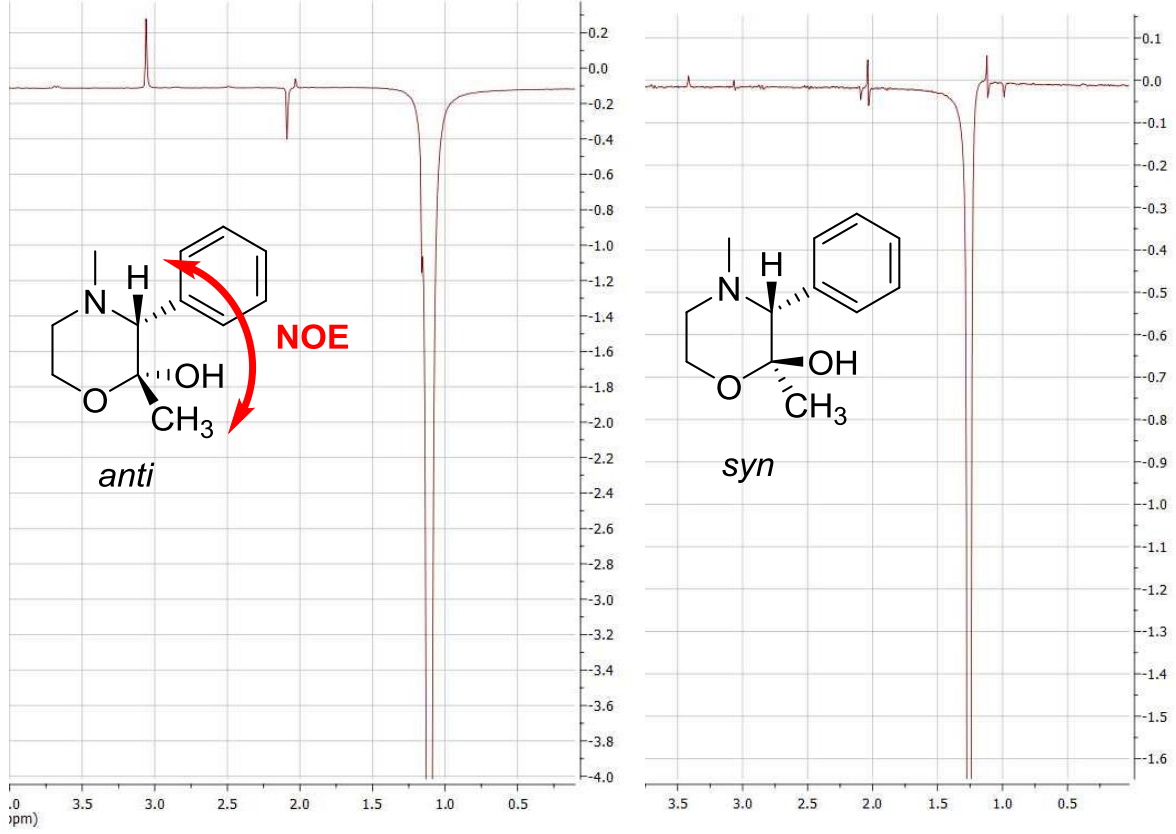

Figure 18. 1D NOE experiment.

We performed the same reaction with optically active nitroepoxide 13a. For our surprise, despite the racemic $\mathbf{1 6}$ was a solid, the obtained compound was a yellow oil. After HPLC analysis, we observed a great loss of enantioselectivity, from 96.6:3.4 e.r. of 13a to 65:35 e.r. of morpholinol. After two weeks, HPLC was repeated and the mixture became almost racemic and the oil became solid. Aminoketone form derived from morpholinol $\mathbf{1 6}$ is supposed to racemize resulting in racemization of morpholinol $\mathbf{1 6}$ (Scheme 59).

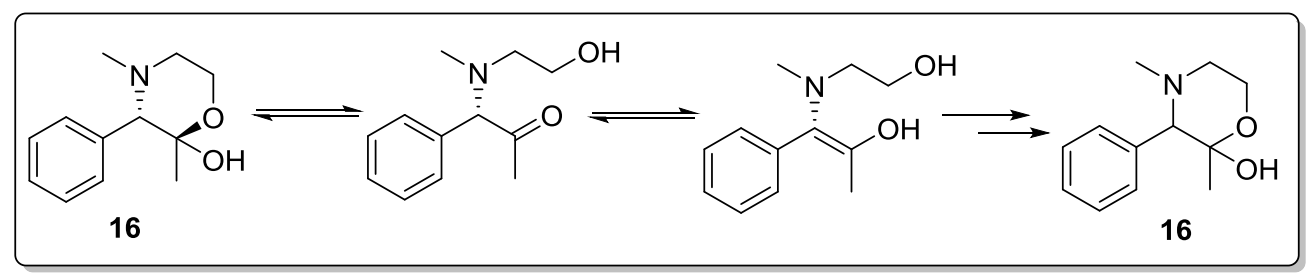

Scheme 59. Racemization of enantiomerically pure morpholinol.

Another strategy that we designed was the tosylation of the hydroxy group to favor the equilibrium into the open conformation (Scheme 60). Morpholinol 16 was then subjected to reaction with tosyl chloride in 
the presence of a base. Despite the efforts, only starting material was recovered. We thought that, at least in solution, morpholinol was the more stable isomer and the equilibrium is entirely displaced to its side.

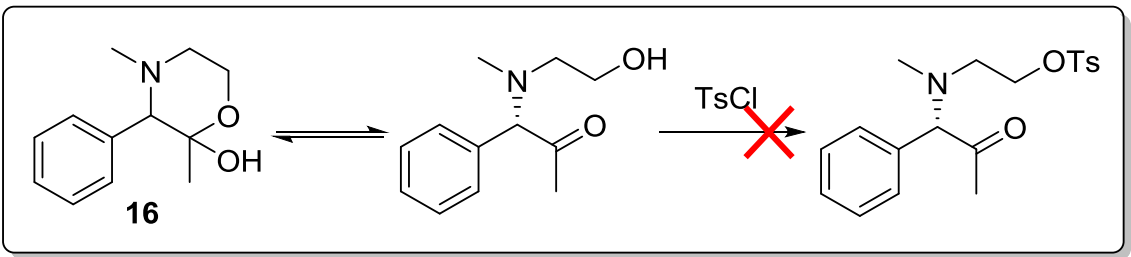

Scheme 60. Tosylation attempt of the open form.

Since we did not succeed in transforming optically pure nitroepoxides into optically active chiral morpholines or morpholinols, we envisioned an approach to obtain thiomorpholines by the use of 2aminoethanethiol (Scheme 61). Thiomorpholine is a bioisostere of morpholine, an analogue in which oxygen atom is replaced by a sulfur atom, which might behave in similar way in biological systems. ${ }^{155}$ Our approach consisted in a ring-opening of the nitroepoxide with $\mathrm{N}$-Bocaminoethanethiol, followed by deprotection and finally reductive amination (Scheme 61).

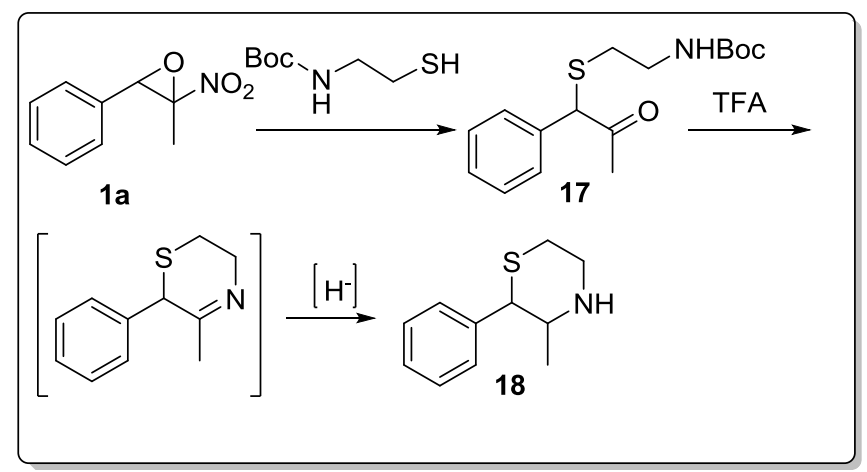

Scheme 61. Synthetic approach to thiomorpholine 18.

The best conditions for the first step were found to be reflux of the nitroepoxide and $N$-Boc-aminoethanethiol in ethanol, affording 1,2thioketone intermediate 17 in $80 \%$ yield (Scheme 62). However, we

155 a) Brown, N. In Bioisosteres in Medicinal Chemistry; 2012; pp 1-14. b) Barillari, C.; Brown, N. In Bioisosteres in Medicinal Chemistry; 2012; pp 15-29. 
found several problems during deprotection step. We started with standard conditions for Boc deprotection which consisted in the use of a TFA/DCM 1/1 solution. Those conditions seemed too harsh for the compound since the mass of the crude was reduced considerably and lots of products were observed on ${ }^{1} \mathrm{H}$ NMR spectrum. Different deprotection conditions were tested, but all of them failed. Then, we tested one-pot sequential deprotection/reductive amination with different deprotecting acid and reductive agent combination. Finally, with a stoichiometric excess of $\mathrm{H}_{3} \mathrm{PO}_{4}$ in $\mathrm{DCE}^{156}$ and $\mathrm{NaBH}(\mathrm{OAc})_{3}$ as a reducing agent, we were able to obtain a cleaner reaction crude which was purified by LC. However, the isolated compound was not the expected thiomorpholine $\mathbf{1 8}$.

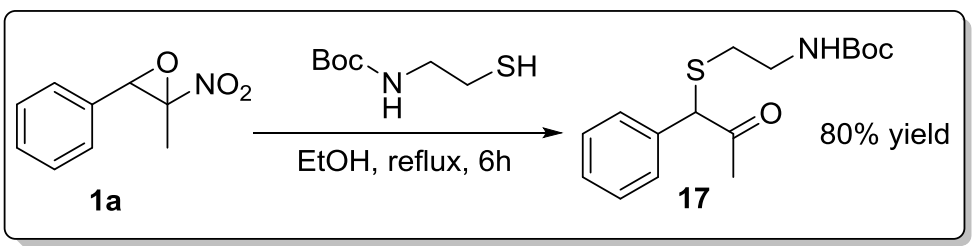

Scheme 62. Ring-opening with N-protected ethanothiolamine.

The isolated product was analyzed by ${ }^{1} \mathrm{H}$ and ${ }^{13} \mathrm{C}$ NMR spectroscopy and interesting peaks were observed (Figure 19). In the ${ }^{1} \mathrm{H}$ NMR spectrum, three different $\mathrm{C}$ backbones were observed, namely an ethyl group, a three $\mathrm{sp}^{3}$ carbon and a phenyl group (Figure 19). ${ }^{13} \mathrm{C}$ NMR showed coherent signals because five $\mathrm{sp}^{3}$ carbon signals were observed and also four $\mathrm{sp}^{2}$ carbon signals on the aromatic region. No ketone peaks were observed. The more reasonable structure seemed to be a derived product from thiomorpholine $\mathbf{1 8}$ in which the C-S bond has been cleaved. However, when mass spectrometry was performed, the product seemed to decompose and no peaks could be identified. More

\footnotetext{
${ }^{156}$ Li, B.; Berliner, M.; Buzon, R.; Chiu, C. K. F.; Colgan, S. T.; Kaneko, T.; Keene, N.; Kissel, W.; Le, T.; Leeman, K. R.; Marquez, B.; Morris, R.; Newell, L.; Wunderwald, S.; Witt, M.; Weaver, J.; Zhang, Z.; Zhang, Z. J. Org. Chem. 2006, 71 (24), 9045.
} 
experiments are undergoing to confirm the structure and elucidate the reaction mechanism.

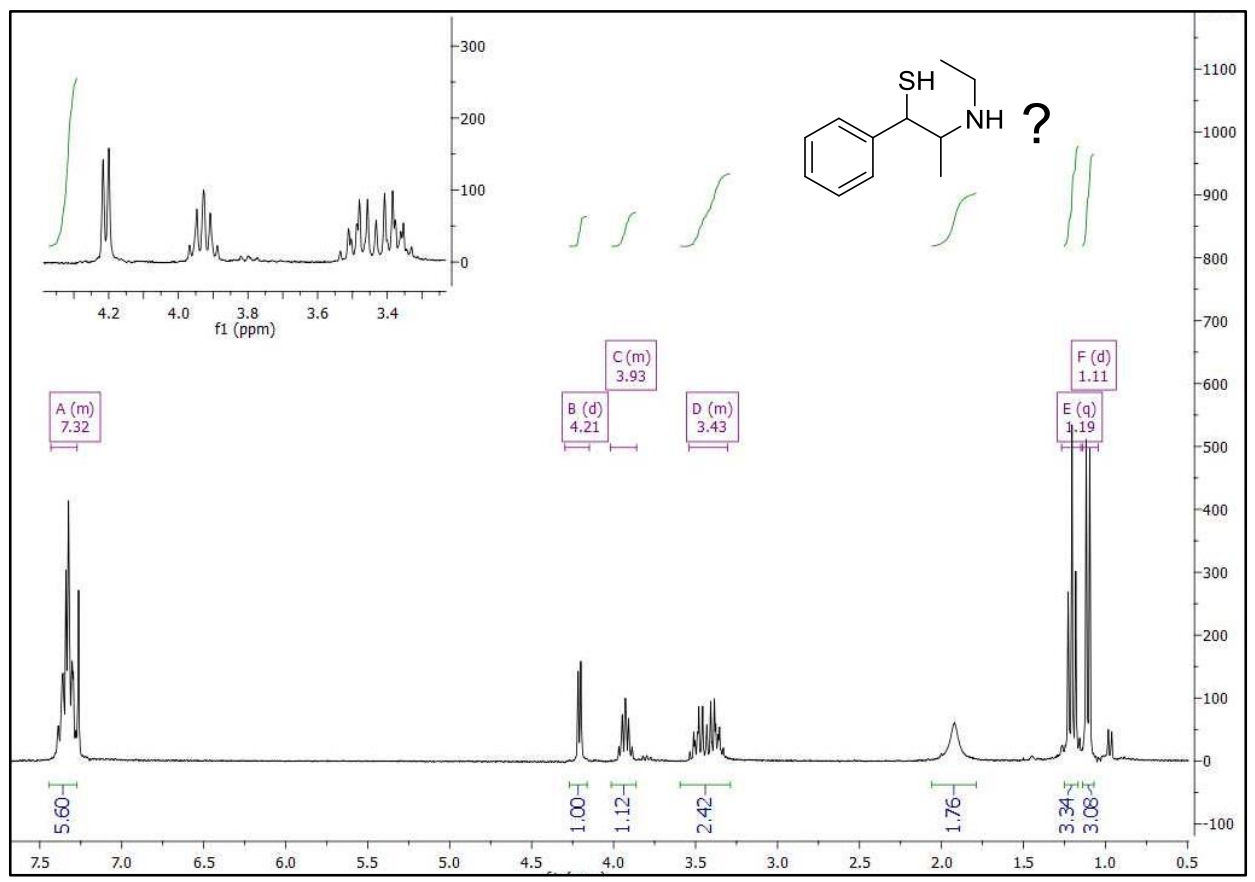

Figure 19. Unidentified isolated compound

A different strategy for the synthesis of thiomorpholine $\mathbf{1 8}$ from nitroepoxide 1a was used. Considering that nitroepoxides can be described as synthetic equivalents of $\alpha$-haloketones, we used a reported experimental procedure for the synthesis of thiomorpholines from $\alpha$ bromoketones. ${ }^{157} \mathrm{We}$ started from the commercially available cysteamine hydrochloride salt, which was solved in ethanol under inert conditions and two equivalents of $\mathrm{KOH}$ were precisely measured and added to the solution (Scheme 63). Then, one equivalent of nitroepoxide was added and stirred until consumption to finally add $\mathrm{NaBH}_{4}$ as reducing agent. The crude showed three similar compounds identified as the two regiomeric thiomorpholines 18 and 19 as a diastereomeric mixture (Scheme 63).

${ }^{157}$ Ziakas, G. N.; Rekka, E. A.; Gavalas, A. M.; Eleftheriou, P. T.; Kourounakis, P. N. Bioorganic Med. Chem. 2006, 14 (16), 5616. 


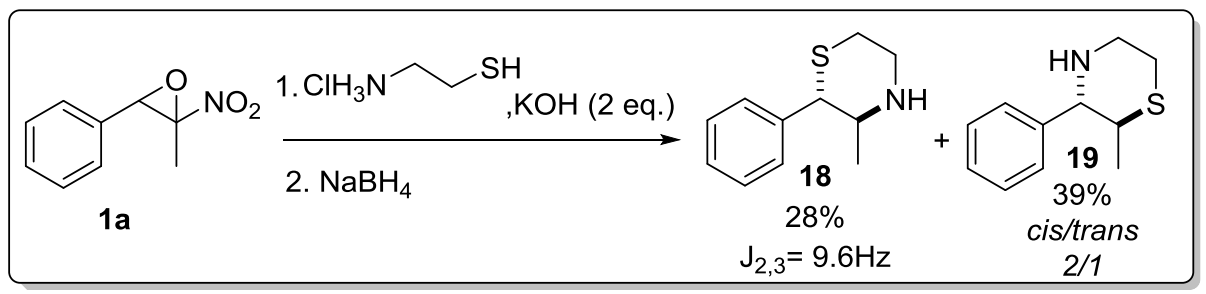

Scheme 63. Synthesis of thiomorpholines 18 and 19

In order to differentiate the two regioisomers, we isolated the compounds by LC and compared the signals on ${ }^{1} \mathrm{H}$ NMR (Figure 20). As reported in the literature for similar compounds, ${ }^{157,158}$ when the ring-opening is performed by the sulfur atom the benzylic proton chemical (3.6 ppm in $\mathrm{CDCl}_{3}$ ) shift is lower than the equivalent signal when the ring opening is performed by the nitrogen atom (4.0 ppm). The observed diastereomer was assigned to the regioisomer 19 due to its benzylic proton chemical shift (4.2 ppm).

${ }^{158}$ García Ruano, J. L.; Martínez, M. C.; Rodríguez, J. H.; Olefirowicz, E. M.; Eliel, E. L. J. Org. Chem. 1992, 57 (15), 4215. 

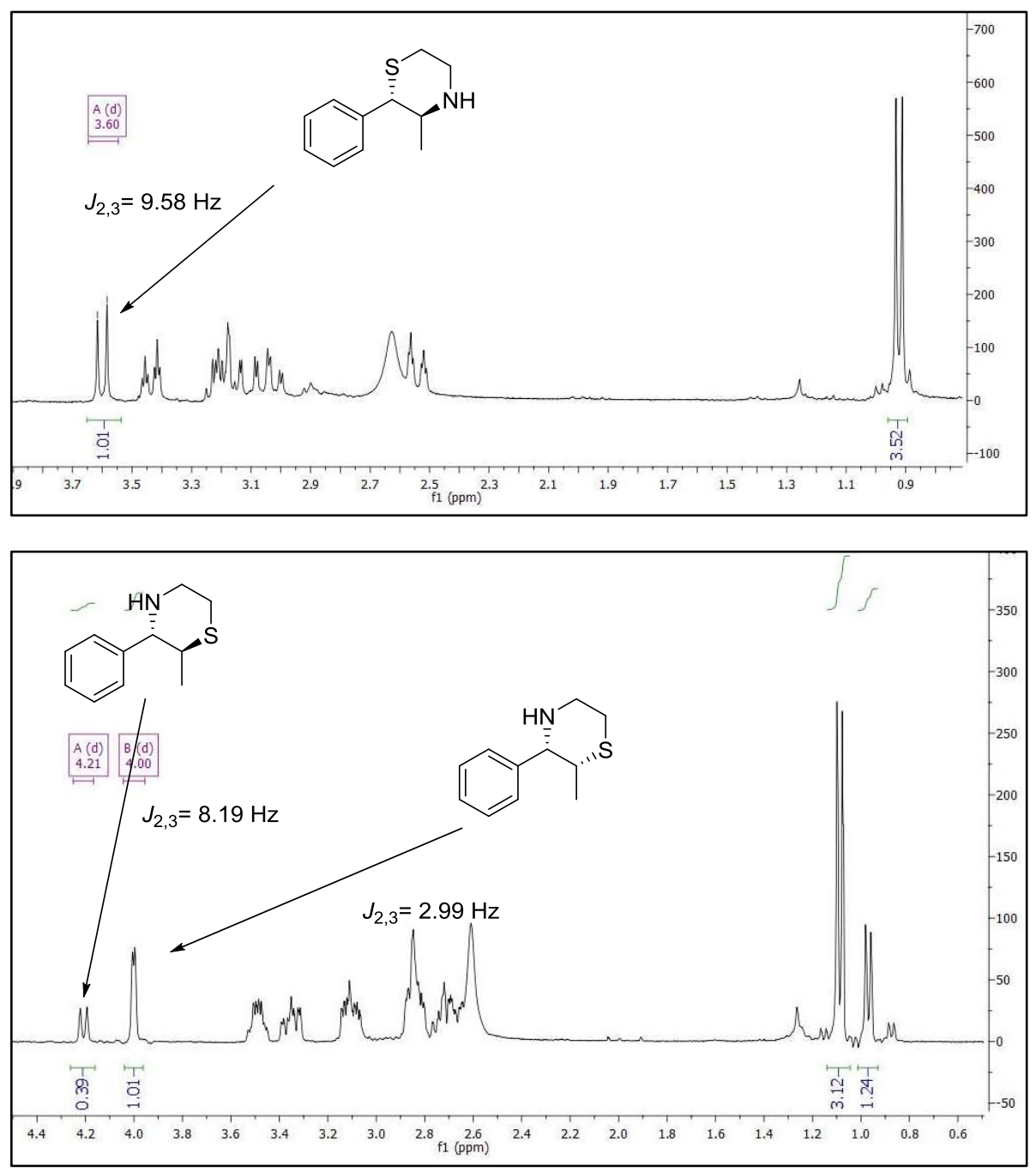

Figure 20. ${ }^{1} \mathrm{H}$ NMR spectra and signals assignment for thiomorpholines $\mathbf{1 8}$ (up) and 19 (down).

The stereochemistry of the corresponding isomers was elucidated by analogy with the piperazines on Chapter 2. For thimorpholine 19, the main diastereomer had a coupling constant between the benzylic and the homobenzylic proton of $2.99 \mathrm{~Hz}$ (cis- isomer) whilst the minor diastereomer had a coupling constant of $8.19 \mathrm{~Hz}$ (trans- isomer). Thiomorpholine 18 was isolated as single diastereomer, with a coupling constant of $9.58 \mathrm{~Hz}$ so trans- isomer was assigned by analogy. 
The reaction was then performed with the optically pure epoxide 13a. Unfortunately, both thiomorpholines $\mathbf{1 8}$ and $\mathbf{1 9}$ were obtained as a racemic mixture. We supposed that the ketone intermediate was very sensitive to epimerization by enolization in the basic media. Despite we could not afford enantiomerically pure compounds, we succeeded in the transformation of nitroepoxides into interesting heterocycles. An extensive research study for the synthesis of thiomorpholines, morpholinols and further morpholines and benzoxazines was performed in collaboration with MSc, student Estefania Capel and it has been already accepted for publication. ${ }^{159}$ Asymmetric applications of enantioenriched nitroepoxides are currently being investigated.

\section{Synthesis of Precursors}

The synthesis of precursors did not present a big challenge since most of them are well known compounds (see experimental section for detail and bibliographic references). Synthesis of nitroalkenes and racemic nitroepoxides has already been described on Chapter 2. PTCs CN-1 to CN-5, CN-8, DHCN-1, QD-1 and CD-1 were prepared by refluxing the corresponding cinchona alkaloid with the corresponding bromides. Those bromides were commercially available or easily synthesizable by bromination with $\mathrm{PBr}_{3}$. It might be worthy to describe the preparation of catalysts CN-8 and CN-9 (Scheme 64).

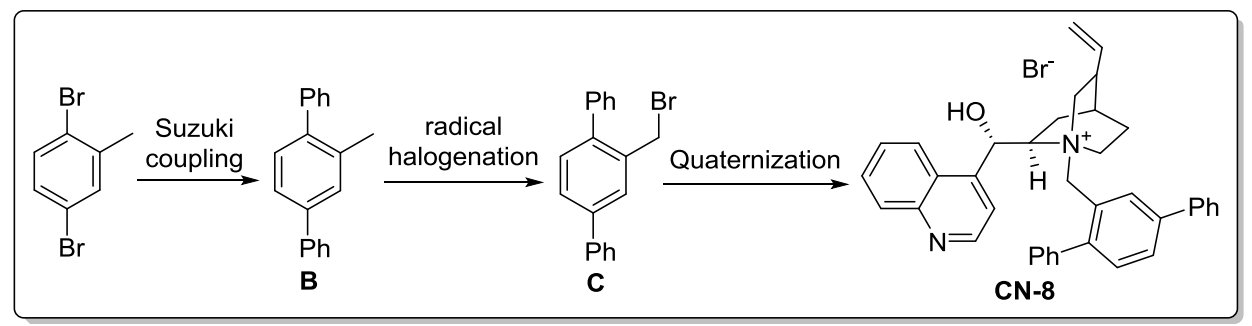

Scheme 64. Synthetic route to the synthesis of catalyst $\mathbf{C N - 8}$

Starting with 2,5-dibromotoluene, a double Suzuki coupling was performed to obtain the intermediate 2,5-diphenyl toluene $\mathbf{B}$, which

\footnotetext{
${ }^{159}$ Capel, E.; Vidal-Albalat, A.; Rodríguez, S.; González, F. V. Synthesis 2016, 48, A1
} 
was isolated by silica flash liquid chromatography. Then, radical bromination with $\mathrm{N}$-bromo succinimide and AIBN was performed to obtain the disubstituted benzyl bromide $\mathbf{C}$, which was used without further purification for the synthesis of $\mathbf{C N - 8}$.

Catalysts CN-6, CN-7 and CN-9 were synthesized from the corresponding PTCs by alkylation with allyl bromide. 


\section{Conclusions}

- Different organocatalytic systems were tested, but phase transfer catalysis was chosen among them due to operability, availability of reagents and the promising results that first trials offered.

- Solvent, substrate concentration, catalyst and many other parameters were wisely optimized to achieve great results in terms of yield and enantioselectivity.

- The scope of the reaction was demonstrated to be suitable for nitroalkenes with aryl and alkyl substitution, and also good results were obtained for aryl and aryl substitution. However, the methodology was not suitable for alkyl and alkyl substrates.

- Experimental evidences suggested that aromatic group in the nitroalkene interacts non-covalently with the aromatic moiety in the $\mathrm{N}$ substitution of the cinchoninium catalyst, probably $\pi-\pi$ stacking interactions. Having a hydroxyl group on position 9 of the catalyst was crucial for enantioselectivity, since alkylation with allyl bromide resulted in inversion of enantioselectivity. Those hypotheses were consistent with the computational calculations.

- Preparation of interesting heterocyclic compounds such as morpholinols, thiomorpholines, morpholines and benzoxazines from nitroepoxides was done, even though optical activity is lost when starting from optically pure nitroepoxides. 


\section{Experimental Section}

\section{General Information}

Unless otherwise specified, all reactions were carried out under nitrogen atmosphere with magnetic stirring. All solvents and reagents were obtained from commercial sources and were purified according to standard procedures before use. ${ }^{1} \mathrm{H}$ NMR spectra and ${ }^{13} \mathrm{C}$ NMR spectra were measured in $\mathrm{CDCl}_{3}\left({ }^{1} \mathrm{H}, 7.27 \mathrm{ppm} ;{ }^{13} \mathrm{C} 77.0 \mathrm{ppm}\right)$ solution at $30{ }^{\circ} \mathrm{C}$ on a $300 \mathrm{MHz}$ or a $500 \mathrm{MHz}$ NMR spectrometer. Mass spectra were measured in a QTOF I (quadrupole-hexapole-TOF) mass spectrometer with an orthogonal Z-spray-electrospray interface. EM Science Silica Gel 60 was used for column chromatography while TLC was performed with precoated plates (Kieselgel 60, $\mathrm{F}_{254}, 0.25 \mathrm{~mm}$ ).

Catalyst CD-1 was synthesized from cinchonidine following a procedure described by Corey, ${ }^{139}$ catalysts $\mathbf{C N}-\mathbf{1}, \mathbf{C N}-2$ and $\mathbf{C N}-3$ from cinchonine as described by Q. Meng, ${ }^{160}$ catalyst $\mathbf{C N}-4$ as described by Arai, ${ }^{135 b}$ catalyst $\mathbf{C N}-6$ as described by O'Donnell. ${ }^{161}$

\section{Experimental Procedures}

General Experimental Procedure for the Synthesis of Ammonium Salts Catalysts CN-5 and CN-8:

Following a modified experimental procedure: To a suspension of cinchonine $(0.71 \mathrm{mmol}, 1 \mathrm{eq})$ in $\mathrm{THF}(7.1 \mathrm{~mL})$ was added the corresponding bromide $(0.78 \mathrm{mmol}, 1.1 \mathrm{eq})$, and the mixture was stirred at reflux for $18 \mathrm{~h}$. The mixture was cooled to $23{ }^{\circ} \mathrm{C}$ and then, diethyl ether was added. The solid was filtered, washed with cold diethyl ether and the resulting slightly-colored solid was finally collected and dried under vacuum.

\footnotetext{
${ }^{160}$ Lian, M.; Li, Z.; Du, J.; Meng, Q.; Gao, Z.; Eur. J. Org. Chem. 2010, 6525-6530.

${ }^{161}$ O'Donnell, M.J.; Delgado, F.; Pottorf, R.S.; Tetrahedron 1999, 55, 6347
} 


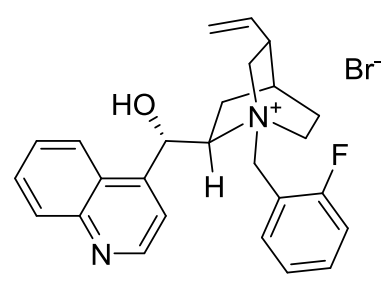

CN-5

$\mathrm{N}$-(2-fluorobenzil)cinchoninium bromide $\mathrm{CN}$ -

5: White solid (mp $225-228{ }^{\circ} \mathrm{C}$ ) (yield $\left.554 \mathrm{mg}, 92 \%\right)$. ${ }^{1} \mathrm{H}$ NMR (500 MHz, DMSO-d6) $\delta 9.00(\mathrm{~d}, J=4.4 \mathrm{~Hz}, 1 \mathrm{H}), 8.38(\mathrm{~d}, J=8.2 \mathrm{~Hz}, 1 \mathrm{H})$, $8.12(\mathrm{~d}, J=8.4 \mathrm{~Hz}, 1 \mathrm{H}), 7.85(\mathrm{dd}, J=14.5,5.9 \mathrm{~Hz}, 2 \mathrm{H}), 7.76(\mathrm{t}, J=7.6$ $\mathrm{Hz}, 1 \mathrm{H}), 7.68$ (dd, $J=13.7,5.8 \mathrm{~Hz}, 1 \mathrm{H}), 7.53-7.39$ (m, 2H), 6.87 (d, $J$ $=3.3 \mathrm{~Hz}, 1 \mathrm{H}), 6.54(\mathrm{~s}, 1 \mathrm{H}), 6.02(\mathrm{ddd}, J=17.4,10.5,7.1 \mathrm{~Hz}, 1 \mathrm{H}), 5.28$ $-5.18(\mathrm{~m}, 1 \mathrm{H}), 5.08(\mathrm{~s}, 1 \mathrm{H}), 4.28-4.18(\mathrm{~m}, 1 \mathrm{H}), 3.99$ (dd, $J=19.8$, $9.4 \mathrm{~Hz}, 2 \mathrm{H}), 3.37$ (t, $J=11.1 \mathrm{~Hz}, 1 \mathrm{H}), 3.18-3.05(\mathrm{~m}, 1 \mathrm{H}), 2.68(\mathrm{dd}, J$ $=17.2,8.1 \mathrm{~Hz}, 1 \mathrm{H}), 2.36-2.24(\mathrm{~m}, 1 \mathrm{H}), 1.93-1.71(\mathrm{~m}, 3 \mathrm{H}), 1.05$ (ddd, $J=13.7,9.1,4.9 \mathrm{~Hz}, 1 \mathrm{H}) \mathrm{ppm} .{ }^{13} \mathrm{C}$ NMR $\left(126 \mathrm{MHz}, \mathrm{DMSO}-\mathrm{d}_{6}\right)$ $\delta 162.2(\mathrm{~d}, J=249.3 \mathrm{~Hz}), 150.6(\mathrm{~d}, J=29.2 \mathrm{~Hz}), 148.1,145.4,137.6$, $137.4,136.3$ (d, $J=21.8 \mathrm{~Hz}), 130.3,127.8,127.5,125.8,125.5,124.9$, 124.2, 120.6, 120.5, 117.5, 116.6, 115.8, 115.7, 67.5 (d, $J=22.7 \mathrm{~Hz})$, $65.4(\mathrm{~d}, J=21.8 \mathrm{~Hz}), 56.4,37.3,37.1,26.5,23.5,21.1 \mathrm{ppm}$. HRMS (ESI) $\left[\mathrm{M}^{+}\right]$calcd for $\mathrm{C}_{26} \mathrm{H}_{28} \mathrm{FN}_{2} \mathrm{O}^{+} 403.2186$, found 403.2184; IR (KBr) $\delta 3607,3037,2966,1655,1418,1312,1028,909,770 \mathrm{~cm}^{-1}$

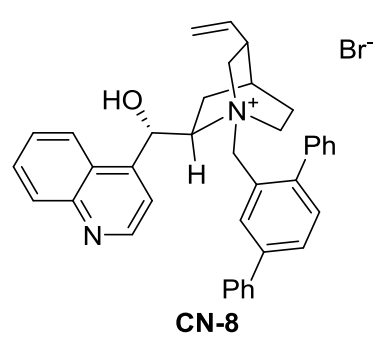

$\mathrm{N}$-(2,5-diphenylbenzil)cinchoninium bromide

CN-8: Orange solid (mp $180{ }^{\circ} \mathrm{C}$ ) (yield $\left.156 \mathrm{mg}, 92 \%\right) .{ }^{1} \mathrm{H}$ NMR (500 $\left.\mathrm{MHz}, \mathrm{CDCl}_{3}\right) \delta 8.67(\mathrm{~s}, 1 \mathrm{H}), 8.62(\mathrm{~s}, 1 \mathrm{H}), 8.39(\mathrm{~m}, 1 \mathrm{H}), 7.72-7.17(\mathrm{~m}$, 13H), $6.61(\mathrm{~s}, 1 \mathrm{H}), 6.40(\mathrm{~m}, 1 \mathrm{H}), 6.00(\mathrm{~m}, 1 \mathrm{H}), 5.77(\mathrm{br} \mathrm{s}, 1 \mathrm{H}), 5.53(\mathrm{~m}$, $1 \mathrm{H}), 5.01(\mathrm{~d}, \mathrm{~J}=10.5 \mathrm{~Hz}, 1 \mathrm{H}), 4.76(\mathrm{~d}, \mathrm{~J}=17.2 \mathrm{~Hz}, 1 \mathrm{H}), 3.00(\mathrm{~m}, 1 \mathrm{H})$, 
$3.48(\mathrm{~m}, 1 \mathrm{H}), 2.94(\mathrm{~s}, 1 \mathrm{H}), 2.68(\mathrm{~m}, 1 \mathrm{H}), 2.12(\mathrm{~s}, 1 \mathrm{H}), 1.80(\mathrm{~m}, 1 \mathrm{H})$, $1.59-1.44(\mathrm{~m}, 2 \mathrm{H}), 0.49(\mathrm{~m}, 1 \mathrm{H}) .{ }^{13} \mathrm{C} \mathrm{NMR}\left(75 \mathrm{MHz}, \mathrm{CDCl}_{3}\right) \delta 149.7$, 147.2, 145.2, 143.7, 140.4, 139.7, 138.6, 135.4, 134.4, 131.9, 129.8, $129.2,128.9,128.5,127.8,127.0,126.8,125.4,124.0,123.0,119.8$, 117.6, 65.2, 55.9, 54.0, 45.8, 37.7, 29.6, 26.8, 23.9, 21.5, 8.5 ppm; HRMS (ESI) $\left[\mathrm{M}^{+}\right]$calcd for $\mathrm{C}_{39} \mathrm{H}_{37} \mathrm{~N}_{2} \mathrm{O} 537.2906$, found 537.2906. IR $(\mathrm{KBr}) \delta 3339,3057,3029,2948,1715,1555,1495,1468,1354,1007$, $922,839,761,730 \mathrm{~cm}^{-1}$.

General Experimental Procedure for O-alkylation of Phase Transfer Catalysts for the Preparation of Catalysts, CN-6, CN-7 and CN-9:

To a suspension of the corresponding phase transfer catalyst $(0.11$ mmol, 1 eq) in $450 \mu 1$ of DCM was added allyl bromide $(0.33 \mathrm{mmol}, 3$ eq) and $30 \mu \mathrm{l}$ of $50 \%$ aqueous $\mathrm{KOH}(0.55 \mathrm{mmol})$. The resulting mixture was stirred vigorously at $23^{\circ} \mathrm{C}$ for $4 \mathrm{~h}$, during which time all of the solids dissolved. The mixture was diluted with $2 \mathrm{~mL}$ of water and was extracted with DCM $(3 \times 5 \mathrm{~mL})$. The combined organic extracts were dried over $\mathrm{Na}_{2} \mathrm{SO}_{4}$, filtered and concentrated in vacuo. Recrystallization of the residue from methanol-diethyl ether (diethyl ether was added dropwise until a solution of the product in methanol turned cloudy at $23^{\circ} \mathrm{C}$ ) at $-20^{\circ} \mathrm{C}$ to afford the pure compound.

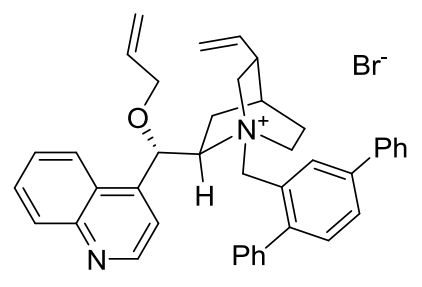

CN-9

$O$-allyl- $N$-(2,5-diphenylbenzil)cinchoninium bromide CN-9: Orange-brown solid (mp $\left.229{ }^{\circ} \mathrm{C}\right) ;{ }^{1} \mathrm{H} \mathrm{NMR}(300 \mathrm{MHz}$, $\left.\mathrm{CDCl}_{3}\right) \delta 9.14(\mathrm{~s}, 1 \mathrm{H}), 8.89(\mathrm{~d}, J=4.4 \mathrm{~Hz}, 3 \mathrm{H}), 8.11(\mathrm{~d}, J=8.2 \mathrm{~Hz}$, 2H), $7.92(\mathrm{~d}, J=7.2 \mathrm{~Hz}, 4 \mathrm{H}), 7.87-7.75(\mathrm{~m}, 4 \mathrm{H}), 7.59-7.33(\mathrm{~m}$, $19 \mathrm{H}), 6.51(\mathrm{~d}, J=11.7 \mathrm{~Hz}, 2 \mathrm{H}), 6.10(\mathrm{~s}, 2 \mathrm{H}), 5.81-5.45(\mathrm{~m}, 4 \mathrm{H}), 5.30$ 
$-5.12(\mathrm{~m}, 4 \mathrm{H}), 5.06(\mathrm{~d}, J=11.7 \mathrm{~Hz}, 4 \mathrm{H}), 4.92(\mathrm{~d}, J=17.0 \mathrm{~Hz}, 2 \mathrm{H})$, $4.61(\mathrm{~s}, 2 \mathrm{H}), 3.78(\mathrm{qd}, J=11.4,4.9 \mathrm{~Hz}, 4 \mathrm{H}), 3.36(\mathrm{dd}, J=16.0,6.1 \mathrm{~Hz}$, 2H), $3.28-3.05(\mathrm{~m}, 2 \mathrm{H}), 2.99-2.81(\mathrm{~m}, 2 \mathrm{H}), 2.36(\mathrm{dd}, J=15.7,7.8$ $\mathrm{Hz}, 2 \mathrm{H}), 2.29-2.09$ (m, 2H), $1.96-1.79$ (m, 3H), $1.16-0.97$ (m, 3H). ${ }^{13} \mathrm{C}$ NMR $\left(75 \mathrm{MHz}, \mathrm{CDCl}_{3}\right) \delta 149.7,147.3,145.2,143.8,140.5,139.8$, $138.6,135.4,134.4,131.9,129.8,129.3,128.9,128.6,127.8,127.0$, 126.8, 125.5, 124.1, 123.1, 119.9, 117.6, 77.20, 65.2, 56.0, 54.1, 45.8, 37.7, 29.7, 26.8, 23.9, 21.5. HRMS (ESI) $\left[\mathrm{M}^{+}\right]$calcd for $\mathrm{C}_{41} \mathrm{H}_{41} \mathrm{~N}_{2} \mathrm{O}^{+}$ 577.3219, found 577.3211. IR $(\mathrm{KBr}) \delta 3051,2980,2949,1585,1419$, $1259,1049,983,893,701,698 \mathrm{~cm}^{-1}$

\section{Experimental Procedure for the Preparation of Phenylnitromethane: ${ }^{162}$}<smiles>O=[N+]([O-])Cc1ccccc1</smiles>

To a solution of the benzyl alcohol $(5 \mathrm{~mL}, 47.3 \mathrm{mmol})$ in DCM (130 $\mathrm{mL}$ ) was added $\mathrm{NaNO}_{2}(11.7 \mathrm{~g}, 167.8 \mathrm{mmol})$. To this mixture was added acetic acid $(7 \mathrm{~mL})$ at room temperature and after 5 minutes, conc. $\mathrm{HCl}(2.4 \mathrm{~mL})$ was added to this mixture and it was left at r.t. without stirring for 6 hours. The reaction mixture was diluted with DCM $(150 \mathrm{~mL})$ and the precipitated NaOAc was filtered off. The organic phase was evaporated in vacuo and the residue was dissolved in hexane $(100 \mathrm{~mL})$ and washed with cold water $(5 \times 200 \mathrm{~mL})$ to remove the acid. The organic phase was dried over anhydrous sodium sulfate, filtered and finally concentrated in vacuo. The crude oil was purified by silica gel LC (hexanes-ethyl acetate, 9:1) to afford a yellow oil (3.4 g, $52 \%$ yield). ${ }^{1} \mathrm{H}$ NMR (500 MHz, $\left.\mathrm{CDCl}_{3}\right) \delta$ 7.49-7.42 (m, 5H), 5.45 (s, $2 \mathrm{H})$.

${ }^{162}$ Baruha, A.; Kalita, B.; Barua, N.C.; Synlett 2000, 7, 1064. 
General Experimental Procedure for the Preparation of Nitroalkenes: ${ }^{163,164}$

As described in Chapter 2 and the indicated bibliographic references.

General Experimental Procedure for the Preparation of Racemic Nitroepoxides:

Racemic epoxides were prepared as reported in Chapter $2{ }^{165}$

General Experimental Procedure for the Optimization of the Epoxidation Reaction:

$20 \mathrm{mg}$ of trans- $\beta$-methyl- $\beta$-nitrostyrene were placed in a small vial with a proper magnetic stirrer and solved with the indicated solvent. Then, the corresponding catalyst was added and the mixture stirred to homogenization. Finally, $\mathrm{NaOCl}$ solution was added and the mixture was constantly and vigorously stirred until consumption of nitroalkene. The reaction was stopped by addition of water, the crude extracted with DCM or EtOAc and concentrated under vacuum. The conversion was measured on ${ }^{1} \mathrm{H}$ NMR and the enantioselectivity on chiral HPLC using ChiralPak IA column (Hexane/i-PrOH 99/1, $1 \mathrm{~mL} / \mathrm{min}, 254 \mathrm{~nm}$ ), Rt $($ minor $)=8.5 \mathrm{~min}, \mathrm{Rt}_{2}$ (major) $=9.7 \mathrm{~min} ; \mathrm{er}=96.1: 3.9$

General Experimental Procedure for the Assymetric Synthesis of Nitroepoxides: ${ }^{166}$

To a cold solution $\left(-20^{\circ} \mathrm{C}\right)$ of the corresponding nitroalkene $(0.253$ mmol, 1 eq) and the phase transfer catalyst CN-2 $(0.020 \mathrm{mmol}, 8$ mol\%) in toluene $(840 \mu 1,0.3 \mathrm{M}), \mathrm{NaOCl}$ aqueous solution $(10-15 \%$ in $\mathrm{Cl}, 420 \mu \mathrm{l}$ ) was added dropwise and the mixture was vigorously stirred at $-20^{\circ} \mathrm{C}$ for 18 hours. Then, hexanes $(3 \mathrm{~mL})$ was added and the mixture

\footnotetext{
${ }^{163}$ Alizadeh, A.; Khodaei, M.M.; Eshghi, A. J. Org. Chem. 2010, 75, 8295.

${ }^{164}$ Anderson, J. C.; Blake, A. J.; Mills, M.; Ratcliffe, P. D.; Org. Lett. 2008, 10, 141.

165 Vankar, Y. D.; Shah, K.; Bawa, A.; Singh, S. P.; Tetrahedron 1991, 47, 8883.

${ }^{166}$ Lygo, B.; Crosby, J.; Lowdon, T. R.; Peterson, J. A.; Wainwright, P .G.

Tetrahedron 2001, 57, 2403.
} 
was filtered through an anhydrous $\mathrm{MgSO}_{4}$ pad, washed with an extra amount of hexane, and the filtered solution was concentrated under vacuum to afford the pure nitroepoxide, which was stored at $-20^{\circ} \mathrm{C}$ to solidification.<smiles>CC1([N+](=O)[O-])OC1c1ccccc1</smiles>

(2S,3R)-2-Methyl-2-nitro-3-phenyloxirane 13a. The product obtained was a pale yellow oil which crystallized when stored at $-20^{\circ} \mathrm{C}$ as a white solid $\left(\mathrm{mp}=82-85^{\circ} \mathrm{C}\right)$ (yield $\left.42 \mathrm{mg}, 92 \%\right) .[\alpha]_{\mathrm{D}}{ }^{23}$ $+72.0\left(\mathrm{c}=1.2, \mathrm{CHCl}_{3}\right) .{ }^{1} \mathrm{H} \mathrm{NMR}\left(500 \mathrm{MHz}, \mathrm{CDCl}_{3}\right) \delta 7.41(\mathrm{~m}, 3 \mathrm{H})$, $7.30(\mathrm{~m}, 2 \mathrm{H}), 4.56(\mathrm{~s}, 1 \mathrm{H}), 1.78(\mathrm{~s}, 3 \mathrm{H}) ;{ }^{13} \mathrm{C} \mathrm{NMR}\left(126 \mathrm{MHz}, \mathrm{CDCl}_{3}\right) \delta$ 131.0, 129.3, 128.7, 126.3, 88.8, 62.6, 12.2 ppm; HRMS (EI) calcd for $\mathrm{C}_{9} \mathrm{H}_{9} \mathrm{NO}_{3}(\mathrm{M}) 179.0582$, found 179.0587; IR (KBr) $\delta 3062,3028,2948$, $1555,1495,1448,1354,1158,1105,982,899 \mathrm{~cm}^{-1}$. Enantiomers were separated by GC/MS Cyclosil-B chiral capillar column (He carrier gas, $1 \mathrm{~mL} / \mathrm{min}), \mathrm{Rt}_{1}($ minor $)=11.2 \mathrm{~min}, \mathrm{Rt}_{2}($ major $)=11.7 \mathrm{~min}$; er $=$ 96.6:3.4.<smiles>CC1([N+](=O)[O-])OC1c1ccc(F)cc1</smiles>

3-(4-Fluorophenyl)-2-methyl-2-nitrooxirane $13 \mathrm{~b}$.

The product obtained was a colorless oil which crystallized when stored at $-20^{\circ} \mathrm{C}$ as a white solid $\left(\mathrm{mp}=60-63{ }^{\circ} \mathrm{C}\right.$ ) (yield $48 \mathrm{mg}, 96 \%$ ). $[\alpha]_{\mathrm{D}}{ }^{23}+68.0\left(\mathrm{c}=1.2, \mathrm{CHCl}_{3}\right) .{ }^{1} \mathrm{H} \mathrm{NMR}\left(300 \mathrm{MHz}, \mathrm{CDCl}_{3}\right) \delta 7.33-7.26$ (m, 2H), 7.13-7.05 (m, 2H), $4.51(\mathrm{~s}, 1 \mathrm{H}), 1.76(\mathrm{~s}, 3 \mathrm{H}) ;{ }^{13} \mathrm{C}$ NMR $(75$ $\left.\mathrm{MHz}, \mathrm{CDCl}_{3}\right) \delta 163.2(\mathrm{~d}, \mathrm{~J}=247.8 \mathrm{~Hz}), 128.3(\mathrm{~d}, \mathrm{~J}=8.4 \mathrm{~Hz}), 126.8(\mathrm{~d}$, $\mathrm{J}=4.0 \mathrm{~Hz}$ ), $115.8(\mathrm{~d}, \mathrm{~J}=22.0 \mathrm{~Hz}), 88.8,62.1,12.1$ ppm; HRMS (EI) calcd for $\mathrm{C}_{9} \mathrm{H}_{8} \mathrm{NFO}_{3}(\mathrm{M}) 197.0488$, found 197.0492. IR (KBr) $\delta 3059$, 3024, 2944, 1546, 1490, 1452, 1205, 896, $830 \mathrm{~cm}^{-1}$. HPLC: ChiralPak IA (Hexane $/ i$-PrOH 500/1, $1 \mathrm{~mL} / \mathrm{min}, 254 \mathrm{~nm}$ ), $\mathrm{Rt}_{1}($ minor $)=14.5 \mathrm{~min}$, $\mathrm{Rt}_{2}$ (major) $=17.5 \mathrm{~min} ; \mathrm{er}=96.1: 3.9$. 
<smiles>CC1([N+](=O)[O-])OC1c1ccc(Cl)cc1</smiles>

3-(4-Chlorophenyl)-2-methyl-2-nitrooxirane $13 \mathrm{c}$. The product obtained was an orange solid $\left(\mathrm{mp}=50-56{ }^{\circ} \mathrm{C}\right.$ ) (yield 50 $\mathrm{mg}, 92 \%) \cdot[\alpha]_{\mathrm{D}}^{23}+71.0\left(\mathrm{c}=2.0, \mathrm{CHCl}_{3}\right) .{ }^{1} \mathrm{H} \mathrm{NMR}\left(300 \mathrm{MHz}, \mathrm{CDCl}_{3}\right)$ $\delta 7.39(\mathrm{~d}, J=8.5 \mathrm{~Hz}, 2 \mathrm{H}), 7.25(\mathrm{~d}, J=8.4 \mathrm{~Hz}, 2 \mathrm{H}), 4.51(\mathrm{~s}, 2 \mathrm{H}), 1.77$ (s, 3H) ppm. ${ }^{13} \mathrm{C}$ NMR (75 MHz, $\left.\mathrm{CDCl}_{3}\right) \delta 135.47,129.47,129.02$, 127.74, 88.60, 61.95, 12.30 ppm; IR (KBr) $\delta 3052,2984,1560,1420$, 1259, 894, $697 \mathrm{~cm}^{-1}$. LRMS (EI): Mass calcd for $\mathrm{C}_{9} \mathrm{H}_{8} \mathrm{ClO}\left[\mathrm{M}-\mathrm{NO}_{2}\right]^{+}$: 167.0; found 167.1, Mass calcd for $\mathrm{C}_{6} \mathrm{H}_{4} \mathrm{Cl}\left[\mathrm{M}-\mathrm{C}_{3} \mathrm{H}_{4} \mathrm{NO}_{3}\right]^{+}$: 111.0; found 111.0. HPLC: ChiralPak IA (Hexanes/i-PrOH 500/1, $1 \mathrm{~mL} / \mathrm{min}$, $254 \mathrm{~nm}), \mathrm{Rt}_{1}($ minor $)=15.4 \mathrm{~min}, \mathrm{Rt}_{2}($ major $)=19.2 \mathrm{~min}$; er $=97: 3$.<smiles>CC1([N+](=O)[O-])OC1c1cccc(Cl)c1</smiles>

3-(3-Chlorophenyl)-2-methyl-2-nitrooxirane 13d. The product obtained was a yellow oil which crystallized when stored at $-20{ }^{\circ} \mathrm{C}$ as a yellow solid $\left(\mathrm{mp}=38-42{ }^{\circ} \mathrm{C}\right.$ ) (yield $\left.47 \mathrm{mg}, 87 \%\right)$. $[\alpha]_{\mathrm{D}}{ }^{23}$ $+80.0\left(\mathrm{c}=1.0, \mathrm{CHCl}_{3}\right) .{ }^{1} \mathrm{H}$ NMR $\left(500 \mathrm{MHz}, \mathrm{CDCl}_{3}\right) \delta 7.42-7.34(\mathrm{~m}$, 1H), $7.31(\mathrm{~s}, 1 \mathrm{H}), 7.22(\mathrm{~d}, J=6.9 \mathrm{~Hz}, 1 \mathrm{H}), 4.53(\mathrm{~s}, 1 \mathrm{H}), 1.80(\mathrm{~s}, 2 \mathrm{H})$. ${ }^{13} \mathrm{C}$ NMR $\left(126 \mathrm{MHz}, \mathrm{CDCl}_{3}\right) \delta 134.97,133.03,130.12,129.66,126.46$, $124.59,88.54,61.72,12.40$; IR (KBr) $\delta 3052,2982,1559,1419,1259$, 893, 700, $698 \mathrm{~cm}^{-1}$. LRMS (EI): Mass calcd for $\mathrm{C}_{9} \mathrm{H}_{8} \mathrm{ClO}\left[\mathrm{M}-\mathrm{NO}_{2}\right]^{+}$: 167.0; found 167.0, mass calcd for $\mathrm{C}_{6} \mathrm{H}_{4} \mathrm{Cl}\left[\mathrm{M}-\mathrm{C}_{3} \mathrm{H}_{4} \mathrm{NO}_{3}\right]^{+}$: 111.0; found 111.0 ; HPLC: ChiralPak IA (Hexane $/ i-\mathrm{PrOH}$ 99/1, $1 \mathrm{~mL} / \mathrm{min}$, $254 \mathrm{~nm}), \mathrm{Rt}_{1}($ minor $)=9.0 \mathrm{~min}, \mathrm{Rt}_{2}($ major $)=13.0 \mathrm{~min}$; er $=91.5: 8.5$.<smiles>CCC1([N+](=O)[O-])OC1c1ccc(F)cc1</smiles>

2-Ethyl-3-(4-fluorophenyl)-2-nitrooxirane 13 e. The product obtained was a pale yellow oil which crystallized when stored at $-20^{\circ} \mathrm{C}$ as a pale yellow solid $\left(\mathrm{mp}=30-37{ }^{\circ} \mathrm{C}\right.$ ) (yield $49 \mathrm{mg}$, $91 \%) \cdot[\alpha]_{\mathrm{D}}^{23}+32.3\left(\mathrm{c}=1.3, \mathrm{CHCl}_{3}\right) .{ }^{1} \mathrm{H}$ NMR $\left(300 \mathrm{MHz}, \mathrm{CDCl}_{3}\right) \delta$ 
7.37-7.19 (m, 2H), $7.10(\mathrm{t}, \mathrm{J}=8.6 \mathrm{~Hz}, 2 \mathrm{H}), 4.49(\mathrm{~s}, 1 \mathrm{H}), 2.45$ (dq, J = 15.1, 7.4 Hz, 1H), 1.67 (dq, J = 14.8, 7.3 Hz, 1H), 1.05 (t, J = 7.4 Hz, $3 \mathrm{H}) .{ }^{13} \mathrm{C}$ NMR $\left(75 \mathrm{MHz}, \mathrm{CDCl}_{3}\right) \delta 163.2(\mathrm{~d}, \mathrm{~J}=247.5 \mathrm{~Hz}), 128.2(\mathrm{~d}, \mathrm{~J}$ $=8.3 \mathrm{~Hz}), 127.0(\mathrm{~d}, \mathrm{~J}=2.3 \mathrm{~Hz}), 115.9(\mathrm{~d}, \mathrm{~J}=21.8 \mathrm{~Hz}), 92.37,62.62$, 19.44, 7.53 ppm; HRMS (EI) calcd for $\mathrm{C}_{10} \mathrm{H}_{10} \mathrm{FNO}_{3}$ (M) 211.0645, found 211.0651; IR (KBr) $\delta 3052$, 2979, 1710, 1606, 1552, 1510, 1347, 1227,1156 $\mathrm{cm}^{-1}$. HPLC: ChiralPak IA (Hexane/i-PrOH 500/1, 1 $\mathrm{mL} / \mathrm{min}, 254 \mathrm{~nm}), \mathrm{Rt}_{1}($ minor $)=11.9 \min , \mathrm{Rt}_{2}($ major $)=12.8 \mathrm{~min} ; \mathrm{er}=$ 95.1:4.9.<smiles>Cc1ccc(C2OC2(C)[N+](=O)[O-])cc1</smiles>

2-Methyl-2-nitro-3-(p-tolyl)oxirane 13f. The product obtained was a yellow oil which crystallized when stored at $20^{\circ} \mathrm{C}$ as a white solid $\left(\mathrm{mp}=65-67^{\circ} \mathrm{C}\right.$ ) (yield $\left.45 \mathrm{mg}, 92 \%\right) .[\alpha]_{\mathrm{D}}{ }^{22}+82.5$ $\left(\mathrm{c}=0.8, \mathrm{CHCl}_{3}\right) .{ }^{1} \mathrm{H} \mathrm{NMR}\left(500 \mathrm{MHz}, \mathrm{CDCl}_{3}\right) \delta 7.26-7.17(\mathrm{~m}, 4 \mathrm{H})$, $4.50(\mathrm{~s}, 1 \mathrm{H}), 2.38(\mathrm{~s}, 3 \mathrm{H}), 1.80(\mathrm{~s}, 3 \mathrm{H}) ;{ }^{13} \mathrm{C} \mathrm{NMR}\left(75 \mathrm{MHz}, \mathrm{CDCl}_{3}\right) \delta$ 139.6, 129.5, 128.0, 126.4, 89.1, 62.8, 21.1, 12.4 ppm; HRMS (EI) calcd for $\mathrm{C}_{10} \mathrm{H}_{11} \mathrm{NO}_{3}(\mathrm{M})$ 193.0739, found 193.0745; IR (KBr) $\delta 3062$, 3025, 2948, 1552, 1449, 1346, 1158, 899, $768 \mathrm{~cm}^{-1}$. HPLC: ChiralPak IA (Hexane/i-PrOH 99/1, $1 \mathrm{~mL} / \mathrm{min}, 254 \mathrm{~nm}$ ), $\mathrm{Rt}_{1}$ (major) $=7.1 \mathrm{~min}$, $\mathrm{Rt}_{2}$ (minor) $=8.0$ min; er $=91.3: 8.7$.<smiles>O=[N+]([O-])C1(c2ccccc2)OC1c1ccccc1</smiles>

2-Nitro-2,3-diphenyloxirane 13g. The product obtained was a pale yellow solid $\left(\mathrm{mp}=65-70{ }^{\circ} \mathrm{C}\right.$ ) (yield $55 \mathrm{mg}, 90 \%$ ); $[\alpha]_{\mathrm{D}}^{22}-64.0\left(\mathrm{c}=0.8, \mathrm{CHCl}_{3}\right) . \quad 1 \mathrm{H} \mathrm{NMR}\left(500 \mathrm{MHz}, \mathrm{CDCl}_{3}\right) \delta 7.54-$ $7.31(\mathrm{~m}, 5 \mathrm{H}), 7.29-7.16(\mathrm{~m}, 3 \mathrm{H}), 7.05(\mathrm{~d}, \mathrm{~J}=7.8 \mathrm{~Hz}, 2 \mathrm{H}), 4.78(\mathrm{~s}$, 1H). 13C NMR (126 MHz, $\left.\mathrm{CDCl}_{3}\right) \delta 134.72,131.06,130.61,130.54$, 130.37, 129.40, 129.34, 128.67, 128.36, 128.27, 126.90, 126.36, 91.68, 63.79. IR (KBr) $\delta 3051,2983,2300,1642,1419,1258,893,789,697$ cm-1 LRMS (EI): $\mathrm{C}_{14} \mathrm{H}_{11} \mathrm{NO}_{2}[\mathrm{M}-\mathrm{O}]^{+}:$225.1; found 225.1, Mass calcd 
for $\mathrm{C}_{14} \mathrm{H}_{11} \mathrm{O}\left[\mathrm{M}-\mathrm{NO}_{2}\right]^{+}:$195.1; found 195.0, Mass calcd for $\mathrm{C}_{6} \mathrm{H}_{5}$ [M$\left.\mathrm{C}_{8} \mathrm{H}_{6} \mathrm{NO}_{3}\right]^{+}:$77.0; found 77.1. Absolute configuration was assigned by X-Ray crystall resolution. HPLC: ChiralPak IA (Hexane/i-PrOH 99/1, $1 \mathrm{~mL} / \mathrm{min}, 254 \mathrm{~nm})$, Rt1 (major) $=8.7 \mathrm{~min}$, Rt2 $($ minor $)=9.9 \mathrm{~min}$; er $=$ 91.5:8.5.

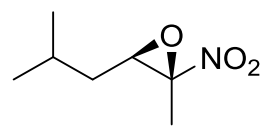

3-Isobutyl-2-methyl-2-nitrooxirane 13h. Yellowish oil (yield $25 \mathrm{mg}, 63 \%)$. 1H NMR (300 MHz, $\left.\mathrm{CDCl}_{3}\right) \delta 3.33$ (dd, $\mathrm{J}=$ 6.8, $5.3 \mathrm{~Hz}, 1 \mathrm{H}), 1.80(\mathrm{~s}, 3 \mathrm{H}), 1.72-1-85(\mathrm{~m}, 1 \mathrm{H}), 1.52-1.31(\mathrm{~m}, 2 \mathrm{H})$, $0.90(\mathrm{~d}, \mathrm{~J}=6.7 \mathrm{~Hz}, 3 \mathrm{H}), 0.89$ (d, J = 6.6 Hz, 3H); 13C NMR (75 MHz, $\left.\mathrm{CDCl}_{3}\right) \delta 87.6,62.0,36.1,26.0,22.3,22.2,13.4$ ppm; HRMS (EI) calcd for $\mathrm{C}_{7} \mathrm{H}_{13} \mathrm{NO}_{3}$ (M) 159.0895, found 159.0901; IR (KBr) $\delta 2940$, 1561, $1167 \mathrm{~cm}^{-1}$. HPLC: ChiralPak IA (Hexane $/ i$-PrOH 99/1, $1 \mathrm{~mL} / \mathrm{min}$, $254 \mathrm{~nm}), \mathrm{Rt}_{1}($ minor $)=5.6 \mathrm{~min}, \mathrm{Rt}_{2}($ major $)=6.6 \mathrm{~min}$; er $=56.5: 43.5$.

\section{Experimental Procedure for the Preparation of Morpholinol 16:}

To an ice-bath cold solution of the corresponding nitroepoxide $(0.56$ $\mathrm{mmol})$ in $\mathrm{MeOH}(1 \mathrm{~mL}), \mathrm{N}$-methyl 2-ethanolamine ( $90 \mu \mathrm{L} ; 1.12 \mathrm{mmol})$ was added. The resulting mixture was stirred for 3.5 hours at room temperature, then $\mathrm{H}_{2} \mathrm{O}(5 \mathrm{~mL})$ was added, extracted with EtOAc $(3 \mathrm{x}$ $20 \mathrm{~mL}$ ), washed with brine $(20 \mathrm{~mL})$, dried with $\mathrm{Na}_{2} \mathrm{SO}_{4}$ and concentrated under vacuum. The resulting crude oil was purified through silica flash liquid chromatography with hexanes/EtOAc (1:1), EtOAc and EtOAc/MeOH (9:1) to afford desired product.

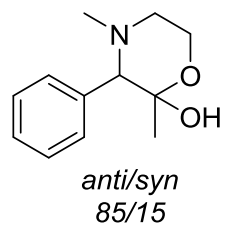

2,4-dimethyl-3-phenylmorpholin-2-ol, 16. white solid, $101 \mathrm{mg}$ (yield $87 \%$ ) mp 64-66 ${ }^{\circ} \mathrm{C}:{ }^{1} \mathrm{H}$ NMR $\left(300 \mathrm{MHz}, \mathrm{CDCl}_{3}\right) \delta 7.49$ -7.27 (m, 5H), 5.29 (s, 1H), 4.23 (ddd, J = 15.4, 8.8, 2.6 Hz, 1H), 3.68 
(ddd, J = 12.0, 4.0, $1.1 \mathrm{~Hz}, 1 \mathrm{H}), 3.07$ (s, 1H), 2.87 (ddd, $\mathrm{J}=11.6,2.9$, $1.0 \mathrm{~Hz}, 1 \mathrm{H}), 2.50$ (ddd, J = 12.5, 11.7, $4.0 \mathrm{~Hz}, 1 \mathrm{H}), 2.04$ (s, 3H), 1.10 (s, $3 \mathrm{H}) .{ }^{13} \mathrm{C}$ NMR $\left(126 \mathrm{MHz}, \mathrm{CDCl}_{3}\right) \delta 137.53,128.04,127.85,95.69$, 77.24, 59.44, 56.15, 44.15, 25.03. HRMS (ESI) calcd. for $\mathrm{C}_{12} \mathrm{H}_{18} \mathrm{NO}_{2}{ }^{+}$ $[\mathrm{M}+\mathrm{H}]^{+}$208.1338, found $[\mathrm{M}+\mathrm{H}]^{+}$208.1335; IR (KBr) $\delta 3500,3049$, $2985,1601 \mathrm{~cm}^{-1}$;

\section{Experimental Procedure for the Preparation of Thiomorpholines} 18 and 19.

2-Amino-ethanothiol hydrochloride $(55 \mathrm{mg}, 0.47 \mathrm{mmol})$ was solved with a solution of $\mathrm{KOH}(53 \mathrm{mg}, 0.95 \mathrm{mmol})$ in $\mathrm{EtOH}(1.2 \mathrm{~mL})$ at $0^{\circ} \mathrm{C}$ and under inert conditions. To this mixture, a previously purged solution of nitroepoxide 1a $(85 \mathrm{mg}, 0.47 \mathrm{mmol})$ in dry EtOH $(0.4 \mathrm{~mL})$ was added and the mixture was stirred below $5^{\circ} \mathrm{C}$ until consumption of nitroepoxide (ca. $3 \mathrm{~h}$ ). Then, solid $\mathrm{NaBH}_{4}(37 \mathrm{mg}, 0.95 \mathrm{mmol}$ ) was added to the cold mixture and kept stirring for $1.5 \mathrm{~h}$. Then, the reaction mixture was quenched with $5 \%$ aqueous solution of $\mathrm{NH}_{4} \mathrm{Cl}(5 \mathrm{~mL})$ and extracted with dichloromethane $(3 \times 10 \mathrm{~mL})$, the combined organic phases washed with brine, dried over $\mathrm{MgSO}_{4}$, filtered and finally concentrated under vacuum to afford a yellow oil. The crude was purified by silica flash LC eluting sequentially with EtOAc/MeOH 9:1 to 7:3 to afford 3-methyl-2-phenylthiomorpholine, $\mathbf{1 8}$ as a pale yellow solid, $26 \mathrm{mg}$ (28\% yield):<smiles>CC1NCCSC1c1ccccc1</smiles>

trans-3-methyl-2-phenylthiomorpholine 18. ${ }^{1} \mathrm{H}$ NMR $\left(300 \mathrm{MHz}, \mathrm{CDCl}_{3}\right) \delta 7.42-7.27(\mathrm{~m}, 5 \mathrm{H}), 3.60(\mathrm{~d}, J=9.6 \mathrm{~Hz}, 1 \mathrm{H})$, $3.44(\mathrm{dt}, J=12.0,2.7 \mathrm{~Hz}, 1 \mathrm{H}), 3.25-3.12(\mathrm{~m}, 2 \mathrm{H}), 3.10-2.98(\mathrm{~m}$, $1 \mathrm{H}), 2.63(\mathrm{bs}, 1 \mathrm{H}), 2.59-2.50(\mathrm{~m}, 1 \mathrm{H}), 0.91(\mathrm{t}, J=6.8 \mathrm{~Hz}, 3 \mathrm{H}) .{ }^{13} \mathrm{C}$ NMR $\left(75 \mathrm{MHz}, \mathrm{CDCl}_{3}\right) \delta 139.7,128.6,128.2,127.6,58.1,52.0,48.0$, 30.1, $20.5 \mathrm{ppm}$. MS (EI) calcd. for $\mathrm{C}_{11} \mathrm{H}_{15} \mathrm{NS}^{+}[\mathrm{M}]^{+}$193.1, found 193.1 IR (KBr) 3360, 3032, 2940, 1574, 1404, 1268, 1070, $707 \mathrm{~cm}^{-1}$; 
and then, compound $\mathbf{1 9}$ as a yellow oil:<smiles>CC1SCCNC1c1ccccc1</smiles>

2-methyl-3-phenylthiomorpholine $19{ }^{1} \mathrm{H}$ NMR (400 $\left.\mathrm{MHz}, \mathrm{CDCl}_{3}\right) \delta 7.40-7.14(\mathrm{~m}, 10 \mathrm{H}), 4.16(\mathrm{dd}, J=8.3,1.7 \mathrm{~Hz}, 1 \mathrm{H})$ (minor), $4.06(\mathrm{~d}, J=3.2 \mathrm{~Hz}, 1 \mathrm{H})$ (major), $3.49(\mathrm{qd}, J=6.6,3.3 \mathrm{~Hz}, 1 \mathrm{H})$ (major), $3.32-3.24(\mathrm{~m}, 1 \mathrm{H}), 3.14-3.05(\mathrm{~m}, 1 \mathrm{H}), 2.90(\mathrm{~m}, 3 \mathrm{H}), 2.84-$ $2.68(\mathrm{~m}, 4 \mathrm{H}), 1.07$ (d, $J=6.7 \mathrm{~Hz}, 1 \mathrm{H})$ (major), $0.91(\mathrm{~d}, J=6.4 \mathrm{~Hz}, 1 \mathrm{H})$ (minor). ${ }^{13} \mathrm{C}$ NMR $\left(75 \mathrm{MHz}, \mathrm{CDCl}_{3}\right) \delta 141.9,128.3,127.8,127.2$, 127.0, 77.7, 77.2, 60.1, 54.3, 48.2, 45.2, 42.5, 39.1, 27.2, 16.6, 15.4 ppm; MS (EI) calcd. for $\mathrm{C}_{11} \mathrm{H}_{15} \mathrm{NS}^{+}[\mathrm{M}]^{+} 193.1$, found $193.1 \mathrm{IR}$ (KBr) 3307, 3022, 2918, 1595, 1448, 1268, 1024, $707 \mathrm{~cm}^{-1}$ 



\section{General Conclusions}

and Futunre Work 



\section{General Conclusions and Future Work}

The general conclusions that can be obtained from the work of the present $\mathrm{PhD}$ Thesis are detailed as follow:

- The singular reactivity of nitroepoxides has been studied.

- An easily accessible methodology for the synthesis of 1,4diazaheterocyclic compounds, including quinoxalines, pyrazines tetrahydroquinoxalines and piperazines, from nitroepoxides has been developed.

- Advances in the enantioselective epoxidation of dicyanoalkylidenes via bifunctional organocatalysts were made during a 4-month stay at Università degli Studi di Salerno (Italy).

- The enantioselective synthesis of nitroepoxides, mediated by phase transfer catalysis, has been achieved with high yields and enantioselectivities (e.r. > 90:10) for the substrates with aryl-alkyl substitution. Currently, the work is under review in a scientific journal.

- Nitroepoxides have been transformed into morpholinols and thiomorpholines. However, optical activity of the nitroepoxide was lost after the transformation.

We think there is still place to study further the reactivity of nitroepoxides and develop new applications. A brief summary of the ongoing work:

- Develop new synthetical applications of nitroepoxides without loss of optical activity.

- Exploit the chemical features of nitroepoxides for the synthesis of new heterocycles in a simple and accessible methodology.

- Study the behaviour of the reaction between nitroepoxides and amines for the synthesis of 1,2-diamines, starting from optically pure nitroepoxides. 

Selected Spectra 



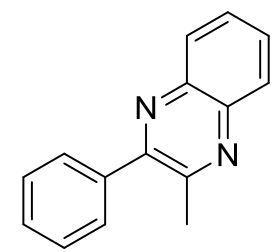

$2 a$
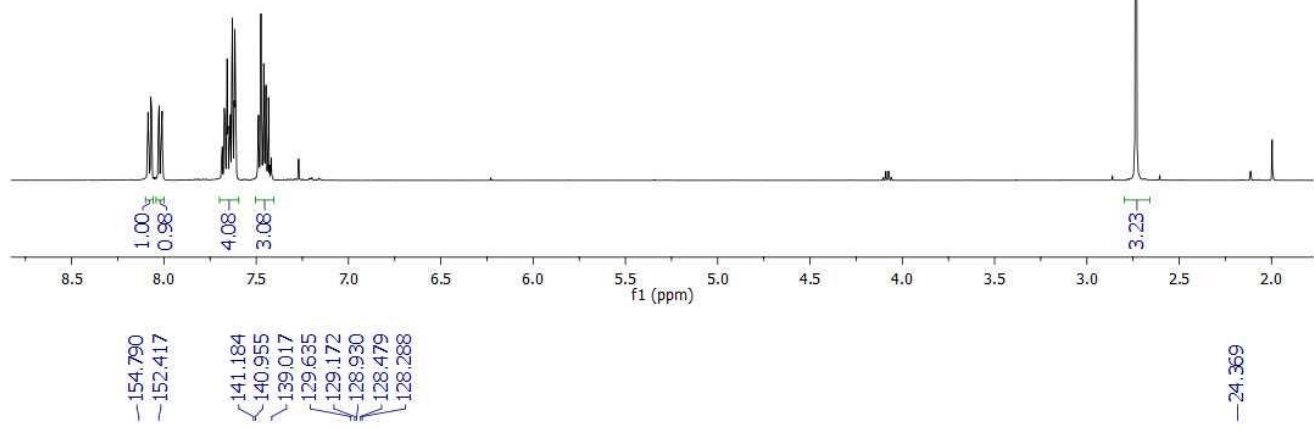

蛋

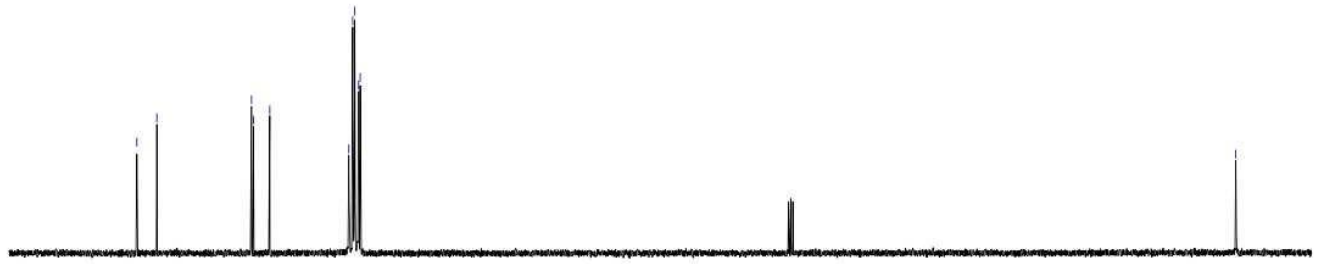

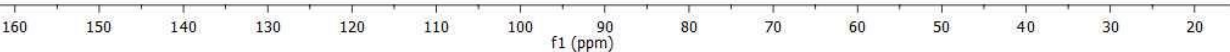



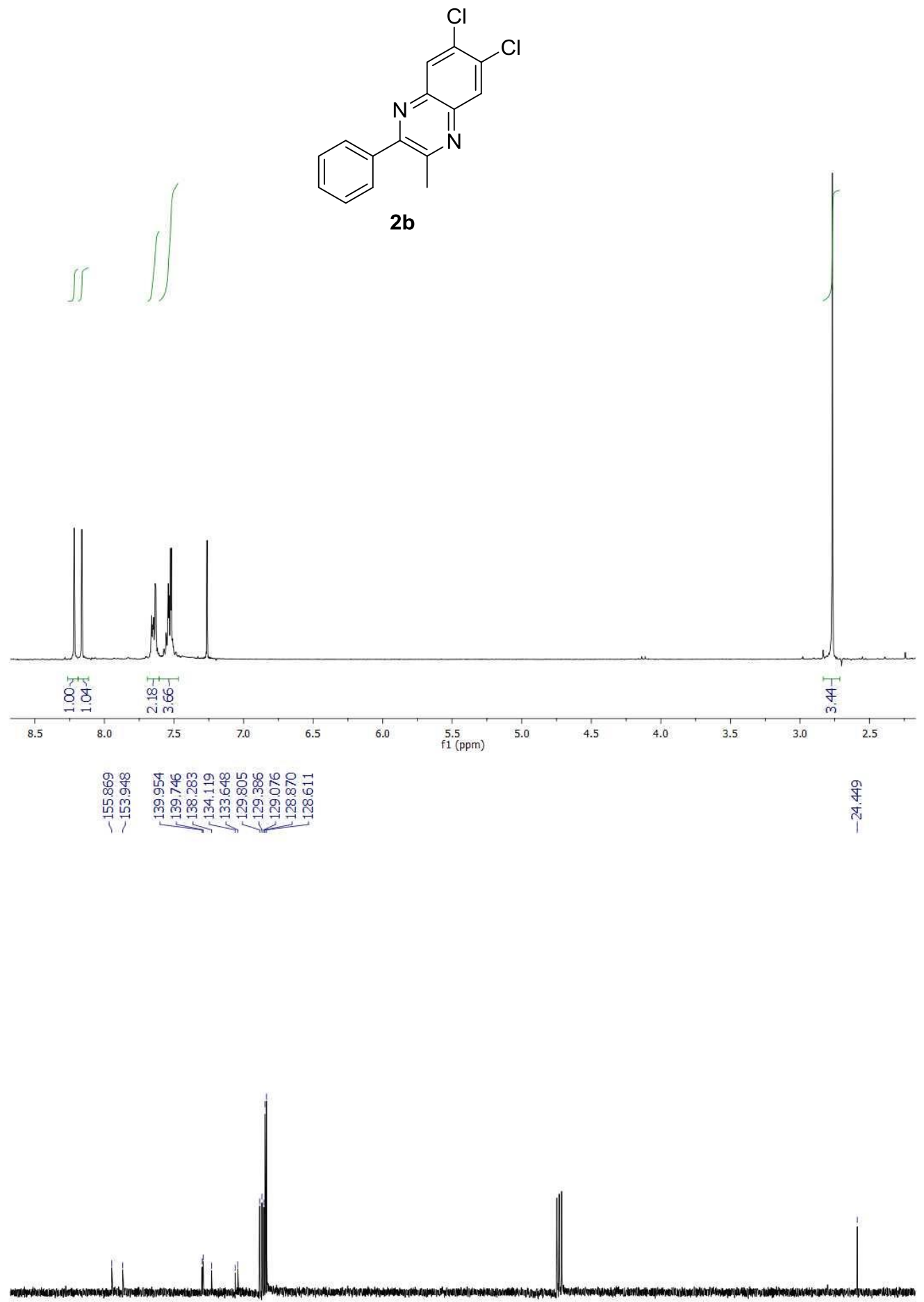

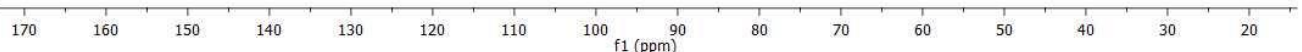



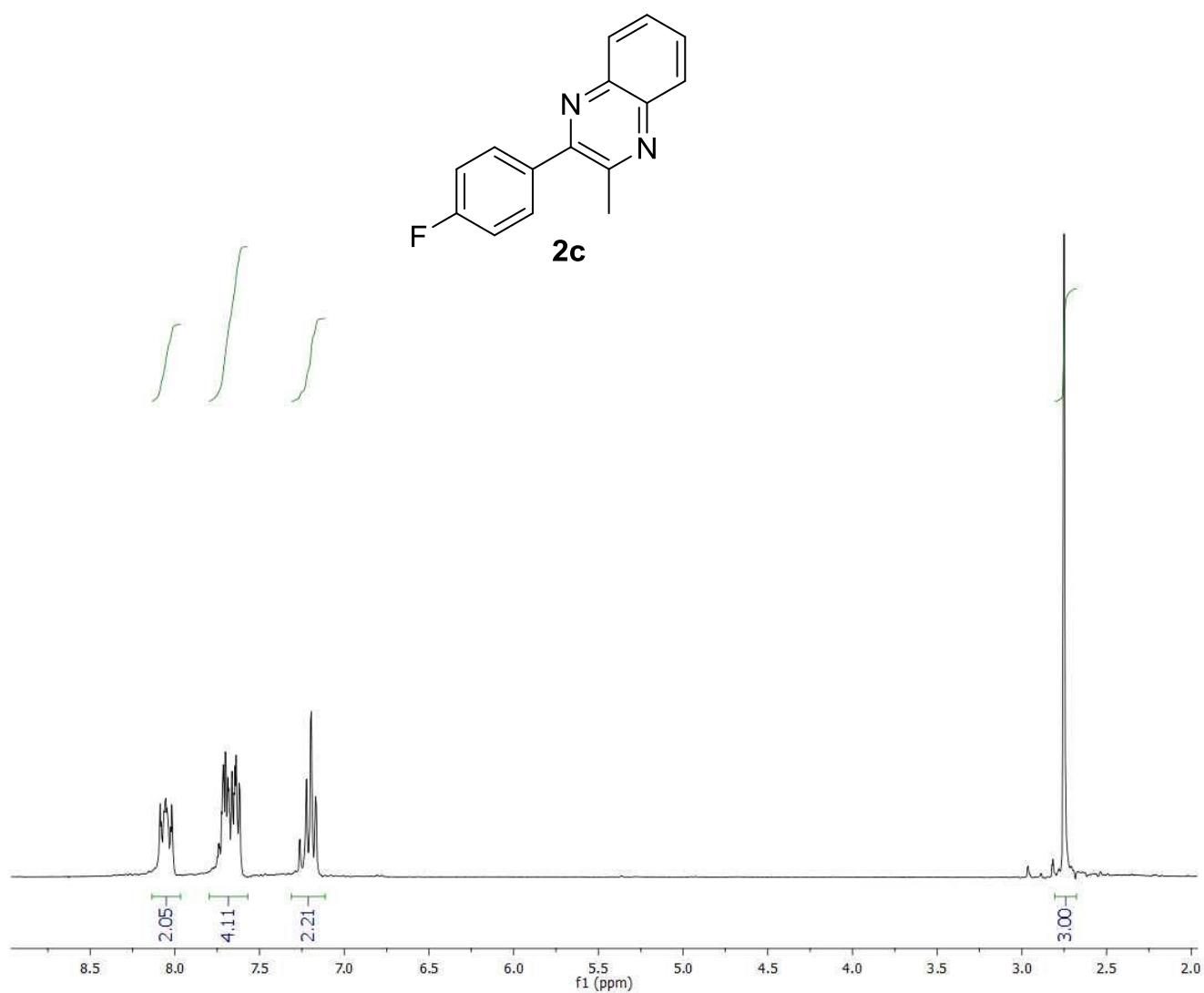

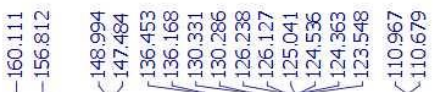

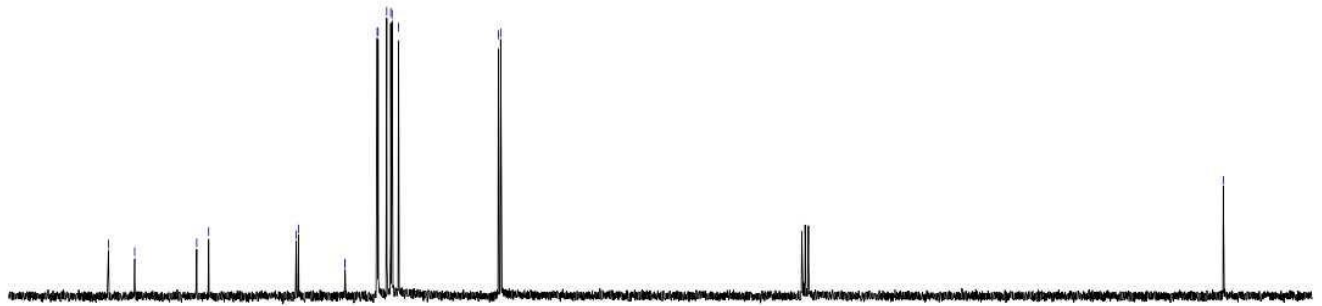



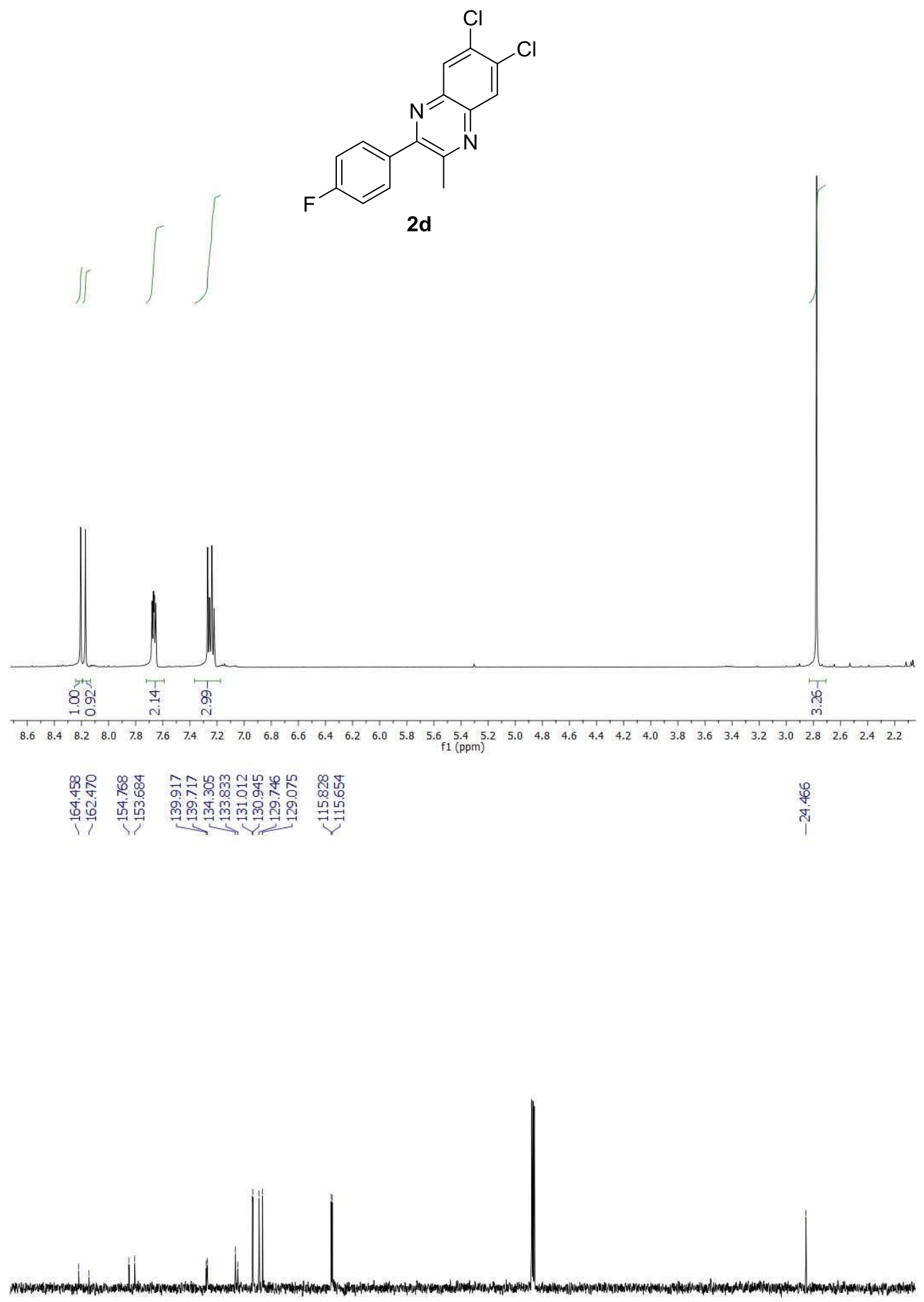

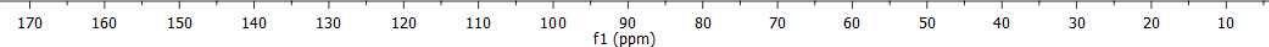


<smiles>Cc1ccc(-c2nc3ccccc3nc2C)cc1</smiles>
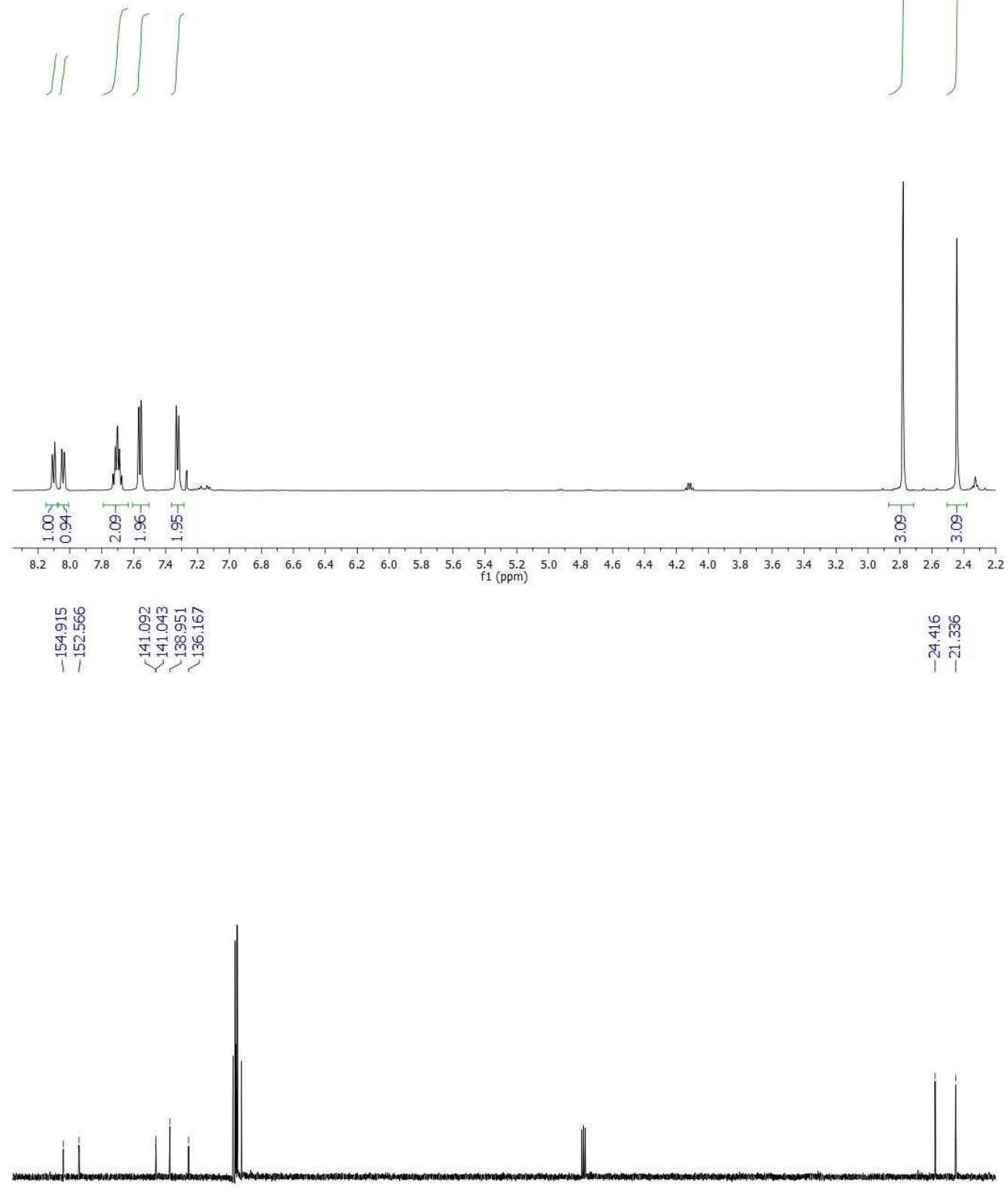

$\begin{array}{llllllllllllllllllllllllllllllllll}160 & 155 & 150 & 145 & 140 & 135 & 130 & 125 & 120 & 115 & 110 & 105 & 100 & 95 & 90 & 85 & 80 & 75 & 70 & 65 & 60 & 55 & 50 & 45 & 40 & 35 & 30 & 25 & 20\end{array}$ 

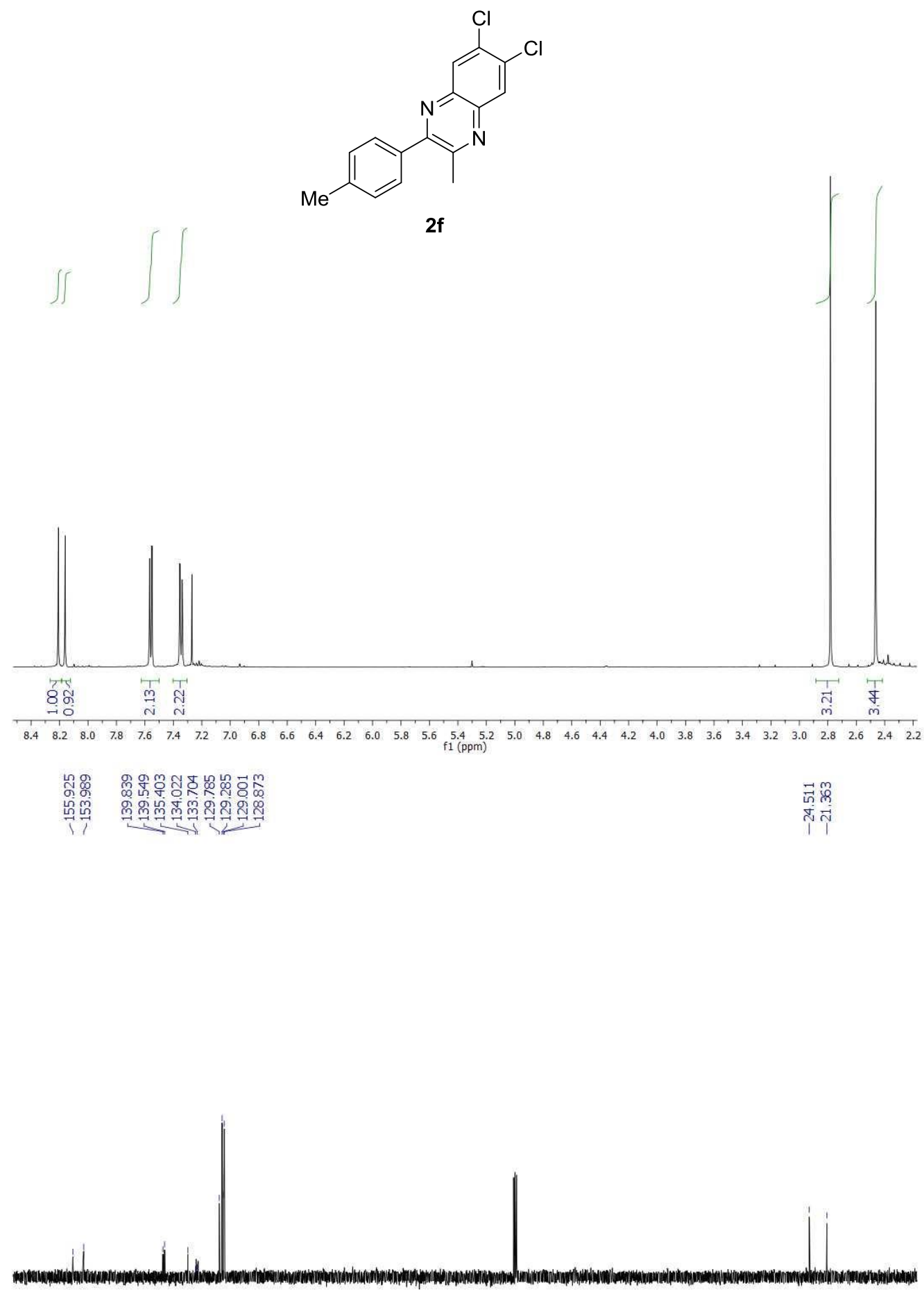

\begin{tabular}{|c|c|c|c|c|c|c|c|c|c|c|c|c|c|c|}
\hline 160 & 150 & 140 & 130 & 120 & 110 & 100 & 90 & 80 & 70 & 60 & 50 & 40 & 30 & 20 \\
\hline
\end{tabular}


<smiles>CCc1nc2ccccc2nc1-c1ccc(F)cc1</smiles>

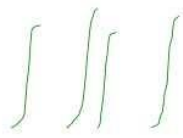

2g
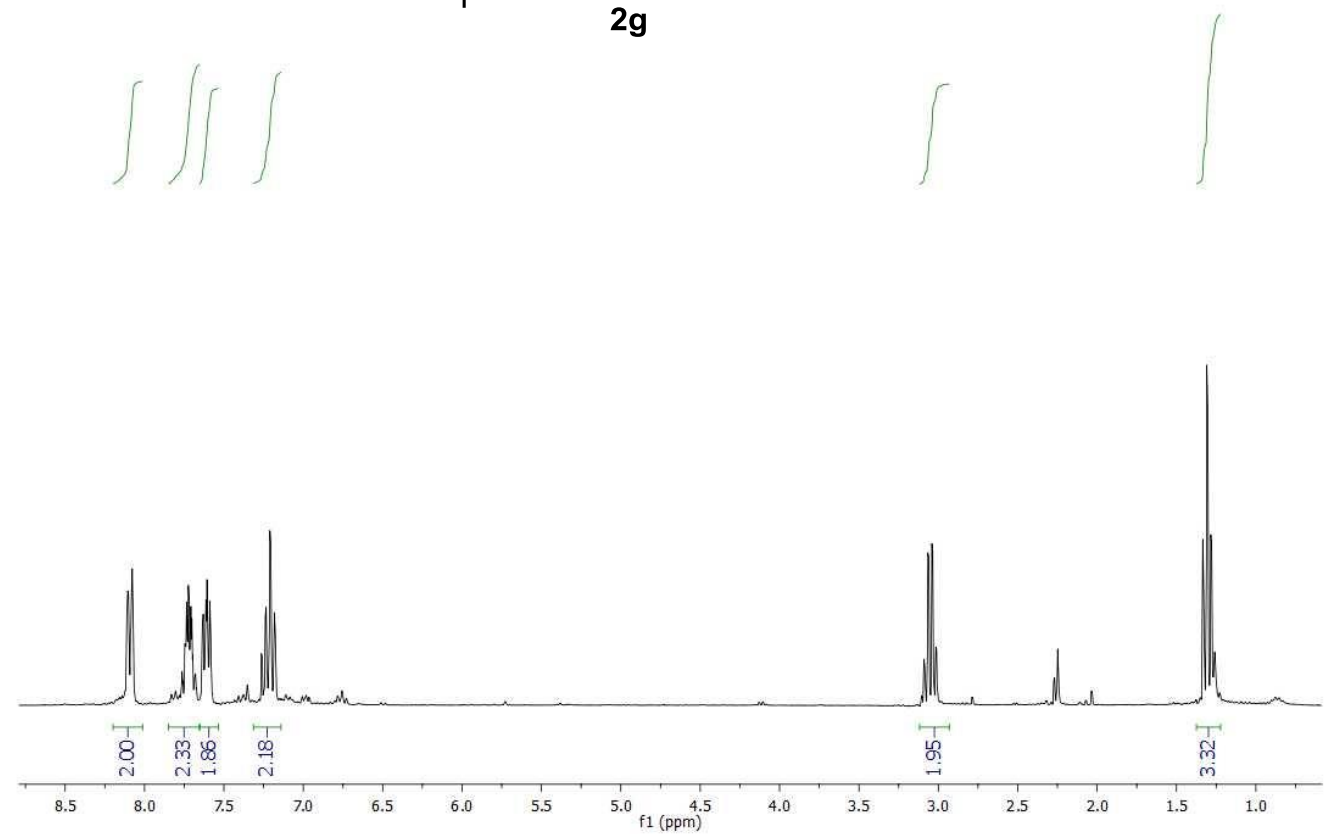

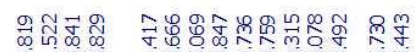

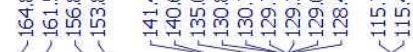

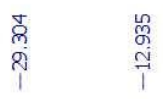

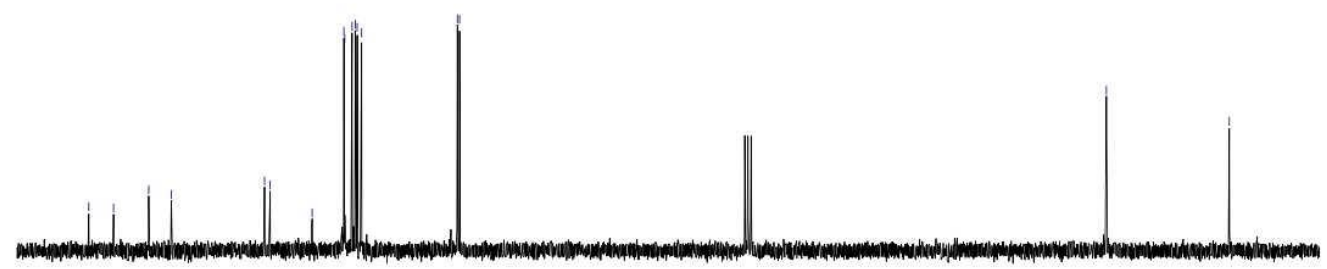

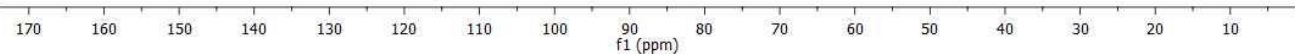



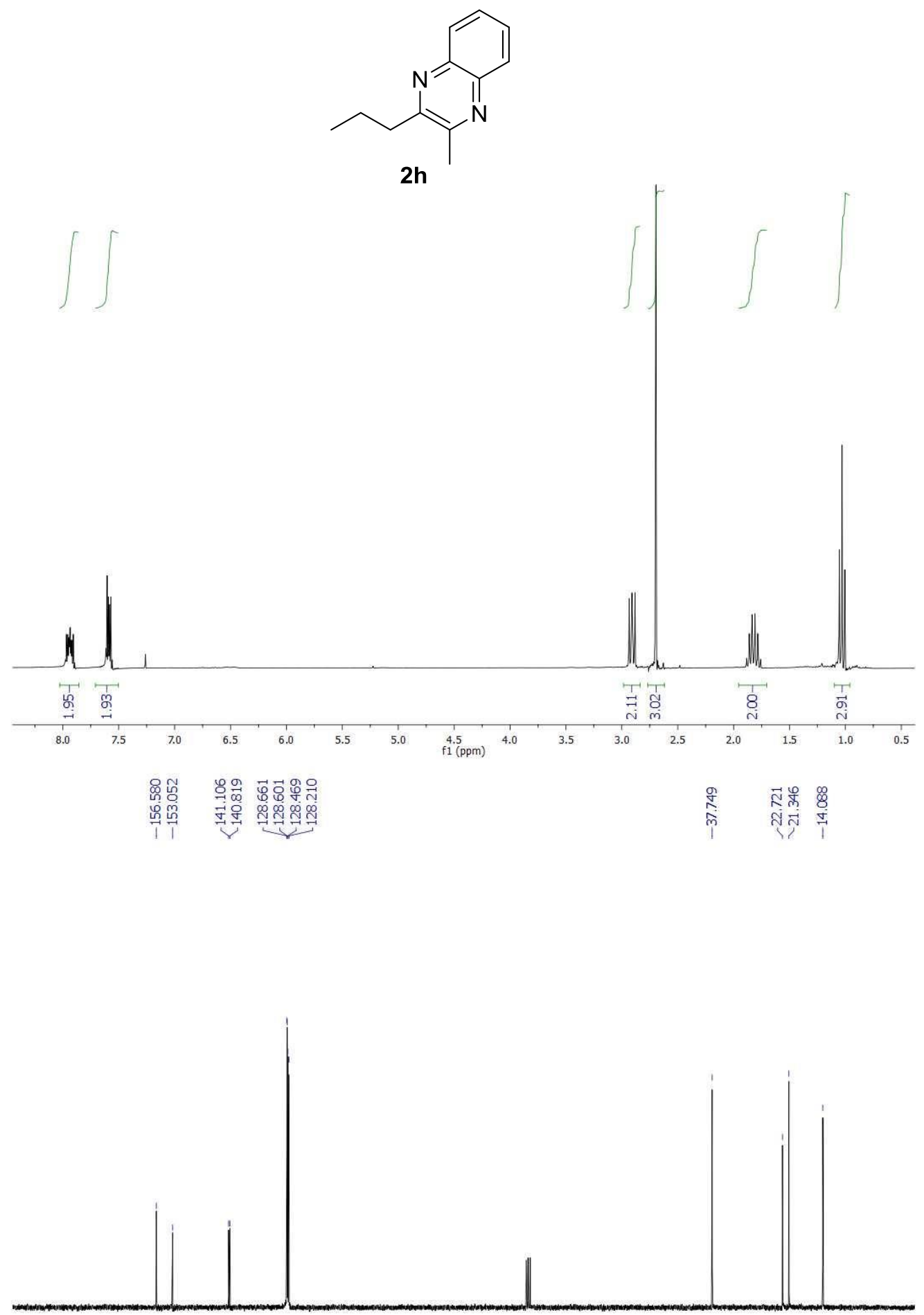

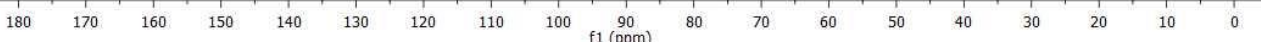



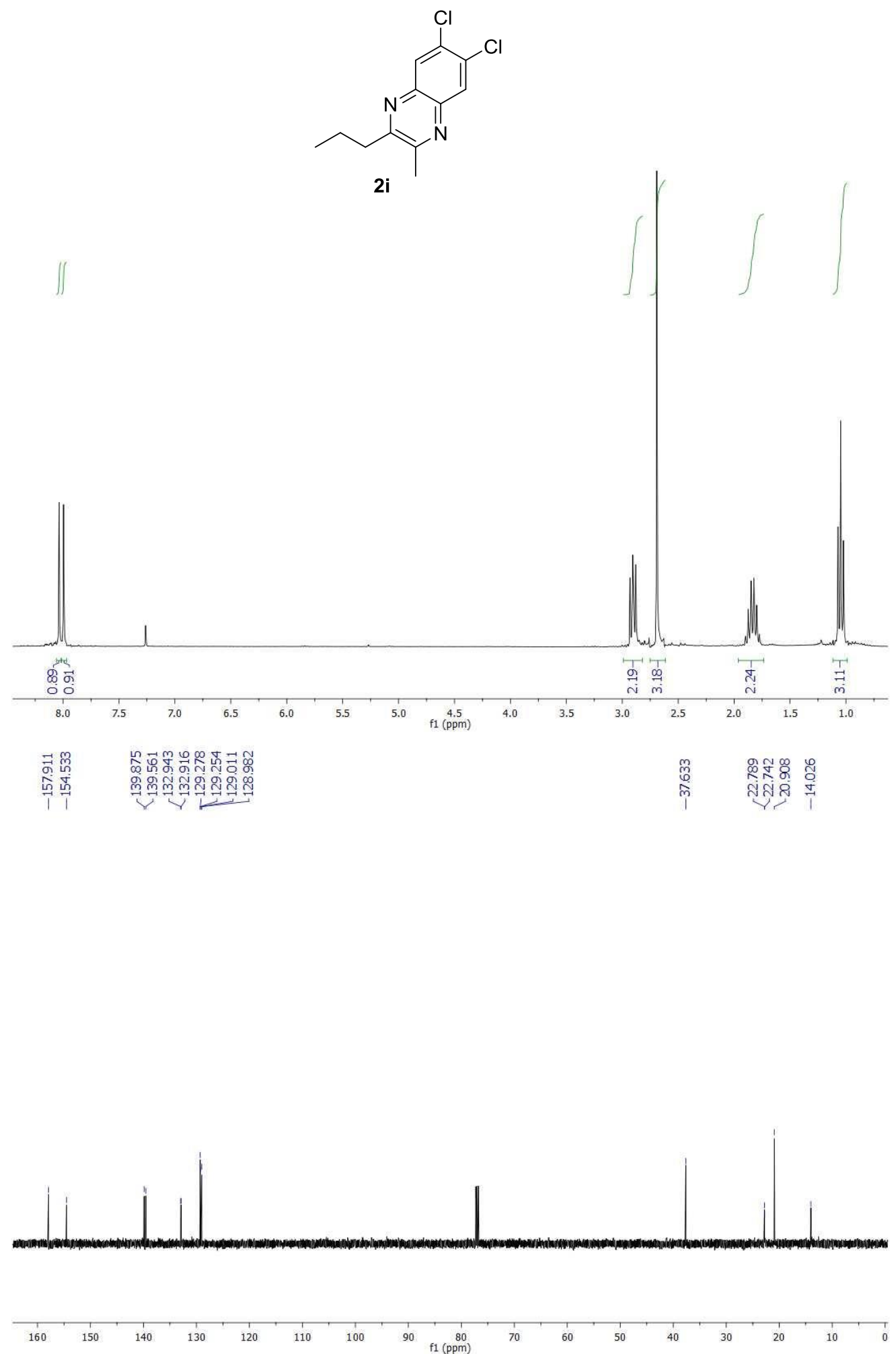
<smiles>CC1NCCNC1c1ccccc1</smiles>

$3 a$
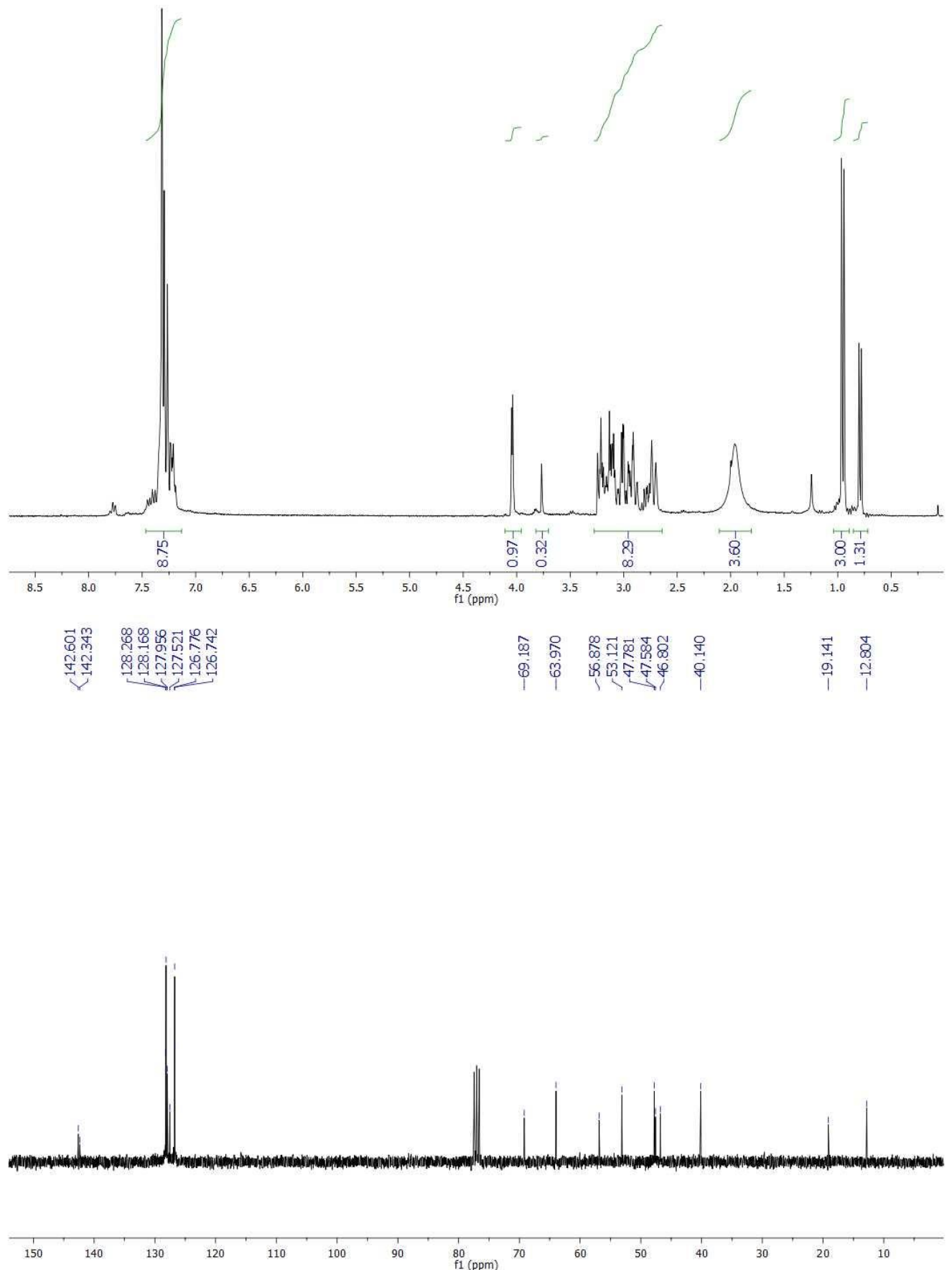

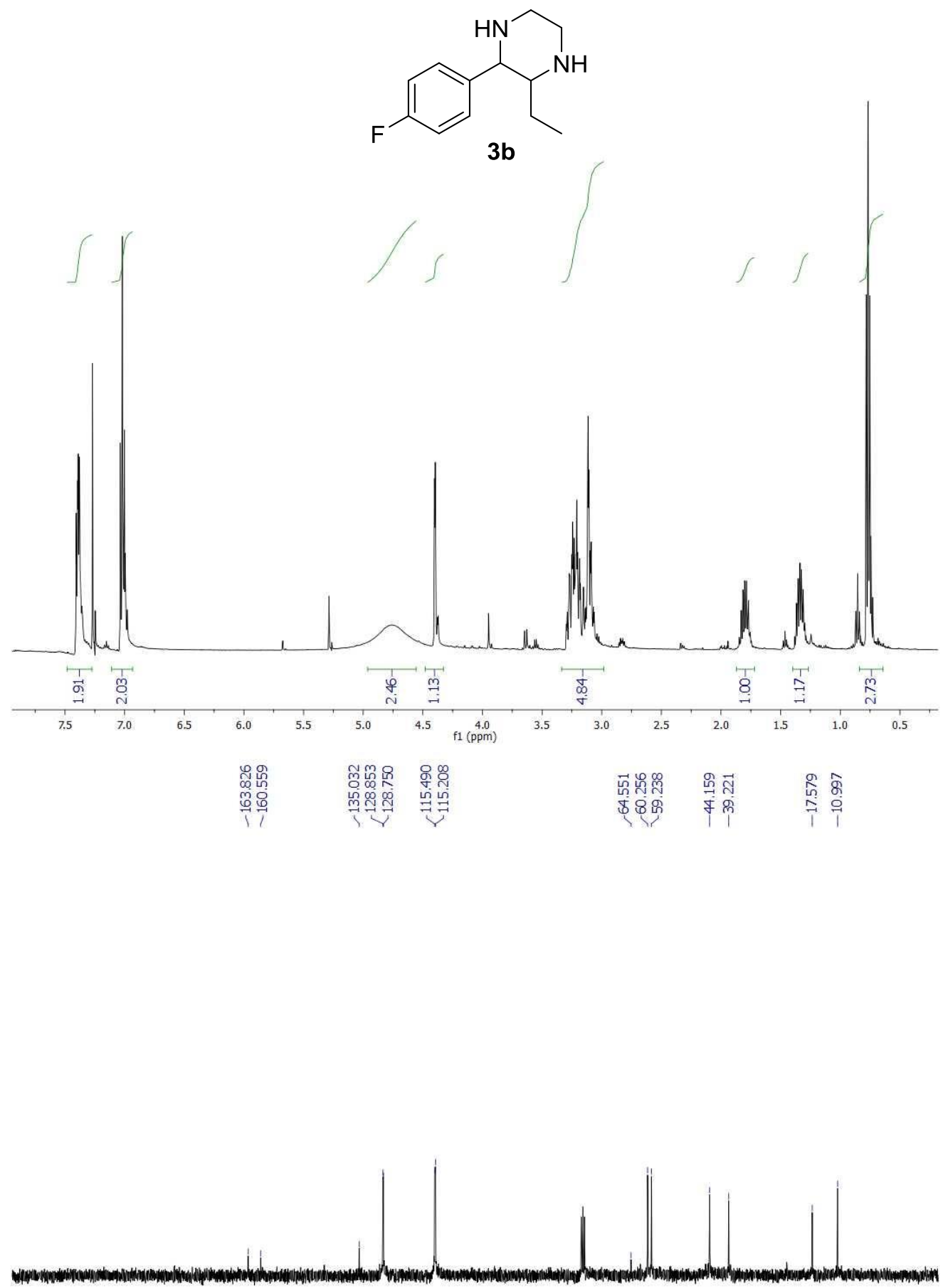

$\begin{array}{lllllllllllllllllllllllll}220 & 210 & 200 & 190 & 180 & 170 & 160 & 150 & 140 & 130 & 120 & 110 & 100 & 90 & 80 & 70 & 60 & 50 & 40 & 30 & 20 & 10 & 0 & -10\end{array}$ 


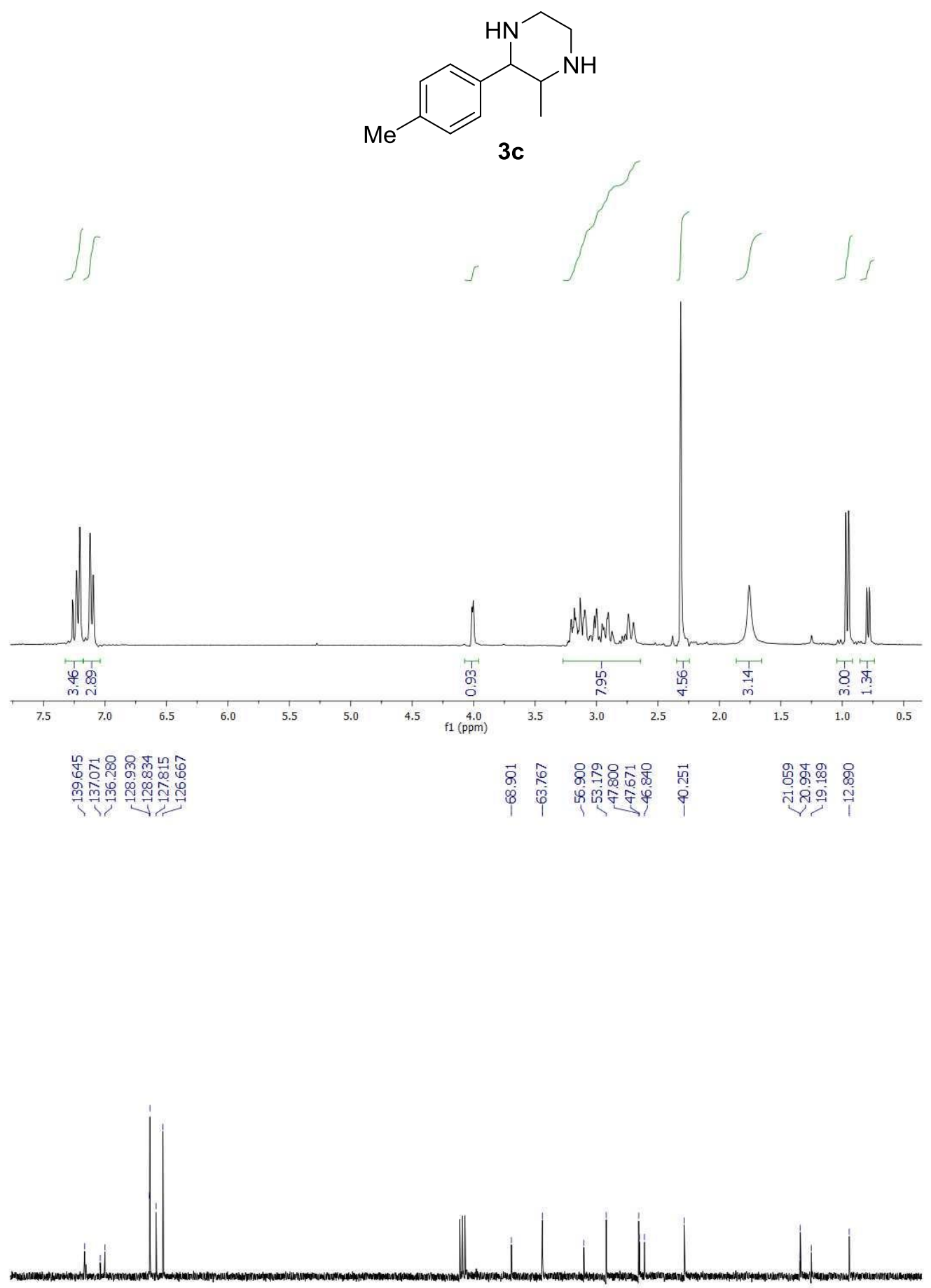

$\begin{array}{llllllllllllllllllllllllllllllllllllllll}150 & 145 & 140 & 135 & 130 & 125 & 120 & 115 & 110 & 105 & 100 & 95 & 90 & 85 & 80 & 75 & 70 & 65 & 60 & 55 & 50 & 45 & 40 & 35 & 30 & 25 & 20 & 15 & 10 & 5\end{array}$ 
<smiles>Cc1ccc(C2NCCNC2C)cc1</smiles>
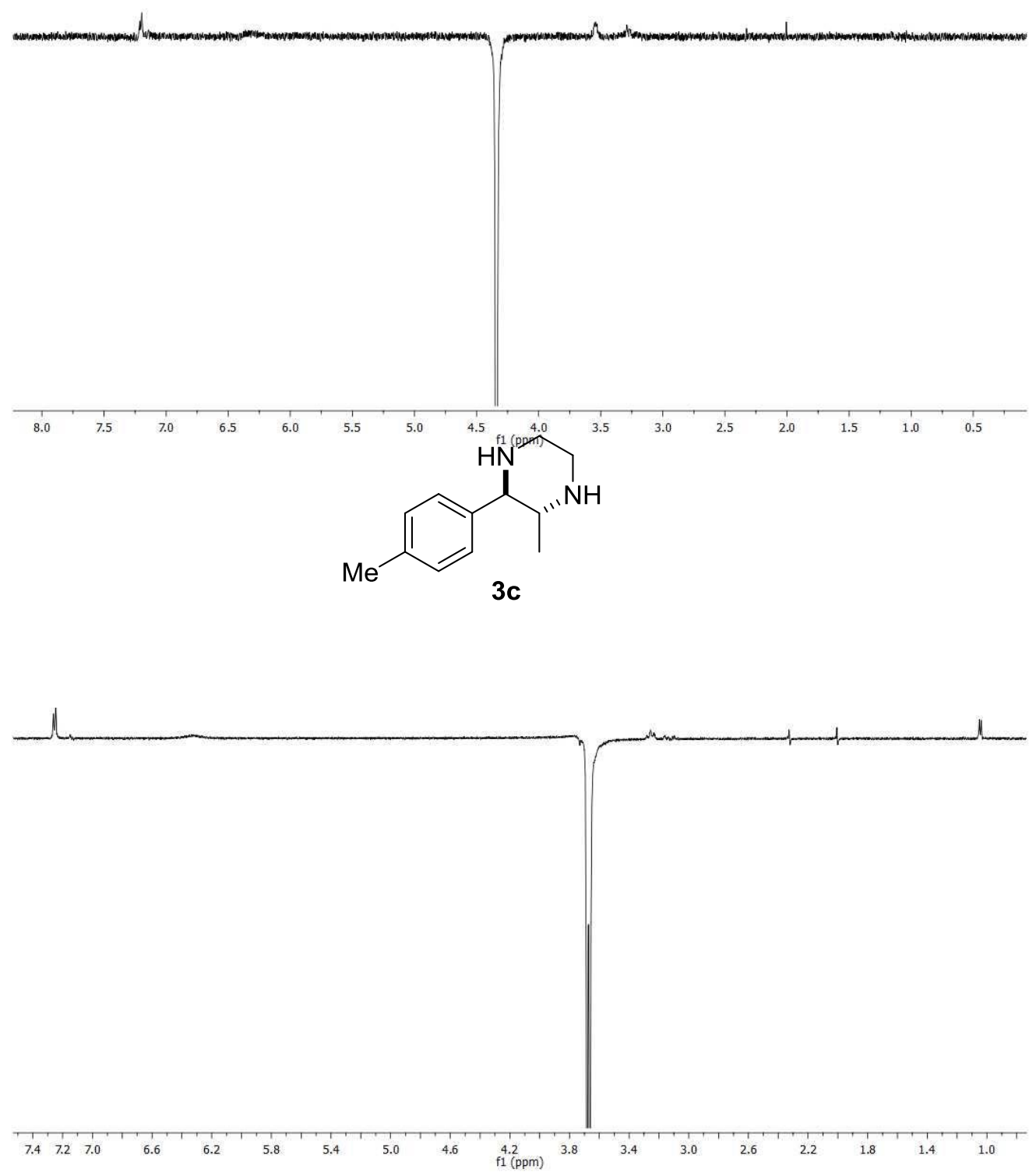
<smiles>CC1Nc2ccccc2NC1c1ccccc1</smiles>

4a

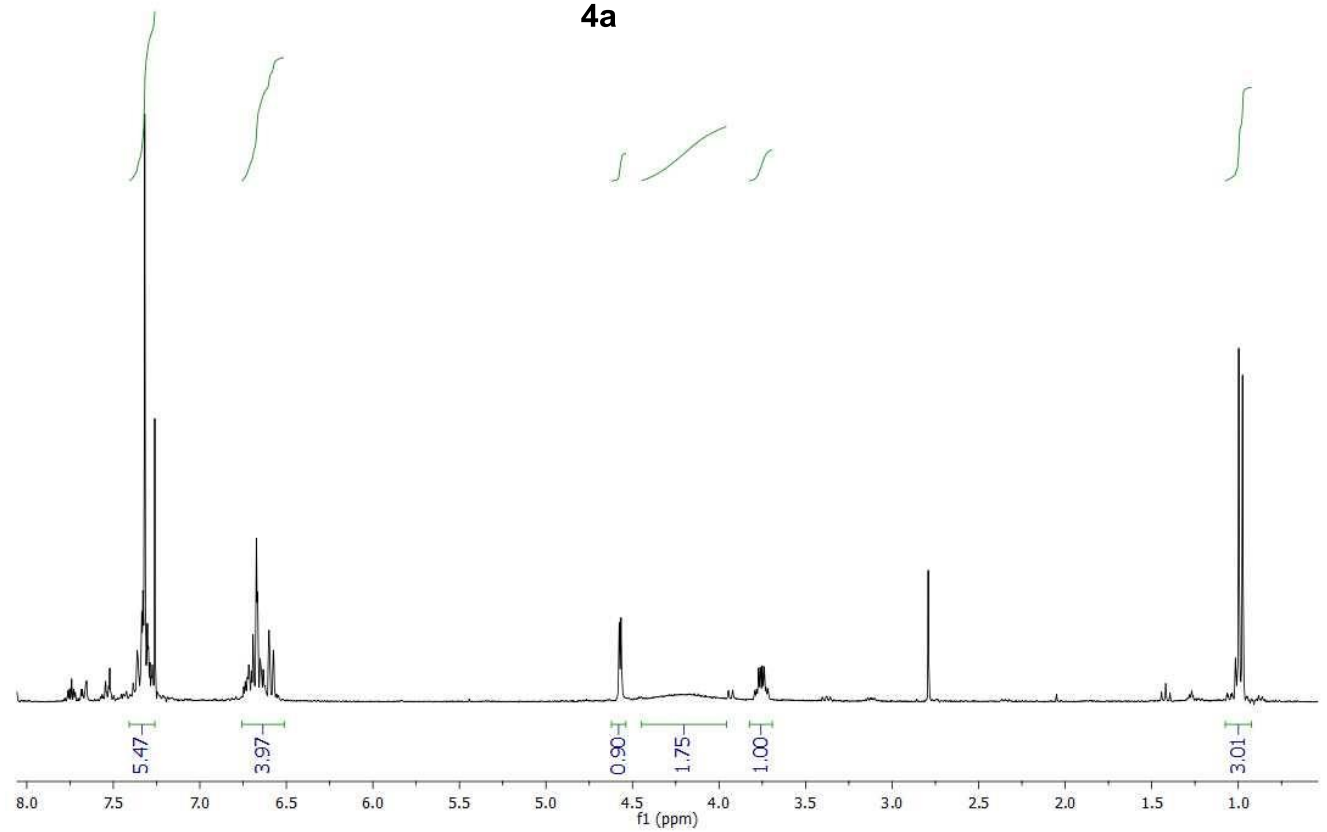

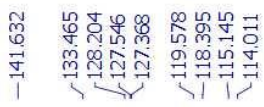

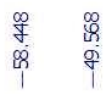

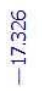

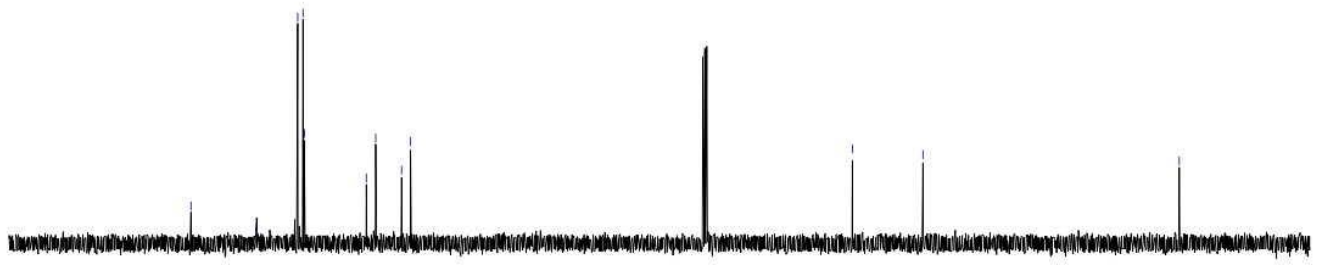

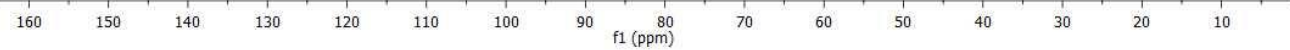


<smiles>CC1Nc2ccccc2N([O-])C1c1ccccc1</smiles>

4b

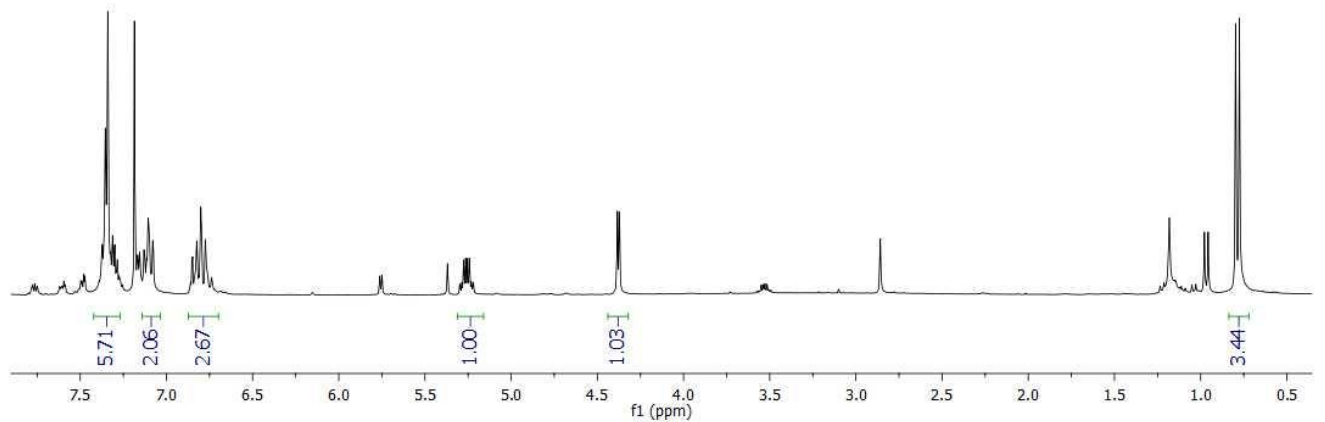

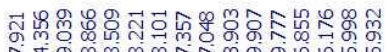

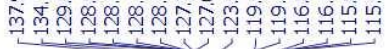

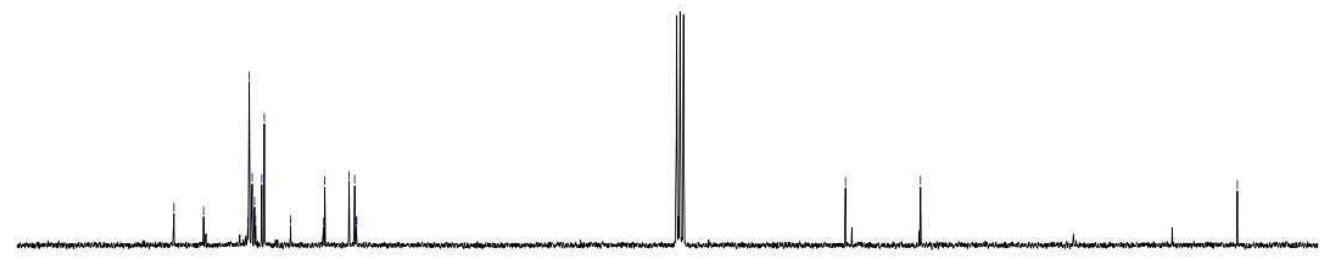


<smiles>Cc1nc(-c2ccccc2)c(C)nc1-c1ccccc1</smiles>

$5 a$
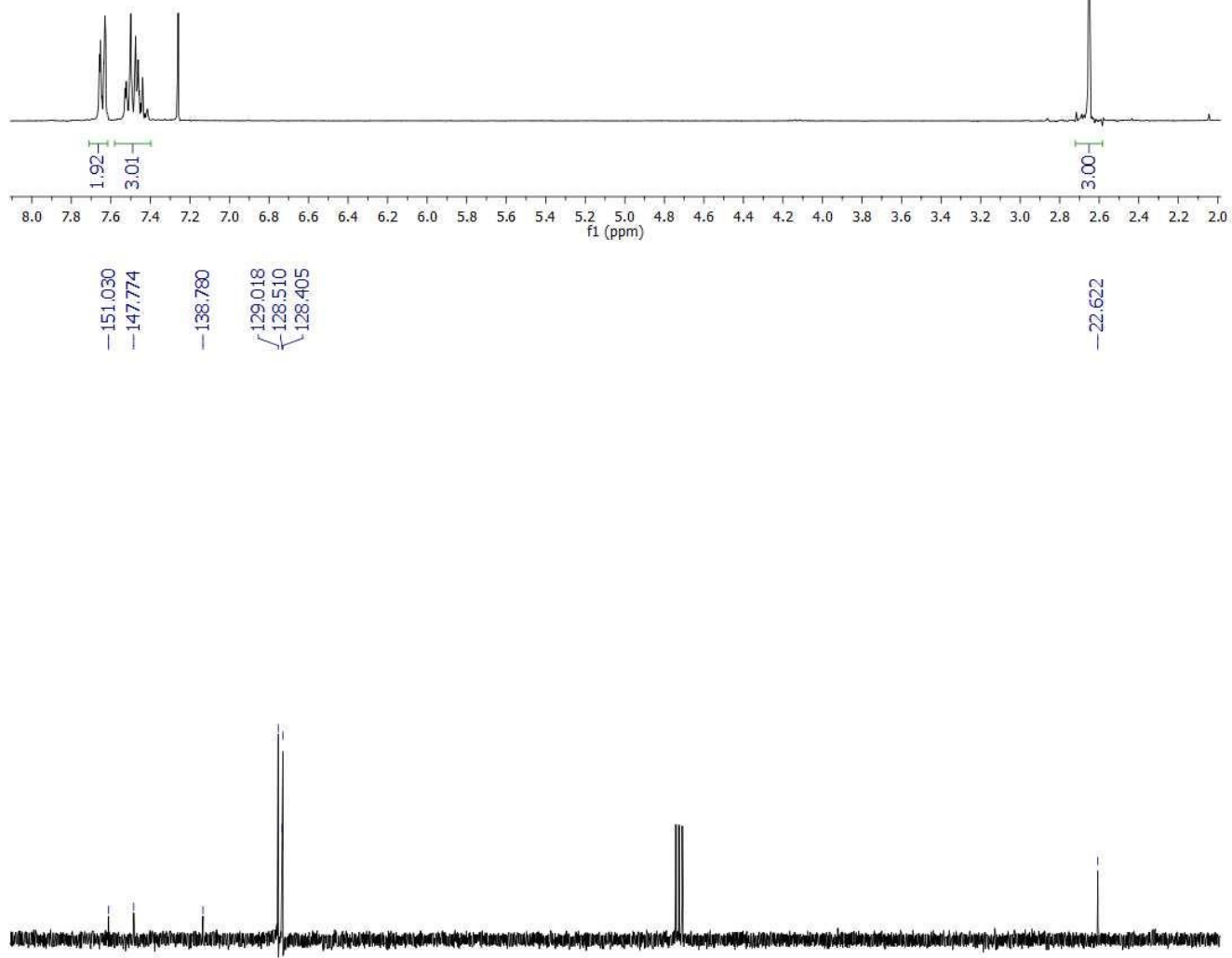

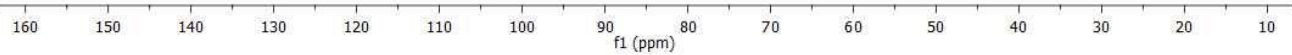



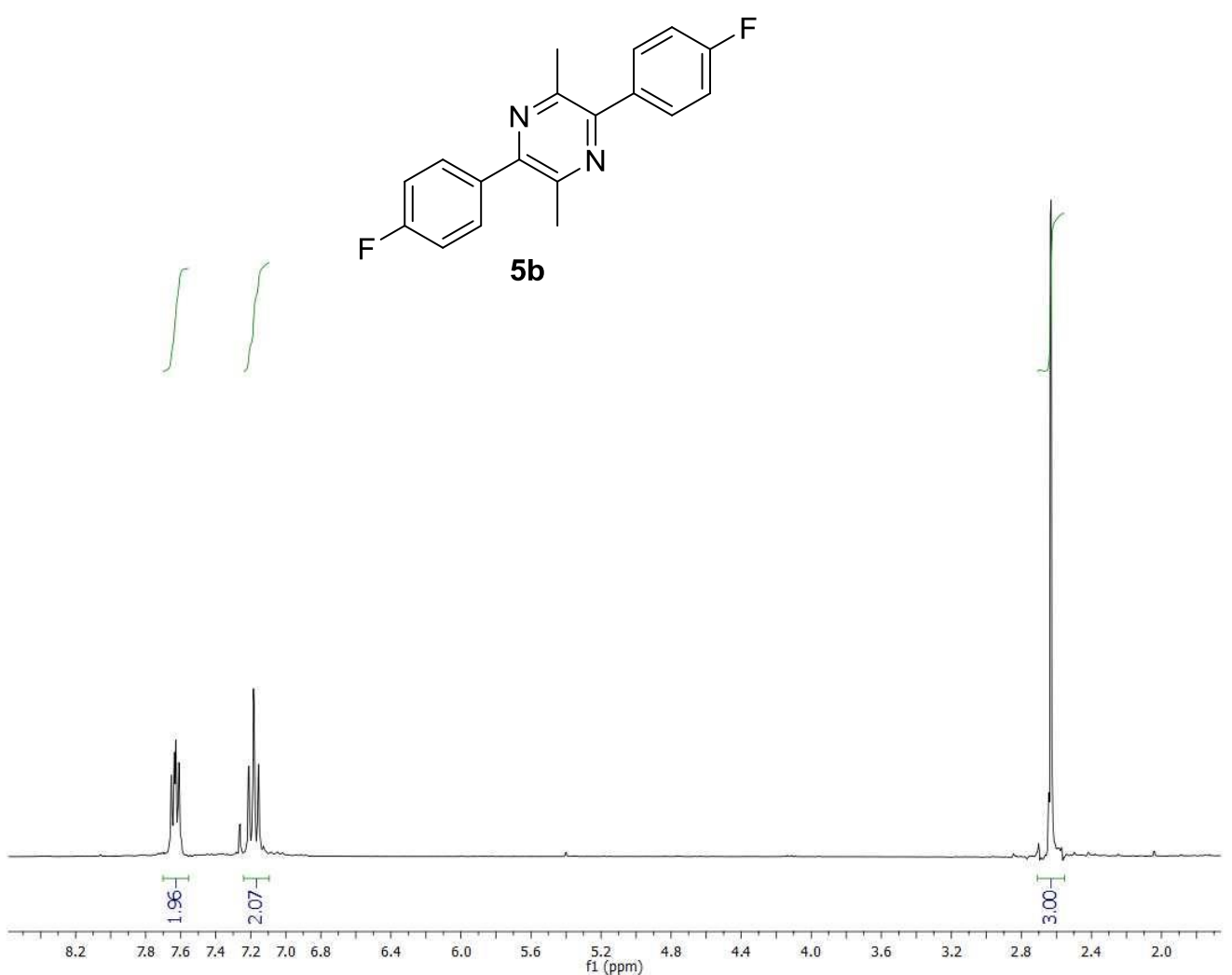

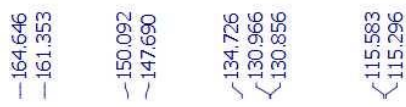
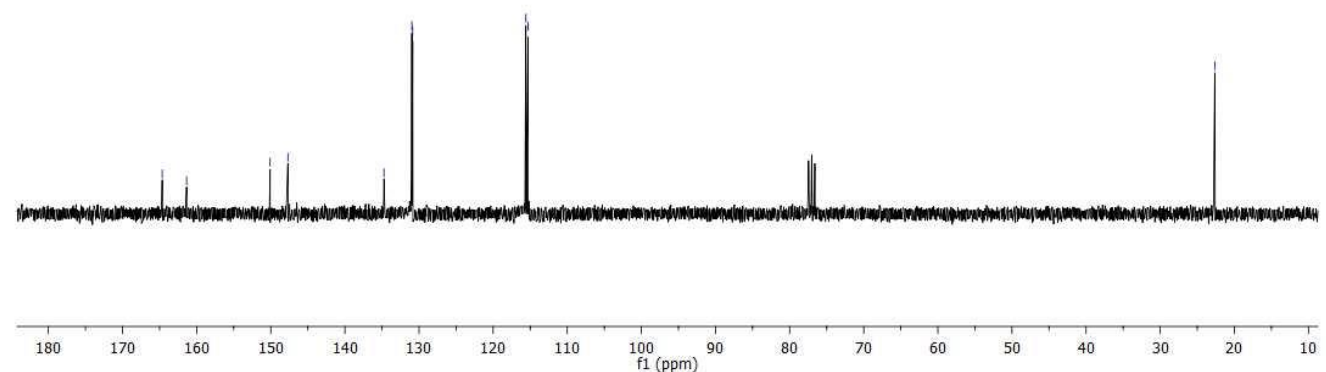


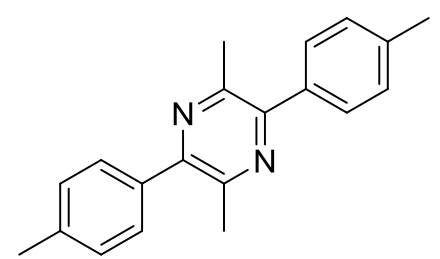

5c
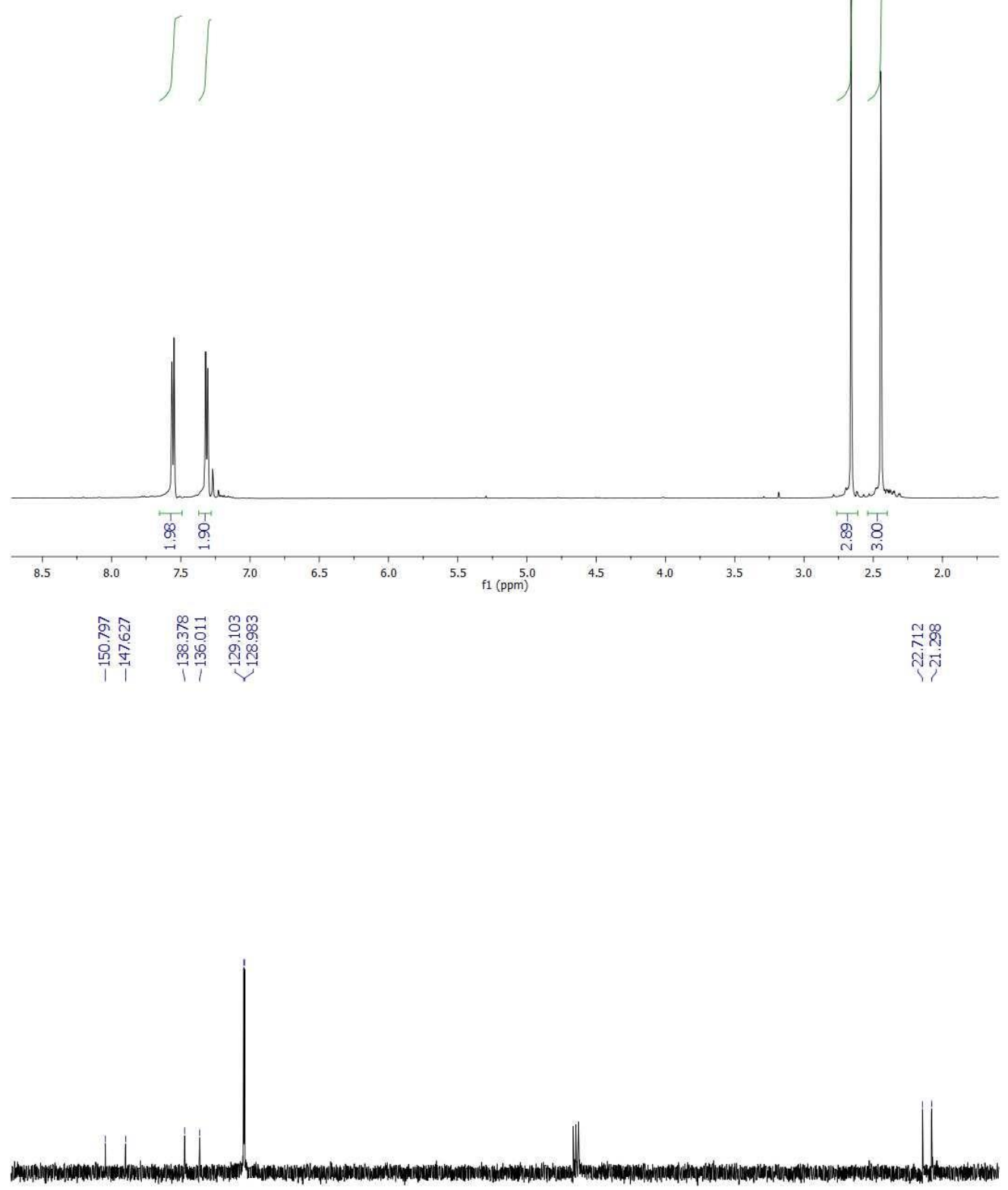

\begin{tabular}{|c|c|c|c|c|c|c|c|c|c|c|c|c|c|c|}
\hline 160 & 150 & 140 & 130 & 120 & 110 & 100 & $\begin{array}{l}90 \\
\mathrm{f1}(\mathrm{ppm})\end{array}$ & 80 & 70 & 60 & 50 & 40 & 30 & 20 \\
\hline
\end{tabular}


<smiles>CCc1nc(-c2ccc(F)cc2)c(CC)nc1-c1ccc(F)cc1</smiles>
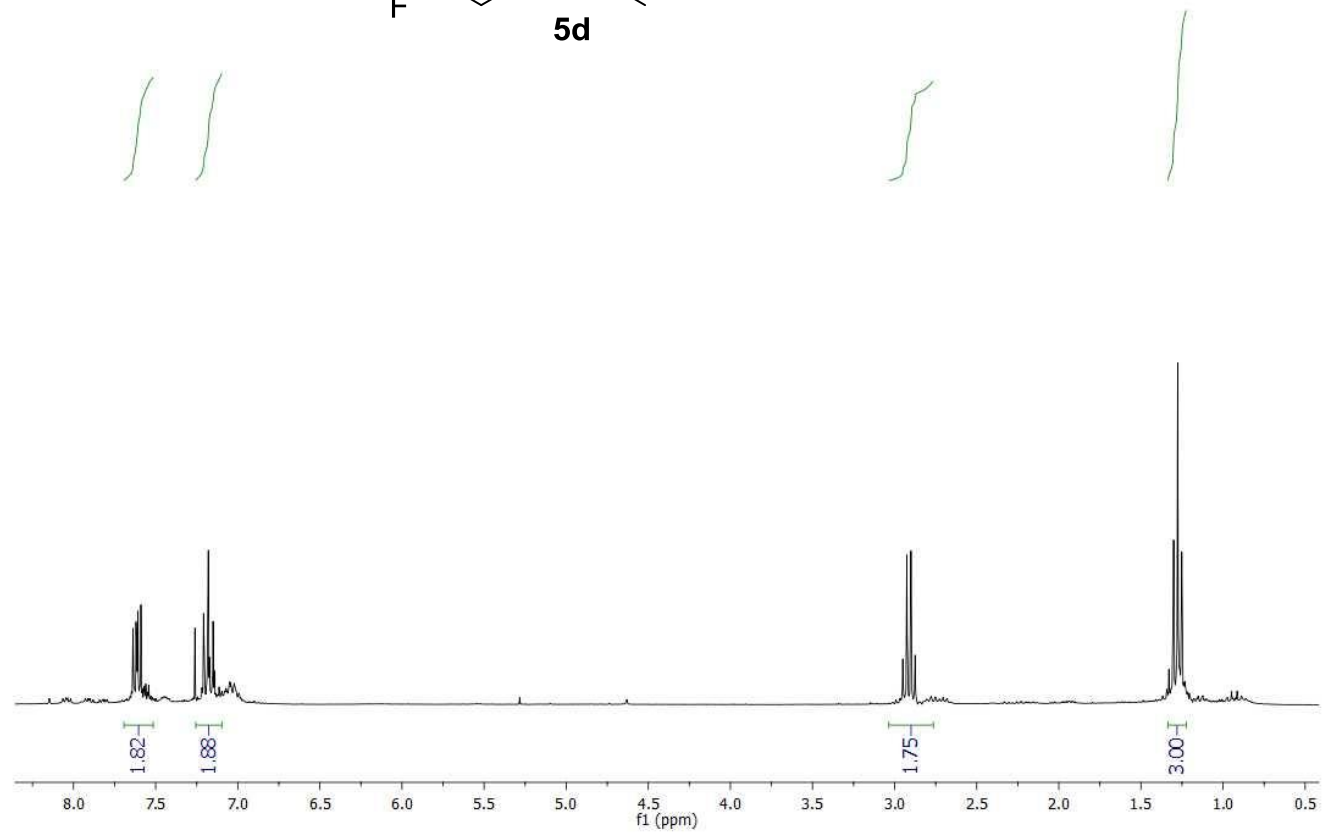

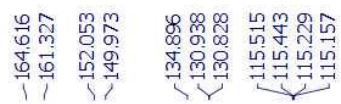

$\underset{\substack{\text { i } \\ \stackrel{i}{i}}}{\stackrel{m}{m}}$

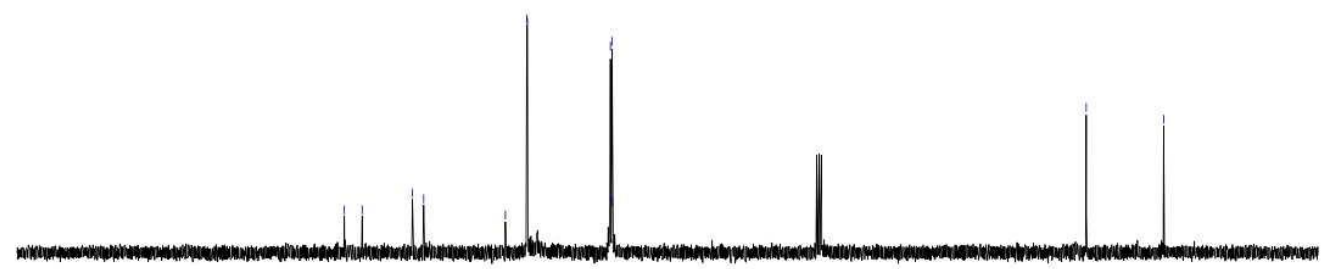

$\begin{array}{lllllllllllllllllllllllllllllll}220 & 210 & 200 & 190 & 180 & 170 & 160 & 150 & 140 & 130 & 120 & 110 & 100 & 90 & 80 & 70 & 60 & 50 & 40 & 30 & 20 & 10 & 0 & -10\end{array}$ 

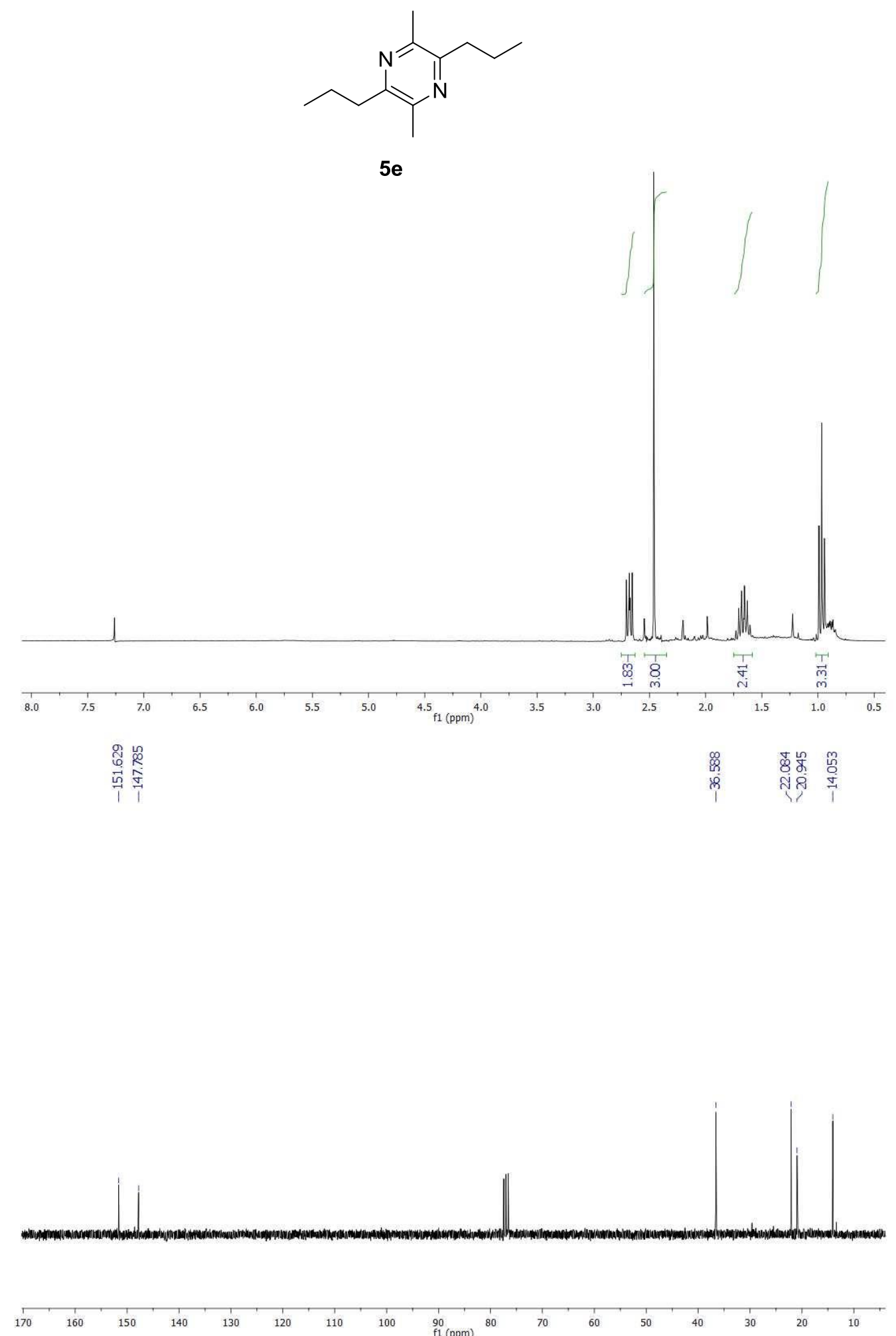
<smiles>CC1([N+](=O)[O-])OC1c1ccccc1</smiles>

$13 a$

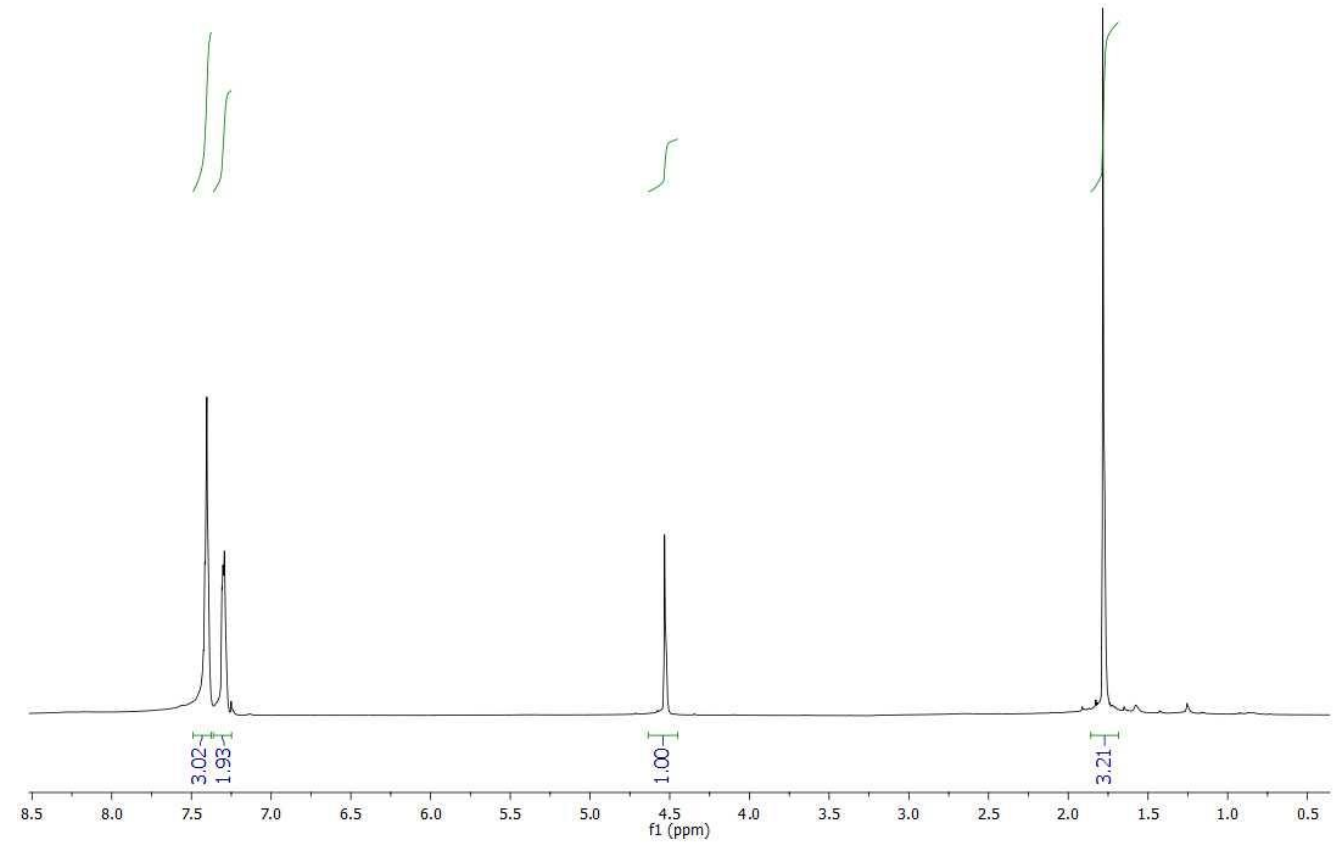

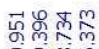

임워

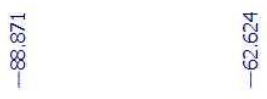

$\underset{\substack{\stackrel{8}{7}\\}}{1}$

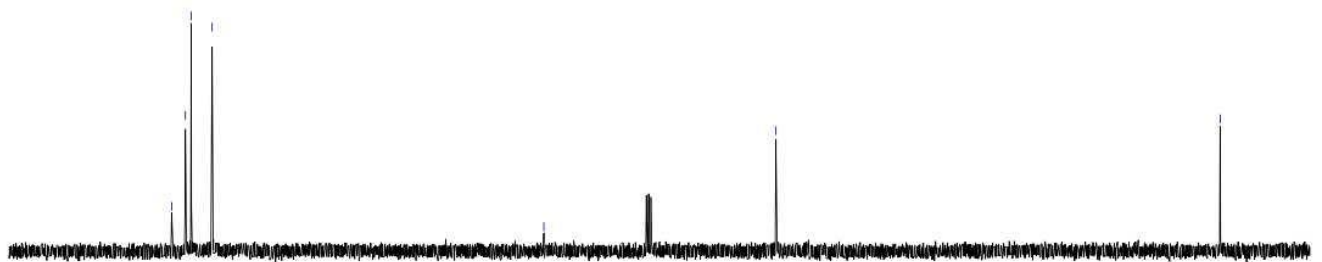

$\begin{array}{llllllllllllllllllllllllllllllllll}145 & 140 & 135 & 130 & 125 & 120 & 115 & 110 & 105 & 100 & 95 & 90 & 85 & 80 & 75 & 70 & 65 & 60 & 55 & 50 & 45 & 40 & 35 & 30 & 25 & 20 & 15 & 10 & 5\end{array}$ 
<smiles>CC1([N+](=O)[O-])OC1c1ccc(F)cc1</smiles>
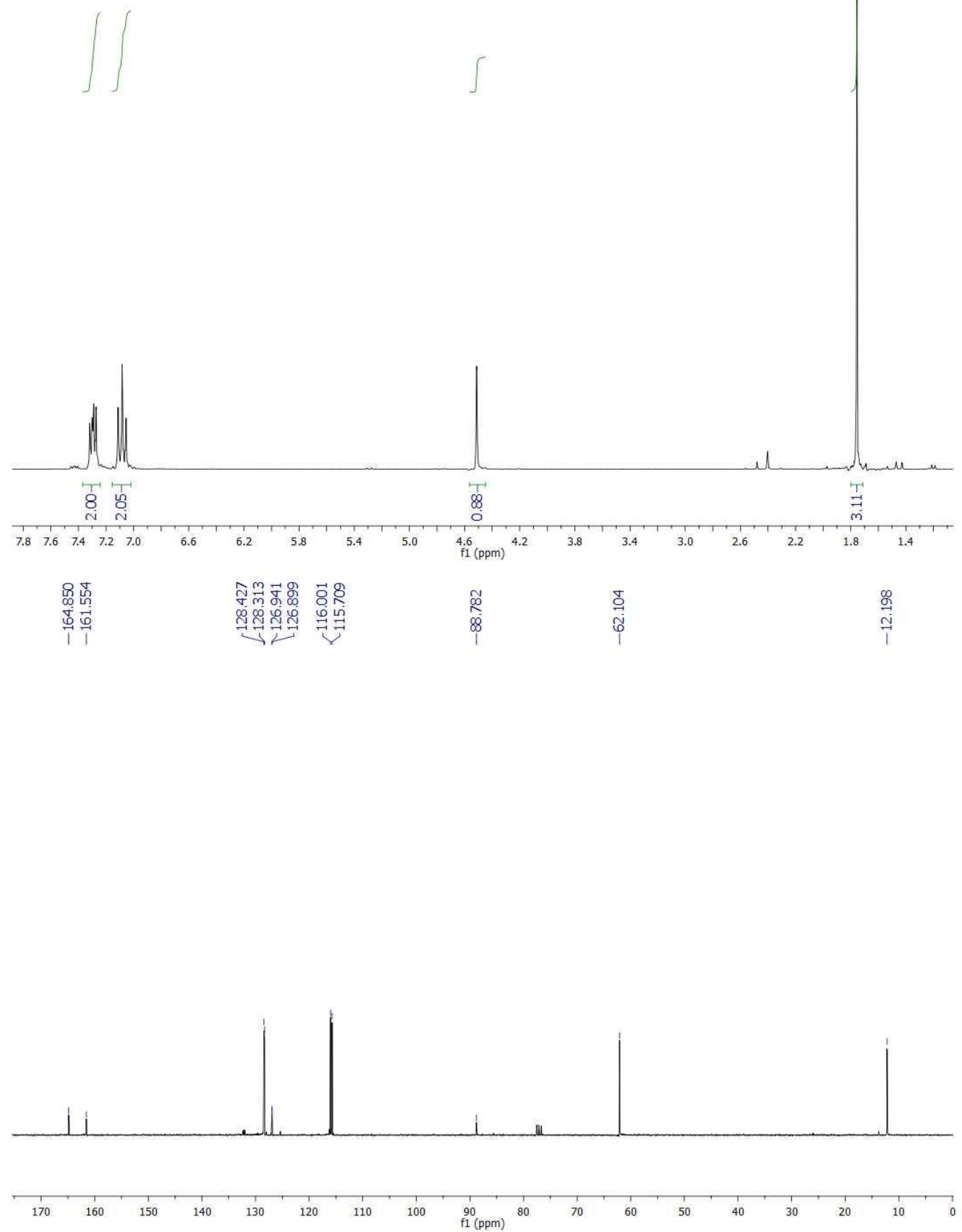
<smiles>CC1([N+](=O)[O-])OC1c1ccc(Cl)cc1</smiles>
$13 c$
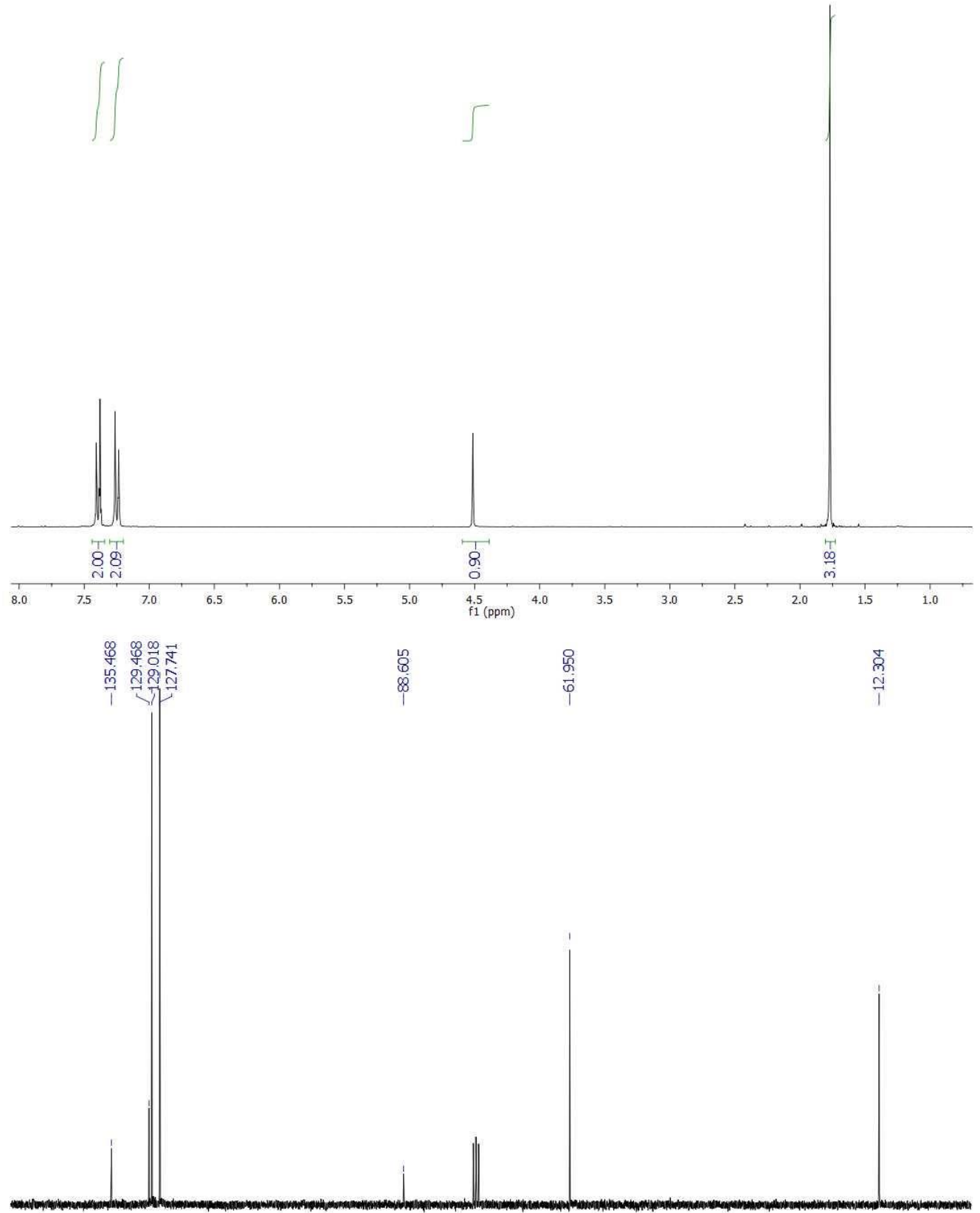

15

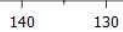

$120 \quad 110$

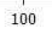

90

$80{ }^{70}$

60

30 

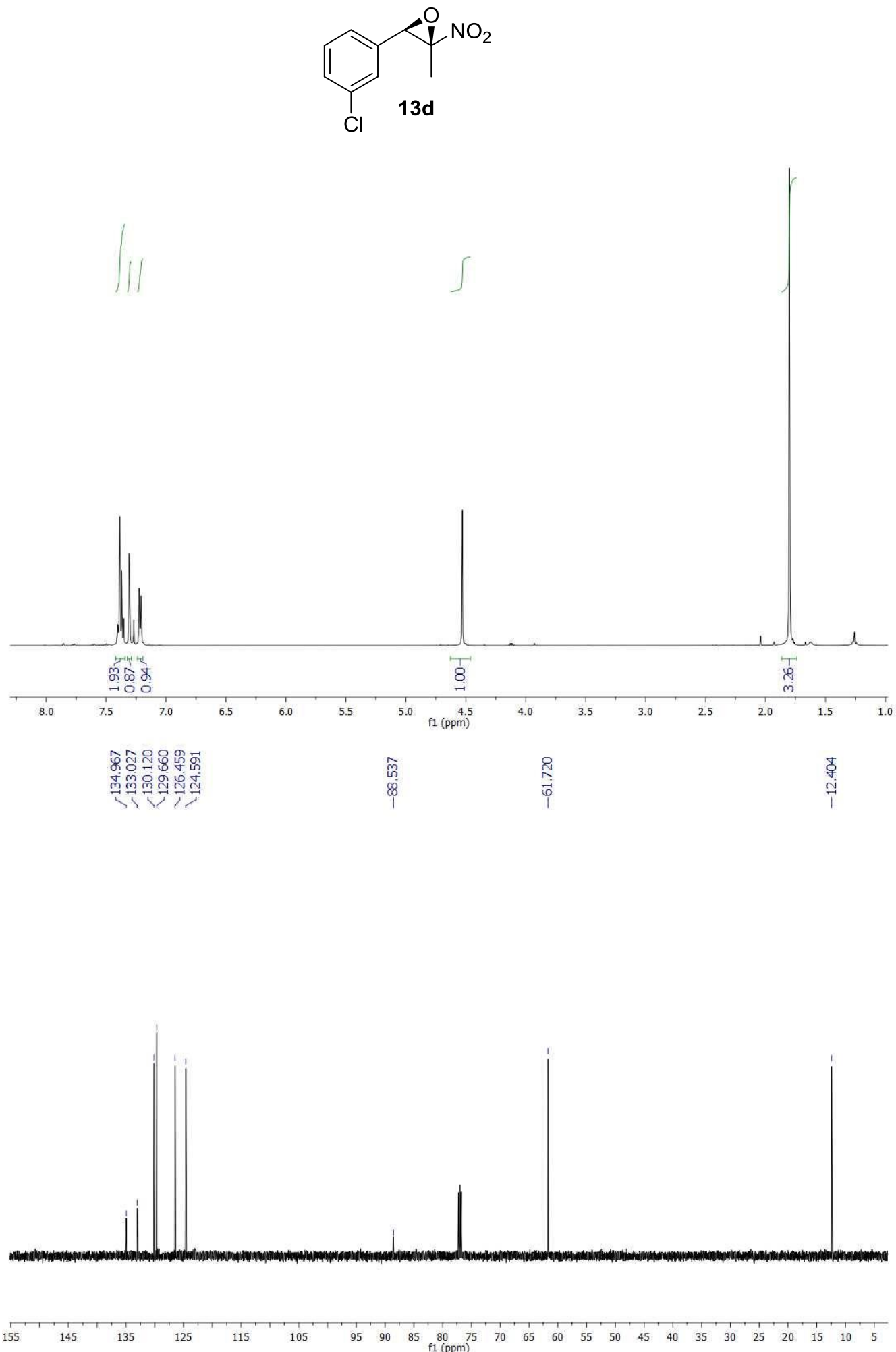
<smiles>CCC1([N+](=O)[O-])OC1c1ccc(F)cc1</smiles>
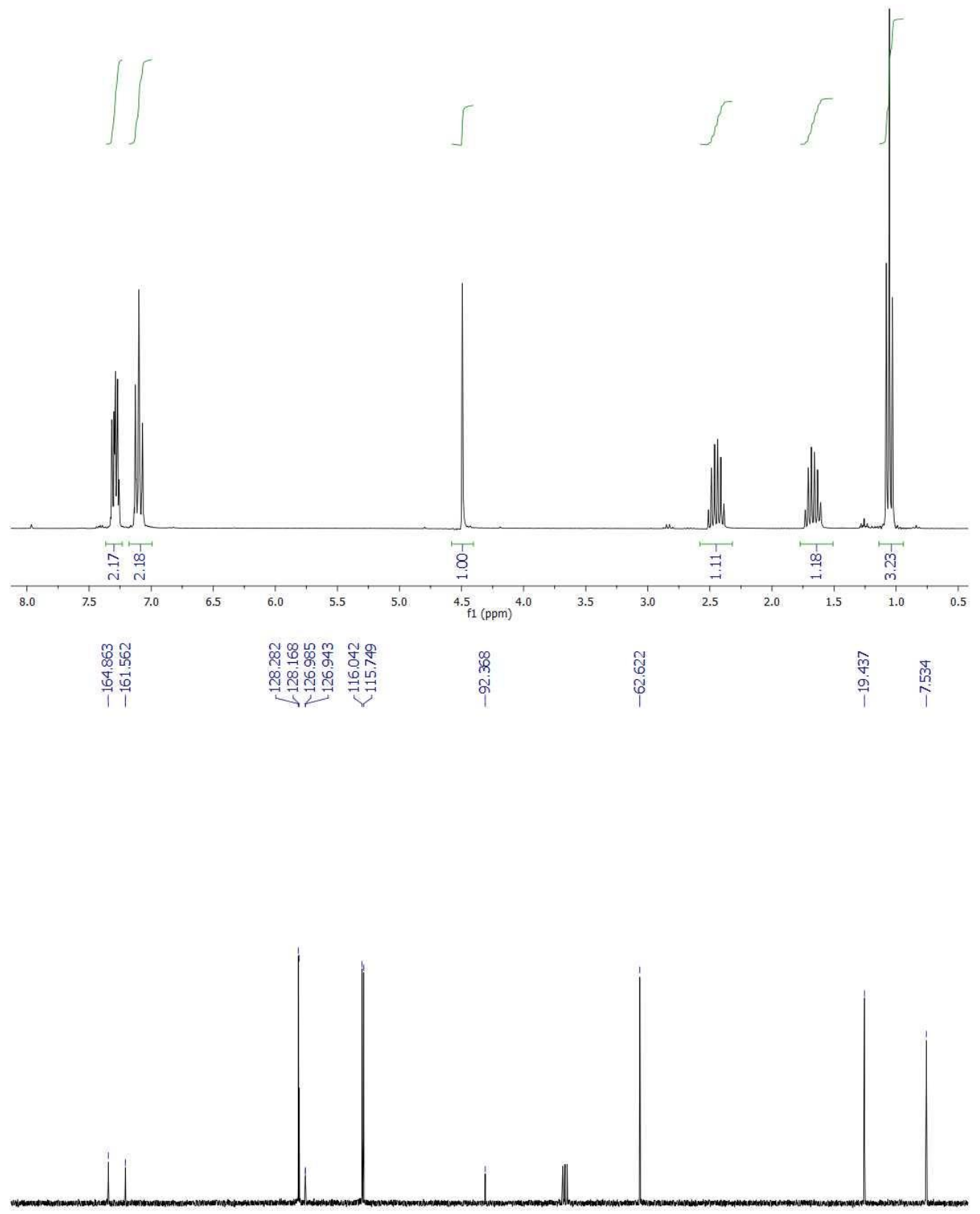

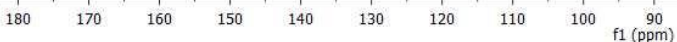



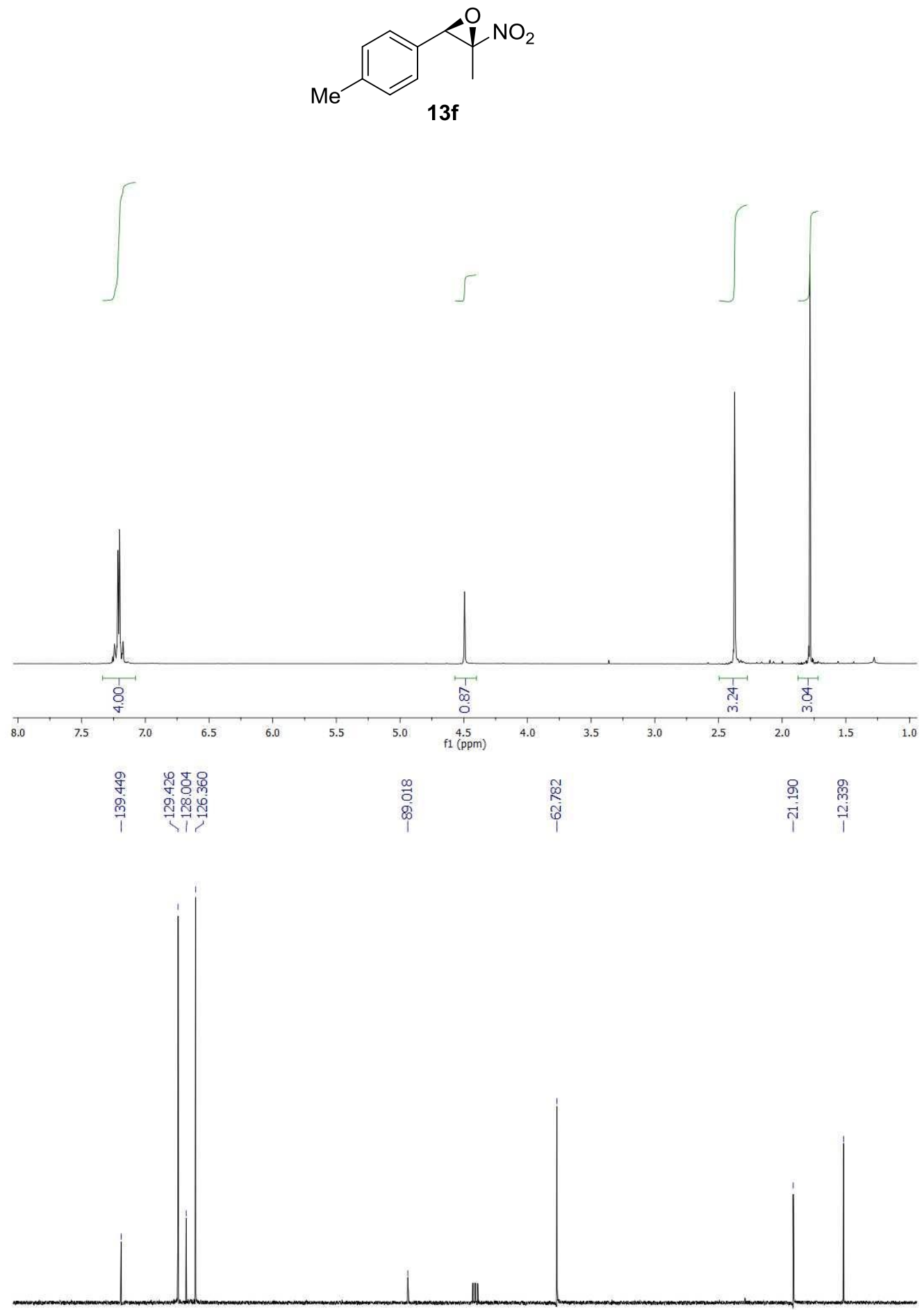

$150 \quad 140 \quad 130$

100

80
$\mathrm{f} 1(\mathrm{ppm})$ 
Selected Spectra

179
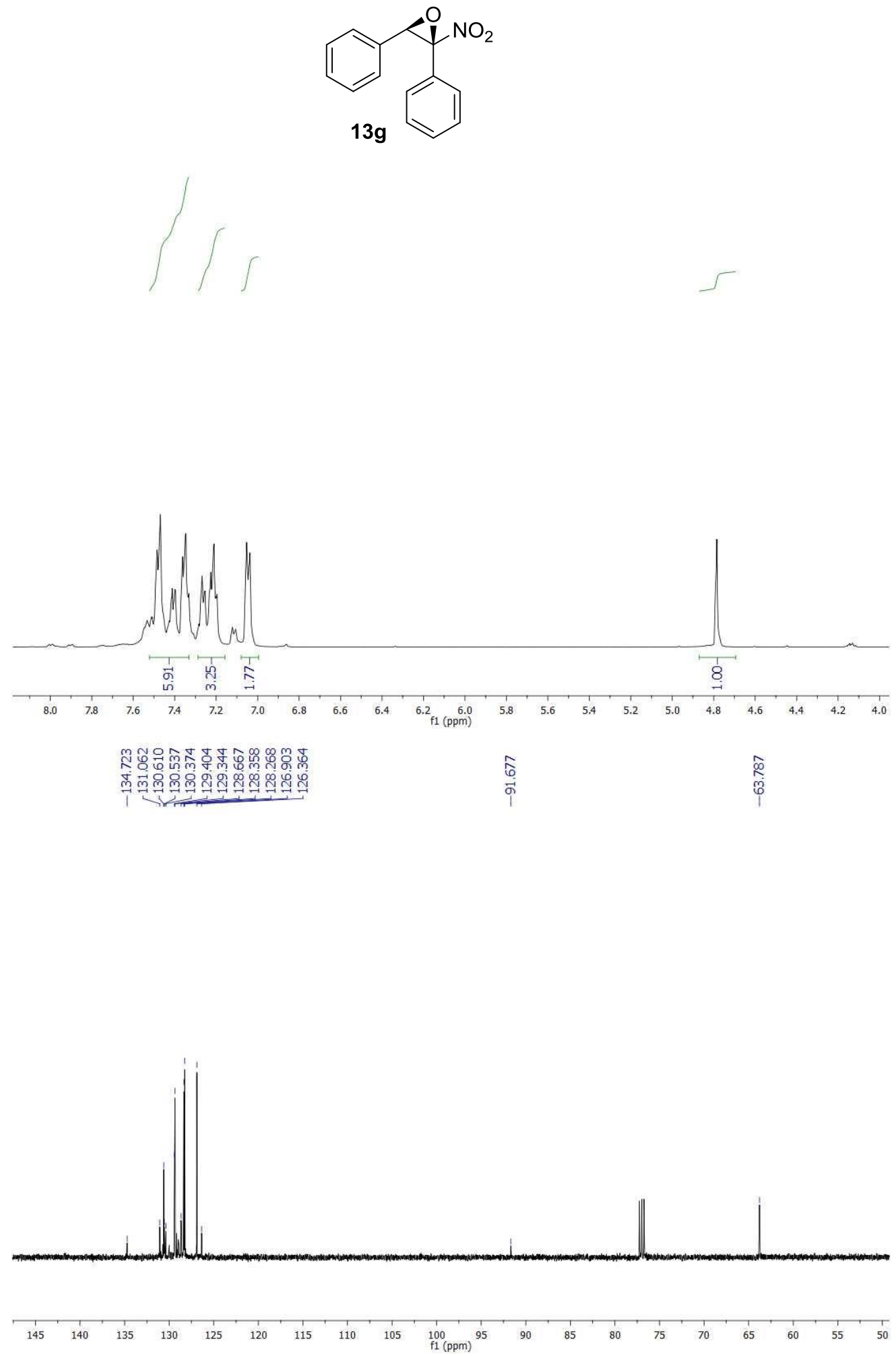


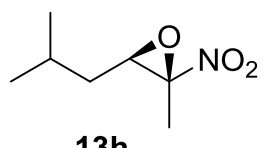

13h

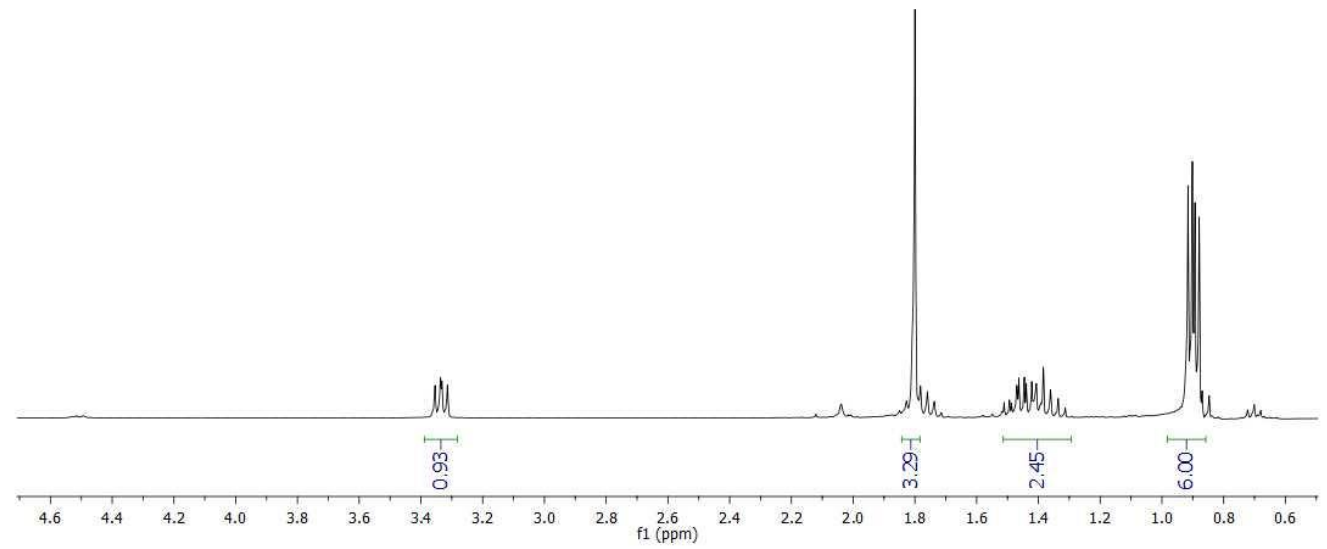

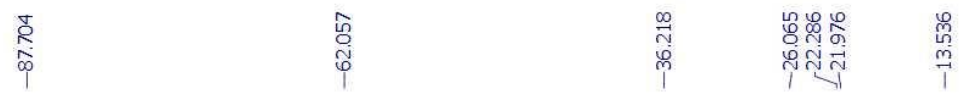

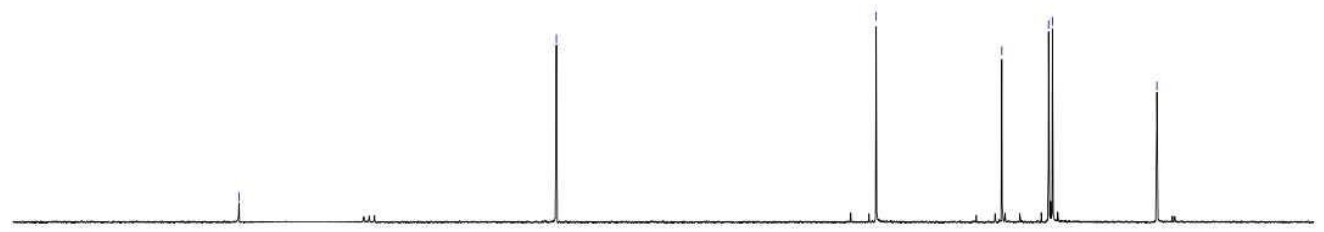

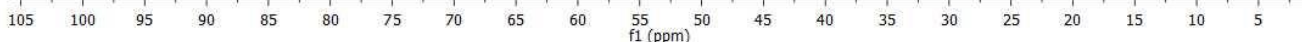



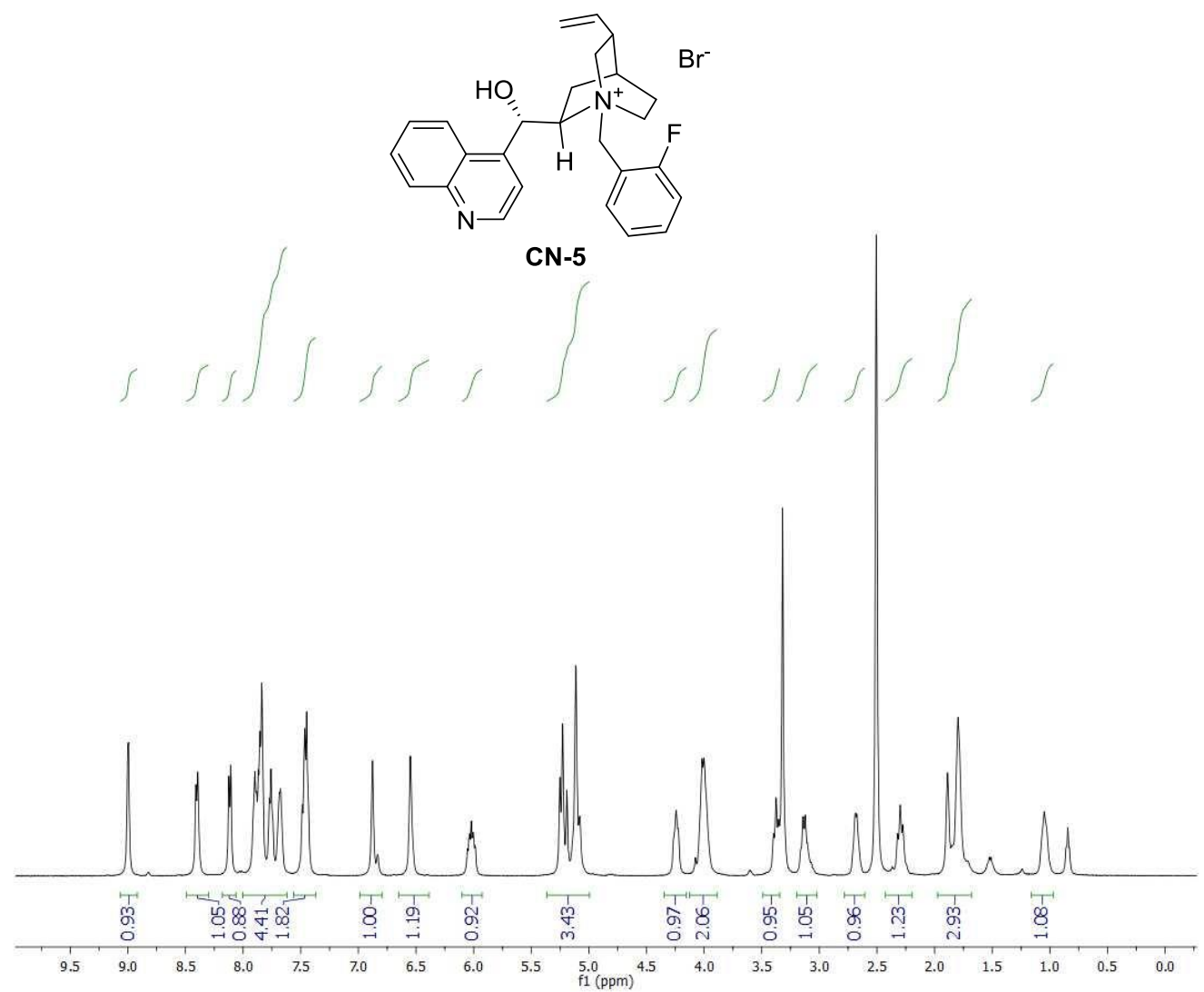

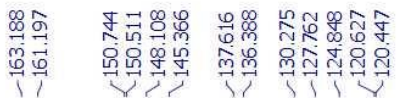

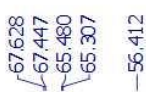

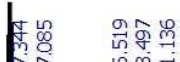

ขึत

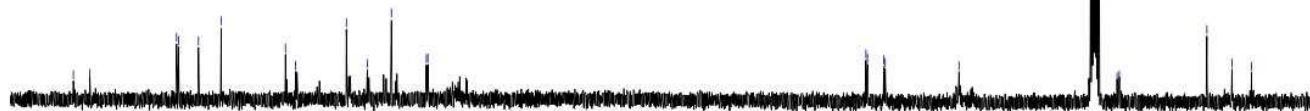



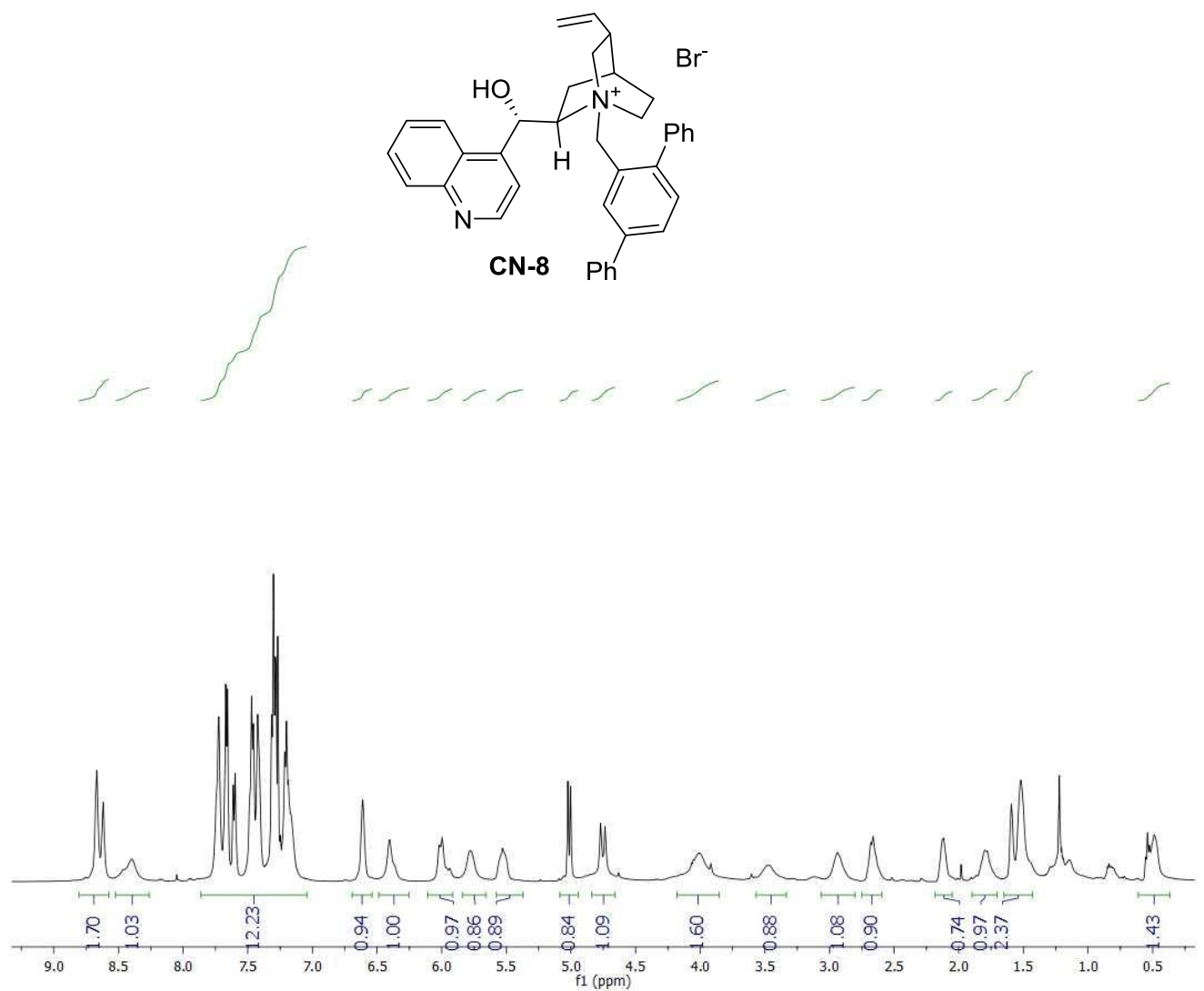

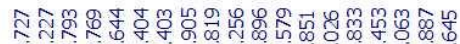

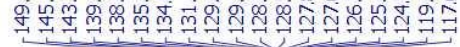

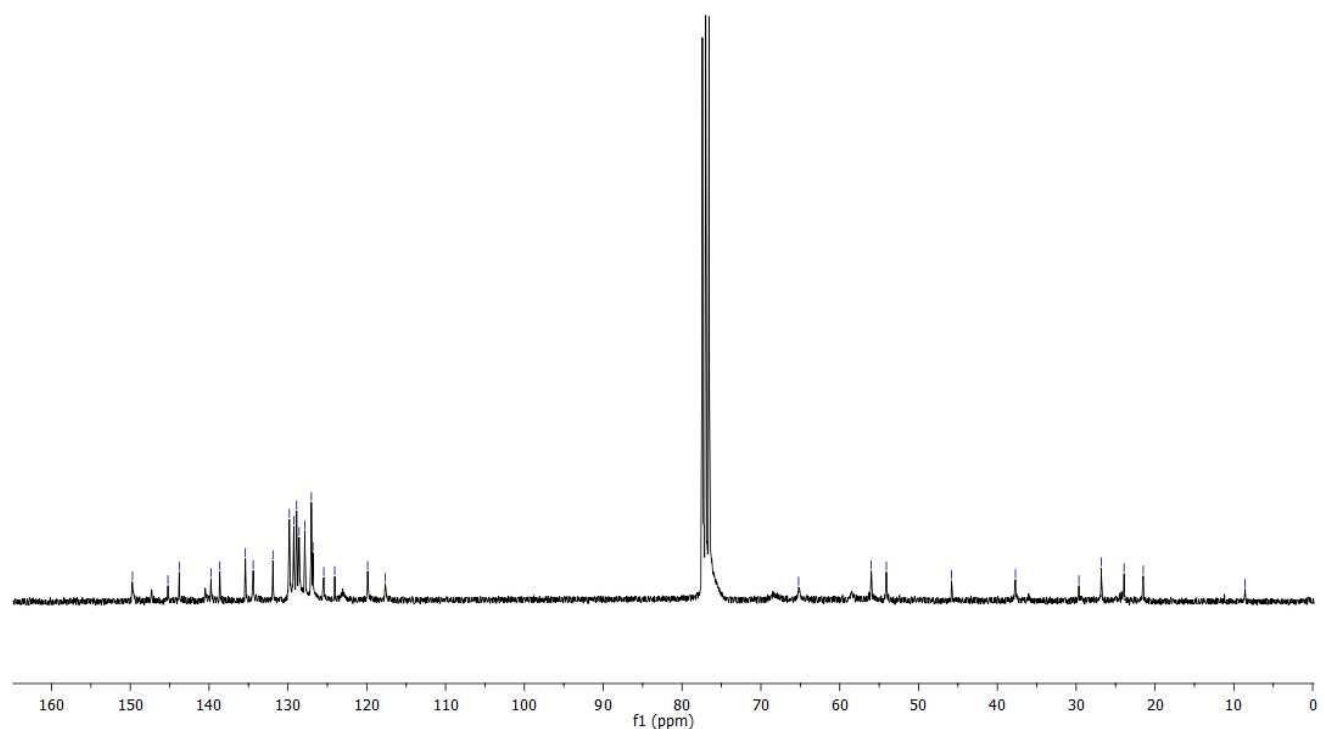




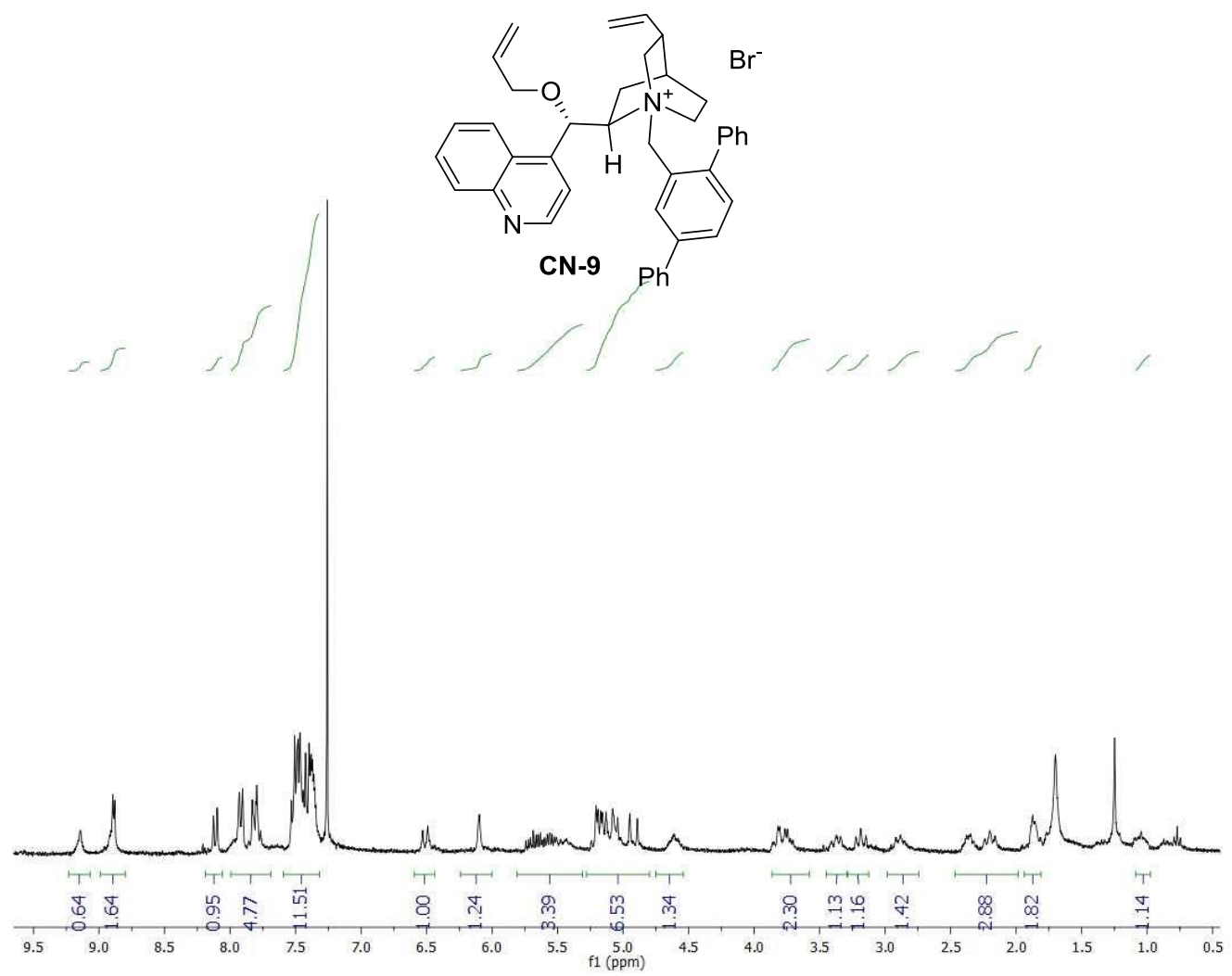

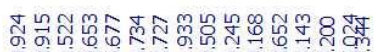

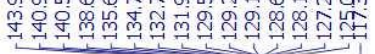

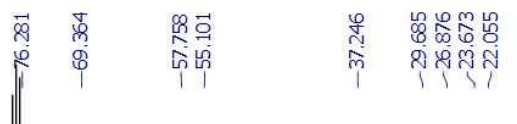

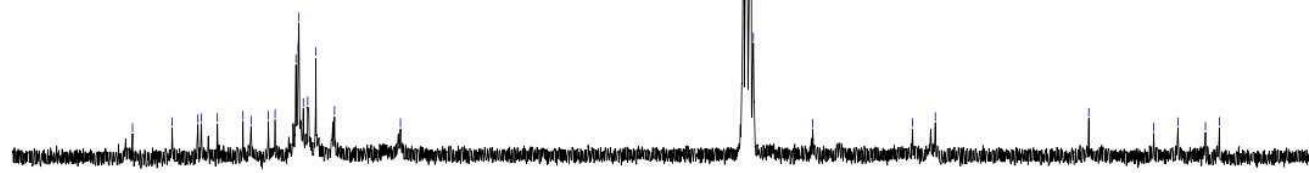

$\begin{array}{lllllllllllllllllllllllllllllll}160 & 155 & 150 & 145 & 140 & 135 & 130 & 125 & 120 & 115 & 110 & 105 & 100 & 95 & \begin{array}{c}90 \\ \mathrm{f} 1(\mathrm{ppm})\end{array} & 80 & 75 & 70 & 65 & 60 & 55 & 50 & 45 & 40 & 35 & 30 & 25 & 20 & 15\end{array}$ 
<smiles>CN1CCOC(C)(O)C1c1ccccc1</smiles>

16
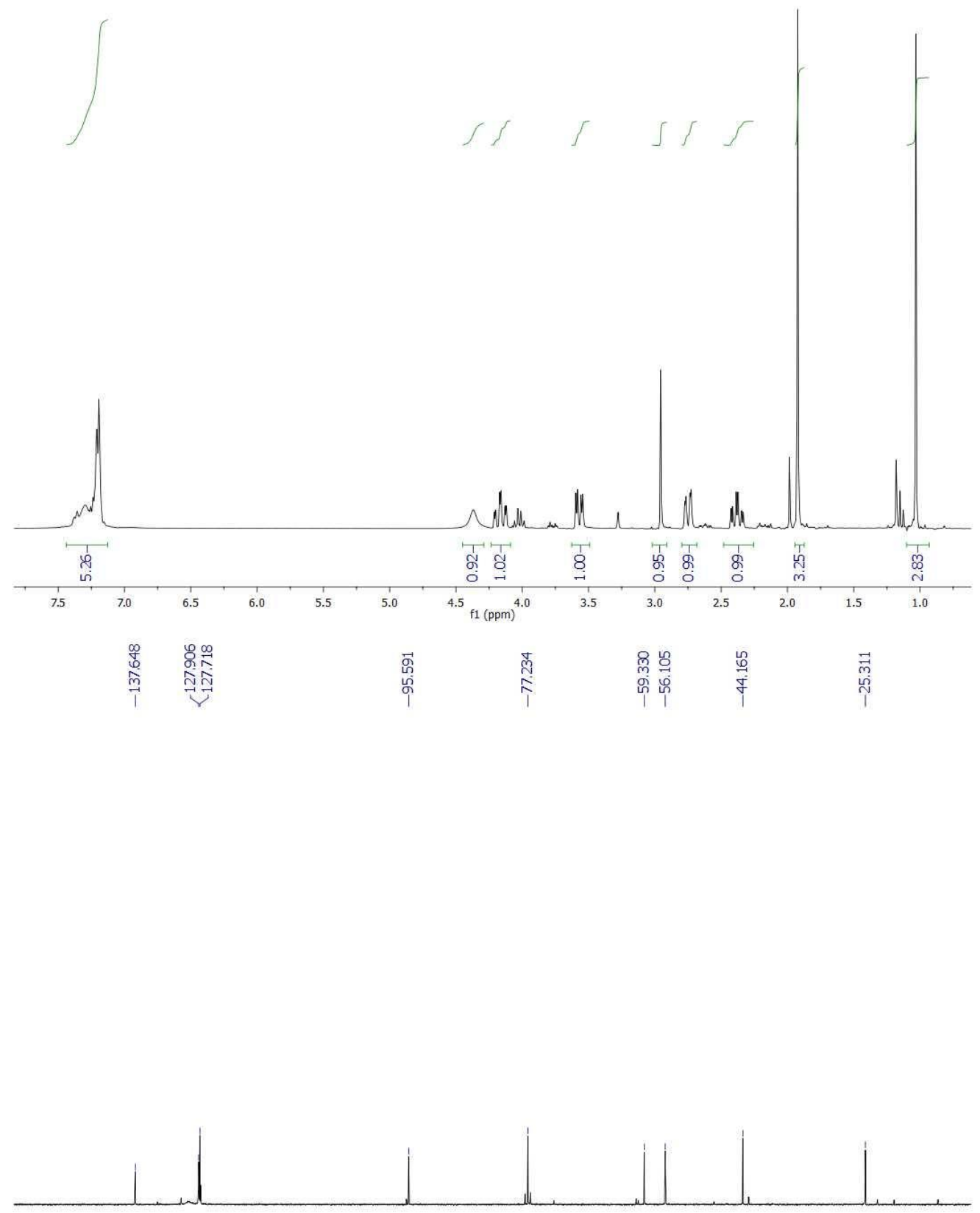

$\begin{array}{lllllllllllllllllllllllllllllllllllll}155 & 150 & 145 & 140 & 135 & 130 & 125 & 120 & 115 & 110 & 105 & 100 & 95 & 90 & \begin{array}{c}85 \\ \mathrm{f}(\mathrm{ppm})\end{array} & 75 & 70 & 65 & 60 & 55 & 50 & 45 & 40 & 35 & 30 & 25 & 20 & 15 & 10\end{array}$ 

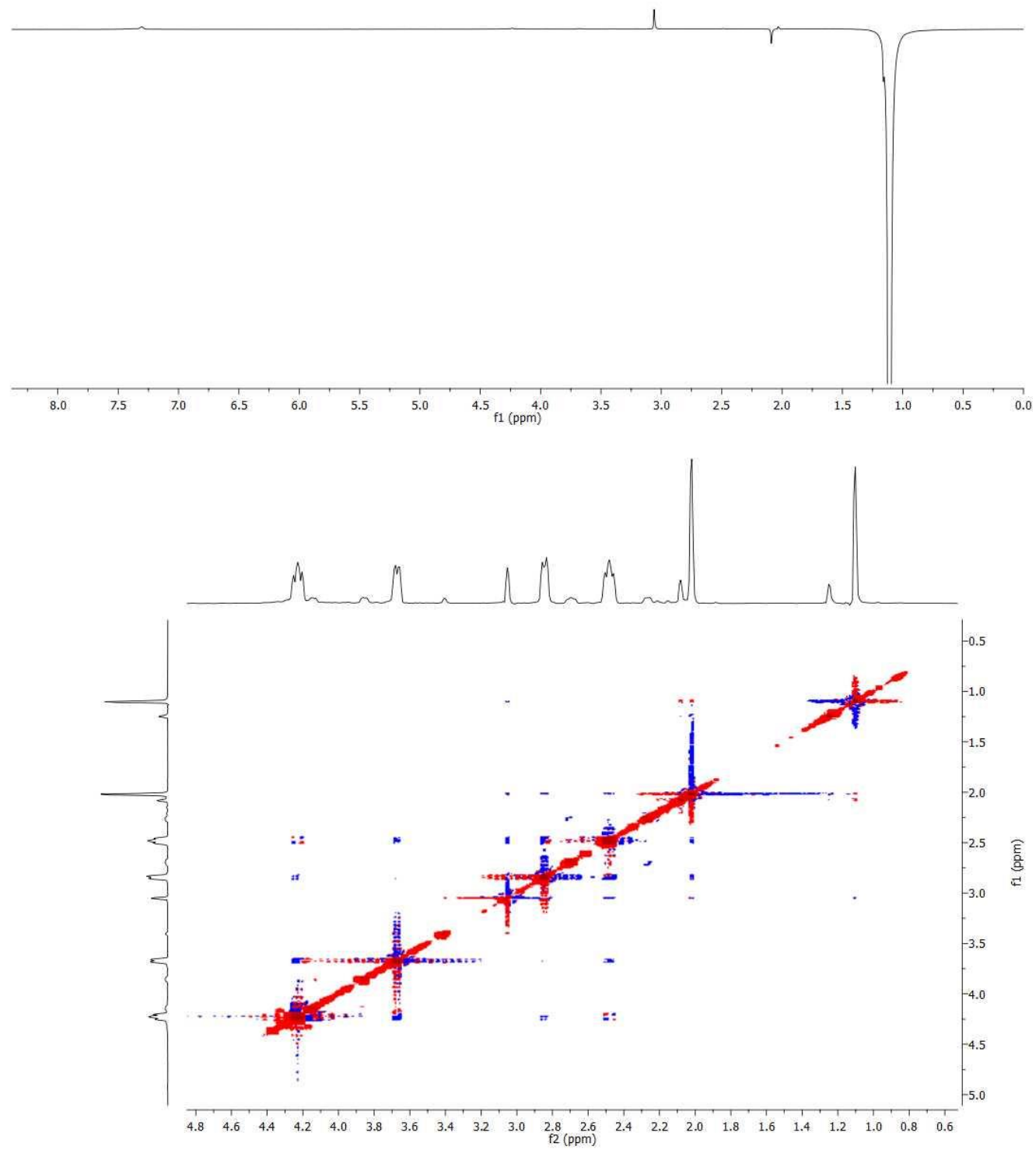
<smiles>C[C@H]1NCCS[C@@H]1c1ccccc1</smiles>

18

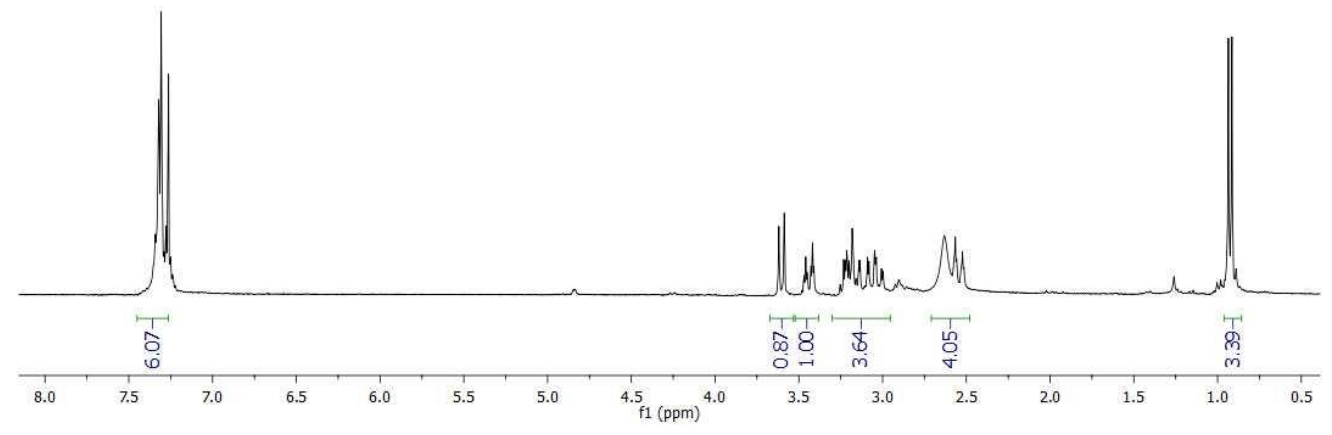

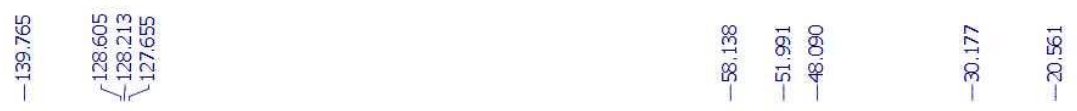

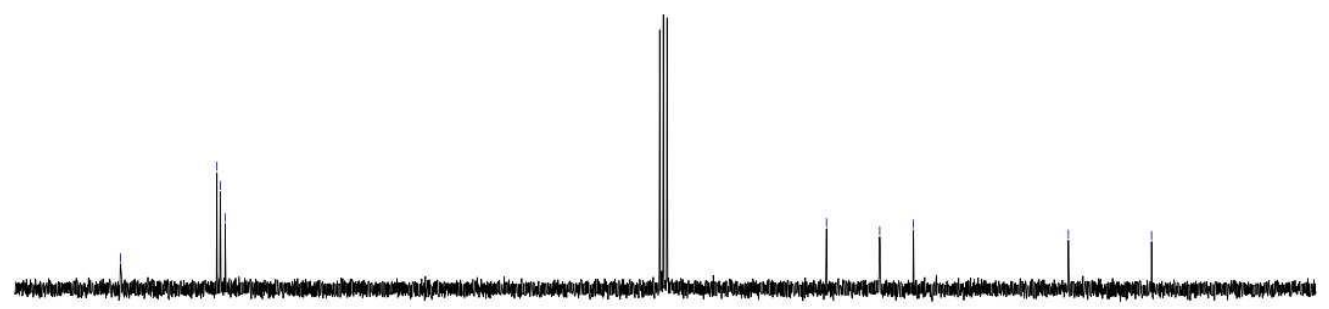

$\begin{array}{lllllllllllllllllllllllllllllllll}150 & 145 & 140 & 135 & 130 & 125 & 120 & 115 & 110 & 105 & 100 & 95 & 90 & 85 & 80 & 75 & 70 & 65 & 60 & 55 & 50 & 45 & 40 & 35 & 30 & 25 & 20 & 15 & 10 & 5\end{array}$ 
<smiles>CC1SCCNC1c1ccccc1</smiles>

19

syn/anti

2/1
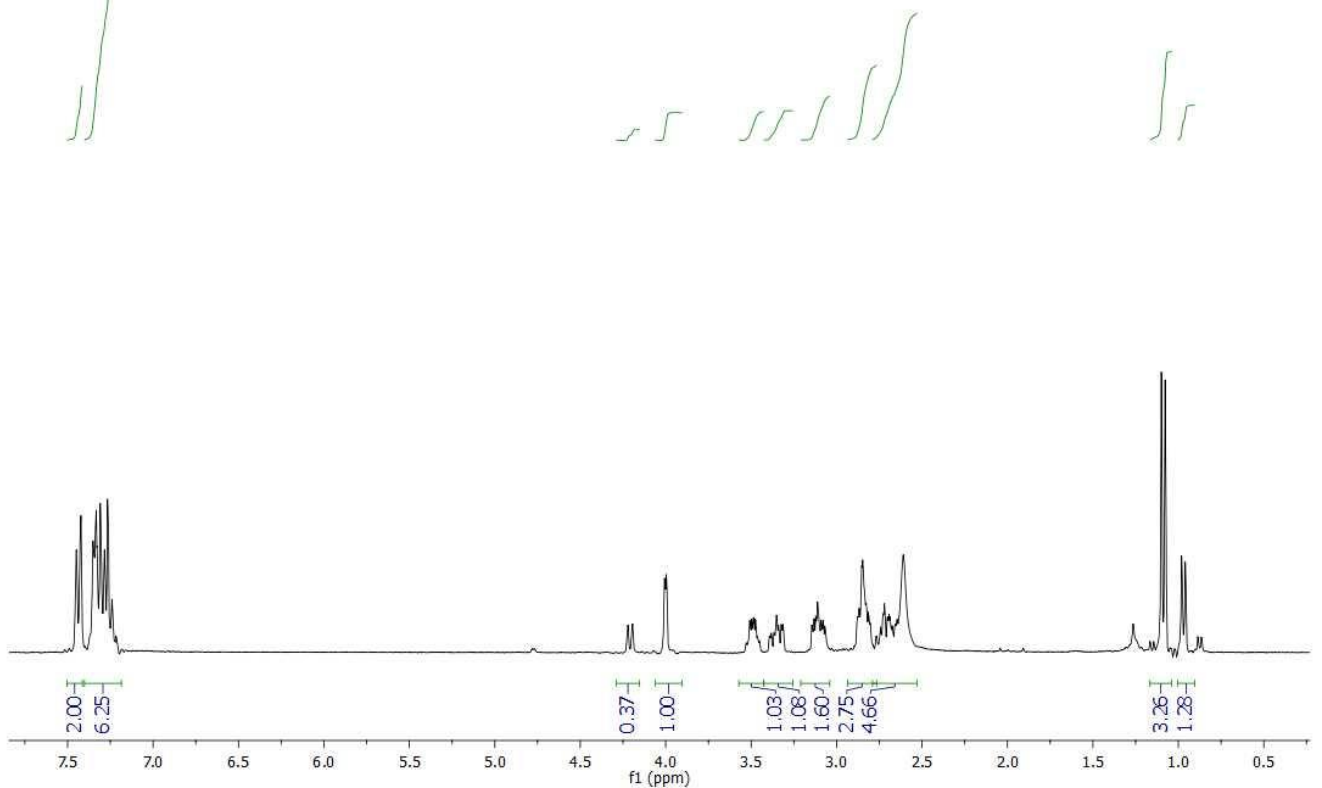



\section{HIPLC and GC}

Chromatograms 

$\overbrace{M e}^{\mathrm{O} \mathrm{NO}_{2}}$

$2 a$

\section{Racemic compound}

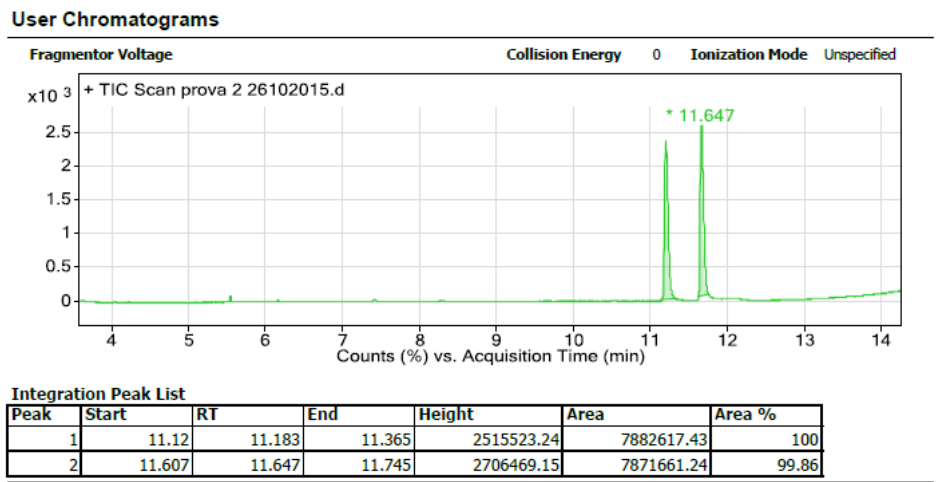

\section{Enantioenriched compound}

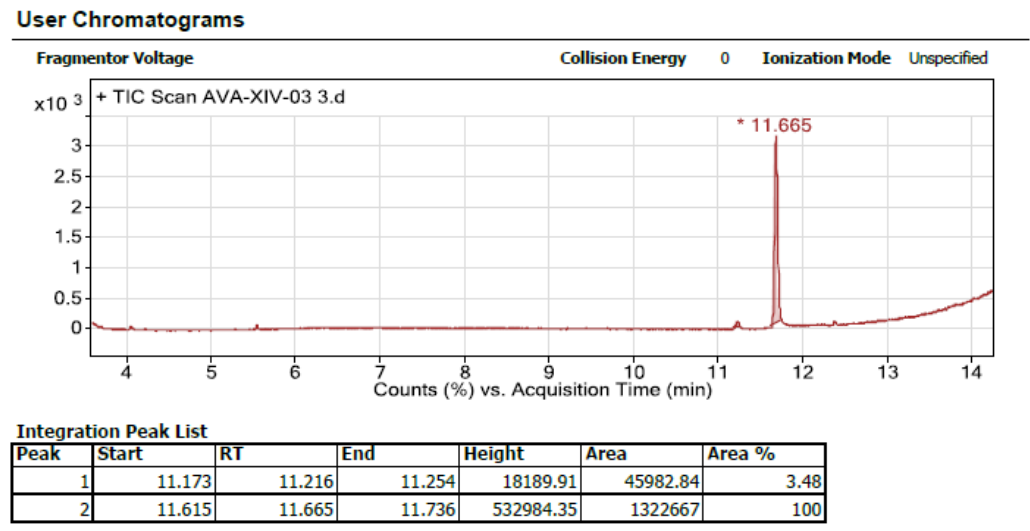


<smiles>CC1([N+](=O)[O-])OC1c1ccc(F)cc1</smiles>

\section{Racemic compound}

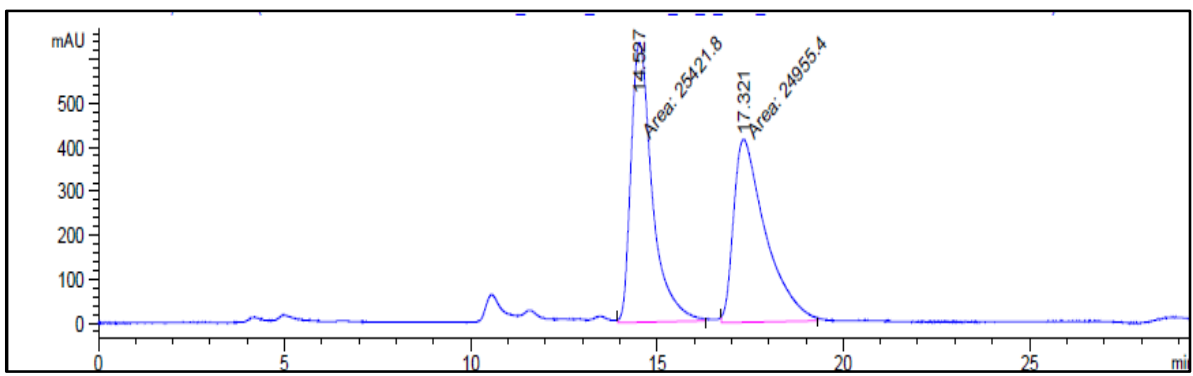

\begin{tabular}{|c|c|c|c|c|c|}
\hline $\begin{array}{c}\text { Peak } \\
\#\end{array}$ & $\begin{array}{l}\text { RetTime Type } \\
\text { [min] }\end{array}$ & $\begin{array}{l}\text { Width } \\
\text { [min] }\end{array}$ & $\begin{array}{c}\text { Area } \\
{[\mathrm{mAU} * \mathrm{~s}]}\end{array}$ & $\begin{array}{l}\text { Height } \\
\text { [mAU] }\end{array}$ & $\begin{array}{c}\text { Area } \\
\%\end{array}$ \\
\hline & & & & & \\
\hline 2 & 17.321 MM T & 0.9982 & $2.49554 \mathrm{e} 4$ & 416.68872 & 49.5370 \\
\hline
\end{tabular}

\section{Enantioenriched compound}
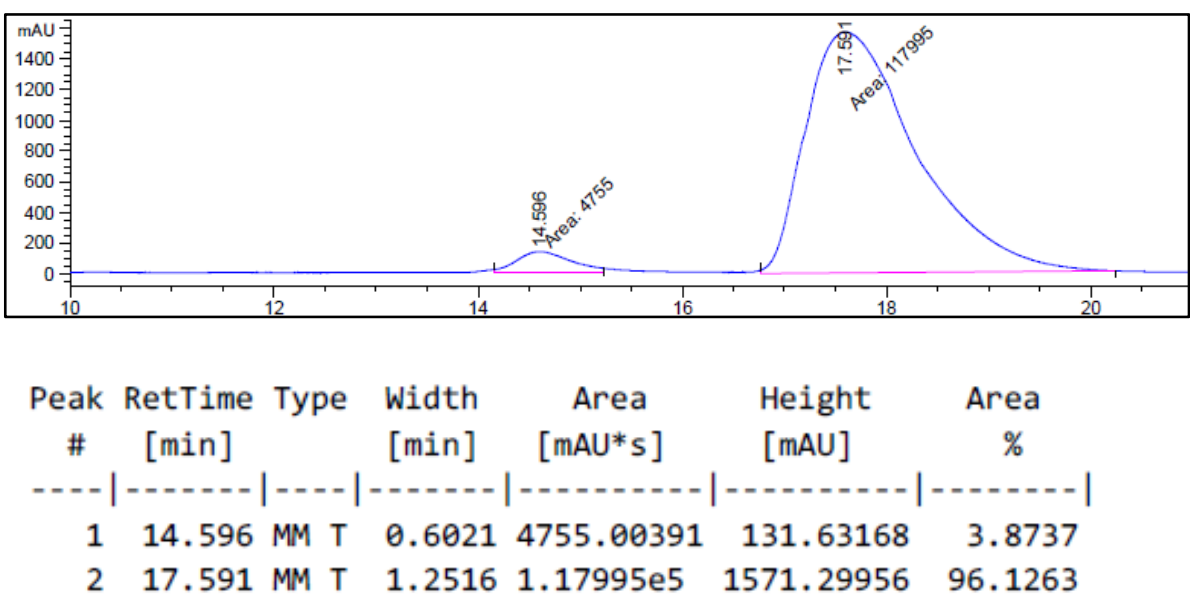
<smiles>CC1([N+](=O)[O-])OC1c1ccc(Cl)cc1</smiles>

\section{Racemic compound}
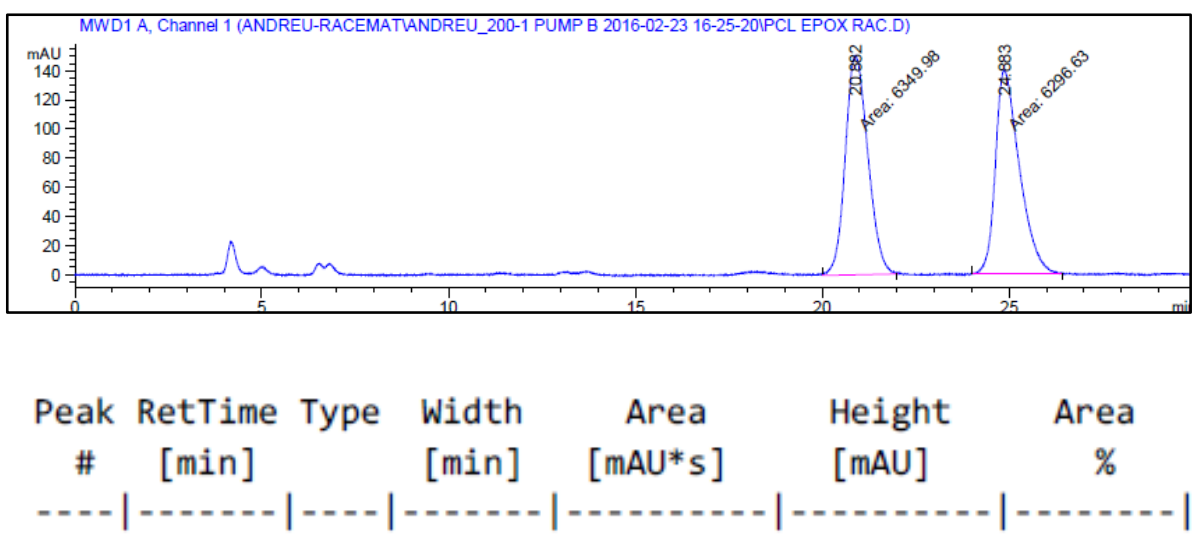

$\begin{array}{lllllll}1 & 20.882 & \text { MM } & 0.7005 & 6349.97705 & 151.07651 & 50.2109\end{array}$

$\begin{array}{lllllll}2 & 24.883 & \text { MM } & 0.7480 & 6296.62988 & 140.29599 & 49.7891\end{array}$

Totals :

$1.26466 \mathrm{e} 4 \quad 291.37250$

\section{Enantioenriched compound}

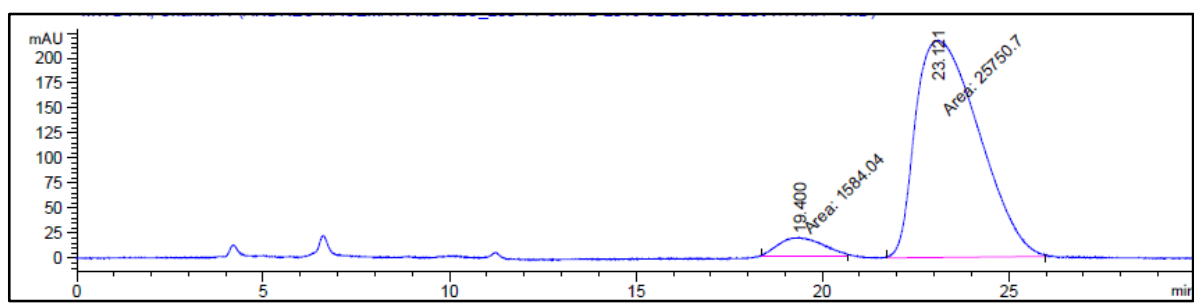

\begin{tabular}{|c|c|c|c|c|c|}
\hline $\begin{array}{c}\text { Peak } \\
\#\end{array}$ & $\begin{array}{l}\text { RetTime Type } \\
\text { [min] }\end{array}$ & $\begin{array}{l}\text { Width } \\
\text { [min] }\end{array}$ & $\begin{array}{c}\text { Area } \\
{[\mathrm{mAU} * \mathrm{~s}]}\end{array}$ & $\begin{array}{l}\text { Height } \\
\text { [mAU] }\end{array}$ & $\begin{array}{c}\text { Area } \\
\%\end{array}$ \\
\hline & & & & & \\
\hline 1 & 19.400 & 9 & 1584.03833 & 8.77824 & 10 \\
\hline 2 & 23.121 & 731 & $2.57507 e 4$ & 217.51802 & 94.2050 \\
\hline
\end{tabular}

Totals :

$2.73347 \mathrm{e} 4 \quad 236.29626$ 
<smiles>CC1([N+](=O)[O-])OC1c1cccc(Cl)c1</smiles>

\section{Racemic compound}

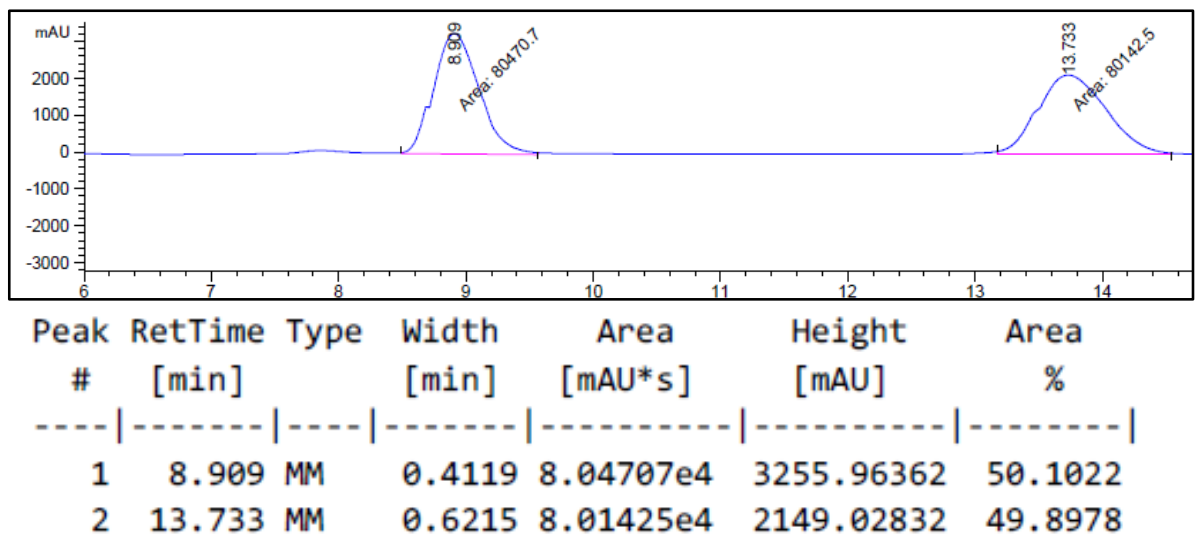

\section{Enantioenriched compound}

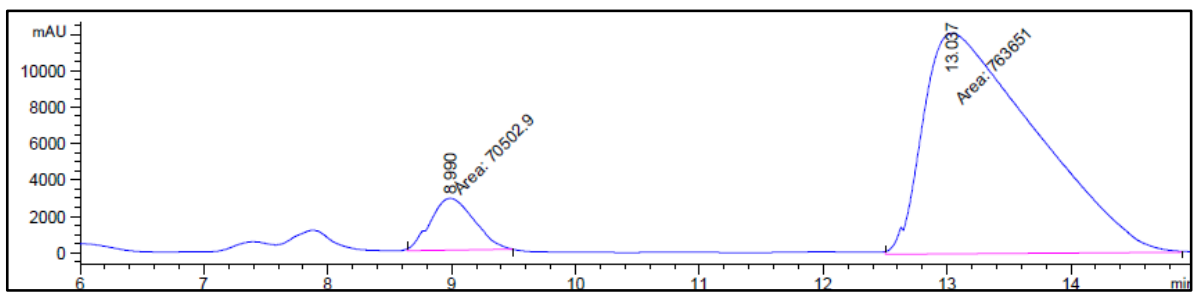

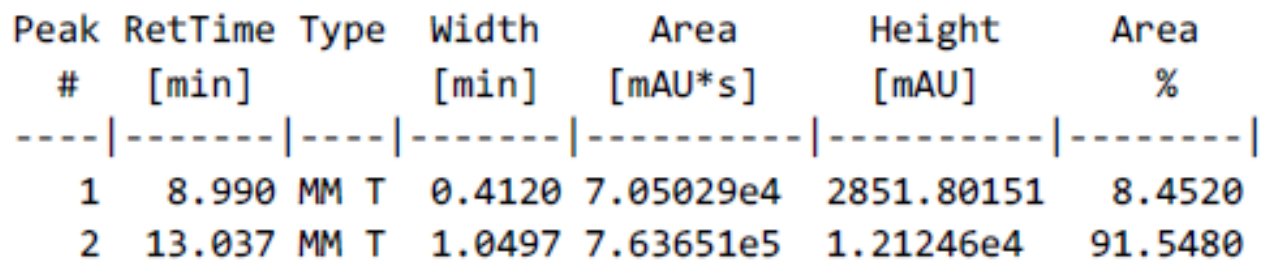


<smiles>CCC1([N+](=O)[O-])OC1c1ccc(F)cc1</smiles>

\section{Racemic compound}
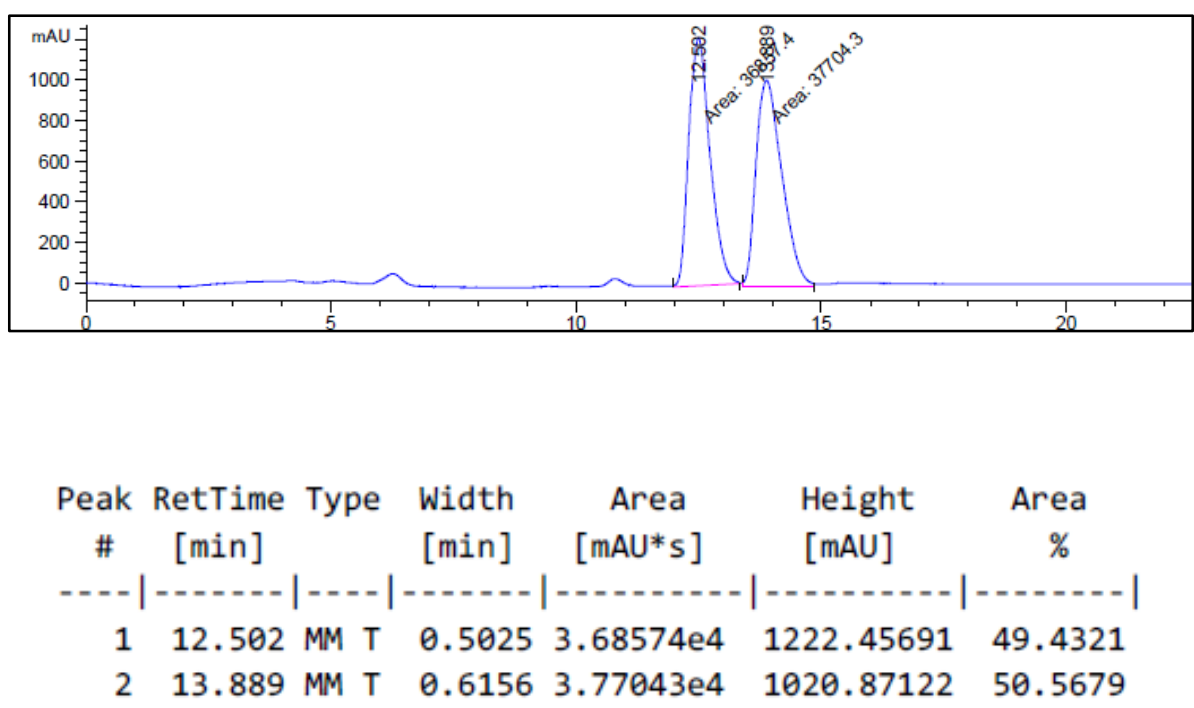

\section{Enantioenriched compound}
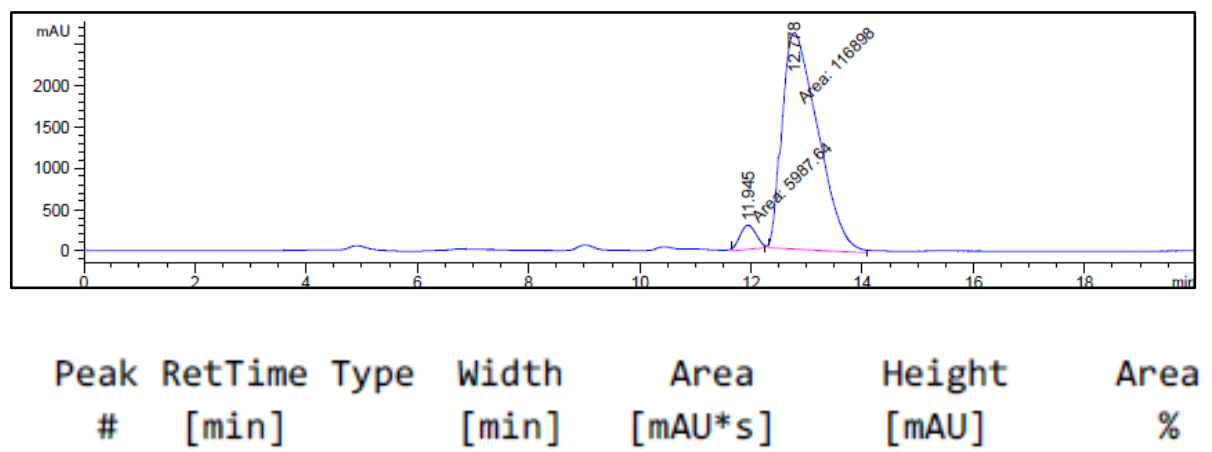

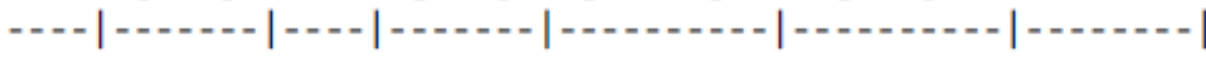

$$
\begin{aligned}
& \begin{array}{lllllll}
1 & 11.945 & \text { MM T } & 0.3396 & 5987.64063 & 293.85883 & 4.8725
\end{array}
\end{aligned}
$$

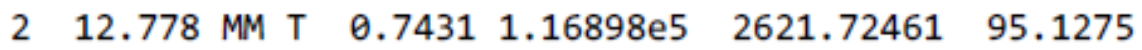


<smiles>CCCCC1(C)OC1c1ccc(C)cc1</smiles>

\section{Racemic compound}
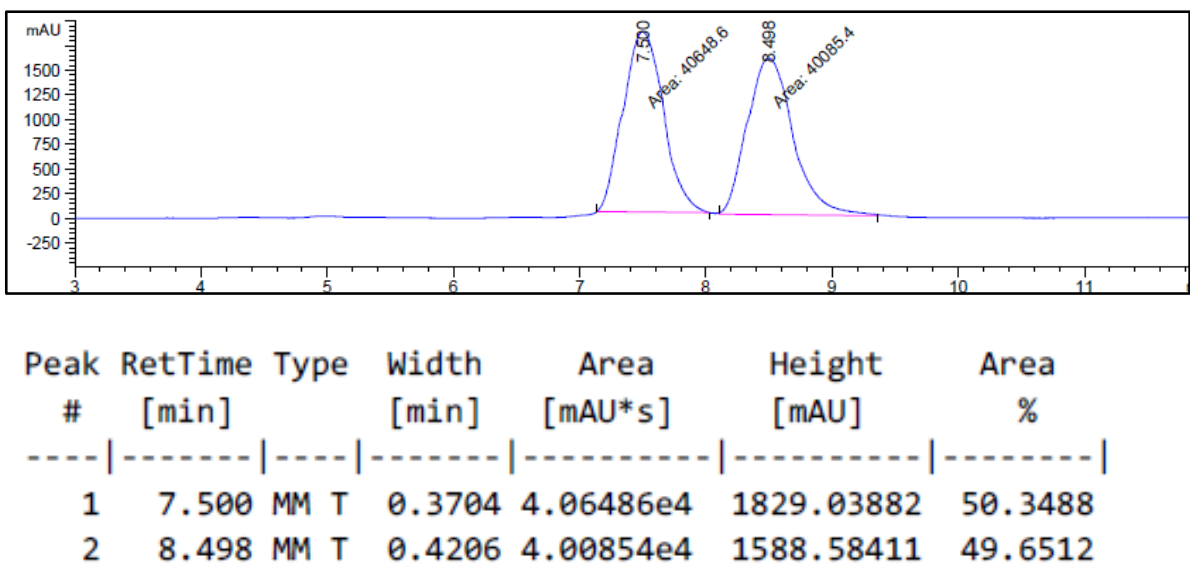

\section{Enantioenriched compound}
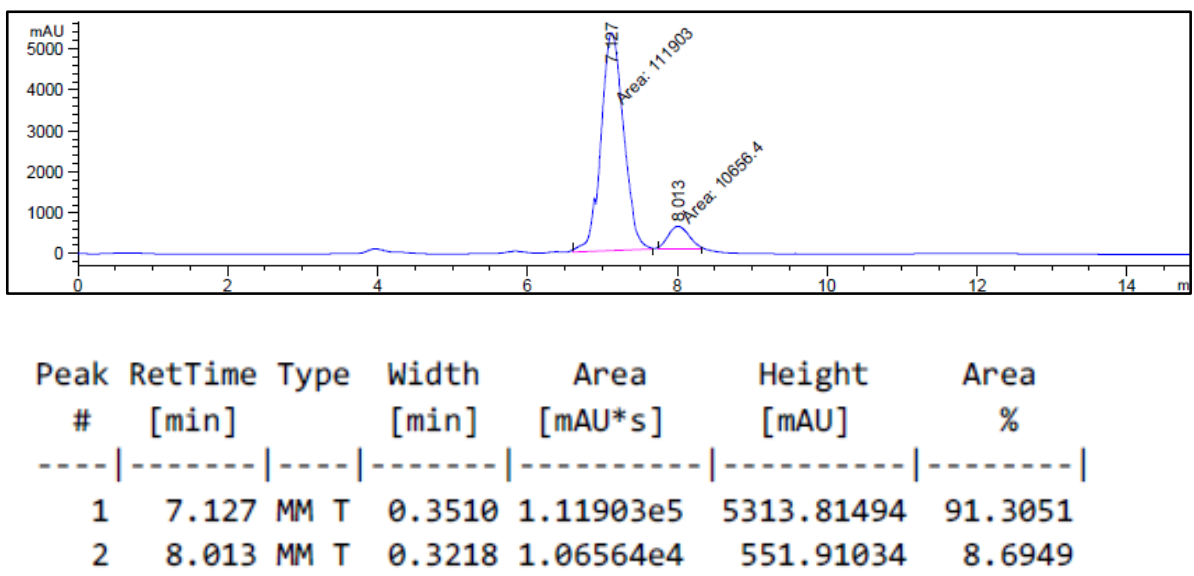
<smiles>O=[N+]([O-])C1(c2ccccc2)OC1c1ccccc1</smiles>

\section{Racemic compound}

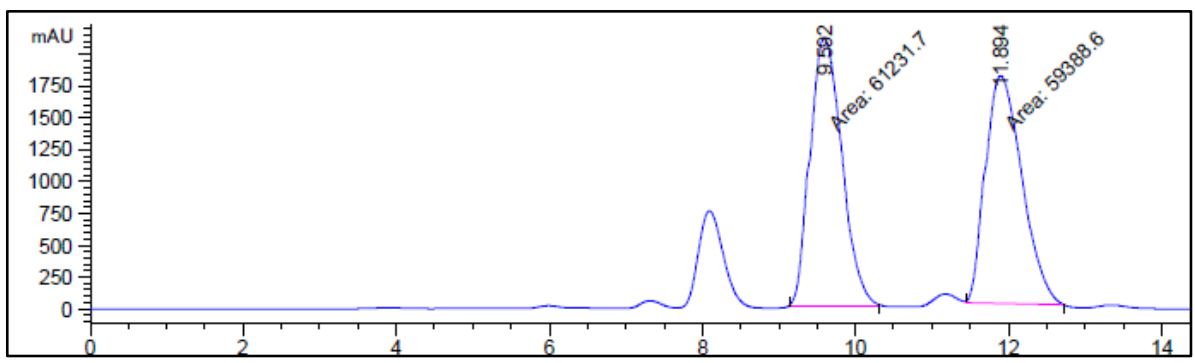

\begin{tabular}{cccccc}
$\begin{array}{c}\text { Peak RetTime Type } \\
\text { W }\end{array}$ & $\begin{array}{c}\text { Width } \\
\text { [min] }\end{array}$ & $\begin{array}{c}\text { Area } \\
\text { [mAU*s] }\end{array}$ & $\begin{array}{c}\text { Height } \\
\text { [mAU] }\end{array}$ & $\begin{array}{c}\text { Area } \\
\%\end{array}$ \\
\hline 1 & 9.592 MM & 0.4846 & 6.12317 e4 & 2106.07007 & 50.7640 \\
2 & 11.894 MM & 0.5546 & $5.93886 \mathrm{e} 4$ & 1784.80640 & 49.2360
\end{tabular}

\section{Enantioenriched compound}

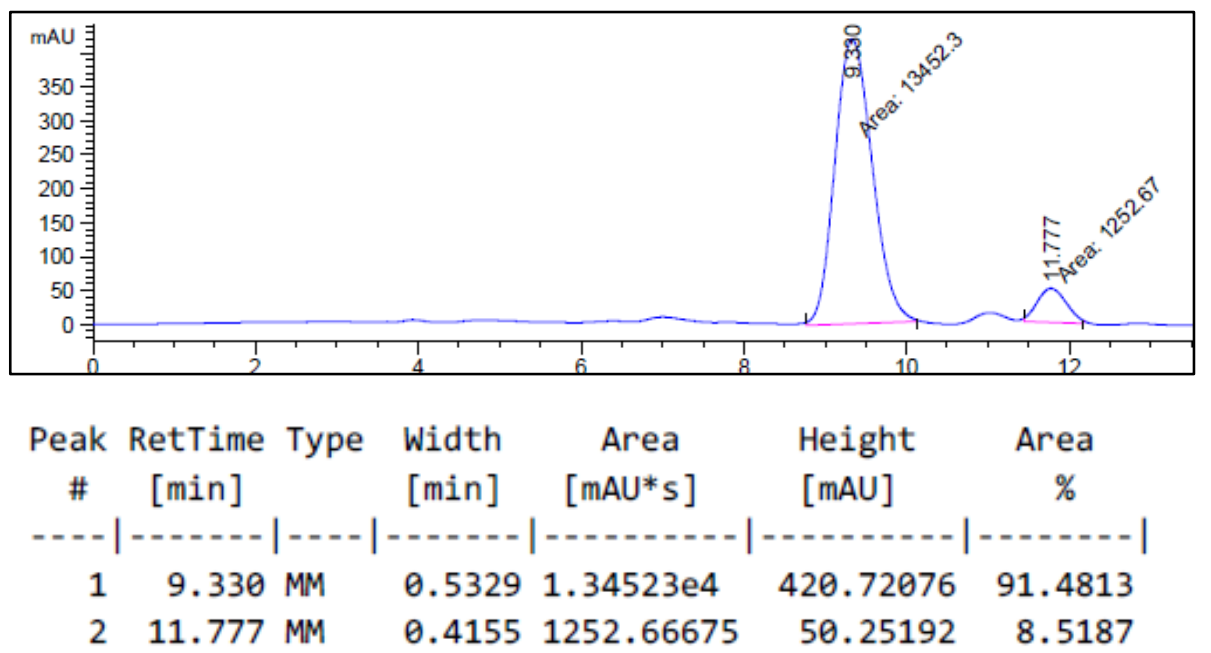



Ammex 



\section{List of Publications:}

\section{Related to this PhD Thesis:}

- "Dynamic Kinetic Asymmetric Ring-Opening/ Reductive Amination Sequence of Racemic Nitroepoxides with Chiral Amines: Enantioselective Synthesis of Chiral Vicinal Diamines"

Agut, J.; Vidal, A.; Rodríguez, S.; González, F. V. J. Org. Chem. 2013, 78 (11), 5717.

- "Nitroepoxides as Versatile Precursors to 1,4Diaminoheterocycles" Vidal-Albalat, A.; Rodríguez, S.; González, F. V. Org. Lett. 2014, 16 (6), 1752.

- "Asymmetric Epoxidation of Alkylidenemalononitriles: Key Step for One-Pot Approach to Enantioenriched 3Substituted Piperazin-2-ones" Meninno, S.; Vidal-Albalat, A.; Lattanzi, A. Org. Lett. 2015, 17 (17), 4348.

- "Preparation of Morpholines and Benzoxazines Starting from Nitroepoxides"

Capel, E.; Vidal-Albalat, A.; Rodríguez, S.; González, F. V. Synthesis 2016, 48, A-1

- "Catalytic Enantioselective Epoxidation of Nitroalkenes" Vidal-Albalat, A; Świderek, K.; Izquierdo, J.; Rodríguez, S.; Moliner, V.; González, F.V. Chem. Commun., under review 


\section{Collaborations and other publications:}

- "Development and Validation of a Liquid

Chromatography Isotope Dilution Mass Spectrometry Method for the Reliable Quantification of Alkylphenols in Environmental Water Samples by Isotope Pattern Deconvolution"

Fabregat-Cabello, N.; Sancho, J. V.; Vidal, A.; González, F. V.; Roig-Navarro, A. F. J. Chromatogr. A 2014, 1328, 43

- Book Chapter: "Natural Products as Cathepsin Inhibitors" Vidal-Albalat, A.; González, F. V. Studies in Natural Products Chemistry, Accepted 


\section{Resumn en Catalå}





\section{Objectius generals}

Els objectius generals d'aquesta tesi doctoral queden englobats en els següents punts:

- Estudi de la reactivitat característica què converteix els nitroepòxids en "peces de construcció" interessants per la seua aplicació en la síntesi química de molècules més complexes.

- Derivació dels nitroepòxids en heterocicles nitrogenats com per exemple quinoxalines, pirazines, piperazines i tetrahidroquinoxalines, què són entitats moleculars que tenen un interés especial en la química mèdica.

- Estudi d'epoxidació asimètrica organocatalítica de dicianoalquilidens per la seua aplicació sintètica.

- Disseny racional i síntesi de catalitzadors de transferència de fase i la seua aplicació per l'epoxidació enantioselectiva de nitroalquens. 


\section{Introducció}

Una de les fites més importants per un químic orgànic sintètic és aconseguir la síntesi d'una molècula específica amb un alt rendiment $\mathrm{i}$ puresa, però emprant mitjans econòmics, de baix impacte per la salut $\mathrm{i}$ l'ambient, i que les operacions realitzades per aquesta finalitat siguen pràctiques, simples i de temps optimitzat. Els darrers anys, els químics orgànics han batejat les molècules que ajuden a aconseguir aquest objectiu com a building blocks (peces de construcció en anglès), ja que es poden comparar amb peces de trencaclosques que permeten múltiples enllaços i combinacions amb diferents grups funcionals per tal de sintetitzar entitats més complexes què tinguen una aplicació en altres branques de la química com puga ser la mèdica o de materials.

El grup d'investigació de la Universitat Jaume I dirigit pel professor Florenci V. González ha enfocat la seua recerca en una determinada família de compostos que compleixen les característiques dels anteriorment mencionats building blocks. Aquests compostos són els nitroepòxids (Figura 1). Els nitroepòxids van ser descrits per primera vegada el 1969 per Newman i Angier i es caracteritzen per posseir un grup nitro en la posició $\alpha$ a l'epòxid, retirant densitat electrònica convertint-lo així en un grup més electrofílic. ${ }^{1}$ En altres paraules, els nitroepòxids es podrien considerar sintons amb dues posicions electrofíliques contigües (Figura 1), tret que els converteix en bons building blocks.

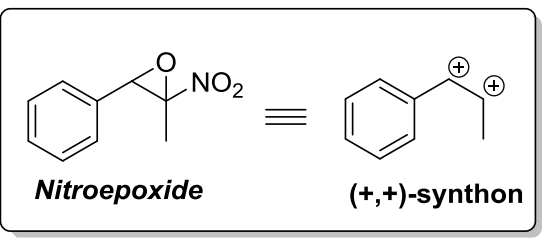

Figura 1. Nitroepòxids com sintons 1,2-electrofílics.

En el seu treball, Newman i Angier descriuen la síntesi de l'epòxid provinent del trans- $\beta$-metil- $\beta$-nitroestirè i la posterior apertura dels epòxids utilitzant diversos nucleòfils. ${ }^{1}$ La reactivitat particular dels

\footnotetext{
${ }^{1}$ a) Newman, H.; Angier, R. B. J. Chem. Soc. D Chem. Commun. 1969, 186, 369. b) Newman, H.; Angier, R. B. Tetrahedron 1970, 26, 826.
} 
nitroepòxids fa que el nucleòfil ataque primer a la posició $\beta$ respecte al grup nitro, ja que aquesta és la menys impedida, provocant l'apertura de l'epòxid i seguidament, degut a que el nitro és molt bon grup eixent, és produeix l'expulsió del grup nitro donant lloc a la cetona com a producte de la reacció (Esquema 1).

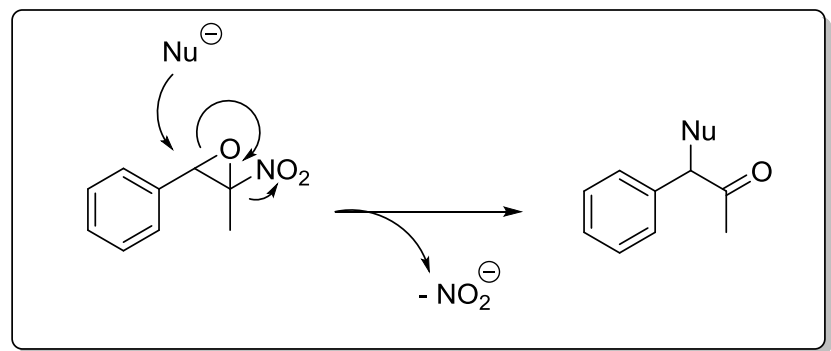

Esquema 1. Reactivitat del nitroepòxid enfront un nucleòfil.

Els precedents estudiats en el nostre grup es basen en l'apertura de nitroepòxids emprant amines com a nucleòfils $\mathrm{i}$ en un segon pas, utilitzant un altre equivalent de la mateixa amina seguit d'un agent reductor per dur a terme una aminació reductiva i obtindre 1,2diamines. ${ }^{2}$ Un fet interessant què vam observar, és que el procés global era diastereoselectiu (depenent dels substrats, la disatereoselectivitat variava de 90:10 a 99:1). A més, si s'emprava una amina amb un centre quiral de la reacció s'obtenia la diamina amb un 55-70\% de rendiment i un dels quatre possibles diastereoisòmers amb elevada selectivitat (e.d. $>88 \%$ ). Donat que una resolució no donaria un rendiment superior al $50 \%$, aquest fet va ser interpretat com una transformació asimètrica dinàmico-cinètica, o DYKAT en les seues segles en anglés (Esquema 2).

\footnotetext{
${ }^{2}$ Agut, J.; Vidal, A.; Rodríguez, S.; González, F. V. J. Org. Chem. 2013, 78 (11), 5717.
} 


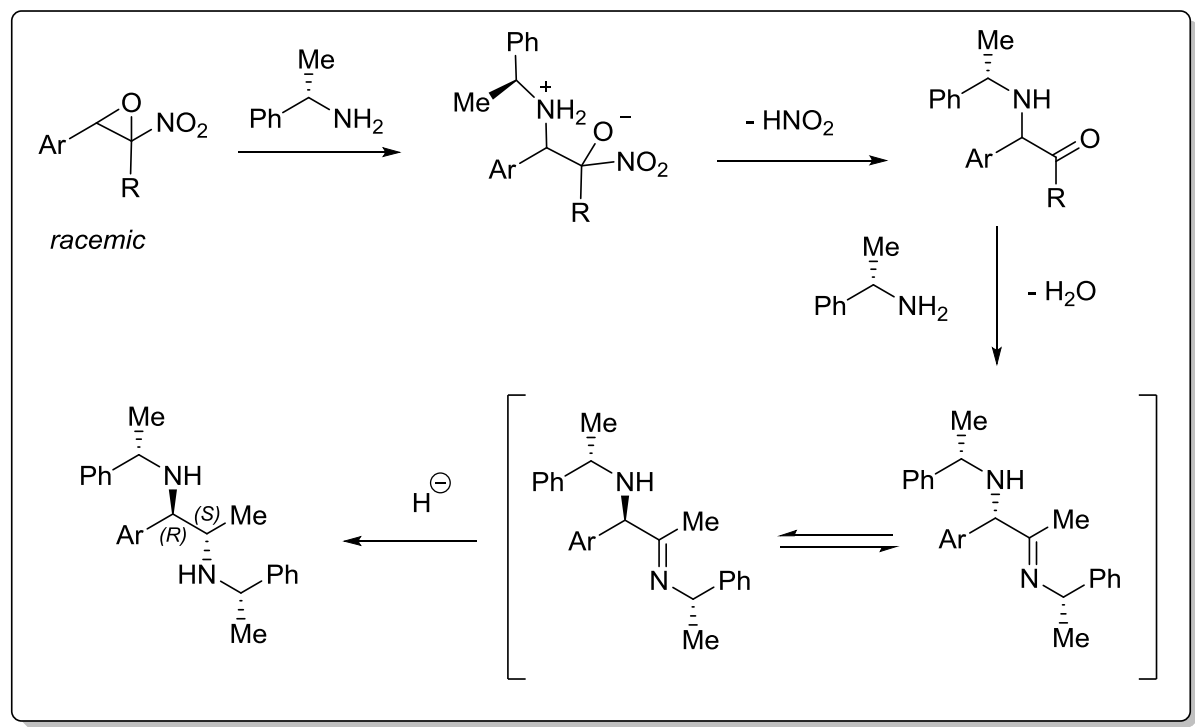

Esquema 2. Transformació asimètrica dinàmico-cinètica o DYKAT.

Donada la reactivitat dels nitroepòxids enfront de les amines per obtindre 1,2-diamines, una de les possibles aplicacions pensades per la realització d'aquesta tesi doctoral és la conversió dels nitroepòxids en 1,4-diazaheterocicles, com per exemple quinoxalines, pirazines, tetrahidroquinoxalines i piperazines. Aquests compostos tenen una certa rellevància en la química mèdica ja que són comuns en molts fàrmacs antibacterians ${ }^{3}$, antivirals ${ }^{4}$ i anticancerígens ${ }^{5}$ (Figura 2). A banda, les quinoxalines i les pirazines tenen una certa presència en la química dels materials, com per exemple tints orgànics per a cèl·lules fotovoltaiques, degut a les seues propietats fotoquímiques ${ }^{6}$.

\footnotetext{
${ }^{3}$ Vieira, M.; Pinheiro, C.; Fernandes, R.; Noronha, J. P.; Prudêncio, C. Microbiol. Res. 2014, 169 (4), 287.

${ }^{4}$ a) You, L.; Cho, E. J.; Leavitt, J.; Ma, L.-C.; Montelione, G. T.; Anslyn, E. V; Krug, R. M.; Ellington, A.; Robertus, J. D. Bioorg. Med. Chem. Lett. 2011, 21 (10), 3007. b) Patel, M.; McHugh, R. J.; Cordova, B. C.; Klabe, R. M.; Bacheler, L. T.; EricksonViitanen, S.; Rodgers, J. D. Bioorg. Med. Chem. Lett. 2001, 11, 1943.

5 a) Zarranz, B.; Jaso, A.; Aldana, I.; Monge, A. Bioorg. Med. Chem. 2004, 12 (13), 3711. b) Horton, D.; Bourne, G. T.; Smythe, M. L. Cancer Res. 2003, 103 (3), 893.

${ }^{6}$ a) Chandrasekaran, Y.; Dutta, G. K.; Kanth, R. B.; Patil, S. Dye. Pigment. 2009, 83

(2), 162. b) Mondal, R.; Ko, S.; Bao, Z. J. Mater. Chem. 2010, 20 (47), 10568.
} 


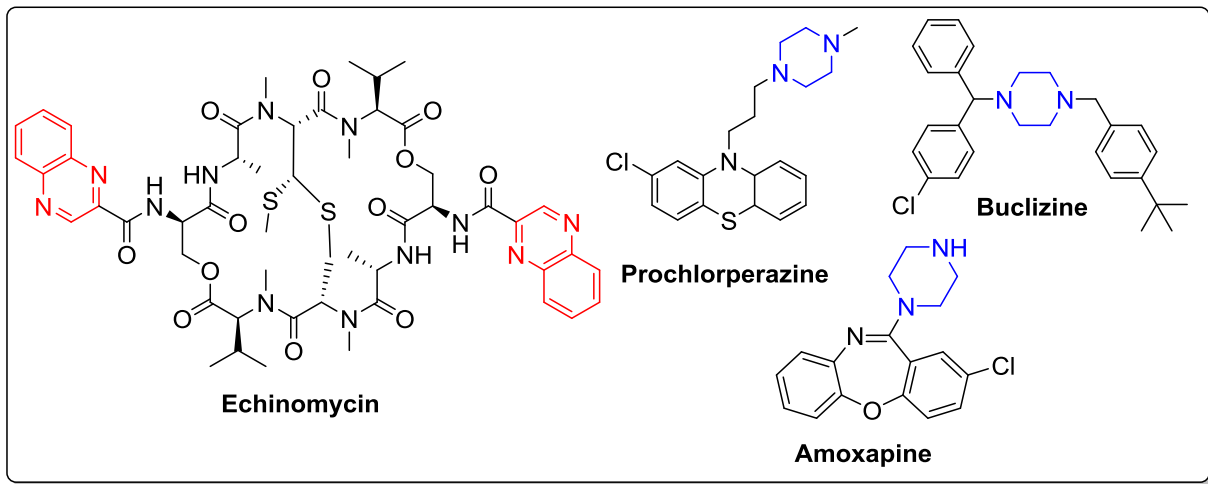

Figura 2. Exemples de fàrmacs i productes naturals bioactius que contenen 1,4diazaheterocicles en la seua estructura.

La síntesi d'aquests heterocicles està comunament lligada a precursors de difícil accés com per exemple 1,2-dicetones, la qual cosa fa què la seua obtenció siga limitada. És per això que, donat el caràcter 1,2electrofílic dels nitroepòxids és semblant al de les 1,2-dicetones però la seua síntesi molt més assequible, per la realització d'aquesta tesi s'ha pensat amb els nitroepòxids com a precursors sintètics d'aquests compostos.

Donada la versatilitat sintètica dels epòxids, i concretament en aquest cas dels nitroepòxids, la seua versió asimètrica proporcionaria una ferramenta valuosa per la síntesi de compostos òpticament actius. Els nitroepòxids es preparen mitjançant l'epoxidació del nitroalquè corresponent. No obstant, a data d'avui no s'ha documentat cap mètode d'epoxidació enantioselectiva de nitroalquens, excepte un treball d'Enders el qual té les seues limitacions per ser molt substratdependent ${ }^{7}$. L'únic mètode d'obtenció de nitroepòxids enantioenriquits que apareix en la literatura es tracta d'una resolució d'una mescla racèmica de nitroepòxids mitjançant anilina i un organocatalitzador quiral $^{8}$. Tanmateix, aquesta metodologia presenta limitacions considerables, tenint en compte que amb la resolució quiral d'una mescla racèmica no es pot obtindre més del $50 \%$ del producte desitjat. És per això, que l'epoxidació enantioselectiva de nitroalquens suposaria un avenç destacable per la síntesi asimètrica.

\footnotetext{
${ }^{7}$ Enders, D.; Kramps, L.; Zhu, J. Tetrahedron: Asymmetry 1998, 9 (22), 3959.

${ }^{8}$ Meninno, S.; Napolitano, L.; Lattanzi, A. Catal. Sci. Technol. 2015, 5 (1), 124.
} 
A pesar de què no hi ha cap mètode disponible per l'epoxidació asimètrica de nitroalquens, en la bibliografia es poden trobar diversos mètodes per l'epoxidació alquens; des de l'epoxidació enantioselectiva de Sharpless amb un catalitzador quiral de titani, fins l'epoxidació d'alquens electró-deficients com les xalcones mitjançant diversos organocatalitzadors i agents oxidants ${ }^{9}$.

Entre els mètodes organocatalítics per l'epoxidació asimètrica d'alquens electró-deficients es podrien destacar els treballs de JuliáColonna amb polipèptids com a catalitzadors ${ }^{10}$, l'epoxidació a través d'enamina catalitzada amb el derivat de prolinol de Jørgensen-Hayashi (Esquema 3) ${ }^{11}$, les sals d'imidazolidinona de MacMillan ${ }^{12} \mathrm{o}$ l'epoxidació mitjançant dioxirans desenvolupada per $\mathrm{Shi}^{13}$. No obstant, aquesta tesi s'ha centrat en l'epoxidació per catalitzadors bifuncionals i per catalitzadors de transferència de fase.

\footnotetext{
${ }^{9}$ Per una revisió general: Zhu, Y.; Wang, Q.; Cornwall, R. G.; Shi, Y. Chem. Rev. 2014, 114, 8199 .

${ }^{10}$ Juliá, S.; Guixer, J.; Masana, J.; Rocas, J.; Colonna, S.; Annuziata, R.; Molinari, H. J. Chem. Soc. Perkin Trans. I 1982, 1317.

${ }^{11}$ a) Hayashi, Y.; Gotoh, H.; Hayashi, T.; Shoji, M. Angew. Chemie - Int. Ed. 2005, 44 (27), 4212. b) Marigo, M.; Wabnitz, T. C.; Fielenbach, D.; Jørgensen, K. A. Angew. Chemie - Int. Ed. 2005, 44 (5), 794. c) Zhuang, W.; Marigo, M.; Jørgensen, K. A. Org. Biomol. Chem. 2005, 3, 3883.

${ }^{12}$ Lee, S.; MacMillan, D. W. C. Tetrahedron 2006, 62 (49), 11413.

${ }^{13}$ Tu, Y.; Wang, Z.; Shi, Y. J. Am. Chem. Soc. 1996, 118 (40), 9806.
} 


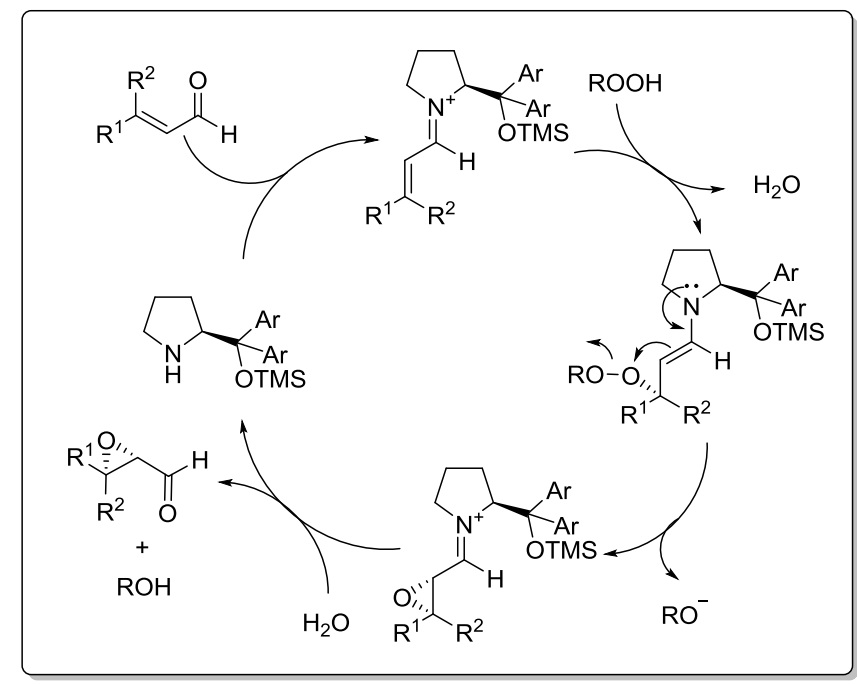

Esquema 3. Procés catalític d'epoxidació enantioselectiva mitjançant un catalitzador de diarilprolinol.

Generalment, s'anomena catalitzador bifuncional a aquell que posseeixi en la seua estructura molecular un grup funcional que actuï com àcid de Lewis i un altre com a base de Lewis. Probablement el més conegut siga el catalitzador de Takemoto $^{14}$, què està composat per una tiourea $i$ una amina terciària. D'altra banda, la catàlisi per transferència de fase, empra sistemes bifàsics (dissolucions en fase aquosa i orgànica, per exemple) amb catalitzadors que són capaços de transportar ions d'una fase a l'altra gràcies a la seua solubilitat en ambdues fases (Esquema 4). Els catalitzadors d'aquest tipus més comunament emprats són sals d'amoni quaternàries derivades d'alcaloides de cincona, en combinació amb solucions aquoses de peròxid o d'hipoclorit sòdic.

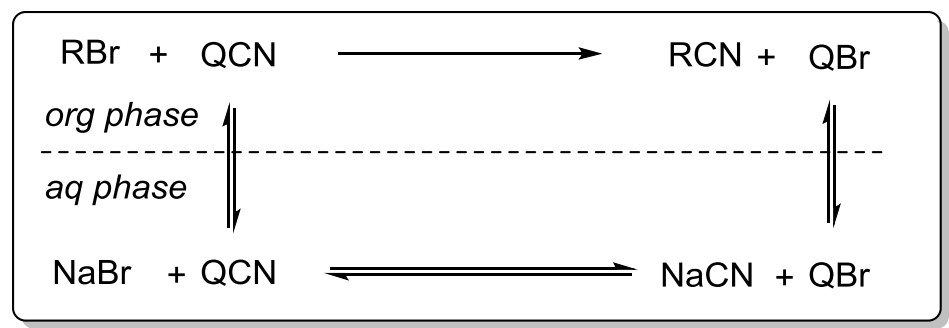

Esquema 4. Representació general d'una reacció de transferència de fase on Q representa el catalitzador.

\footnotetext{
${ }^{14}$ Okino, T.; Hoashi, Y.; Takemoto, Y. J. Am. Chem. Soc. 2003, 125 (42), 12672.
} 
En l'apartat de resultats i discussió s'oferiran els detalls experimentals sobre els objectius especificats i la seua relació amb el que s'ha explicat en aquest apartat d'introducció. 


\section{Resultats i discussió}

\subsection{Heterocicles}

Tenint en compte la reactivitat dels nitroepòxids amb les amines per obtenir 1,2-diamines ${ }^{2}$, es va dissenyar l'apertura de l'anell epoxídic amb compostos que ja contingueren l'estructura 1,2-diamina per tal de formar heterocicles de nitrogen. A més, donat que l'intermedi de reacció vindria a ser una amino-imina, s'obtindria una situació ideal per tal de de sintetitzar un heterocicle aromàtic o saturat treballant en condicions oxidants o reductores, respectivament (Esquema 5).

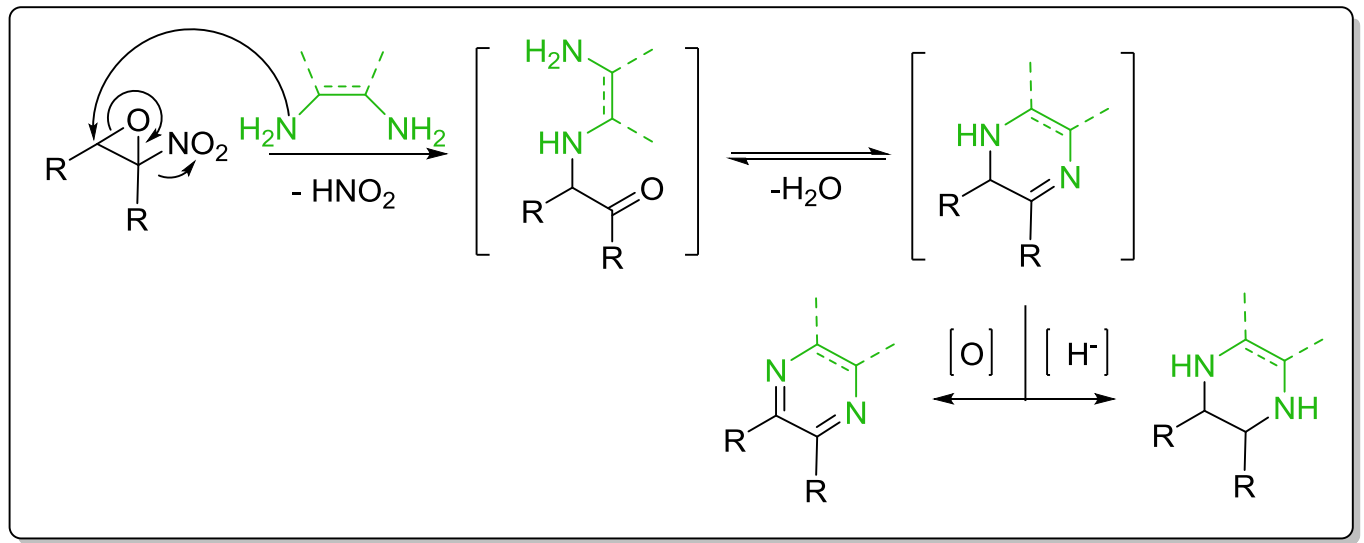

Esquema 5. Transformació de nitroepòxids en heterocicles de nitrogen insaturats i saturats.

La primera prova d'apertura de l'epòxid del trans- $\beta$-metil- $\beta$-nitroestirè (1a) es va dur a terme emprant 1,2-diaminobenzè com a nucleòfil i 1,2dicloroetà (DCE) com a dissolvent a temperatura ambient durant 24 hores. Per la nostra sorpresa, una anàlisi per RMN d'una alíquota de reacció va mostrar la formació de l'heterocicle oxidat, la quinoxalina 2a, a banda de la formació de la cetona, sense l'addició de cap agent oxidant. La nostra interpretació dels resultats consistia en què una vegada es tanca el cicle, l'oxigen atmosfèric és capaç d'oxidar l'intermedi amino-imina el qual guanya aromaticitat i és converteix en un compost més estable (Esquema 6). Aquesta hipòtesi es va veure reforçada quan, després d'haver parat la reacció en condicions ambient, 
al RMN únicament es veia el producte aromàtic 2a sense restes dels possibles intermedis.

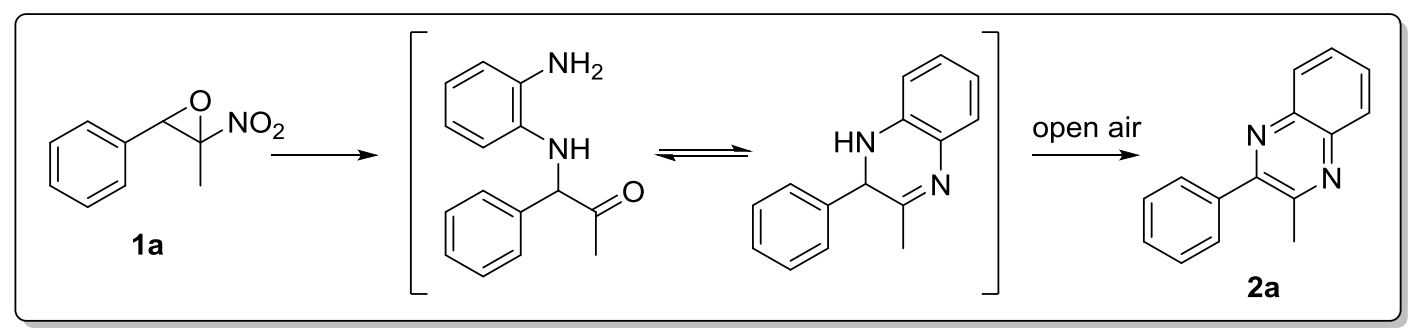

Esquema 6. Formació de l'intermedi amino-imina i aromatització amb oxigen atmosfèric per obtindre $\mathbf{2 a}$.

El procés d'optimització de la reacció va ser senzill: canviar de dissolvent a etanol va augmentar la solubilitat dels reactius afavorint així el rendiment i acurtant el temps de reacció. Fer la reacció amb el matràs obert a l'atmosfera també va augmentar la velocitat de reacció. Es va establir com a criteri general un canvi de color en la dissolució, de groc clar a roig intens, com a indicador de formació de la quinoxalina. Diversos substrats es van testar en les mateixes condicions, obtenint diverses quinoxalines amb bons rendiments (70-83\%), excepte en el cas de què els substituents del nitroepòxid fossin ambdós grups alquil (Taula 1).

\section{Taula 1. Síntesi de quinoxalines. ${ }^{a}$}

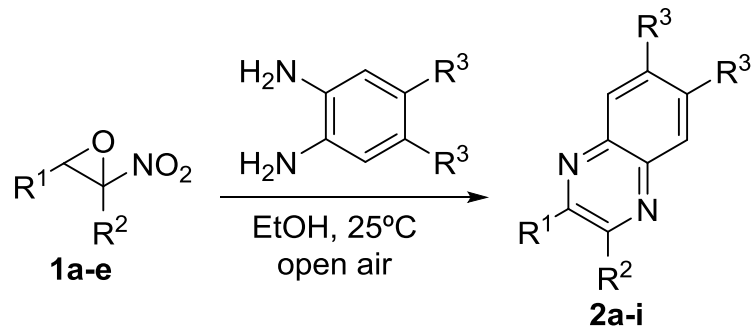

\begin{tabular}{llllll}
\hline Entrada & $\mathbf{R}^{\mathbf{1}}, \mathbf{R}^{\mathbf{2}}$ & Epòxid & $\mathbf{R}^{\mathbf{3}}$ & Quinoxalina & $\begin{array}{l}\text { Rendiment } \\
(\mathbf{\%})^{\mathbf{b}}\end{array}$ \\
\hline $\mathbf{1}$ & $\mathrm{Ph}, \mathrm{Me}$ & $\mathbf{1 a}$ & $\mathrm{H}$ & $\mathbf{2 a}$ & 86 \\
$\mathbf{2}$ & $\mathrm{Ph}, \mathrm{Me}$ & $\mathbf{1 a}$ & $\mathrm{Cl}$ & $\mathbf{2 b}$ & 82 \\
$\mathbf{3}$ & $p-\mathrm{F}-\mathrm{Ph}, \mathrm{Me}$ & $\mathbf{1 b}$ & $\mathrm{H}$ & $\mathbf{2 c}$ & 80 \\
$\mathbf{4}$ & $p-\mathrm{F}-\mathrm{Ph}, \mathrm{Me}$ & $\mathbf{1 b}$ & $\mathrm{Cl}$ & $\mathbf{2 d}$ & 75 \\
$\mathbf{5}$ & $p-\mathrm{Me}-\mathrm{Ph}$, & $\mathbf{1 c}$ & $\mathrm{H}$ & $\mathbf{2 e}$ & 78 \\
\hline
\end{tabular}




\begin{tabular}{llllll}
\hline $\mathbf{6}$ & $\mathrm{Me}$ & & & & \\
& $p-\mathrm{Me}-\mathrm{Ph}$, & $\mathbf{1 c}$ & $\mathrm{Cl}$ & $\mathbf{2 f}$ & 70 \\
$\mathrm{Me}$ & & & & \\
$\mathbf{7}$ & $p-\mathrm{F}-\mathrm{Ph}, \mathrm{Et}$ & $\mathbf{1 d}$ & $\mathrm{H}$ & $\mathbf{2 g}$ & 80 \\
$\mathbf{8}$ & $n-\mathrm{Pr}, \mathrm{Me}$ & $\mathbf{1 e}$ & $\mathrm{H}$ & $\mathbf{2 h}$ & 63 \\
$\mathbf{9}$ & $n-\mathrm{Pr}, \mathrm{Me}$ & $\mathbf{1 e}$ & $\mathrm{Cl}$ & $\mathbf{2 i}$ & 48 \\
\hline
\end{tabular}

${ }^{a}$ Les reaccions es van dur a terme emprant nitroepòxid (1.0 equiv) i 1,2-diaminobenzè (1.5 equiv) a temperatura ambient per $16 \mathrm{~h} .{ }^{b}$ Rendiment sobre el producte aillat.

Motivats pels resultats de les quinoxalines, vam decidir sintetitzar piperazines, emprant 1,2-etilendiamina i $\mathrm{NaBH}(\mathrm{OAc})_{3}$ com agent reductor, en DCE a temperatura ambient. En aquest cas, els resultats no van ser tan bons com en el cas de les quinoxalines, però després d'un treball d'optimització i purificació, es van obtindre piperazines amb rendiments moderats i una lleugera diastereoselectivitat (Taula 2).

\section{Taula 2. Síntesi de piperazines. ${ }^{a}$}

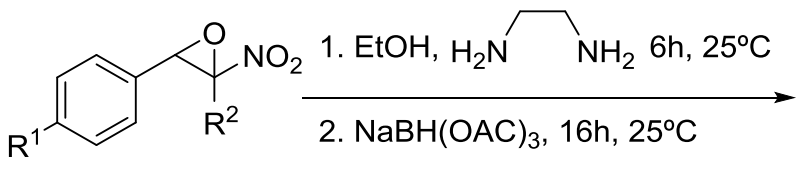

$1 a, c, d$

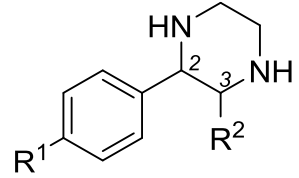

3a-c

\begin{tabular}{llllll}
\hline Entrada & $\mathbf{R}^{\mathbf{1}}, \mathbf{R}^{\mathbf{2}}$ & Epòxid & Piperazina & $\begin{array}{l}\text { Rendiment } \\
\mathbf{( \% )}^{b}\end{array}$ & $\begin{array}{l}\text { d.r. } \\
(\text { cis/trans })\end{array}$ \\
\hline $\mathbf{1}$ & $\mathrm{H}, \mathrm{Me}$ & $\mathbf{1 a}$ & $\mathbf{3 a}$ & $44 \%$ & $2: 1$ \\
$\mathbf{2}$ & $\mathrm{Me}$, & $\mathbf{1 c}$ & $\mathbf{3 b}$ & $64 \%$ & $4: 1$ \\
$\mathbf{3}$ & $\mathrm{Me}$ & & & & \\
\hline
\end{tabular}

${ }^{a}$ Les reaccions es van dur a terme emprant nitroepòxid (1.0 equiv) i 1,2-etilendiamina (1.5 equiv) a temperatura ambient durant 6 h. Després, es va afegir $\mathrm{NaBH}(\mathrm{OAc})_{3}(3.0$ equiv) i la mescla es va seguir agitant per $16 \mathrm{~h} .{ }^{b}$ Rendiment sobre el producte aillat.

L'estereoquímica dels diastereoisòmers es va assignar per les constants d'acoblament en l'espectre de ${ }^{1} \mathrm{H}$ RMN (la constant $J_{2,3}$ és major per l'isòmer trans que per al cis) i per experiments de NOE. La piperazina 3a va mostrar una constant d'acoblament de $3.3 \mathrm{~Hz}$ per l'isòmer majoritari, mentre que el minoritari va mostrar una constant de $9 \mathrm{~Hz}$. 
Tenint en compte la relació descrita per Karplus ${ }^{15}$ entre constant d'acoblament $\mathrm{i}$ angle dièdric, a l'isòmer majoritari se li va assignar la conformació cis i al minoritari trans (Esquema 7). A més, els experiments de NOE van confirmar acoblament en l'isòmer trans (Esquema 7).
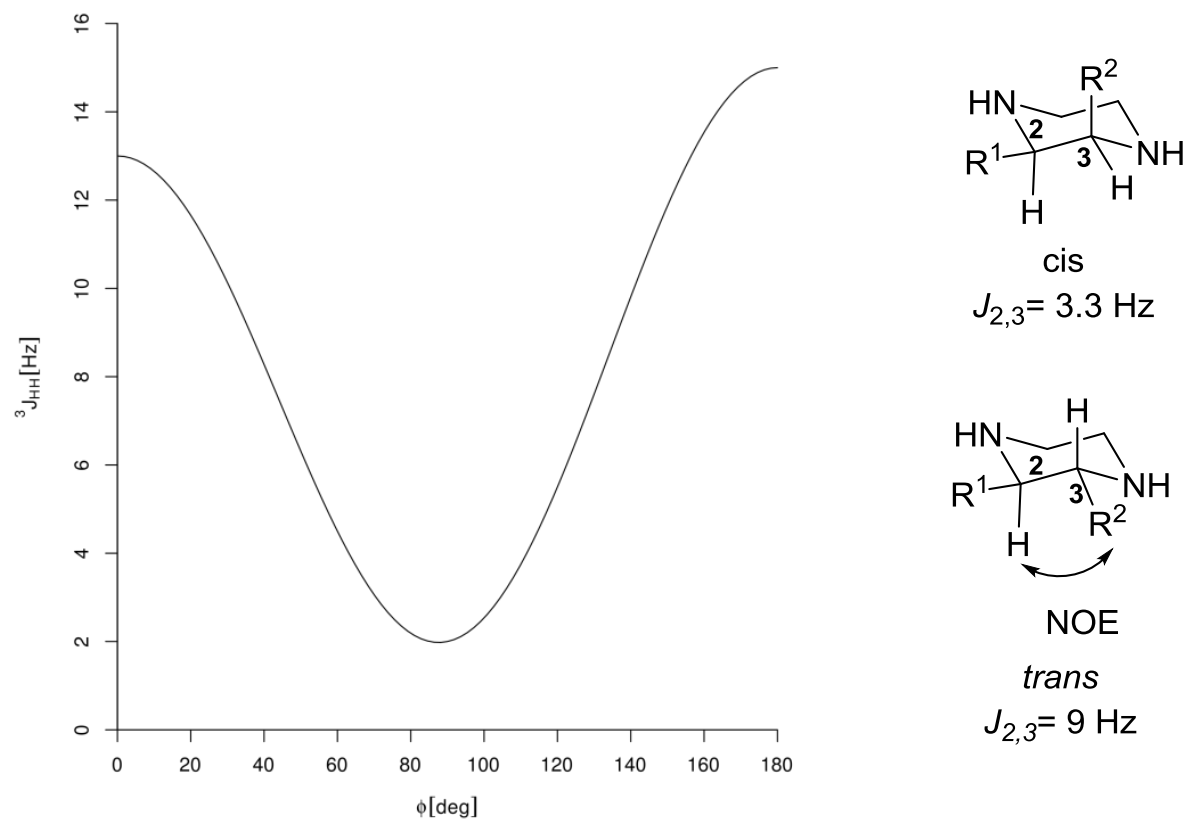

Esquema 7. Equació general de Karplus per els confórmers d'età (esquerra).

Assignació de l'estereoquímica de les piperazines (dreta).

El següent pas va consistir en l'obtenció del cicle de tetrahidroquinoxalina 4 per la reducció in situ de l'intermedi aminoimina, provinent de l'epòxid 1a, amb $\mathrm{NaBH}(\mathrm{OAc})_{3}$. No obstant, amb aquesta metodologia, la quinoxalina 2a seguia sent el compost majoritari. Després de diversos intents d'optimitzar les condicions, es va decidir canviar d'estratègia, i afegir el reductor, en aquest cas $\mathrm{BH}_{3} \cdot \mathrm{THF}$, una volta s'hagués format el compost 2a. D'aquesta manera, la tetrahidroquinoxalina 4 es va obtindre en un procés one-pot amb un $72 \%$ de rendiment, sobre el producte aïllat, i una mescla de diastereoisòmers (cis/trans 3:1) (Esquema 8). La configuració dels

15 a) Karplus, M. J. Chem. Phys. 1959, 30 (1), 11. b) Gutowsky, H. S.; Karplus, M.; Grant, D. M. J. Chem. Phys. 1959, 31 (5), 1278. c) Minch, M. J. Concepts Magn. Reson. 1994, 6, 41. 
diastereoisòmers es va assignar de la mateixa manera que per les piperazines 3a-c.

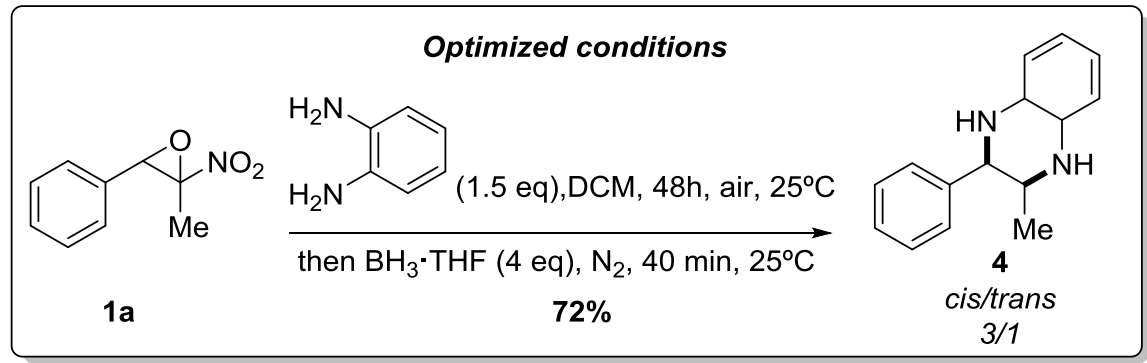

Esquema 8. Condicions optimitzades per la síntesi one-pot de 4.

Finalment, es van sintetitzar una sèrie de pirazines a partir de diferents nitroepòxids (Taula 3). Per aconseguir-ho, es van fer reaccionar els nitroepòxids amb una dissolució metanòlica d'amoníac. En un primer pas, l'amoníac reacciona amb l'epòxid per formar l'intermedi aminocetona, què immediatament condensa amb una altra amino-cetona per formar un dímer. Aquest, en presència d'oxigen, aromatitza per tal de formar la pirazina. La reacció va resultar ser ràpida i neta, obtenint-se les pirazines amb rendiments elevats i sense més necessitat de purificació que una extracció amb èter etílic del medi de reacció.

\section{Taula 3. Síntesi de pirazines. ${ }^{a}$}

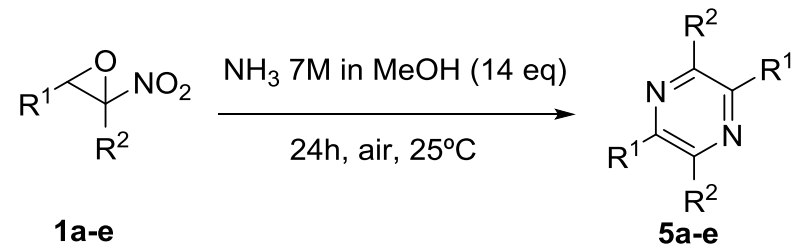

\begin{tabular}{|c|c|c|c|c|}
\hline Entada & $\mathbf{R}^{1}, \mathbf{R}^{2}$ & Epòxid & Pirazina & Rendiment $(\%)^{b}$ \\
\hline 1 & $\mathrm{Ph}, \mathrm{Me}$ & $1 \mathrm{a}$ & $5 \mathbf{a}$ & 93 \\
\hline 2 & $p$-F-Ph, Me & $1 b$ & $5 \mathbf{b}$ & 92 \\
\hline 3 & $p$-Me-Ph, Me & 1c & $5 c$ & 90 \\
\hline 4 & $p-\mathrm{F}-\mathrm{Ph}, \mathrm{Et}$ & 1d & $5 d$ & 96 \\
\hline 5 & $n$-Pr, Me & 1e & $5 e$ & 89 \\
\hline
\end{tabular}

${ }^{a}$ Les reaccions es van dur a terme emprant nitroepòxid (1.0 equiv) i una dissolució $7 \mathrm{M}$ d'amoníac en metanol (14 equiv) a temperatura ambient durant 24 h. ${ }^{b}$ Rendiment sobre el producte aïllat. 
La síntesi de diversos heterocicles, aromàtics i no aromàtics, a partir de nitroepòxids i diamines (o amoníac en el cas de les pirazines) ha quedat constatada en aquest resum, i el treball s'ha publicat en una revista d'alt índex d'impacte en l'àmbit de la química orgànica. ${ }^{16}$

${ }^{16}$ Vidal-Albalat, A.; Rodríguez, S.; González, F. V. Org. Lett. 2014, 16 (6), 1752. 


\subsection{Epoxidació enantioselectiva de dicianoalquilidens}

El treball descrit en aquest apartat es va realitzar durant una estada de 4 mesos a la Università degli Studi di Salerno (Itàlia), sota la supervisió de la professora Alessandra Lattanzi. Aquest estudi es va centrar en l'epoxidació organocatalítica enantioselectiva del dicianoalquilidè 7 per obtindre l'epòxid 8 (Esquema 9). A l'igual que passa amb el grup nitro, els grups ciano són electró-atraents, per la qual cosa l'epòxid $\mathbf{8}$ es converteix en un building block electròfil.

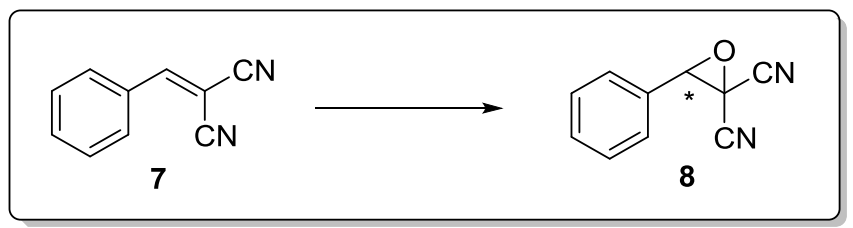

Esquema 9. Esquema general per la conversió de $\mathbf{7}$ en $\mathbf{8}$.

Les aplicacions d'un sintètiques de l'epòxid $\mathbf{8}$ serien molt interessants, ja que per exemple, si es fa reaccionar el dicianoepòxid amb 1,2etilendiamina, al tindre dos grups ixents, es formaria una piperazin-2ona quiral (Esquema 10). Aquest tipus d'estructura és comuna en alguns productes d'origen natural que podrien presentar activitat biològica interessant des d'un punt de vista farmacològic ${ }^{17}$.

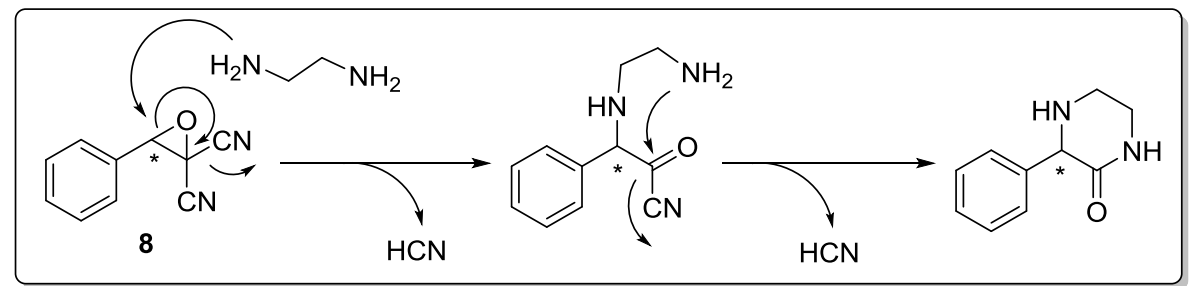

Esquema 10. Ruta mecanística per la sintesí de piperazin-2-ones a partir de dicianoepòxids

Per tal d'aconseguir l'epoxidació asimètrica dels dicianoalquilidens, es va optar per l'epoxidació amb hidroperòxids catalitzada per tiourees

${ }^{17}$ a) Korch, K. M.; Eidamshaus, C.; Behenna, D. C.; Nam, S.; Horne, D.; Stoltz, B. M. Angew. Chem. Int. Ed. 2015, 54 (1), 179. b) Prangé, T.; Billion, M. A.; Vuilhorgne, M.; Pascard, C.; Polonsky, J. Tetrahedron Lett. 1981, 22 (21), 1977. c) Nakao, Y.; Masuda, A.; Matsunaga, S.; Fusetani, N. J. Am. Chem. Soc. 1999, 121 (11), 2425. d) Martínez-Luis, S.; Rodríguez, R.; Acevedo, L.; González, M. C.; Lira-Rocha, A.; Mata, R. Tetrahedron 2006, 62 (8), 1817. 
bifuncionals, ja que treballs anteriors de la professora Lattanzi havien donat bons resultats quan s'havia optat per aquest sistema ${ }^{18}$. El mecanisme general que descriu el paper d'un organocatalitzador bifuncional en una reacció d'epoxidació, es podria resumir d'aquesta manera: una funció bàsica de la molècula (generalment, una amina terciària) desprotona l'hidroperòxid mentre un altre grup funcional del catalitzador activa l'electròfil (a través de ponts d'H, per exemple) per fer-lo més reactiu. Si a més, el catalitzador és òpticament actiu, pot orientar els substrats per tal d'afavorir la formació d'un enantiòmer respecte el seu oposat. Diversos catalitzadors s'han sintetitzat i testat per l'epoxidació de 7 en les mateixes condicions (Taula 4).

\section{Taula 4. Proves de catalitzadors per l'epoxidació asimètrica de 7.a”}

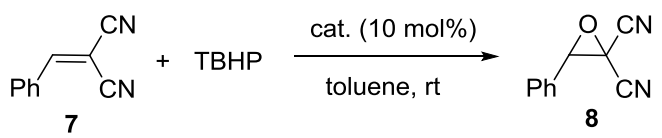

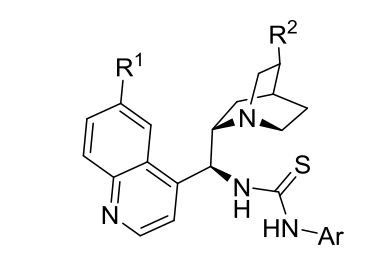

eQNT $\mathrm{R}^{1}=\mathrm{OMe}, \mathrm{R}^{2}=\mathrm{CH}=\mathrm{CH}_{2}$ eCDT $\mathrm{R}^{1}=\mathrm{H}, \mathrm{R}^{2}=\mathrm{CH}=\mathrm{CH}_{2}$ eHQNT $\mathrm{R}^{1}=\mathrm{OMe}, \mathrm{R}^{2}=\mathrm{CH}_{2} \mathrm{CH}_{3}$<smiles>C=CC1CCCN1C(NC(=S)NC)c1ccnc2ccc(OC)cc12</smiles>
eQDT<smiles>C=CC1CCN2CCC1C2C(NC(=O)N[Al])c1ccnc2ccc(OC)cc12</smiles>

eQNU

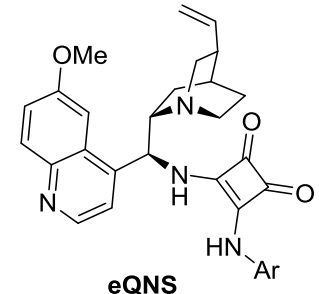

eQNS<smiles>C=CC1CC2CCC1N2C[C@H](OCc1ccccc1)c1ccnc2ccc(NC(=S)NC(=S)NC(=S)NC(C)c3ccccc3)cc12</smiles><smiles>CCCCCCCN(C)[C@H]1CCCC[C@H]1NC(=S)NC</smiles>

9<smiles>CN(C1CCCCC1)[C@@H](c1ccccc1)C(NC(=S)NC1CCCCC1)c1ccccc1</smiles><smiles>O=C(NC(=S)NC(c1ccccc1)C(O)c1ccccc1)c1ccccc1</smiles><smiles>O=C(NC(=S)NC(c1ccccc1)C(O)c1ccccc1)c1ccccc1</smiles><smiles>O=[N+]([O-])NC(=S)NC(c1ccccc1)C(O)c1ccccc1</smiles>

11<smiles>O=C(NC(=O)OCc1ccccc1)NC(=S)NC(=O)NC(=S)NC(c1ccccc1)C(O)c1ccccc1</smiles>

\footnotetext{
${ }^{18}$ Russo, A.; Galdi, G.; Croce, G.; Lattanzi, A. Chem. Eur. J. 2012, 18 (20), 6152.
} 


\begin{tabular}{|c|c|c|c|c|}
\hline Entrada & Catalitzador & Temps (h) & Rendiment $(\%)^{b}$ & e.r. $(\%)^{c}$ \\
\hline 1 & eQNT & 15 & 58 & $67.5: 32.5$ \\
\hline 2 & eQNU & 16 & 48 & 65.4:34.6 \\
\hline $3^{d}$ & eQNS & 40 & 70 & $62.2: 37.8$ \\
\hline 4 & eCDT & 21 & 57 & 59.5:40.5 \\
\hline 5 & eHQNT & 24 & 63 & $56.2: 43.8$ \\
\hline $6^{\mathrm{e}}$ & eQDT & 21 & 84 & 44.9:55.1 \\
\hline 7 & 9 & 29 & 43 & $54.2: 45.8$ \\
\hline 8 & 10 & 15 & 72 & 52.4:47.6 \\
\hline $9^{e}$ & Takemoto & 24 & 55 & 44.3:55.7 \\
\hline $10^{e}$ & 11 & 24 & 34 & 31.3:68.7 \\
\hline 11 & $12 \mathbf{a}$ & 22 & 90 & $77.2: 22.8$ \\
\hline $12^{e}$ & $12 b$ & 21 & 80 & $42.8: 57.2$ \\
\hline 13 & $12 \mathrm{c}$ & 18 & 75 & $71: 29$ \\
\hline $14^{e}$ & 12d & 17 & 74 & $49.8: 50.2$ \\
\hline $15^{\mathrm{e}}$ & $12 \mathrm{e}$ & 16 & 87 & $23: 77$ \\
\hline
\end{tabular}

${ }^{\mathrm{a}}$ Les reaccions es van dur a terme a una escala de $0.1 \mathrm{mmol}$ per a $7(\mathrm{C}=0.2 \mathrm{M})$ emprant TBHP (1.2 equiv). ${ }^{b}$ Determinat per anàlisi ${ }^{1} \mathrm{H}$ RMN amb $1,3,5-(\mathrm{MeO})_{3} \mathrm{C}_{6} \mathrm{H}_{3}$ com a patró intern. ${ }^{\mathrm{c}}$ Determinat per anàlisi quiral $\mathrm{d}^{\prime} \mathrm{HPLC}$. ${ }^{\mathrm{d}} \mathrm{La}$ reacció es va fer a escala $5 \mathrm{~mol} \%$ de eQNS en $\mathrm{CHCl}_{3}$. ${ }^{\mathrm{e}} \mathrm{Es}$ va obtindre preferentment l'enantiòmer oposat.

Una sèrie de catalitzadors es van preparar utilitzant l'estructura de derivats de cincona (quinina, per exemple) als quals se'ls va afegir un grup funcional amb l'habilitat d'afavorir ponts d'hidrogen (tiourea, urea i esquaramida). Comparant els resultats del catalitzador de tiourea, urea i esquaramida derivats de l'epi-quinina (entrades $1-3$, respectivament) que en termes de conversió i enantioselectivitat, el catalitzador de tiourea eQNT era més eficient per al sistema estudiat. Arran dels resultats obtinguts, es va decidir seguir amb el grup tiourea, però modificant els esquelets de cincona (entrades 4 -6). Canviar la quinina (entrada 1) per cinconidina (entrada 4) va resultar en un detriment de l'enantioselectivitat i la velocitat de reacció, mentre que per al pseudoenantiòmer de quinidina (entrada 6) la conversió va ser bona, però l'enantioselectivitat, a banda de canviar de signe com s'esperava, també es va veure reduïda. Canviar la posició de la tiourea en l'estructura de quinina o el seu substituent (entrades 7 - 8) tampoc van afavorir l'enantioselectivitat. El catalitzador de Takemoto (entrada 9) tampoc va donar bons resultats però en canvi, utilitzar el catalitzador 11 (entrada 10) va millorar l'enantioselectivitat, tot i què per l'enantiòmer oposat $\mathrm{i}$ amb la pitjor conversió de la taula. 
Arribats a aquest punt, i donada la naturalesa dels dicianoalquilidens, vam pensar que afegir més grups donadors de hidrogen per enllaços no covalents podria resultar en una millora de l'efectivitat del catalitzador. Una sèrie de catalitzadors amb la funcionalitat de 1,2-aminoalcohol (entrades $11-15$ ) es va dissenyar i testar per la reacció d'epoxidació. Afortunadament, el catalitazador 12a (entrada 11) va donar millors resultats tant en termes de conversió com d'enantioselectivitat. El catalitzador 12e (entrada 15) es va preparar amb quinidina, l'estructura de cincona pseudoenantiomèrica respecte a 12a, i els resultats entre ambdós en termes d'enantioselectivitat van ser quasi idèntics, però de signe contrari. Altres variables van ser testades per la doctora Sara Meninno per tal de millorar els resultats amb 12a com a millor catalitzador i estendre les condicions a altres substrats, aconseguint millorar els excessos enantiomèrics ${ }^{19}$.

A la vista dels resultats, i d'acord amb les observacions experimentals, es va proposar un estat de transició per tal d'explicar l'enantioselectivitat (Figura 3). Un dels grups ciano estaria activat per l'hidroxil del catalitzador, mentre que l'altre estaria activat pels $\mathrm{NH}$ de la funció tiourea. Aquesta hipòtesi es va fer en base a un estudi computacional que afirmava que era més plausible una doble activació del grup ciano per ambdós NH que solament amb un ${ }^{20}$.

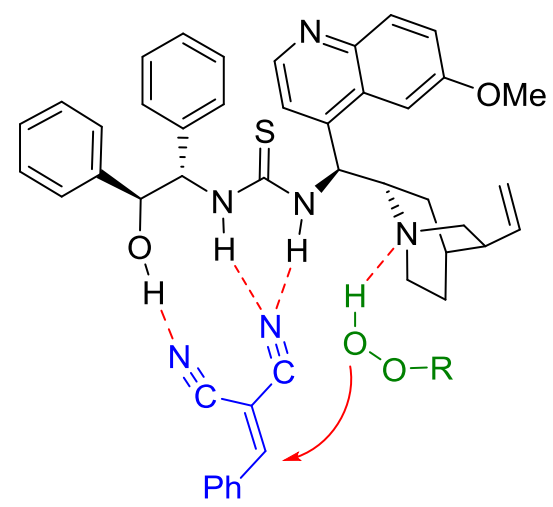

Figura 3. Estat de transició proposat per l'epoxidació enantioselectiva de dicianoalquilidens.

\footnotetext{
${ }^{19}$ Meninno, S.; Vidal-Albalat, A.; Lattanzi, A. Org. Lett. 2015, 17 (17), 4348.

${ }^{20}$ Qi, Z.-H.; Zhang, Y.; Ruan, G.-Y.; Zhang, Y.; Wang, Y.; Wang, X.-W. RSC Adv. 2015, 5 (43), 34314.
} 


\subsection{Epoxidació asimètrica de nitroalquens}

Donat l'interés que presenten els nitroepòxids per l'aplicació en química sintètica com a building blocks, ser capaços d'obtindre'ls de forma asimètrica proporcionaria una ferramenta molt valuosa de cara a la síntesi orgànica. Tal com s'ha mencionat abans, a dia d'avui no hi ha un mètode efectiu i general per l'epoxidació asimètrica de nitroalquens.

Russo i Lattanzi van intentar epoxidar els nitroalquens emprant catalitzadors bifuncionals del tipus tiourea sense gaire èxit, obtenint principalment el peròxid com a producte d'addició oxa-Michael ${ }^{21}$. Així que, nosaltres vam decidir canviar d'estratègia i provar l'epoxidació mitjançant catàlisi de transferència de fase (PTC en anglès). Les primeres proves van donar resultats esperançadors ja que la conversió de la reacció era completa a les dues hores, a pesar de què l'excés enantiomèric fóra només del $18 \%$. Per aquesta reacció, vam emprar el bromur de N-benzil cinconini com a catalitzador, en diclorometà, i una dissolució concentrada de hipoclorit sòdic com a catalitzador (Esquema $11)$.

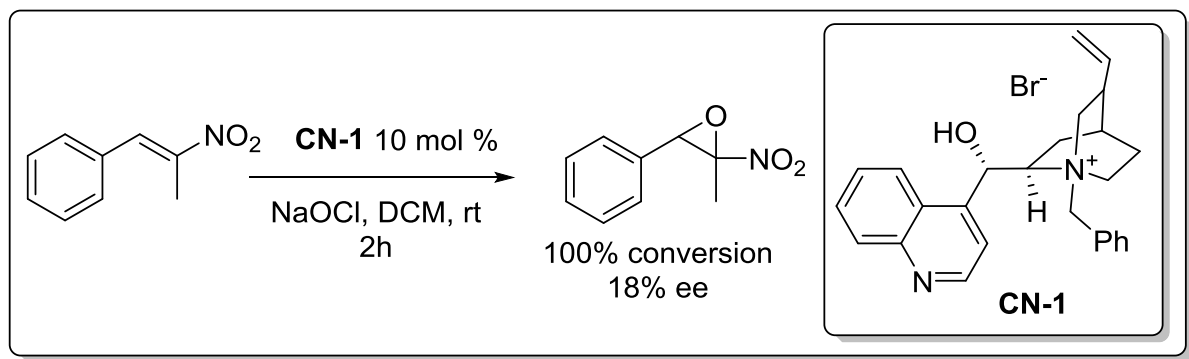

Esquema 11. Prova d'epoxidació asimètrica mitjançant PTC.

Al ser un sistema bifàsic, el nombre de variables per estudiar i optimitzar era considerable. En primer lloc, es van estudiar la quantitat d'oxidant i la seua concentració en la fase aquosa. Es va observar que en ambdós casos, quan es reduïa el nombre d'equivalents d'oxidant o la seua concentració en la fase aquosa, la velocitat de reacció disminuïa, però l'enantioselectivitat no es va veure afectada de forma significativa. En canvi, la càrrega de catalitzador sí que va tindre un impacte en l'enantioselectivitat (Taula 5). A mesura que disminuïa la càrrega de

${ }^{21}$ Russo, A.; Lattanzi, A. Adv. Synth. Catal. 2008, 350 (13), 1991. 
catalitzador, també ho feia l'enantioselectivitat. Malauradament, augmentar la càrrega més del $10 \%$ mol, no suposava un augment significatiu de l'enantioselectivitat (entrada 1). Sobre aquest fet, hem proposat la hipòtesi de què la concentració de catalitzador arriba al seu punt de saturació i llavors la porció de catalitzador que queda en suspensió no participa de forma significativa en la catàlisi.

Taula 5. Efecte de la càrrega de catalitzador sobre la conversió $i$ l'enantioselectivitat. ${ }^{a}$

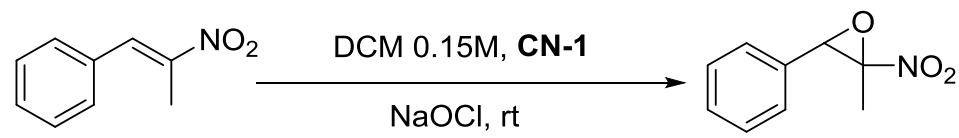

\begin{tabular}{clllc}
\hline Entrada & Càrrega cat. & Temps (h) & Conversió (\%) & e.r. $^{\mathbf{c}}$ \\
\hline $\mathbf{1}$ & $20 \mathrm{~mol} \%$ & 2 & 100 & $59: 41$ \\
$\mathbf{2}$ & $10 \mathrm{~mol} \%$ & 2 & 100 & $58: 42$ \\
$\mathbf{3}$ & $5 \mathrm{~mol} \%$ & 2 & 76 & $54: 46$ \\
$\mathbf{4}$ & $1 \mathrm{~mol} \%$ & 4 & 20 & $50.5: 49.5$ \\
\hline
\end{tabular}

${ }^{a}$ Les reaccions es van dur a terme a escala de $20 \mathrm{mg}$ del trans- $\beta$-metil- $\beta$-nitrostirè, en DCM amb una proporció 1:1 org/aq i durant el temps indicat. ${ }^{b}$ Mesurat sobre ${ }^{1} \mathrm{H}$ NMR. ${ }^{\mathrm{c}}$ Mesurat en HPLC.

Lygo ja havia postulat que la concentració de catalitzador en la fase orgànica era un tret important ${ }^{22}$. Una sèrie d'experiments es van realitzar a diferents concentracions de la fase orgànica respecte al nitroalquè (Taula 6). Tal com es pot observar en la taula, el millor resultat va ser a una concentració de $0.3 \mathrm{M}$ (entrada 2).

Taula 6. Variació de conversió i e.r. en funció de la concentració. ${ }^{a}$

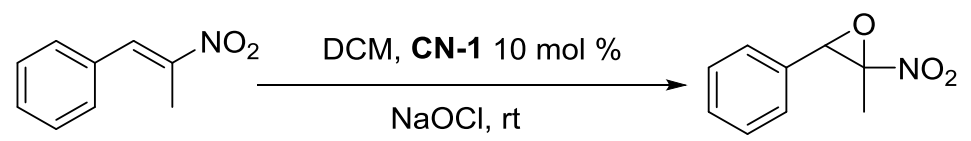

\begin{tabular}{clllll}
\hline Entry & Conc. $(\mathbf{M})$ & Org/Aq $^{\mathbf{b}}$ & Temps (h) & Conversion $^{(\%)^{\mathbf{c}}}$ & e.r. $^{\mathbf{d}}$ \\
\hline $\mathbf{1}$ & 0.6 & $1: 1$ & 2.5 & 100 & $54: 46$ \\
$\mathbf{2}$ & 0.3 & $2: 1$ & 3 & 100 & $59: 41$ \\
$\mathbf{3}$ & 0.15 & $4: 1$ & 5 & 100 & $57: 43$ \\
$\mathbf{4}$ & 0.07 & $7.5: 1$ & 6 & 96 & $55: 45$ \\
\hline
\end{tabular}

${ }^{22}$ Lygo, B.; To, D. C. M. Chem. Commun. 2002, 20, 2360. 
${ }^{a}$ Les reaccions es van dur a terme a escala de $20 \mathrm{mg}$ del trans- $\beta$-metil- $\beta$-nitrostirè, en DCM amb una quantitat constant d'oxidant i durant el temps indicat. ${ }^{b}$ Proporció de volum. ${ }^{\mathrm{c}}$ Mesurat sobre ${ }^{1} \mathrm{H}$ NMR. ${ }^{\mathrm{d}}$ Mesurat en HPLC.

Un altra variable que segons la literatura sembla ser primordial, és el dissolvent emprat (Taula 7). En aquells sistemes on el catalitzador no era soluble, o hi havia miscibilitat entre la fase aquosa i l'orgànica, no hi va haver reacció (entrades 5 i 7), o en el cas d'haver-la (entrada 6), no hi va haver enantioselectivitat. La reacció va resultar ser més efectiva en els dissolvents apolars, especialment en el cas del cloroform (entrada 9). Curiosament, en el cas del toluè (entrada 3), a pesar de ser un dissolvent bastant comú en aquest tipus de sistemes, la conversió va ser molt baixa i l'enantioselectivitat no es va mesurar.

Taula 7. Estudi de l'efecte del dissolvent en la conversió i l'enantioselectivitat. ${ }^{\text {a }}$

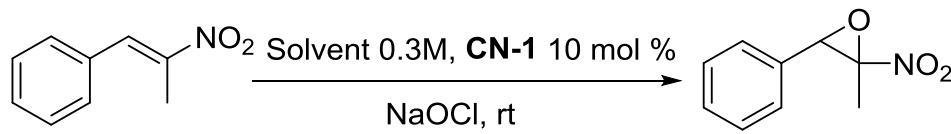

\begin{tabular}{cllll}
\hline Entry & Solvent & Time $(\mathbf{h})$ & Conversion $\left.^{(\%)}\right)^{\mathbf{b}}$ & e.r. $^{\mathbf{c}}$ \\
\hline $\mathbf{1}$ & DCM & 2 & 100 & $59: 41$ \\
$\mathbf{2}$ & EtOAc & 6 & 48 & $50: 50$ \\
$\mathbf{3}$ & Toluene & 24 & 20 & n.d. \\
$\mathbf{4}$ & Hexane & 24 & $<5$ & n.d. \\
$\mathbf{5}$ & Methanol & 24 & No reaction & n.d. \\
$\mathbf{6}$ & THF & 6 & 45 & $50: 50$ \\
$\mathbf{7}$ & Et $_{2} \mathrm{O}$ & 24 & No reaction & n.d. \\
$\mathbf{8}$ & $1,2-$ DCE & 2 & 75 & $55: 45$ \\
$\mathbf{9}$ & Chloroform & 1.5 & 70 & $74: 26$ \\
\hline
\end{tabular}

${ }^{\mathrm{a}} \mathrm{Les}$ reaccions es van dur a terme a escala de $20 \mathrm{mg}$ del trans- $\beta$-metil- $\beta$-nitrostirè, a una concentració de $0.3 \mathrm{M}$ amb una proporció de fase $1: 1$ org/aq i durant el temps indicat. ${ }^{\mathrm{b}}$ Mesurat sobre ${ }^{1} \mathrm{H}$ NMR. ${ }^{\mathrm{c}}$ Mesurat en HPLC. ${ }^{\mathrm{d}}$ Sense dades.

Amb les principals condicions estudiades, sols quedava estudiar l'efecte de l'estructura del catalitzador sobre la reacció (Taula 8). Diversos catalitzadors es van dissenyar i estudiar a mesura que nous dubtes i observacions experimentals anaven sorgint. Utilitzant l'estructura de la cinconina, diversos compostos es van emprar per 
quaternitzar el nitrogen de l'anell de quinuclidina (entrades 1 - 5), amb el millor resultat per al catalitzador $\mathbf{C N}-2$ amb el grup metilantracè com a substituent (entrada 2).

Taula 8. Estudi sobre els efectes del catalitzador. ${ }^{a}$
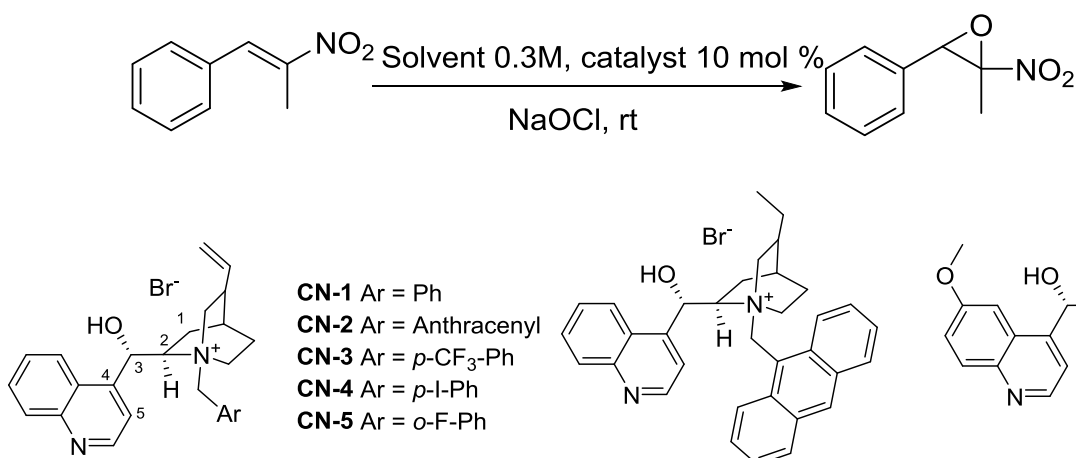

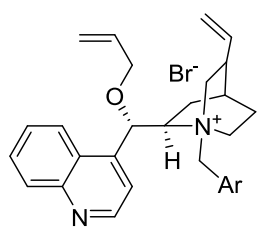

CN-6 Ar = Anthracenyl CN-7 Ar $=0-F-P h$
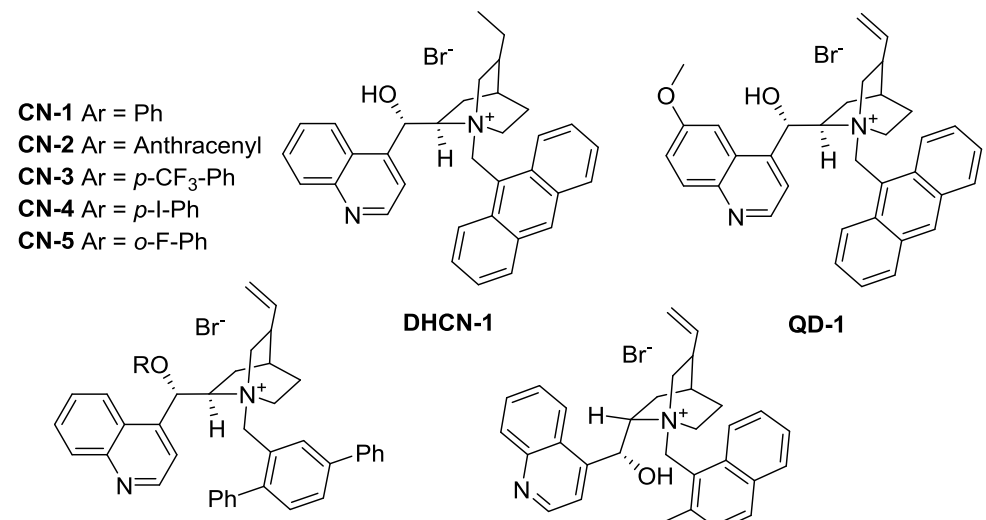

CN-8 $\mathrm{R}=\mathrm{H}$

CN-9 R = allyl
DHCN-1

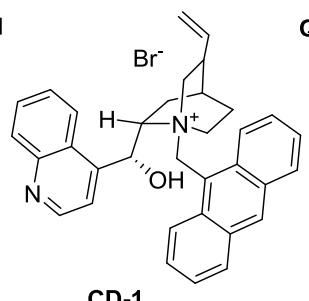

CD-1
QD-1

\begin{tabular}{clllll}
\hline Entrada & Solvent & Catalitzador & Temps (h) & Conversió (\%) $^{\mathbf{b}}$ & e.r. $^{\mathbf{c}}$ \\
\hline $\mathbf{1}$ & $\mathrm{CHCl}_{3}$ & $\mathbf{C N - 1}$ & 5 & 100 & $74: 26$ \\
$\mathbf{2}$ & $\mathrm{CHCl}_{3}$ & $\mathbf{C N - 2}$ & 3 & 100 & $84: 16$ \\
$\mathbf{3}$ & $\mathrm{CHCl}_{3}$ & $\mathbf{C N - 3}$ & 5 & 100 & $81: 19$ \\
$\mathbf{4}$ & $\mathrm{CHCl}_{3}$ & $\mathbf{C N - 4}$ & 3 & 100 & $81: 19$ \\
$\mathbf{5}$ & $\mathrm{CHCl}_{3}$ & $\mathbf{C N - 5}$ & 5 & 100 & $53: 47$ \\
$\mathbf{6}$ & $\mathrm{CHCl}_{3}$ & $\mathbf{D H C N - 1}$ & 2 & 100 & $81: 19$ \\
$\mathbf{7}$ & $\mathrm{CCl}_{4}$ & $\mathbf{C N - 2}$ & 2 & 100 & $89: 11$ \\
$\mathbf{8}$ & $\mathrm{Toluene}_{\mathbf{9}}$ & $\mathbf{C N - 2}$ & 24 & 100 & $87: 13$ \\
$\mathbf{9}$ & Toluene $_{\mathbf{1 0}}$ & $\mathbf{C N - 4}$ & 16 & 60 & $84: 16$ \\
$\mathbf{1 1}$ & $\mathrm{Tollu}_{3}$ & $\mathbf{Q D - 1}$ & 4 & 100 & $62: 38$ \\
$\mathbf{1 2}$ & $\mathrm{CHCl}_{3}$ & $\mathbf{Q D}-1$ & 4 & 98 & $75: 25$ \\
$\mathbf{1 3}$ & Toluene & $\mathbf{C N - 6}$ & 5 & 80 & $45: 55$ \\
$\mathbf{1 4}$ & $\mathrm{CHCl}_{3}$ & $\mathbf{C N - 7}$ & 4 & 100 & $33.5: 66.5$ \\
$\mathbf{1 5}$ & Toluene & $\mathbf{C N - 7}$ & 4 & 98 & $50: 50$ \\
$\mathbf{1 6}$ & Toluene & $\mathbf{C N - 8}$ & 4.5 & 100 & $39.5: 60.5$ \\
$\mathbf{1 7}$ & Toluene & $\mathbf{C N - 9}$ & 5 & 100 & $41: 59$ \\
\hline
\end{tabular}




\begin{tabular}{lllllc}
\hline $\mathbf{1 8}^{\mathbf{d}}$ & Toluene & $\mathbf{C N - 2}$ & 16 & $92^{\mathrm{e}}$ & $96.5: 3.5$ \\
$\mathbf{1 9}^{\mathbf{d}}$ & Toluene & $\mathbf{C D}-1$ & 16 & $86^{\mathrm{e}}$ & $18: 82$ \\
\hline
\end{tabular}

${ }^{\mathrm{a}}$ Les reaccions es van dur a terme a escala de $20 \mathrm{mg}$ del trans- $\beta$-metil- $\beta$-nitrostirè, a una concentració de $0.3 \mathrm{M}$ amb una proporció de fase $2: 1$ org/aq a temperatura ambient $\mathrm{i}$ durant el temps indicat. ${ }^{\mathrm{b}}$ Mesurat sobre ${ }^{1} \mathrm{H}$ NMR. ${ }^{\mathrm{c}}$ Mesurat en HPLC. ${ }^{\mathrm{d}}$ Temperatura de la reacció $-20^{\circ} \mathrm{C}$. ${ }^{\mathrm{e}}$ Rendiment aïllat.

L'efectivitat de $\mathbf{C N}-2$ es va mesurar també en $\mathrm{CCl}_{4} \mathrm{i}$ en toluè (entrades 7 i 8, respectivament) obtenint millors resultats que amb cloroform (entrada 2). Es va seguir amb el toluè per ser un dissolvent més benigne tan des d'un punt de vista ambiental com toxicològic. Diverses modificacions en l'estructura del catalitzador es van testar (entrades 10 - 17). Curiosament, per aquells catalitzadors en els quals s'havia alquilat l'hidroxil, l'enantioselectivitat no solament es va veure reduïda, sinó que va canviar de signe $(12-15)$. Aquest fet sembla indicar què l'hidroxil podria dirigir la reacció i controlar l'enantioselectivitat. També es va veure un canvi de signe quan un grup més voluminós es va introduir (entrades 16 -17). Com a conclusió, es va argumentar que el grup antracenil podria afavorir interaccions del tipus $\pi$ - $\pi$ stacking entre el catalitzador i el substrat.

L'efecte d'additius, generalment àcids de Lewis, també es va estudiar, però cap d'ells va donar un resultat favorable. Així, amb les condicions ja optimitzades per al compost d'estudi, es va estudiar la naturalesa del substrat en l'efectivitat de la reacció (Taula 9).

Taula 9. Abast de la reaccióa

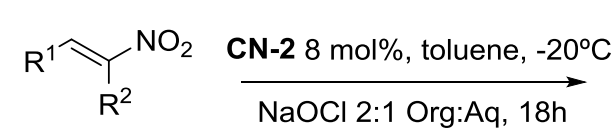<smiles>[R]C1OC1([R])[N+](=O)[O-]</smiles>

12a-h

\begin{tabular}{llllc}
\hline Entrada & $\mathbf{R}^{\mathbf{1}}, \mathbf{R}^{2}$ & Epòxid & Rendiment $(\boldsymbol{\%})^{b}$ & ${\text { e.r. }(\boldsymbol{\%})^{\boldsymbol{c}}}^{\boldsymbol{b}}$ \\
\hline $\mathbf{1}$ & $\mathrm{Ph}, \mathrm{Me}$ & $\mathbf{1 2 a}$ & 92 & $96.6: 3.4$ \\
$\mathbf{2}$ & $p$-F-Ph, Me & $\mathbf{1 2 b}$ & 96 & $96.1: 3.9$ \\
$\mathbf{3}$ & $p$-Cl-Ph, $\mathrm{Me}$ & $\mathbf{1 2 c}$ & 92 & $94.2: 5.8$ \\
$\mathbf{4}$ & $m$-Cl-Ph, Me & $\mathbf{1 2 d}$ & 87 & $91.5: 8.5$ \\
$\mathbf{5}$ & $p$-F-Ph, $\mathrm{Et}$ & $\mathbf{1 2 e}$ & 91 & $95.1: 4.9$ \\
$\mathbf{6}$ & $p$ - $\mathrm{Me}-\mathrm{Ph}, \mathrm{Me}$ & $\mathbf{1 2 f}$ & 92 & $91.3: 8.7$ \\
$\mathbf{7}$ & $\mathrm{Ph}, \mathrm{Ph}$ & $\mathbf{1 2 g}$ & 90 & $91.5: 8.5$ \\
\hline
\end{tabular}




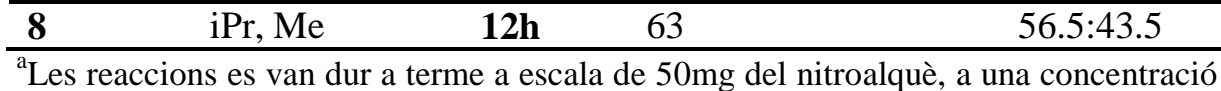
de $0.3 \mathrm{M}$ amb una proporció de fase $2: 1$ org/aq a $-20^{\circ} \mathrm{C}$ i durant el temps indicat. ${ }^{\mathrm{b}}$ Rendiment aïllat. ${ }^{\mathrm{c}}$ Mesurat en HPLC.

Com es pot observar, per als compostos on el substituent $\mathrm{R}^{1}$ és un grup aril (entrades 1 - 6) els rendiments són alts, així com l'enantioselectivitat; mentre que en el cas de ser ambdós substituents grups alquílics (entrada 8), l'enantioselectivitat es veu afectada dràsticament. Açò esta en concordança amb la hipòtesis de les interaccions $\pi-\pi$ stacking entre el substrat i el catalitzador. Càlculs computacionals també s'han realitzat per tal d'elucidar la relació estructura/activitat del catalitzador, i vénen a confirmar que l'hidroxil i les interaccions $\pi$ - $\pi$ stacking tenen un pes considerable en la conformació de l'estat de transició.

Els mateixos substrats s'han epoxidat amb el catalitzador pseudoenantiomèric CD-1 obtenint bons resultats en termes de rendiment, i una inversió en la quiralitat de l'epòxid obtingut. No obstant, l'enantioselectivitat no ha estat tan elevada com en els compostos de la taula 9 .

Finalment, s'han intentat diverses transformacions sintètiques sobre el nitroepòxid òpticament pur, però malauradament no s'han trobat les condicions adequades per conservar la puresa òptica. Tot i així, els resultats obtinguts han sigut mereixedors d'una publicació, ja que s'ha desenvolupat un mètode senzill i efectiu per l'obtenció d'heterocicles a partir de nitroepòxids, tal com morfolinols, morfolines, tiomorfolines i benzoxazines ${ }^{23}$.

\footnotetext{
${ }^{23}$ Capel, E.; Vidal-Albalat, A.; Rodríguez, S.; González, F. V. Synthesis 2016, 48, A1
} 


\section{Conclusions generals}

Del treball realitzat per aquesta tesi, es poden traure aquestes conclusions generals:

- S'ha estudiat la reactivitat característica dels nitroepòxids i la seua aplicació a la química sintètica.

- S'ha desenvolupat una metodologia senzilla que permet accedir a compostos heterocíclics nitrogenats tals com quinoxalines, piperazines, tetrahidroquinoxalines i pirazines, a partir de nitroepòxids.

- Durant l'estada d'investigació a la Università degli Studi di Salerno (Itàlia), s'ha avançat en l'epoxidació enantioselectiva de dicianoalquilidens mitjançant organocatalitzadors quirals. Posteriorment, el treball s'ha millorat obtenint bons resultats.

- S'ha reportat la síntesi enantioselectiva de nitroepòxids a partir de nitroalquens mitjançant catalitzadors de transferència de fase, amb rendiments elevats i e.r. > 90:10 en els casos on els substituents eren aril-alquil. El treball es troba actualment sota revisió en la revista Chemical Communications.

- S'han convertit els nitroepòxids en morfolines i tiomorfolines, a pesar de què no s'ha conservat la puresa òptica.

D'aquest treball han sorgit noves idees, i d'altres n'han quedat pendents de ser explotades o s'han obtingut resultats que encara necessiten ser millorats; com per exemple:

- Derivar els nitroepòxids òpticament purs en compostos d'interès sintètic o farmacològic sense perdre la seua puresa òptica.

- Explotar els nitroepòxids per la síntesi de nous heterocicles amb una metodologia senzilla i pràctica.

- Estudiar el comportament de la síntesi de 1,2-diamines a partir dels nitroepòxids òpticament purs. 